


\section{INTEGRATED CARDIOVASCULAR RISK MANAGEMENT IN PRIMARY CARE}




\section{Integrated cardiovascular risk management in primary care}

Author: Suzanne Marchal

Julius Center for Health Sciences and Primary Care, University Medical Center Utrecht $\mathrm{PhD}$ thesis, Utrecht University, the Netherlands

ISBN:

978-94-6421-319-5

Cover design: Marilou Maes, persoonlijkproefschrift.nl

Layout: Marilou Maes, persoonlijkproefschrift.nl

Printed by Ipskamp Printing, proefschriften.net

Financial support by the SBOH, employer of GP trainees, and the Dutch Heart Foundation for the publication of this thesis is gratefully acknowledged.

\section{SBCHK}

voor artsen in opleiding

(C) S. Marchal, Utrecht, the Netherlands, 2021 


\title{
Integrated cardiovascular risk management in primary care
}

\author{
Geïntegreerd cardiovasculair risicomanagement \\ in de eerste lijn \\ (met een samenvatting in het Nederlands)
}

Proefschrift

ter verkrijging van de graad van doctor aan de Universiteit Utrecht op gezag van de rector magnificus, prof.dr. H.R.B.M. Kummeling, ingevolge het besluit van het college voor promoties in het openbaar te verdedigen op donderdag 20 mei 2021 des middags te 12.15 uur

door

Suzanne Marchal

geboren op 26 juni 1987

te Wijk bij Duurstede 
Promotoren: Prof. dr. A. W. Hoes

Prof. dr. A. W. J. van 't Hof

Copromotor: Dr. M. Hollander 


\section{CONTENTS}

$\begin{array}{lll}\text { Chapter } 1 & \text { Introduction } & 7\end{array}$

Chapter 2 The new European guideline on cardiovascular disease prevention; 19 how to make progress in general practice?

Chapter 3 Design of the ZWOT-CASE study: an observational study on the effectiveness of an integrated programme for cardiovascular risk management compared to usual care in general practice

Chapter 4 Integrated cardiovascular risk management programme versus usual care in high CV risk patients: an observational study in general practice

Chapter 5 Fidelity to a cardiovascular risk management programme in patients with a high cardiovascular risk in primary care; a process evaluation

Chapter 6 Unravelling the impact of integrated care for cardiovascular risk management on hospital care and costs; a retrospective cohort study among patients with cardiovascular disease

Chapter 7 Inadequate management of dyslipidaemia in primary care

Chapter 8 General discussion

Summary

Samenvatting

Dankwoord

Curriculum Vitae 


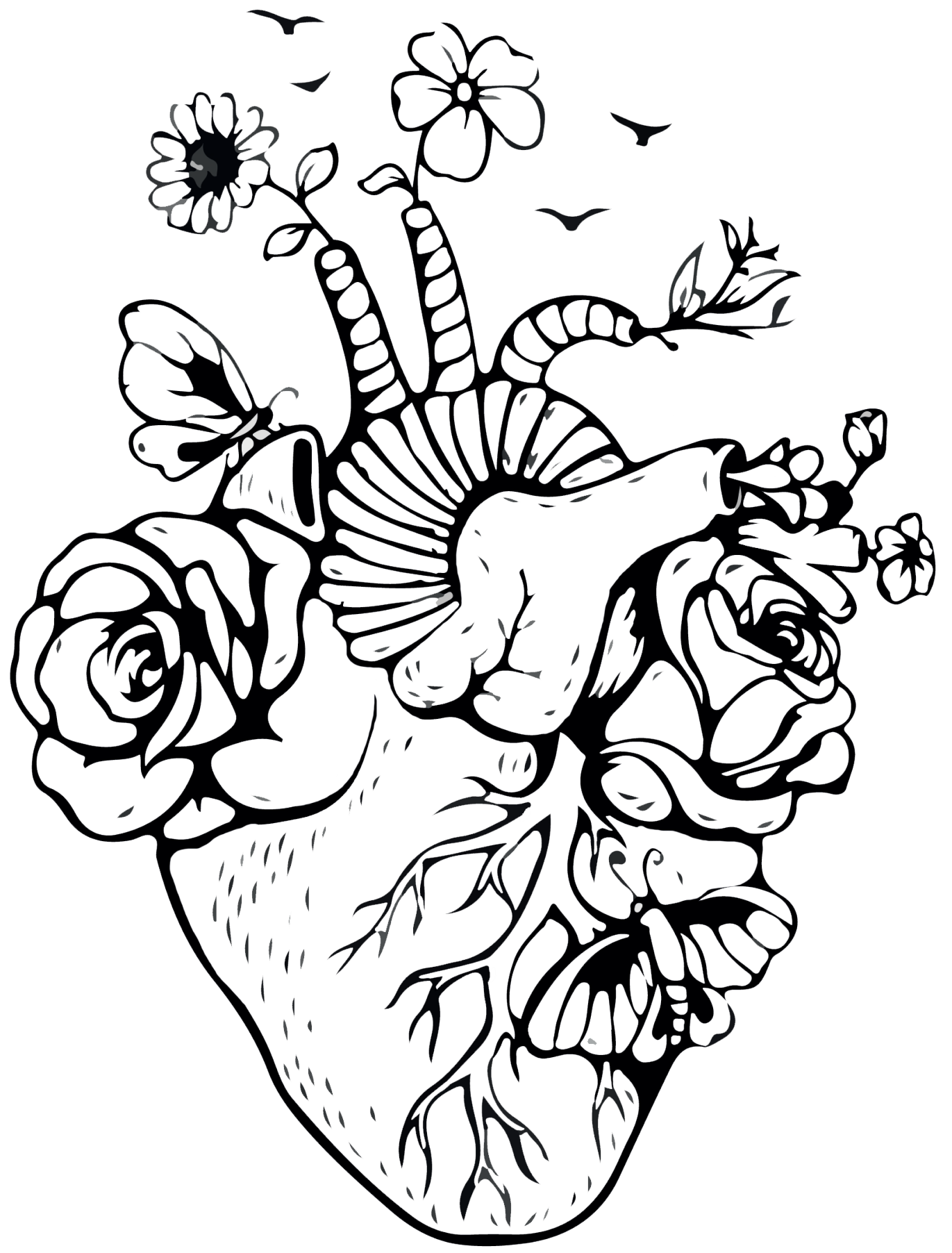




\section{CHAPTER 1}

Introduction 


\section{The burden of cardiovascular disease}

Cardiovascular disease (CVD) has remained the leading cause of death worldwide as well as in the region of Europe, accounting for $47 \%$ and $39 \%$ of all deaths in respectively females and males in Europe. ${ }^{1,2}$ Despite sustained declines in CVD mortality in many countries across Europe, it is unlikely that the World Health Organisation (WHO) target to achieve a 25\% relative reduction in the overall mortality from CVD, cancer, diabetes, and chronic respiratory disease will be attained. ${ }^{1}$ Besides, the decline in the age-standardized incidence and prevalence of CVD has been small during the last 27 years. ${ }^{1}$ In the Netherlands, the prevalence of CVD increased with 150,000 to 1.55 million people between 2015 and 2019, possibly due to ageing, but at least also partly attributable to an increase in prevalence of obesity. ${ }^{3}$ There is concern about achievement of the WHO and United Nations targets in cardiovascular risk factor reductions by $2025 .{ }^{1,4}$ In Europe, the prevalence of obesity has more than doubled in the last 36 years, 1 in 3 adults is insufficiently physically active and the downward trend in prevalence of elevated blood pressure appears to be minimal. ${ }^{1}$

The burden of CVD also poses a financial challenge. In the Netherlands, CVD accounted for more than $10 \%$ of health expenditure and was at the top of the list of hospital spending in 2016. ${ }^{5}$ Health-care expenditures in Western countries are already high and expected to increase further due to the ageing of the population and an increase in the prevalence of chronic disease. If health expenditure increases steadily in the near future, it will rise to $30 \%$ of the gross domestic product in 2040 in the Netherlands.

\section{Cardiovascular risk factors}

The concept of cardiovascular risk factors, including age, smoking and blood pressure, was already introduced over 50 years ago by the Framingham Heart study investigators. ${ }^{6}$ Especially cardiovascular risk factors that are modifiable and when appropriately treated reduce cardiovascular risk are of major significance for public health. Major modifiable risk factors include high blood pressure, elevated blood lipids, smoking, physical inactivity, obesity and an unhealthy diet.

Blood pressure (BP) has a strong log-linear association with the occurrence of CVD. ${ }^{7}$ A reduction of $10 \mathrm{~mm} \mathrm{Hg}$ in systolic BP or $5 \mathrm{~mm} \mathrm{Hg}$ in diastolic BP is associated with about $40 \%$ lower relative risk of stroke death and about $30 \%$ lower 
relative risk of death from CVD in middle age, ${ }^{8}$ with larger absolute risk reductions for patients with a higher baseline cardiovascular risk. ${ }^{9}$

There is convincing evidence that reducing plasma LDL-cholesterol levels reduces CVD risk. Meta-analyses have showed that statin therapy can safely reduce the 5 -year incidence of major coronary events, coronary revascularisation, and stroke by about one fifth per mmol/L reduction in LDL cholesterol. ${ }^{10} \mathrm{~A}$ more intensive lowering of LDL-cholesterol by statins further reduces major vascular events, ${ }^{11}$ but it remains unclear whether below a certain level of LDL-cholesterol the benefit ends and/or harm occurs.

Besides the clear associations of blood pressure and LDL-cholesterol with CVD risk and the beneficial effects of lowering the levels of these risk factors, it is well known that cardiovascular disease and mortality risk can be reduced by a adopting a healthier lifestyle, including increasing physical activity, keeping a healthy diet, smoking cessation and weight reduction. ${ }^{12-16}$ In 2017, smoking, high body mass index (i.e. weight $/$ length $^{2}$ ), alcohol abuse and diets high in sodium were among the largest contributors to global disability-adjusted life-years (DALYs). ${ }^{17}$ While contributing to the burden of chronic disease, including CVD, these risk factors also provide opportunities for intervention.

A strong dose-response relationship between the number of cigarettes smoked and CVD exists, ${ }^{18}$ and smoking cessation is the most effective measure to prevent CVD. ${ }^{14}$

An increase in physical activity to levels recommended in cardiovascular prevention guidelines has a substantial positive impact on incident CVD and allcause and cardiovascular mortality. ${ }^{19}$ Benefits already start from any physical activity and can reduce mortality by about $31 \%$ in individuals who meet guidelines compared with individuals reporting no physical activity. ${ }^{19,20}$ Guidelines recommend 150 to 300 minutes a week of moderate intensity physical activity in healthy adults and avoid sitting for more than eight hours a day. ${ }^{21,22}$

Further, a healthy diet, low in sodium intake, rich in vegetables, fruits, and low-fat dairy products, can lower blood pressure substantially. ${ }^{23}$ Also, higher intakes of polyunsaturated fatty acids (PUFAs) and carbohydrates from whole grains are 
significantly associated with a lower risk of CHD. ${ }^{24}$ In addition, it is well known that smoking is associated with excess mortality. ${ }^{25}$ Lastly, an increased BMI is associated with an adverse effect on all major CVD risk factors, including a higher LDL- and lower HDL-cholesterol levels and in increase in blood pressure. ${ }^{26}$ Weight reduction in overweight and obese people will improve their CVD risk. ${ }^{27}$

\section{The evidence to practice gap}

A wide gap still exists between evidence-based cardiovascular risk factor management recommendations in CVD prevention guidelines and everyday clinical practice. Despite the clear relation between lifestyle, blood pressure, LDLcholesterol and CVD risk, cardiovascular risk factors are generally insufficiently controlled. Also in primary care poor implementation of preventive measures are of major concern, as consistently shown by EUROASPIRE surveys. ${ }^{28-30}$ The most recent EUROASPIRE V cross sectional primary care study among 16 European countries found that among patients at high risk, without a history of CVD in primary care, $18.1 \%$ was smoker, $43.5 \%$ obese (body mass index $\geq 30 \mathrm{~kg} / \mathrm{m} 2$ ) and $63.8 \%$ centrally obese (waist circumference $\geq 88 \mathrm{~cm}$ for women, $\geq 102 \mathrm{~cm}$ for men). ${ }^{30}$ Of patients on BP lowering medication $47.0 \%$ reached the target of $<140 / 90 \mathrm{~mm} \mathrm{Hg}$ and among treated dyslipidaemia patients only $46.9 \%$ attained the LDL-cholesterol target of $<2.6 \mathrm{mmol} / \mathrm{l}$. Besides, many patients in the primary care arm of EUROASPIRE $\mathrm{V}$ reported low rates of having received lifestyle advice. For example, one-fifth of obese patients were never told that they were overweight, and more than a third were unaware of their weight target. Also, less than half of patients on lipid-lowering medication were aware of their cholesterol levels and less than a third knew their cholesterol target.

These, and others, findings clearly show that to achieve adequate prevention of CVD an effective integrated strategy that can address multiple risk factors is needed. ${ }^{31}$

\section{Cardiovascular risk management and the role of primary care}

Healthcare providers face the challenge to identify, manage and monitor cardiovascular risk factors in large numbers of individuals at increased risk for developing CVD. Moreover, most patients have more than one risk factor. The total CVD risk is a consequence of the interaction of many risk factors and modest increases of several risk factors can be more harmful than a high level 
of a single risk factor. ${ }^{32}$ This underlines the importance of multifactorial and multidisciplinary cardiovascular risk factor management (CVRM) interventions, as also recommended by the European guidelines on cardiovascular disease prevention. ${ }^{27}$ These interventions include promoting a healthy lifestyle through behavioural changes, including diet, physical activity and smoking cessation programmes for resistant smokers. Further, psychosocial risk factors (stress, social isolation, and negative emotions) should be taken into account as these may act as barriers against behavioural change.

General practitioners play a key role in multifactorial and multidisciplinary CVRM, as they have a longstanding relationship with their patients and, often, family members. The longitudinal nature of primary care provides multiple opportunities for clinicians to provide health behaviour advice and counselling over long periods of time. Therefore, an integrated multidisciplinary CVRM programme in primary care offers a potentially effective way to improve the implementation of CVD guideline recommendations and thereby the quality of CVD prevention. ${ }^{33}$

\section{Integrated care to improve cardiovascular risk management}

In some European countries, integrated and multidisciplinary CVRM programmes were introduced in primary care in recent years. Most of these programmes are based on the Chronic Care Model (CCM). ${ }^{34}$ This model is a guide to improve care for patients with chronic conditions such as cardiovascular diseases. ${ }^{35}$ The model predicts that improvement in its 6 interrelated components - self-management support, clinical information systems, delivery system redesign, decision support, health care organization, and community resources - can produce system reform in which informed, activated patients interact with prepared, proactive practice teams (figure 1). ${ }^{35}$ Programmes based on the CCM have shown to improve process and outcome measures, particularly in patients with diabetes. ${ }^{36}$ However, evidence on the effect of integrated care programmes for CVRM in primary care on outcomes such as blood pressure, cholesterol levels, smoking status and cardiovascular risk is scarce. ${ }^{31,37-39}$ Furthermore, multidisciplinary integrated CVRM is a heterogeneous concept. Therefore, an overall assessment of the effectiveness of integrated programmes for CVRM is hindered by heterogeneity in intervention strategies, target populations and reported outcomes. A systematic review of 31 randomized controlled trials (RCTs) on the effects of multiple health behavioural changes in primary care to reduce cardiovascular risk in people 
without established CVD found a modest, statistically significant effect on some $\mathrm{CV}$ risk factors, including blood pressure and cholesterol, but not on lifestyle (smoking, diet, physical activity) and overall CVD risk. ${ }^{40}$ Also for patients with known CVD RCTs have shown positive effects of CVRM programmes on blood pressure and cholesterol ${ }^{41}$, whereas other RCTs did not find an effect. ${ }^{42}$ Moreover, effects are often not sustained on the long term. ${ }^{43}$ A possible explanation might be that many interventions that prove to be efficacious in randomized trials are much less effective in the real world setting, which may be attributable to many factors, including differences in patient populations. ${ }^{44}$ Importantly, most evidence on complex interventions is based on RCTs, presenting the effect of the intervention when carefully implemented according to the existing guidelines under optimal conditions. ${ }^{45}$ However, such studies oversimplify reality and the results are not automatically applicable in daily practice. Therefore, more real-world evidence is needed.

\section{The Chronic Care Model}

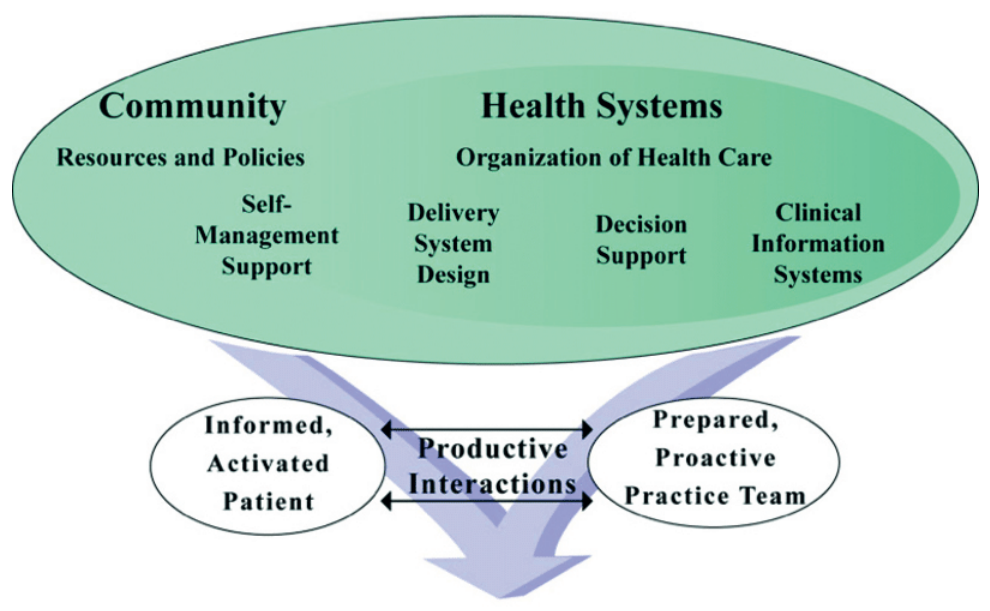

Improved Outcomes

Developed by The MacColl Institute Developed by The Maccoll Institute
A ACP-ASIM Journals and Books

Figure 1. The different components of Wagner's Chronic Care Model and how they are used to facilitate productive interactions between the patient and healthcare team to improve outcomes. 


\section{Aim and outline of this thesis}

The principle aim of this thesis is to provide insight in the effectiveness of an integrated and multidisciplinary programme for CVRM in a real-world primary care setting. Furthermore, this thesis describes the challenges of the implementation of CVRM in general practice in chapters about the process of implementation and therapeutic inertia.

In Chapter 2 we comment on the 2016 European Guidelines on cardiovascular disease prevention in clinical practice and address challenges and feasibility of the recommendations for everyday general practice. Chapter $\mathbf{3}$ describes the design of the ZWOT-CASE study ((ZWOlle inTegrated care for CArdiovaScular risk managEment study), a prospective observational study among patients with a high CV risk, assessing the effects of an integrated care programme for cardiovascular risk management (CVRM) in general practice on systolic blood pressure and LDL-cholesterol compared to usual care. The results of the ZWOTCASE study are presented in Chapter 4. In Chapter $\mathbf{5}$ we evaluated the process of the implementation of the integrated care programme for CVRM within the framework of the ZWOT-CASE study, to gain a deeper understanding of the lack of effectiveness of the programme. In Chapter 6 we compared hospital care and costs related to CVRM in the period before and after implementation of an integrated care programme for CVRM in primary care among patients with established CVD. Chapter 7 describes therapeutic inertia in dyslipidaemia in primary care. This thesis ends with a general discussion (Chapter 8) including an overall interpretation of the main findings, recommendations for improvement in integrated CVRM in primary care and suggestions for further research. The RE-AIM model is used to discuss the potential impact of the integrated multidisciplinary CVRM programme in daily practice. 


\section{REFERENCES}

1. Timmis A, Townsend N, Gale CP, et al. European society of cardiology: Cardiovascular disease statistics 2019. Eur Heart J. 2020;41(1):12-85.

2. Roth GA, Abate D, Abate KH, Abay SM, Abbafati C, Abbasi N. Global, regional, and national age-sex-specific mortality for 282 causes of death in 195 countries and territories, 1980-2017: A systematic analysis for the global burden of disease study 2017. Lancet. 2018;392(10159):1736-1788.

3. de Boer AR, van Dis I, Visseren F, Vaartjes I, Bots ML. Hart- en vaatziekten in nederland 2019, cijfers over incidentie, prevalentie, ziekte en sterfte. Hartstichting. 2019.

4. Roth GA, Nguyen G, Forouzanfar MH, Mokdad AH, Naghavi M, Murray CJ. Estimates of global and regional premature cardiovascular mortality in 2025. Circulation. 2015;132(13):1270-1282.

5. OECD. Expenditure by disease, age and gender-focus on health spending. 2016. https://www.oecd.org/els/health-systems/estimating-expenditure-by-dis ease-ageand-gender.htm. Updated 2019.

6. KANNEL WB, DAWBER TR, KAGAN A, REVOTSKIE N, STOKES J. Factors of risk in the development of coronary heart disease--six year follow-up experience. the framingham study. Ann Intern Med. 1961;55:33-50.

7. Rapsomaniki E, Timmis A, George J, et al. Blood pressure and incidence of twelve cardiovascular diseases: Lifetime risks, healthy life-years lost, and age-specific associations in 1.25 million people. Lancet. 2014;383(9932):1899-1911.

8. Lewington S, Clarke R, Qizilbash N, Peto R, Collins R, Prospective Studies Collaboration. Age-specific relevance of usual blood pressure to vascular mortality: A meta-analysis of individual data for one million adults in 61 prospective studies. Lancet. 2002;360(9349):1903-1913.

9. Blood Pressure Lowering Treatment Trialists' Collaboration. Blood pressure-lowering treatment based on cardiovascular risk: A meta-analysis of individual patient data. Lancet. 2014;384(9943):591-598.

10. Baigent C, Keech A, Kearney PM, et al. Efficacy and safety of cholesterol-lowering treatment: Prospective meta-analysis of data from 90,056 participants in 14 randomised trials of statins. Lancet. 2005;366(9493):1267-1278.

11. Baigent C, Blackwell L, Emberson J, et al. Efficacy and safety of more intensive lowering of LDL cholesterol: A meta-analysis of data from 170,000 participants in 26 randomised trials. Lancet. 2010;376(9753):1670-1681. 
12. Chiuve SE, McCullough ML, Sacks FM, Rimm EB. Healthy lifestyle factors in the primary prevention of coronary heart disease among men: Benefits among users and nonusers of lipid-lowering and antihypertensive medications. Circulation. 2006;114(2):160-167.

13. Barbaresko J, Rienks J, Nothlings U. Lifestyle indices and cardiovascular disease risk: A meta-analysis. Am J Prev Med. 2018;55(4):555-564.

14. Chow CK, Jolly S, Rao-Melacini P, Fox KA, Anand SS, Yusuf S. Association of diet, exercise, and smoking modification with risk of early cardiovascular events after acute coronary syndromes. Circulation. 2010;121(6):750-758.

15. Yusuf S, Hawken S, Ounpuu S, et al. Effect of potentially modifiable risk factors associated with myocardial infarction in 52 countries (the INTERHEART study): Case-control study. Lancet. 2004;364(9438):937-952.

16. Hulsegge G, Looman M, Smit HA, Daviglus ML, van der Schouw, Y T, Verschuren WM. Lifestyle changes in young adulthood and middle age and risk of cardiovascular disease and all-cause mortality: The doetinchem cohort study. J Am Heart Assoc. 2016;5(1):10.1161/JAHA.115.002432.

17. GBD 2017 Risk Factor Collaborators. Global, regional, and national comparative risk assessment of 84 behavioural, environmental and occupational, and metabolic risks or clusters of risks for 195 countries and territories, 1990-2017: A systematic analysis for the global burden of disease study 2017. Lancet. 2018;392(10159):1923-1994.

18. Holme I, Retterstol K, Norum KR, Hjermann I. Lifelong benefits on myocardial infarction mortality: 40-year follow-up of the randomized oslo diet and antismoking study. J Intern Med. 2016;280(2):221-227.

19. Kraus WE, Powell KE, Haskell WL, et al. Physical activity, all-cause and cardiovascular mortality, and cardiovascular disease. Med Sci Sports Exerc. 2019;51(6):1270-1281.

20. Arem H, Moore SC, Patel A, et al. Leisure time physical activity and mortality: A detailed pooled analysis of the dose-response relationship. JAMA Intern Med. 2015;175(6):959-967.

21. King AC, Whitt-Glover MC, Marquez DX, et al. Physical activity promotion: Highlights from the 2018 physical activity guidelines advisory committee systematic review. Med Sci Sports Exerc. 2019;51(6):1340-1353.

22. Dutch College of General Practitioners Guideline Development Group. Guideline cardiovascular risk management (third revision). Huisarts Wet. 2019:62: 55-7.

23. Sacks FM, Svetkey LP, Vollmer WM, et al. Effects on blood pressure of reduced dietary sodium and the dietary approaches to stop hypertension (DASH) diet. DASH-sodium collaborative research group. N Engl J Med. 2001;344(1):3-10. 
24. Li Y, Hruby A, Bernstein AM, et al. Saturated fats compared with unsaturated fats and sources of carbohydrates in relation to risk of coronary heart disease: A prospective cohort study. J Am Coll Cardiol. 2015;66(14):1538-1548.

25. Doll R, Peto R, Boreham J, Sutherland I. Mortality in relation to smoking: 50 years' observations on male british doctors. BMJ. 2004;328(7455):1519.

26. Lamon-Fava S, Wilson PW, Schaefer EJ. Impact of body mass index on coronary heart disease risk factors in men and women. the framingham offspring study. Arterioscler Thromb Vasc Biol. 1996;16(12):1509-1515.

27. Piepoli MF, Hoes AW, Agewall S, et al. 2016 european guidelines on cardiovascular disease prevention in clinical practice: The sixth joint task force of the european society of cardiology and other societies on cardiovascular disease prevention in clinical practice (constituted by representatives of 10 societies and by invited experts): Developed with the special contribution of the european association for cardiovascular prevention \& rehabilitation (EACPR). Eur Heart J. 2016.

28. Kotseva K, Wood D, De Backer G, et al. EUROASPIRE III. management of cardiovascular risk factors in asymptomatic high-risk patients in general practice: Cross-sectional survey in 12 european countries. Eur J Cardiovasc Prev Rehabil. 2010;17(5):530-540.

29. Kotseva K, De Bacquer D, De Backer G, et al. Lifestyle and risk factor management in people at high risk of cardiovascular disease. A report from the european society of cardiology european action on secondary and primary prevention by intervention to reduce events (EUROASPIRE) IV cross-sectional survey in 14 european regions. Eur J Prev Cardiol. 2016;23(18):2007-2018.

30. Kotseva K, De Backer G, De Bacquer D, et al. Primary prevention efforts are poorly developed in people at high cardiovascular risk: A report from the european society of cardiology EURObservational research programme EUROASPIRE V survey in 16 european countries. Eur J Prev Cardiol. 2020:2047487320908698.

31. Goldstein MG, Whitlock EP, DePue J, Planning Committee of the Addressing Multiple Behavioral Risk Factors in Primary Care Project. Multiple behavioral risk factor interventions in primary care. summary of research evidence. Am J Prev Med. 2004;27(2 Suppl):61-79.

32. Yusuf S, Islam S, Chow CK, et al. Use of secondary prevention drugs for cardiovascular disease in the community in high-income, middle-income, and low-income countries (the PURE study): A prospective epidemiological survey. Lancet. 2011;378(9798):1231-1243.

33. Osteresch R, Fach A, Schmucker J, et al. Long-term risk factor control after myocardial infarction-A need for better prevention programmes. J Clin Med. 2019;8(8):10.3390/ jcm8081114. 
34. Wagner EH, Austin BT, Davis C, Hindmarsh M, Schaefer J, Bonomi A. Improving chronic illness care: Translating evidence into action. Health Aff(Millwood). 2001;20(6):64-78.

35. Bodenheimer T, Wagner EH, Grumbach K. Improving primary care for patients with chronic illness. JAMA. 2002;288(14):1775-1779.

36. Bodenheimer T, Wagner EH, Grumbach K. Improving primary care for patients with chronic illness: The chronic care model, part 2. JAMA. 2002;288(15):1909-1914.

37. Martinez-Gonzalez NA, Berchtold P, Ullman K, Busato A, Egger M. Integrated care programmes for adults with chronic conditions: A meta-review. Int J Qual Health Care. 2014;26(5):561-570.

38. Snaterse M, Dobber J, Jepma P, et al. Effective components of nurse-coordinated care to prevent recurrent coronary events: A systematic review and meta-analysis. Heart. 2016;102(1):50-56.

39. Fleming P, Godwin M. Lifestyle interventions in primary care: Systematic review of randomized controlled trials. Can Fam Physician. 2008;54(12):1706-1713.

40. Alageel S, Gulliford MC, McDermott L, Wright AJ. Multiple health behaviour change interventions for primary prevention of cardiovascular disease in primary care: Systematic review and meta-analysis. BMJ Open. 2017;7(6):e015375-015375.

41. Khunti K, Stone M, Paul S, et al. Disease management programme for secondary prevention of coronary heart disease and heart failure in primary care: A cluster randomised controlled trial. Heart. 2007;93(11):1398-1405.

42. Murphy AW, Cupples ME, Smith SM, et al. Effect of tailored practice and patient care plans on secondary prevention of heart disease in general practice: Cluster randomised controlled trial. BMJ. 2009;339:b4220.

43. Murphy AW, Cupples ME, Murphy E, et al. Six-year follow-up of the SPHERE RCT: Secondary prevention of heart disease in general practice. BMJ Open. 2015;5(11):e007807-007807.

44. Glasgow RE, Vogt TM, Boles SM. Evaluating the public health impact of health promotion interventions: The RE-AIM framework. Am J Public Health. 1999;89(9):1322-1327.

45. Minary L, Trompette J, Kivits J, Cambon L, Tarquinio C, Alla F. Which design to evaluate complex interventions? toward a methodological framework through a systematic review. BMC Med Res Methodol. 2019;19(1):92-6. 


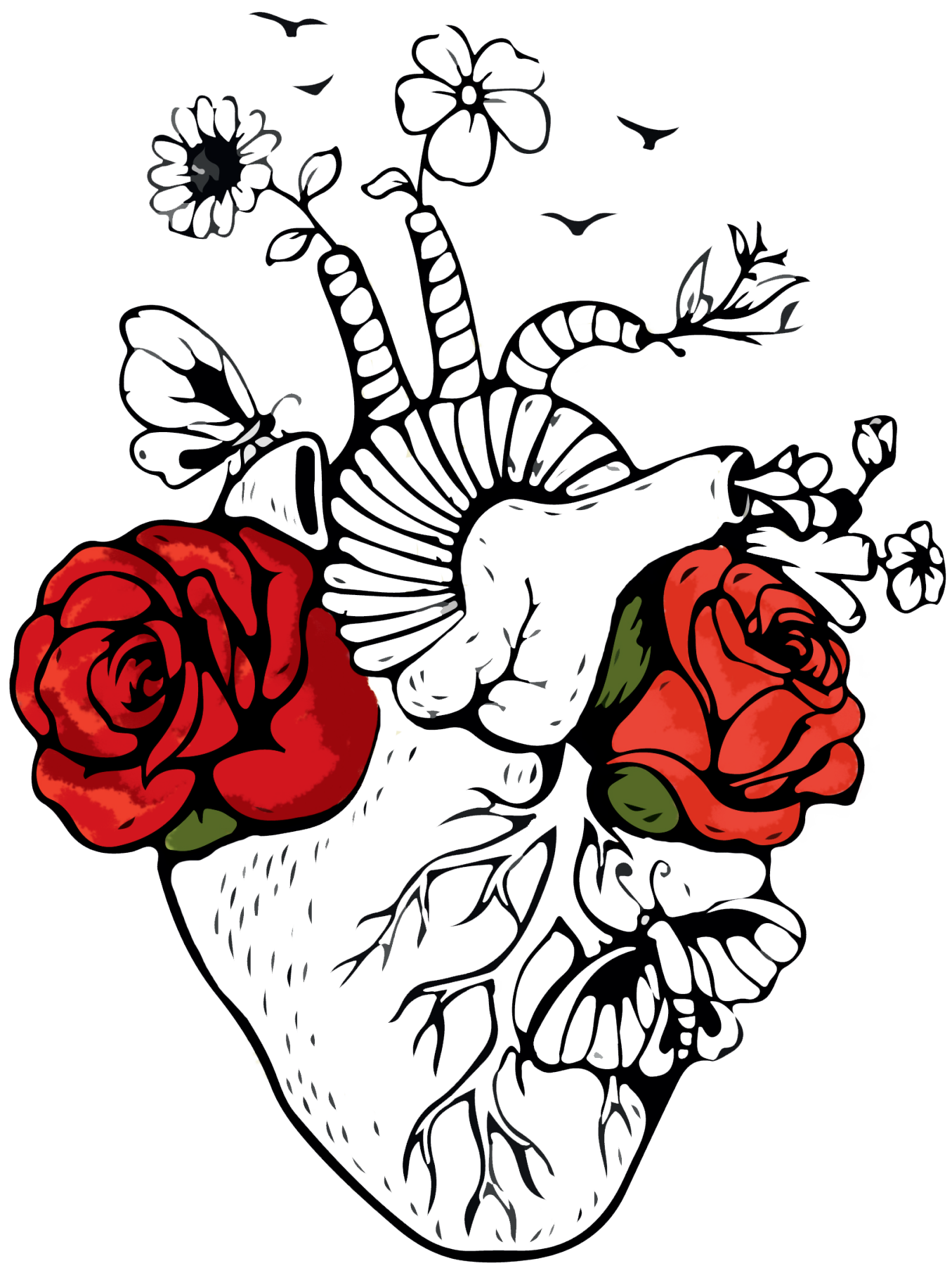




\section{CHAPTER 2}

\section{The new European guideline on cardiovascular disease prevention; how to make progress in general practice?}

Suzanne Marchal

Arnoud W. J. van't Hof

Monika Hollander

European Journal of General Practice, 2017 


\section{ABSTRACT}

The new guideline on cardiovascular disease (CVD) prevention, issued by the European Society of Cardiology was endorsed by 10 other societies, including Wonca Europe. It advices on how to reduce the cardiovascular (CV) risk in the population and attributes an important role to the general practitioner (GP). The GP is involved in treatment of the high-risk population as well as in public health measures to encourage a healthy lifestyle and CV risk factor reduction in the whole population. The new guideline gives room for a personalized approach and emphasizes that $\mathrm{CV}$ risk estimation and counselling need regular follow-up. We highlight the recommendations that most caught our eye and comment on the challenges for general practice.

\section{KEY MESSAGES}

- CVD prevention asks for a personalized approach, taking into account biological age, ethnicity, vitality, comorbidity and personal preferences.

- Estimation of the CV risk and assessment of lifestyle factors, including psychosocial aspects, should regularly be repeated.

- Depending on the healthcare system, GPs can play an essential role both in individual risk assessment and implementation of the guideline in national and regional prevention frameworks.

- CVD prevention needs to get a prominent place in clinical practice, supported by a clear policy and adequate organization. 


\section{COMMENTARY}

\section{Risk estimation and personalized approach}

In the new guideline ${ }^{1}$, the accessible and simple to use risk chart to estimate the short-term (10 years) risk of cardiovascular death remains the basis for the total $\mathrm{CV}$ risk approach for prevention. Given that in this algorithm, age is the main driver of CV risk, young people may have many risk factors but almost never reach the treatment threshold, while most elderly have a high short-term risk based on age alone. A challenge is how to motivate young people for lifestyle change, even when the short-term risk is low. Fortunately, the new guideline provides practical tools that can help in the communication about CV risk and the urgency of lifestyle change, namely the relative risk score and 'risk age.' They can be used in all populations, irrespective of baseline risk. In the elderly, the new guideline recommends personalized care by taking into account quality of life, frailty or biological age. In general, more lenient treatment goals could be applied in elderly, for example, for systolic blood pressure or HbA1c. However, in vital elderly a more strict treatment regimen should be applied than in the frail. For the GP, guidance that is more practical is needed on how to assess and discuss vitality and personal preferences in the elderly. ${ }^{2}$ Furthermore, attention is paid to the higher CVD risk in some ethnic minorities, survivors of cancer after treatment with chemotherapy or radiotherapy, women with a history of pre-eclampsia, pregnancy-induced hypertension, gestational DM, and/or a history of giving birth prematurely. Besides, estimation of the CV risk should be repeated every five years. For individuals with risks close to treatment thresholds, an even more frequent $\mathrm{CV}$ risk assessment is recommended and patients with adverse lifestyle factors should regularly be counselled. The new guideline continues to recognize the role of psychosocial stressors as CVD risk modifiers, barriers to treatment adherence and hampering factors for efforts to promote a healthy lifestyle. It provides a questionnaire to screen for psychosocial factors. However, implementation of this kind of tool in daily general practice has not been evaluated yet and will require sufficient consultation time and a plan to alleviate stress factors. Furthermore, referral options to social and psychological healthcare workers and support from local frameworks should be provided if indicated. Altogether, it is a challenge for general practice to organize the care aligned to these recommendations. For the implementation of broad CVD prevention, adequate ICT support, as well as a trained multidisciplinary team, is essential including, e.g. GPs, practice nurses, dieticians, 
physiotherapists, psychologists and medical specialists. One of the challenges that lie ahead is how to exchange smoothly patient data and responsibilities in the healthcare chain.

\section{Role of measures of subclinical vascular disease in persons with moderate $\mathrm{CV}$ risk}

The new guideline acknowledges that especially in patients with moderate risk who are near the treatment threshold, additional information on the presence of subclinical vascular diseases such as carotid plaques, coronary calcium score and the ankle-brachial index could be of help to reclassify the patient's CV risk. However, systematically measuring these markers is not recommended since they have not yet been studied as screening tools. Further, clear thresholds above which a risk is substantially higher are also lacking. In clinical practice, GPs are increasingly confronted with information on measurements that could reclassify someone's risk. Weighing this information should be done with caution and should be done continuously at the discretion of the GP. It could be discussed in the shared decision-making process with the patient and/or the vascular specialist.

\section{Role of the GP and public health}

Organizing broad CVD prevention is still a huge challenge in which the general practice plays an important role in promoting a healthy lifestyle across the population. It is important to realize that the responsibility of the GP extends beyond the clinical practice. What do GPs need to make it feasible? In addition, what is the role of the GP in unifying different stakeholders? If a policy exists, GPs should have a role in integrating this policy into national and regional prevention frameworks. At the same time, the extra efforts of GPs in CVD prevention should be supported by concordant actions of surrounding organizations and (local) government and adequate finance. All involved organizations, including the government, local and regional authorities, and insurance companies need to take a stand on this issue. The guideline acknowledges that organizing CVD prevention is resource dependent. A fundamental question to be answered is who is the problem-owner and who is responsible for orchestrating the process? To take responsibility, but also to explore borders, GPs have to outline a clear vision of their role in CVD prevention. ${ }^{3}$ This vision may be dependent on the organization of healthcare in different countries. 


\section{Evaluation of CVD prevention}

Due to various causes, about half of the GPs use the European guidelines. ${ }^{4}$ To improve the translation of the recommendations into clinical practice, the new guideline recommends monitoring and evaluating CVD prevention. Furthermore, there are still gaps in the evidence for CVD prevention. ${ }^{5}$ For example, the combined effect of the high-risk and population approach should be studied. Since this concerns a combination of two complex interventions, several methodological challenges will be encountered.

\section{Conclusion}

The new European guideline on cardiovascular disease prevention provides room for improvement of CVD prevention in general practice. As we have to deal with an ageing population, an increasing prevalence of $\mathrm{DM}$, a diverse target population for CVD prevention and the need for a more personalized approach and repeated CV risk-assessment of diverse target groups, GP's will have to develop a vision on how to organize the practice providing the adequate care as is recommended in this guideline. GPs need to be proactive and need to collect data on possible CV risk factors systematically and routinely. Adequate ICT support with a reminder system should be considered and collaboration with other healthcare providers needs to be established. GPs need to show leadership and to look over the walls of their practices to help build foundations for CVD prevention across the whole spectrum and to help promote a healthy lifestyle in the whole population. Finally, scientific evaluation of the effects of the combined high risk and population approach is needed for sustainable CVD prevention. 


\section{REFERENCES}

1. Piepoli MF, Hoes AW, Agewall S, et al. 2016 european guidelines on cardiovascular disease prevention in clinical practice: The sixth joint task force of the european society of cardiology and other societies on cardiovascular disease prevention in clinical practice (constituted by representatives of 10 societies and by invited experts): Developed with the special contribution of the european association for cardiovascular prevention \& rehabilitation (EACPR). Eur Heart J. 2016.

2. Jansen J, McKinn S, Bonner C, et al. General practitioners' decision making about primary prevention of cardiovascular disease in older adults: A qualitative study. PLoS One. 2017;12(1):e0170228.

3. Heijmans N, van Lieshout J, Wensing M. Information exchange networks of health care providers and evidence-based cardiovascular risk management: An observational study. Implement Sci. 2017;12(1):7-1.

4. Byrne D, O'Connor L, Jennings S, Bennett K, Murphy AW. A survey of GPs awareness and use of risk assessment tools and cardiovascular disease prevention guidelines. Ir Med J. 2015;108(7):204-207.

5. Dyakova M, Shantikumar S, Colquitt JL, et al. Systematic versus opportunistic risk assessment for the primary prevention of cardiovascular disease. Cochrane Database Syst Rev. 2016;1:CD010411. 


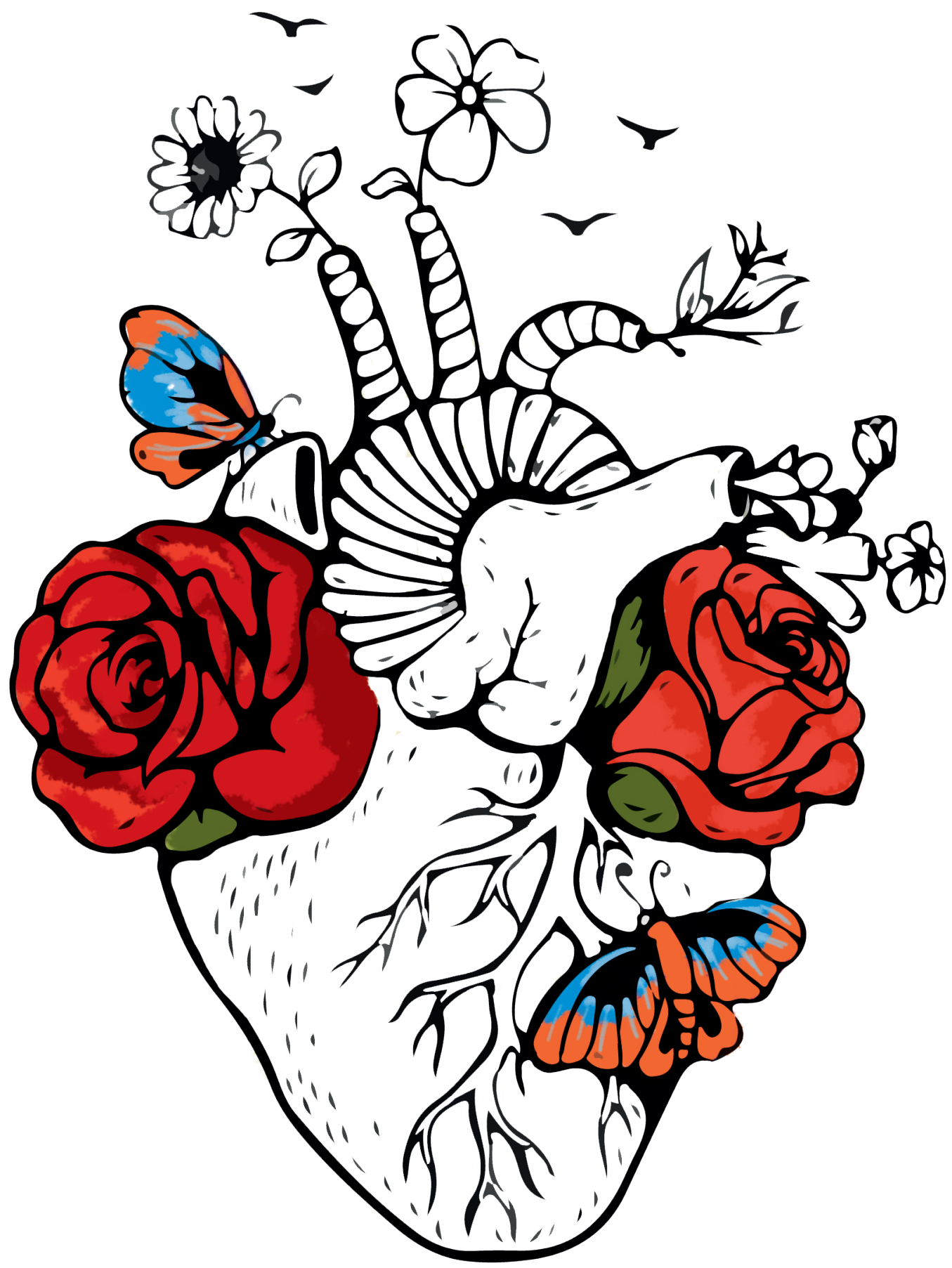




\title{
CHAPTER 3
}

Design of the ZWOT-CASE study: an

observational study on the effectiveness of an integrated programme for cardiovascular risk management compared to usual care in general practice

\author{
Suzanne Marchal \\ Monika Hollander \\ Marieke Schoenmakers \\ Michiel Schouwink \\ Jorik R. Timmer \\ Henk J. G. Bilo \\ Olof Schwantje \\ Arnoud W. J. van 't Hof \\ Arno W. Hoes
}

BMC Family Practice, 2019 


\section{ABSTRACT}

\section{Background}

Cardiovascular diseases (CVD) contribute considerably to mortality and morbidity. Prevention of CVD by lifestyle change and medication is important and needs full attention.

In the Netherlands an integrated programme for cardiovascular risk management (CVRM), based on the Chronic Care Model (CCM), has been introduced in primary care in many regions in recent years, but its effects are unknown.

In the ZWOT-CASE study, we will assess the effect of integrated care for CVRM in the region of Zwolle on two major cardiovascular risk factors: systolic blood pressure (SBP) and low-density lipoprotein cholesterol (LDL-cholesterol) in patients with or at high risk of CVD.

\section{Methods}

This study is a pragmatic observational study comparing integrated care for CVRM with usual care among patients aged 40-80 years with CVD $(n=370)$ or with a high CVD risk $(n=370)$ within 26 general practices. After one year follow-up, primary outcomes (SBP and LDL-cholesterol level) are measured. Secondary outcomes include lifestyle habits (smoking, dietary habits, alcohol use, physical activity), risk factor awareness, 10-year risk of cardiovascular morbidity or mortality, health care consumption, patient satisfaction and quality of life.

\section{Conclusion}

The ZWOT-CASE study will provide insight in the effects of integrated care for CVRM in general practice in patients with CVD or at high CVD risk. 


\section{INTRODUCTION}

Cardiovascular disease (CVD) is still the leading cause of death in the world and the second cause of death in Western societies. ${ }^{1,2}$ Because of the ageing population, the prevalence and associated costs of CVD are expected to increase considerably. ${ }^{3}$ Moreover, due to adverse lifestyle factors an increase in the prevalence of obesity and diabetes mellitus has been observed in the past 25 years. In addition, we are dealing with high levels of persistent smoking. These trends partly negate the beneficial effect of improvements in blood pressure and lipid control achieved in the last decades. ${ }^{4}$ Therefore, prevention of (re)occurrence of CVD remains crucial.

To prevent CVD, national and international guidelines for cardiovascular risk management (CVRM) provide clinical and organisational recommendations. ${ }^{5-7}$ However, implementation of evidence-based guidelines is far from optimal and treatment goals are often not achieved. ${ }^{8-10}$ Thus, despite the availability of accurate guidelines, CVRM needs improvement.

In the Netherlands, integrated care programmes were introduced to implement CVRM in general practices in recent years. The integrated CVRM care programme includes a patient-centred focus, use of clinical information systems, execution by practice nurses (PNs) and systematic invitation of patients for a CV risk assessment. The integrated CVRM care programme is based on the Chronic Care Model (CCM) that focuses on informed and activated patients who interact with trained, proactive practice teams. ${ }^{11,12}$

Integrated programmes compose a promising procedure to enhance chronic care and management of cardiovascular risk factors. However, solid evidence on the effect of integrated care programmes for CVRM in primary care on outcomes such as blood pressure, cholesterol levels, smoking status and cardiovascular risk is limited. ${ }^{13-15}$

A nurse-coordinated CVD prevention programme (Euro Action) has been shown to improve blood pressure targets. ${ }^{16}$ Also, a disease management programme for patients with coronary heart disease (CHD) in primary care led to more adequate treatment of blood pressure and cholesterol compared to usual care and to a better-controlled hypertension in high-risk patients. ${ }^{17}$ Additionally, a 
tailored implementation of cardiovascular risk management in general practice increases physical activity in cardiovascular patients, but did not affect other cardiovascular risk factors. ${ }^{18}$ More recently, a multicomponent cardiovascular prevention programme did not improve the overall risk profile in older adults free from CVD in primary care, compared to usual care. ${ }^{19}$ However, the usefulness of these previous studies is restricted by the heterogeneity in study designs, variety in the interventions tested and in the target populations. Most of the previous studies evaluated only a limited number of elements of the disease management programme for CVRM, such as lifestyle treatment or educational interventions. Rarely, effects of an integrated approach programme has been evaluated by analysing clinical parameters before and after implementation of the intervention, but adequate comparisons with control groups are lacking. ${ }^{20}$

In the ZWOT-CASE study (ZWOlle inTegrated care for CArdiovaScular risk managEment study), we will investigate the effect of integrated care for CVRM compared to usual care within general practices in the region of Zwolle in the eastern part of the Netherlands. In this paper, we describe the design of the study.

\section{METHODS/ DESIGN}

\section{Study aim}

The primary aim of the ZWOT-CASE study is to investigate whether the execution of an integrated primary care programme for CVRM in general practice leads to a more favourable CV risk profile in patients with known CVD or at high CVD risk as compared to usual care.

\section{Study design}

The ZWOT-CASE study is a prospective pragmatic observational study, performed among 740 patients with known CVD or at high CVD risk in general practice, comparing integrated care for CVRM with usual care. Patients in the usual care group are matched with patients in the intervention group according to age, gender and risk group (high CV risk or CVD). After one year of follow-up outcomes are compared between the intervention group and the usual care group. Primary outcomes are levels of systolic blood pressure and LDL-cholesterol. The study was reviewed by the Isala hospital Review Board and exempted from full assessment under the Medical Research Involving Human Subjects Act on the $16^{\text {th }}$ of June 2016. 


\section{Setting}

The study is performed in the Zwolle region in the Netherlands. This region includes 56 general practices (solo, duo and group practices) with in total 157 general practitioners (GPs), which are all affiliated to a care group 'Medrie'. Integrated care for CVRM is implemented in this region and coordinated by this care group by providing a practical guideline for the implementation of integrated care for CVRM, offering training to the PNs and organizing yearly benchmark meetings. Furthermore, all general practices collaborate with the same regional hospital (Isala Hospital) with dedicated medical specialists involved in organizing integrated care for CVRM. The care group reached an agreement on integrated care for CVRM with the regionally largest health care insurance company for three years. Implementation of other disease management programmes e.g. for diabetes mellitus and COPD is also organized by the same care group.

From January 2016, all practices were given the opportunity to participate in the integrated care for CVRM. Every three months there was a possibility to start with the programme. Participation was not mandatory. Consequently, the intervention was not randomly allocated to the practices Prior to our study, approximately two third of the general practices $(n=37)$ chose to implement integrated care for CVRM, while the remaining general practices $(n=19)$ will continue usual care due to a variety of reasons. The practices in the usual care group will not have the opportunity to start with the integrated care for CVRM during the study. This allowed the opportunity to compare integrated care for CVRM (intervention group) with usual care.

\section{The integrated CVRM programme}

The intervention under study is the integrated care programme for CVRM (see table 1), based on the Dutch CVRM guideline and the practical manual for CVRM provided by the Dutch Society of General Practitioners. ${ }^{7,21}$ The intervention includes features of the Chronic Care Model (CCM), such as self-management support (help patients to set limited goals and identify barriers to reach their goals), regular follow-up, registration of patient data in clinical information systems, a structured, nurse-led health care organization and easy accessible consultation of a specialist. ${ }^{22}$ The aim of the integrated care programme for CVRM is to decrease the risk of CVD for patients with a high CV risk or history of CVD by lifestyle treatment and medication if needed. Treatment goals are according to the 
Dutch guideline for CVRM, including systolic blood pressure $\leq 140 / 90 \mathrm{mmHg}$, LDLcholesterol $<2,5 \mathrm{mmol} / \mathrm{L}$, no smoking, $\mathrm{BMI} \leq 25 \mathrm{~kg} / \mathrm{m} 2$ ( $<70$ years) or $\leq 30 \mathrm{~kg} / \mathrm{m} 2$ ( $\geq 70$ years), $\geq 5$ days a week moderate intense physical activity $\geq 30$ minutes/day, and a healthy diet (daily 150 - 200 grams vegetables and 200 grams fruit; daily 30 - 40 grams dietary fibres; twice a week 100 - 150 gram fish, at least once fatty fish; maximum of 6 grams salt per day; maximum of 2 (men) or 1 (women) alcohol consumptions per day).

Table 1. Elements of the integrated care for CVRM

\begin{tabular}{|c|c|}
\hline Element & Contents \\
\hline \multirow[t]{3}{*}{ Systematic selection of target population } & $\begin{array}{l}\text { Systematic screening of practice population } \\
\text { based on ICPC-codes }\end{array}$ \\
\hline & $\begin{array}{l}\text { Systematic screening of practice population } \\
\text { based on ATC-codes }\end{array}$ \\
\hline & $\begin{array}{l}\text { Check of medical records according to in- and } \\
\text { exclusion criteria of the programme }\end{array}$ \\
\hline \multirow[t]{2}{*}{ Active invitation of patients for the programme } & $\begin{array}{l}\text { Active invitation for an intake consultation by } \\
\text { letter }\end{array}$ \\
\hline & Reminder in case of no response \\
\hline \multirow[t]{3}{*}{ Collaboration with different disciplines } & Well trained practice nurses, supervised by GPs \\
\hline & $\begin{array}{l}\text { Optional involvement of physiotherapist or } \\
\text { dietician }\end{array}$ \\
\hline & Online consultation of medical specialist \\
\hline $\begin{array}{l}\text { Data registration in multidisciplinary } \\
\text { information system for integrated care (KIS, } \\
\text { Portavita } ® \text { ) }\end{array}$ & $\begin{array}{l}\text { Including data on laboratory measurement, } \\
\text { intake consultation and follow-up controls }\end{array}$ \\
\hline Benchmark meetings & $\begin{array}{l}\text { Comparison op patient data of general practice } \\
\text { with national data }\end{array}$ \\
\hline \multirow[t]{3}{*}{$\begin{array}{l}\text { Laboratory measurement (prior to intake } \\
\text { consultation) }\end{array}$} & $\begin{array}{l}\text { Lipids (total cholesterol, HDL-cholesterol, } \\
\text { TC/HDL-cholesterol ratio, LDL-cholesterol, } \\
\text { triglycerides) }\end{array}$ \\
\hline & $\begin{array}{l}\text { Renal function (creatinine, GFR estimated by } \\
\text { MDRD) }\end{array}$ \\
\hline & Glucose \\
\hline \multicolumn{2}{|l|}{ Intake consultation } \\
\hline \multirow[t]{5}{*}{ Interview } & Cardiovascular complaints \\
\hline & Family history of CVD \\
\hline & Medication adherence \\
\hline & Lifestyle \\
\hline & Motivation to change behaviour \\
\hline Physical examination & Length, weight, BMI and waist circumference \\
\hline
\end{tabular}


Table 1. (Continued)

\begin{tabular}{ll}
\hline Element & Contents \\
\hline & Blood pressure \\
\hline Estimation of 10-years cardiovascular risk & Pulse rate \\
Individual treatment goals & Based on the risk chart in the Dutch guideline \\
General lifestyle advice & According to physical activity and diet \\
Medication (initiated or adapted if & Blood pressure lowering drugs \\
necessary) & \\
\hline Referral (if necessary) & Lipid lowering drugs \\
& Anticoagulants \\
& Smoking cessation programmes \\
\hline Regular follow-up & Dietician \\
\hline & Exercise programmes \\
\hline & Physiotherapist \\
\hline & Medical specialist \\
\hline
\end{tabular}

\section{Organisation strategies of the integrated CVRM programme}

The organisation strategies of integrated CVRM programme include:

- $\quad$ Systematic identification of patients eligible for CVRM

- Active invitation of patients for the programme

- Regular follow-up of patients

- Collaboration with different disciplines in the health care chain

- Registration of data in an information system for integrated care

General practices need to systematically organize their practice and identify the eligible population prior to implementation of integrated care for CVRM, based on a regional protocol ('Organized Practice') provided by the care group. According to this protocol patients with a history of CVD, at high CV risk ( $>10 \%)$ or prescribed blood pressure or lipid lowering drugs are included in the programme. To identify the patients, the practice population is systematically screened based on International Classification of Primary Care (ICPC)-coded diagnoses and on Anatomical Therapeutic Chemical-codes (ATC-codes), a classification system for drugs (tables 2, 3 and 4). Since they already are included in a separate disease management programme, patients with diabetes mellitus (DM) with ICPC-codes 
T90.01 (DM type I) and T90.02 (DM type II) are not included in the CVRM care programme. Subsequently, medical records of identified patients are manually checked to define whether they meet the in- and exclusion criteria.

Table 2. ICPC-coded diagnoses for patients with cardiovascular disease

\begin{tabular}{ll}
\hline Diagnosis & ICPC-code \\
\hline Angina pectoris & K74/ K74.01/ K74.02 \\
Acute myocardial infarction & K75 \\
Other/chronical ischemic heart disease & K76 \\
Coronary sclerosis & K76.01 \\
Previous myocardial infarction (>4 weeks ago) & K76.02 \\
Transient ischaemic attack (TIA) & K89.01 \\
Cerebral infarction & K90.3 \\
Intermittent claudication & K92.01 \\
Aneurysm aortae & K99.01 \\
\hline
\end{tabular}

Table 3. ICPC-coded diagnoses for patients with high ( $>10 \%)$ cardiovascular risk

\begin{tabular}{ll}
\hline Diagnosis & ICPC-code \\
\hline Hypertension without organ damage & K86.00 \\
Hypertension with organ damage & K87.00 \\
Disorder of lipid metabolism & T93.00 \\
Hypercholesterolemia & T93.01 \\
Mixed hyperlipidaemia & T93.03 \\
Familial hypercholesterolemia/-lipidaemia & T93.04 \\
Rheumatoid arthritis & L88.01 \\
M. Bechterew & L88.02 \\
Psoriatic arthritis & S91.00 \\
\hline
\end{tabular}

Table 4. ATC-codes

\begin{tabular}{ll}
\hline Medicine & ATC-code \\
\hline Antithrombotic agents & B01 \\
Cardiac therapy & $\mathrm{C} 01$ \\
Blood pressure lowering drugs & $\mathrm{C} 02$ \\
Diuretics & $\mathrm{C} 03$ \\
Beta blocking agents & $\mathrm{C} 07$ \\
Calcium channel blockers & $\mathrm{C} 08$ \\
Agents acting on the renin-angiotensin system & $\mathrm{C} 09$ \\
Lipid modifying agents & $\mathrm{C} 10 \mathrm{~A}$ \\
\hline
\end{tabular}


Once the eligible patients are identified, patients are actively invited by mail for an intake consultation. In this letter, patients are informed about the CVRM programme and invited to make an appointment for an intake consultation. If a patient does not respond to the invitation letter, a reminder is sent.

After the intake consultation, patients are monitored on a regular base in general practice. The frequency of follow-up visits depends on cardiovascular risk and treatment goals of individual patients, but a follow-up visit should be performed at least once a year.

Collaboration with several disciplines in the health care chain, such as GPs, medical specialists, practice nurses and -assistants, dieticians and physiotherapists, is an important focus of the CVRM programme. General practices implementing the integrated care intervention have well trained PNs, who identify the patients, review medical records and interview and examine the patients. All the PNs followed basic training including basic education in CVRM. In addition, some of the PNs followed a specialization course in CVRM, but this is not obligatory. The GP supervises the PNs. A dietician or physiotherapist may be involved if necessary. In addition, a hospital specialist can be consulted easily online if necessary. If other disciplines are involved, they are given access to the patient data collected in a multidisciplinary information system for integrated care (KIS, Portavita ${ }^{\circledR}$ ). This KIS is also used as a communication platform between the disciplines.

All patient data collected during the intake visit and follow-up visits will be registered in the KIS. These data will be used for benchmark purposes, including comparison of mean systolic blood pressure and LDL-cholesterol levels and smoking rates per practice with national data. Practices receive a benchmark report once a year and benchmark meetings will be organized by the care group.

\section{Integrated CVRM programme for individual patients}

For individual patients, the integrated CVRM programme includes:

- An intake consultation

- Regular follow-up visits

- Options for referral to get support in changing lifestyle 
All eligible patients are invited for an individual face-to-face intake consultation at the general practice. Prior to the consultation, lipids (total cholesterol, HDLcholesterol, TC/HDL-cholesterol ratio, LDL-cholesterol, triglycerides), renal function (creatinine, glomular filtration rate (GFR) estimated by the formula based on the Modification of Diet in Renal Disease study (MDRD)) and glucose are measured. The consultation consists of several components, including an interview to assess cardiovascular complaints, family history of CVD and difficulties with taking medication. Further, smoking habits, diet, alcohol, physical activity and psychological stress are assessed, as well as the patient's motivation to change any factor if needed (table 5).

Table 5. Assessment of lifestyle during intake consultation

\begin{tabular}{ll}
\hline Assessment of lifestyle & \\
\hline Smoking & Units per day \\
& Smoking history \\
Attempts to quit & Motivation to quit \\
Dietary habits & Knowledge of healthy dietary habits \\
& Insight into own dietary habits \\
& Necessity to change dietary habits \\
& Motivation to change dietary habits \\
Alcohol use & Units per week \\
& Knowledge of effects of alcohol use \\
& Insight into own alcohol use \\
& Necessity to change alcohol use \\
& Motivated to change alcohol use \\
& Days a week \\
Physical activity & Knowledge of importance of physical activity \\
Insight into own physical activity \\
Necessity to change physical activity \\
Motivated to change physical activity \\
Stress symptoms > 3 months \\
Insight into own stress \\
\end{tabular}

Physical examination includes measurement of length, weight, (calculation of) BMI, waist circumference, blood pressure (manual or electronic oscillometric measurement, at least 2 measurements with an interval of 1-2 minutes) and pulse rate. 
For patients without CVD an up-to-date 10 -years CV morbidity and mortality risk based on the risk chart in the Dutch guideline (based on the SCORE risk function) will be estimated. ${ }^{5}$

During the intake visit, individual treatment goals are determined, regarding smoking, physical activity, dietary habits, weight, BMI, blood pressure and LDLcholesterol. These treatment goals are set by shared decision making between the caregiver and the patient based on the Dutch guideline for CVRM within the context of a patient's personal preferences. If indicated, treatment with medication, including blood pressure and lipid lowering drugs, and anticoagulants will be initiated. All patients will be given general lifestyle advice by the PN. Patients not achieving a healthy lifestyle according to the Dutch guideline can be referred to smoking cessation programmes, dieticians and exercise programmes or a physiotherapist to get support in changing their lifestyle.

After the intake consultation, patients will be monitored on a regular base in general practice to evaluate and when necessary adjust their personal goals. At least once yearly, all measurements including estimation of the 10-years CV risk will be repeated.

\section{Usual care}

Usual care is based on the Dutch CVRM guideline, describing how to calculate the $\mathrm{CV}$ risk and advice to lower this risk by lifestyle intervention and/or medication. However systematic identification of patients eligible for CVRM, actively inviting patients for a visit, regular follow-up and standardized collaboration with other disciplines in the health care chain are not routinely part of usual care. Usual care practices may work with a PN. Most PNs in the Netherlands have had a basic training in CVRM. Furthermore, data are not registered in an information system for integrated care and GPs do not participate in benchmark meetings.

\section{ZWOT-CASE study population}

The ZWOT-CASE study population will consist of a subgroup of 370 patients from the integrated CVRM care group (intervention) and 370 patients in the usual care group. Both groups consist of respectively i) 185 patients with known CVD and ii) 185 patients with a high ( $>10 \%$ ) ten year risk of CVD morbidity and mortality based on the Dutch Guideline for CVRM. ${ }^{7,23,24}$ 
Inclusion criteria for patients with CVD:

- Patients with a history of atherosclerotic CVD defined as documented angina pectoris, myocardial infarction, chronic ischemic heart disease, coronary sclerosis, transient ischaemic attack (TIA), cerebral infarction, intermittent claudication or aneurysm of the abdominal aorta

- The CV risk of the patient is managed in primary care, not in the hospital or outpatient clinic by a medical specialist

- Age between 40 and 80 years

Inclusion criteria for high-risk patients:

- Use of blood pressure lowering or lipid lowering drugs

- A 10 -years CV risk > 10\%, based on the Dutch guideline for CVRM and i) either 1 strongly cardiovascular risk enhancing factor or 2 mildly cardiovascular risk enhancing factors (see table 6) or ii) $\geq 1 \mathrm{CV}$ risk factor (current smoking, SBP>140 mmHg, LDL>2.5 mmol/L, TC/HDL-ratio > 8, chronic renal impairment (age < 65 years: eGFR $<60 \mathrm{ml} / \mathrm{min} / 1,73 \mathrm{~m} 2$; age $\geq 65$ years: eGFR $<45 \mathrm{ml} / \mathrm{min} / 1,73 \mathrm{~m} 2$, and/or (micro)albuminuria).

- A 10 -year CV risk of $>20 \%$ and $\geq 1 \mathrm{CV}$ risk factor (current smoking, SBP $>140$ $\mathrm{mmHg}, \mathrm{LDL}>2.5 \mathrm{mmol} / \mathrm{L}, \mathrm{TC} / \mathrm{HDL}-$ ratio $>8$, chronic renal impairment age $<65$ years: eGFR < $60 \mathrm{ml} / \mathrm{min} / 1,73 \mathrm{~m} 2$; age $\geq 65$ years: eGFR < $45 \mathrm{ml}$ / $\min / 1,73 \mathrm{~m} 2$, and/or (micro-)albuminuria).

- The CV risk of the patient is managed in primary care, not in the hospital or outpatient clinic by a medical specialist

- $\quad$ Age between 40 and 80 years

Table 6. Risk enhancing factors ${ }^{7}$

\begin{tabular}{llll}
\hline & Not risk enhancing & Mildly risk enhancing & Strongly risk enhancing* \\
\hline $\begin{array}{l}\text { First-degree } \\
\text { relative with CVD }\end{array}$ & No & $\begin{array}{l}1 \text { family member }<65 \\
\text { years }\end{array}$ & $\begin{array}{l}\geq 2 \text { family members with } \\
\text { CVD }<65 \text { years or } 1<60 \\
\text { years }\end{array}$ \\
Physical activity & $\geq 30 \mathrm{~min} / \mathrm{d}, \geq 5 \mathrm{~d} / \mathrm{wk}$ & $<30 \mathrm{~min} / \mathrm{d}, \leq 5 \mathrm{~d} / \mathrm{wk}$ & Sedentary \\
Body mass index & $\mathrm{BMI}<30 \mathrm{~kg} / \mathrm{m} 2$ & BMI $30-35 \mathrm{~kg} / \mathrm{m} 2$ & $\mathrm{BMI}>35 \mathrm{~kg} / \mathrm{m} 2$ \\
eGFR & $<65$ years: $>60 \mathrm{ml} /$ & $<65$ years: $30-60 \mathrm{ml} /$ & All ages: $<30 \mathrm{ml} /$ \\
& $\begin{array}{l}\text { min } / 1,73 \mathrm{~m} 2 \\
\text { min } / 1,73 \mathrm{~m} 2\end{array}$ & min $/ 1,73 \mathrm{~m} 2$ \\
& $\geq 65$ years: $>45 \mathrm{ml} /$ & $\geq 65$ years: $30-45 \mathrm{ml} /$ & \\
& min $/ 1,73 \mathrm{~m} 2$ & min/1,73 m2 & \\
\hline
\end{tabular}

CVD = cardiovascular disease; eGFR = estimated glomerular filtration rate; $\mathrm{d}$ = day or days; $\mathrm{wk}=$ week. *In patients with rheumatoid arthritis a high disease activity is a strongly risk enhancing factor. 
Exclusion criteria for all patients:

- Diabetes mellitus, as these patients are already included in a disease management programme for diabetes mellitus

- Limited life expectancy, as assessed by the GP

- Cognitive impairment, as assessed by the GP

- No Dutch language proficiency

- Staying abroad for longer than three months during the duration of the study.

- The CV risk of the patient is managed in the hospital or outpatient clinic by a medical specialist

\section{Recruitment of patients for the ZWOT-CASE study}

The source population consists of 56 general practices. All practices were invited to participate in the study. Eventually, 26 general practices agreed to participate (17 in the intervention group and 9 in the usual care group).

Intervention group

Between September and December 2016, general practices randomly invited eligible patients for an intake visit for the integrated CVRM programme. After one year of follow-up, these patients are invited for the study until enough patients are included. The invitation for the study will be sent just before the yearly followup visit in the CVRM programme. This visit will be used as the endpoint visit for the study. Just before this follow-up visit, the patients receive a letter from their GP to inform them about the study. If the patient agrees to participate, informed consent is obtained during the follow-up visit.

Patients will be selected in such way, that $50 \%$ will be below 65 years and $50 \%$ over 65 years, to achieve a reasonable distribution across age categories.

\section{Usual care group}

In order to create the same study population as in the intervention group, we identify patients in the usual care group according to the protocol ('Organized Practice') as described before, including systematically screening of the practice population based on ICPC-coded diagnoses and ATC-codes, and manually checking of medical records. As the general practices in the usual care group do not start with the integrated care programme for CVRM, patients in the usual care group 
will not be invited for an intake consultation at baseline. Subsequently, a risk profile based on complete data on age, sex, smoking status, blood pressure and lipid spectrum may be missing. In that case, patients can be included if the 10-yeas risk is at least $10 \%$, based on the data that are available. For example, a 55 -year old male patient with a missing smoking status and missing total cholesterol/ HDL- cholesterol ratio can be classified as having a CV risk $>10 \%$ based on a known systolic blood pressure of $160 \mathrm{mmHg}$.

Patients in the usual care group are matched to patients in the intervention group. Therefore, the patient in the usual care group will only be invited for the study after the patient in the intervention group agreed to participate. Patients in the usual care group will be invited by letter and subsequently by telephone. If this patient does not agree with participation in the study, the second matched patient from the usual care group will receive an invitation. If the second matched patient also does not agree with participation, we will randomly invite one of the remaining patients from the usual care group who were not invited for the study.

\section{Matching}

Patients in the usual care group are consecutively matched with the intervention group according to age (per 5 years age categories), gender and risk group (high $\mathrm{CV}$ risk or CVD) at the beginning of the study. Each patient in the intervention group is matched to two patients in the usual care group. These patients in the usual care group are randomly selected from the eligible population in practices delivering usual care.

\section{Study procedures}

Patients will be identified at the beginning of the study in order to be able to analyse factors such as mortality and comorbidity during follow-up. The study starts when patients in the intervention group visit the general practice for an intake consultation $(t=0)$. After the intake visit, the one year follow-up period commences. After one year of follow-up, patients are invited for an endpoint visit. A questionnaire will be attached to the invitation letter.

Prior to the endpoint visit, all patients who agree with participation in the study will be asked to fill out the questionnaire at home. The timeline of the study procedures is represented in figure 1 . 
Figure 1. Schedule of enrolment, interventions, and assessments.

\begin{tabular}{r|c|c|c}
\hline & Enrolment & Allocation & Post-allocation \\
\hline TIMEPOINT & $-t_{1}$ & 0 & $t_{1}$ \\
\hline ENROLMENT: & & & \\
Eligibility screen & $\mathrm{X}$ & & $\mathrm{X}$ \\
\hline Matching & $\mathrm{X}$ & & \\
Allocation & & $\mathrm{X}$ & \\
\hline INTERVENTIONS: & & & \\
\hline Integrated care for CVRM & & & \\
\hline Usual care & & & $\mathrm{X}$ \\
\hline $\begin{array}{r}\text { ASSESSMENTS: } \\
\text { Baseline variables: age, sex, risk } \\
\text { category }\end{array}$ & $\mathrm{X}$ & $\mathrm{X}$ & $\mathrm{X}$ \\
\hline comorbidity, medication use & & & $\mathrm{X}$ \\
\hline $\begin{array}{r}\text { Primary outcomes: systolic blood } \\
\text { pressure and LDL-cholesterol }\end{array}$ & & & \\
\hline Secondary outcomes & & & \\
\hline
\end{tabular}

*These baseline variables are collected retrospectively after one year of follow-up

\section{Ethical aspects and informed consent}

General practices in both groups will not be informed about which patients are identified at baseline to prevent any influence on their management. Consequently, it will not always be possible to take into account the life expectancy, cognitive function and language skills of the identified patients at baseline, as information on these exclusion criteria is not always adequately registered in the medical records. Just before the end of follow-up, GPs will be informed about the identified patients and asked to assess these exclusion criteria.

In addition, at baseline patients in both groups will not yet be informed about the study to prevent that they are aware of being observed and modify their behaviour (Hawthorne effect). Based on the Dutch law for data protection, obtaining informed consent for the identification of patients is not necessary. All obtained data (age, gender and risk category) during the identification will be processed pseudo anonymised and the key to the data will be kept within the general practices. The researchers do have access to this information. Baseline data will be collected 
retrospectively for all patients, as patients are not invited for a baseline visit in the context of the study.

Written informed consent is obtained by the GP or PN during the end-point visit and includes an agreement stating that he or she i) is sufficiently informed, had the opportunity to ask additional questions and had enough time to make a decision; ii) agrees with voluntary participation and at any time can withdraw from participation; iii) agrees with use of medical data and data of questionnaires for the purposes described in the information form; iv) agrees with the storage of the study data for 15 years after this study.

The study was reviewed by the Isala hospital Review Board and exempted from full assessment under the Medical Research Involving Human Subjects Act on the $16^{\text {th }}$ of June 2016 (reference number 16.06104).

\section{Outcomes and data collection}

An overview of the outcomes of the ZWOT-CASE study is shown in Table 7. The primary outcome is systolic blood pressure and LDL-cholesterol. Patients fill out a questionnaire prior to the endpoint-visit including physical activity (squash questionnaire), quality of life (EQ-5D and SF-12), employment (iPCQ), patient satisfaction regarding the provided care (Patient Reported Experience Measure (PREM)), self-management (Patient Activity Measure (PAM)), and anxiety and depression (Hospital Anxiety and Depression Scale (HADS)). Besides, social status, education (UCC-1 questionnaire) ${ }^{25}$, food habits, and CV risk perception are measured by a questionnaire. Further, a blood sample is taken for measurement of lipids (total cholesterol, HDL-cholesterol, TC/HDL-cholesterol ratio, LDLcholesterol, triglycerides), renal function (creatinine, MDRD), glucose and for patients with CVD hs-CRP.

The endpoint visit consists of the same components as the intake consultation in the integrated programme for CVRM as described before. Data collected during the endpoint visit will be registered in the electronic medical record. 
Table 7. Primary and secondary endpoints

\section{Primary endpoints}

1. Systolic blood pressure

2. LDL-cholesterol

\section{Secondary endpoints}

1. 10-years cardiovascular morbidity or mortality risk (percentage) (Risk chart Dutch guideline or SMART)

2. Smoking status

3. Body mass index (BMI)

4. Lifestyle (modification) (smoking cessation, healthy food habits, physical activity, motivation for modification and awareness of received advices with respect to weight, food habits and physical activity in the past year)

5. Awareness of CVD and cardiovascular risk factors

6. Use of adequate medication (blood pressure lowering drugs, anticoagulants and lipid lowering drugs)

7. Morbidity (newly developed CVD)

8. Developed comorbidity (CVD, diabetes mellitus, COPD, heart failure, atrial fibrillation)

9. Mortality

10. Primary treating practitioner (GP or medical specialist)

11. Health care consumption in the past year

12. Self-management in the past year (patient knowledge, skills, and confidence in managing one's health and healthcare) (Patient Activity Measure (PAM))

13. Self-measurements of blood pressure in the past year

14. Patient satisfaction regarding the provided care in the past year Patient Reported Experience Measure (PREM)

15. Quality of life (EQ-5D and SF-12)

16. Anxiety and depression (Hospital Anxiety and Depression Scale (HADS)

17. Cost-efficiency (iPCQ)

${ }^{*}$ HIS = general practice information system

An up-to-date 10-years cardiovascular morbidity or mortality risk will be estimated according to the algorithm of the Dutch national guideline for CVRM. This algorithm is based on the SCORE-function, adapted to the Dutch population and converted from a mortality risk to morbidity and mortality risk (based on the MORGEN-cohort and the Rotterdam Study-cohort). ${ }^{26-29}$ The risk chart takes into account age, sex, smoking status, systolic blood pressure and total cholesterol-HDL cholesterol ratio. ${ }^{23,24}$ For patients taking blood pressure or lipid lowering drugs, the actual SBP and cholesterol levels during treatment are used. For patients with CVD the SMART-function will be used to calculate the CV risk. ${ }^{30}$ This function is based on age, sex, smoking status, systolic blood pressure, history of diabetes mellitus, ischemic heart disease, cerebrovascular disease, aortic aneurysm, peripheral arterial disease, time since first diagnosis of CVD, HDL-cholesterol, 
total cholesterol, renal function (eGFR), and high-sensitivity CRP. Furthermore, baseline data and data concerning health care use in the past year and in the period prior to the study will be collected by scrutinizing the electronic medical files. Finally, GPs will be asked to complete a survey about the CVRM care, including questions on the practice setting (rural/urban, solo/group), organization of their practice, availability of trained PNs, CVRM programme and possibilities to refer for lifestyle treatment (social map).

\section{Sample size calculation}

Calculation of the sample size is based on a reduction in SBP and LDL-cholesterol in the intervention group after 1 year of follow-up. We consider a $5 \mathrm{mmHg}$ absolute reduction in SBP and a $0.3 \mathrm{mmol} / \mathrm{L}$ reduction in LDL-cholesterol in the intervention group as clinically relevant. ${ }^{5,31}$ We assume that SBP and LDL-cholesterol levels in the usual care group remain stable. To detect these differences we need a sample size of 370 patients in the intervention group. This calculation is based on an alpha of 0.05 , a power of $80 \%$, and an intra-cluster correlation coefficient of 0.05 for the general practice cluster level. Furthermore, we take into account the response rate. We expect that the response rate in the intervention group will be $70 \%$. This results in a sample size of 587 patients in the intervention group. The intervention patients are matched to patients from the usual care group. In the usual care group we estimated a lower response rate of $50 \%$, as these patients might be less used to visit the general practice compared to the probably regularly controlled patients in the intervention group. Therefore, each intervention patient will be matched with two patients from the usual care group. This results in $587 \times 2=1174$ patients in the usual care group. The intervention group and usual care group are both divided into two groups (patients with CVD and patients with high CV risk) equal in size. The intervention group is selected from 17 general practices and the usual care group from 9 general practices.

\section{Statistical analyses}

The aim of the main analysis is to compare the SBP and LDL-cholesterol levels after one year of follow-up between patients in the intervention group receiving integrated care for CVRM and the patients in the usual care group receiving usual CVRM care. For the main analysis, we will use linear regression. For secondary outcomes, linear regression will be used for continuous outcomes, logistic regression for dichotomous outcomes and multinomial logistic regression for categorical outcomes. All analyses will be corrected for clustering. 
Given that patients of clusters of patients are not randomly allocated to the intervention or usual care group, we anticipate that differences in baseline risk might be present between both groups. Hence, we will adjust the analyses for these confounders, including patient characteristics and practice characteristics. To do such adjusted analysis we a priori define the following baseline covariates which are well-known to be related to the outcomes: i) patient characteristics, including relevant medication use, such as blood pressure lowering drugs ${ }^{32}$, anticoagulant $\mathrm{s}^{33}$ and lipid lowering drugs ${ }^{34}$, relevant comorbidity, including $\mathrm{COPD}^{35}$, heart failure ${ }^{36,37}$, atrial fibrillation ${ }^{38}$, renal failure ${ }^{39}$, ii) practice characteristics, such as involved disciplines in CVRM care (including number of PNs) ${ }^{31}$, number of patients, and number of GPs. Results will be reported both without (i.e. crude results) and after correction for confounders. Confounders are defined a priori and not selected based on statistical significance.

Furthermore, we will examine whether the effect of the integrated care for CVRM is modified by differences in the following practice characteristics: practice organization (solo/duo/group), availability of CVRM protocol and existence of other disease management programmes (COPD, DM). This will be done by adding interaction effects.

All analyses are applicable to patient data matched on age and gender.

\section{DISCUSSION}

Disease management programmes for CVRM are gradually implemented in Western countries. So far, it is unclear whether such integrated programmes have a positive effect on cardiovascular risk factors and this may lead to discussions between GPs, health insurers and policy makers. Previous studies are heterogeneous in studied interventions and study populations differ substantially in for example included risk categories and the way they are selected, e.g. by active screening or not. In addition, adequate comparisons with control groups are lacking. ${ }^{20}$

In the region of Zwolle, we have the opportunity to compare integrated care for CVRM with usual care. The aim of the ZWOT-CASE study is to evaluate the effectiveness of integrated care for CVRM compared to usual care in real practice. Since this is a pragmatic study, some choices in the study design were made 
that may have some methodological drawbacks. Below the major strengths and limitations of our study will be discussed.

\section{Strengths}

First, the pragmatic design of the ZWOT-CASE study will give insight into whether integrated care for CVRM compared to usual care is effective in a real world environment. If integrated care for CVRM has a positive effect on our outcomes, it supports the idea that the intervention is beneficial in daily practice.

Furthermore, all the general practices are affiliated to the care group 'Medrie'. The regional implementation of integrated care for CVRM will lead to a more uniform intervention and to less differences between general practices in the intervention group and consequently to less between-cluster variability. In addition, the care group reached an agreement on integrated care for CVRM with the health care insurance for the coming three years, ensuring an adequately financed and stable health care environment during the follow-up of the ZWOT-CASE study. GPs in the usual care group are also members of the care group. This makes the usual care group probably more comparable with the intervention group with regard to socioeconomic characteristics and available opportunities for referrals.

Finally, a strength of the ZWOT-CASE study is the lenient inclusion criteria, i.e. patients with a CV risk of $>10 \%$. Since usually more strict inclusion criteria are used in other regions, subgroup analysis will enable us to translate our results to other regions. 


\section{LIMITATIONS}

One limitation is the lack of random allocation to the two arms. This might lead to differences in practice characteristics between the intervention group and the usual group, and lead to either an over- or underestimation of the effect of integrated care for CVRM, when these differences are not adequately adjusted for. Besides, there may be differences in given care before implementation of integrated care for CVRM between different practices within the intervention group. This could also influence the effect of integrated care of CVRM. However, due to the complete registration of patient data in the Dutch general practice information system, we will be able to accurately collect patient data on years prior to the study and take into account the given care prior to the intervention. Furthermore, ample measures have been taken (notably matching of patients, multivariable analyses) to prevent confounding in our study.

Since patients will be selected from different general practices, we have to deal with a cluster effect. The intervention under study may be heterogeneous. ${ }^{40}$ For example, differences in practice size, practice facilities and space, training of GP and staff, availability of supportive staff, time-management, attitude towards prevention and the GP-patient relationship might lead to cluster-level differences.

Another limitation of our study design is that it is not possible to blind GPs, PNs and participants for the intervention. Blinding is impossible due to the nature of the intervention. To minimize bias and maximize the validity of the results, participants are selected just before the end of the study. In addition, during followup the general practices are not informed about which patients are identified as eligible to participate in the study.

A disadvantage of the regional approach of our study is the risk of contamination between the usual care group and the intervention group. Usual care may change in the direction of the intervention and therefore the effect of the intervention may be underestimated. However, as GPs in the usual care group do not use the guideline for the implementation of integrated care for CVRM, do not register patient data in an information system for integrated care, and yearly benchmark meetings are not mandatory, we expect the effect of contamination to be minimal. We will collect data on provided CVRM care to assess contamination. 
The regional approach of this study could reduce the generalizability of the findings to other regions in the Netherlands. However, we expect that most of the integrated care programmes for CVRM are based on the same Dutch guideline for CVRM and the same international guidelines for CVRM.

The follow-up of 1 year could be too short to analyse the full effect of integrated care for CVRM. However, we expect that the largest gained improvements in cardiovascular risk factors will occur within one year. Therefore, a follow-up of one year will be sufficient to assess the effectiveness of the intervention on these cardiovascular risk factors. But, if integrated care for CVRM is effective, it would be interesting to analyse whether the effect continues. In addition, improvements in cardiovascular risk factors will only translate in a lower cardiovascular morbidity and mortality in the longer term. ${ }^{3}$ To observe the durability of an effect, and to assess the effect of integrated care for CVRM on absolute cardiovascular morbidity and mortality, studies with a longer follow-up period should be conducted.

Finally, a general limitation of studies in general practice is that due to a lot of variation in the organization of primary care across Europe and beyond ${ }^{41,42}$, the results of a study in one country will probably only be generalizable to countries with similarly organised primary health care systems. However, to support the implementation as well as continuation of disease management programmes scientific evidence is needed. Integrated programmes for CVRM have been introduced in Western countries in recent years. Evidence on the effect of such integrated CVRM care is very limited. The ZWOT-CASE study will give insight into the effectiveness of integrated care for CVRM compared to usual care in general practice. 


\section{REFERENCES}

1. WHO. The top 10 causes of death, factsheet no.310, updated may 2014 .

2. Centraal Bureau voor de Statistiek (CBS). Overledenen; belangrijke doodsoorzaken, leeftijd en geslacht. 2016.

3. Bots ML, Buddeke J, Van Dis I, Vaartjes I, Visseren FLJ. Hart- en vaatziekten in nederland 2015.

4. Kotseva K, De Bacquer D, Jennings C, et al. Time trends in lifestyle, risk factor control, and use of evidence-based medications in patients with coronary heart disease in europe: Results from 3 EUROASPIRE surveys, 1999-2013. Glob Heart. 2016.

5. Piepoli MF, Hoes AW, Agewall S, et al. 2016 european guidelines on cardiovascular disease prevention in clinical practice: The sixth joint task force of the european society of cardiology and other societies on cardiovascular disease prevention in clinical practice (constituted by representatives of 10 societies and by invited experts): Developed with the special contribution of the european association for cardiovascular prevention \& rehabilitation (EACPR). Eur Heart J. 2016.

6. Dutch College of General Practitioners Guideline Development Group. Guideline cardiovascular risk management (third revision). Huisarts Wet. 2019:62: 55-7.

7. Dutch College of General Practitioners Guideline Development Group. Guideline cardiovascular risk management (second revision). Huisarts Wet. 2012(55):14-28.

8. Kotseva K, Wood D, De Bacquer D, et al. EUROASPIRE IV: A european society of cardiology survey on the lifestyle, risk factor and therapeutic management of coronary patients from 24 european countries. Eur J Prev Cardiol. 2016;23(6):636648.

9. van Lieshout J, Grol R, Campbell S, et al. Cardiovascular risk management in patients with coronary heart disease in primary care: Variation across countries and practices. an observational study based on quality indicators. BMC Fam Pract. 2012;13:96-2296-13-96.

10. Ludt S, Wensing M, Campbell SM, et al. The challenge of cardiovascular prevention in primary care: Implications of a european observational study in 8928 patients at different risk levels. Eur J Prev Cardiol. 2014;21(2):203-213.

11. Bodenheimer T, Wagner EH, Grumbach K. Improving primary care for patients with chronic illness. JAMA. 2002;288(14):1775-1779.

12. Bodenheimer T, Wagner EH, Grumbach K. Improving primary care for patients with chronic illness: The chronic care model, part 2. JAMA. 2002;288(15):1909-1914. 
13. Khunti K, Stone M, Paul S, et al. Disease management programme for secondary prevention of coronary heart disease and heart failure in primary care: A cluster randomised controlled trial. Heart. 2007;93(11):1398-1405.

14. Ebrahim S, Taylor F, Ward K, Beswick A, Burke M, Davey Smith G. Multiple risk factor interventions for primary prevention of coronary heart disease. Cochrane Database Syst Rev. 2011;(1):CD001561.

15. Alvarez-Bueno C, Cavero-Redondo I, Martinez-Andres M, Arias-Palencia N, RamosBlanes R, Salcedo-Aguilar F. Effectiveness of multifactorial interventions in primary health care settings for primary prevention of cardiovascular disease: A systematic review of systematic reviews. Prev Med. 2015;76 Suppl:S68-75.

16. Wood DA, Kotseva K, Connolly S, et al. Nurse-coordinated multidisciplinary, family-based cardiovascular disease prevention programme (EUROACTION) for patients with coronary heart disease and asymptomatic individuals at high risk of cardiovascular disease: A paired, cluster-randomised controlled trial. Lancet. 2008;371(9629):1999-2012.

17. Deales A, Fratini M, Romano S, et al. Care manager to control cardiovascular risk factors in primary care: The raffaello cluster randomized trial. Nutr Metab Cardiovasc Dis. 2014;24(5):563-571.

18. van Lieshout J, Huntink E, Koetsenruijter J, Wensing M. Tailored implementation of cardiovascular risk management in general practice: A cluster randomized trial. Implement Sci. 2016;11:115-016-0460-0.

19. van Bussel EF, Hoevenaar-Blom MP, Busschers WB, et al. Effects of primary cardiovascular prevention on vascular risk in older adults. Am J Prev Med. 2018;55(3):368-375.

20. Transparante ketenzorg diabetes mellitus, COPD en VRM rapportage zorggroepen over 2013.

21. Den Boer JKW. Protocollair CVRM. Nederlands Huisartsen Genootschap; 2016.

22. Wagner EH, Austin BT, Davis C, Hindmarsh M, Schaefer J, Bonomi A. Improving chronic illness care: Translating evidence into action. Health Aff (Millwood). 2001;20(6):64-78.

23. Conroy RM, Pyorala K, Fitzgerald AP, et al. Estimation of ten-year risk of fatal cardiovascular disease in europe: The SCORE project. Eur Heart J. 2003;24(11):9871003.

24. van Dis I, Kromhout D, Geleijnse JM, Boer JM, Verschuren WM. Evaluation of cardiovascular risk predicted by different SCORE equations: The netherlands as an example. Eur J Cardiovasc Prev Rehabil. 2010;17(2):244-249. 
25. Asselbergs FW, Visseren FL, Bots ML, et al. Uniform data collection in routine clinical practice in cardiovascular patients for optimal care, quality control and research: The utrecht cardiovascular cohort. Eur J Prev Cardiol. 2017:2047487317690284.

26. Verschuren WMM, van Leer EM, Blokstra A, Seidell JC, Smit HA, Bueno de Mesquita HB. Cardiovascular disease risk factors in the netherlands. Neth J Cardiol. 1993;4:205.

27. Houterman S, Verschuren WM, Oomen CM, Boersma-Cobbaert CM, Kromhout D. Trends in total and high density lipoprotein cholesterol and their determinants in the netherlands between 1993 and 1997. Int J Epidemiol. 2001;30:1063.

28. Hofman A, Grobbee DE, de Jong PT, van den Ouweland FA. Determinants of disease and disability in the elderly: The rotterdam elderly study. European journal of epidemiology [- 4]. 1991;7(4):403.

29. Ikram MA, Brusselle GGO, Murad SD, et al. The rotterdam study: 2018 update on objectives, design and main results. European journal of epidemiology [-9]. 2017;32(9):807.

30. Dorresteijn JA, Visseren FL, Wassink AM, et al. Development and validation of a prediction rule for recurrent vascular events based on a cohort study of patients with arterial disease: The SMART risk score. Heart. 2013;99(12):866-872.

31. Voogdt-Pruis HR, Beusmans GH, Gorgels AP, Kester AD, Van Ree JW. Effectiveness of nurse-delivered cardiovascular risk management in primary care: A randomised trial. Br J Gen Pract. 2010;60(570):40-46.

32. Law MR, Morris JK, Wald NJ. Use of blood pressure lowering drugs in the prevention of cardiovascular disease: Meta-analysis of 147 randomised trials in the context of expectations from prospective epidemiological studies. BMJ. 2009;338:b1665.

33. Antithrombotic Trialists' Collaboration. Collaborative meta-analysis of randomised trials of antiplatelet therapy for prevention of death, myocardial infarction, and stroke in high risk patients. BMJ. 2002;324(7329):71-86.

34. Cholesterol Treatment Trialists' (CTT) Collaborators, Mihaylova B, Emberson J, et al. The effects of lowering LDL cholesterol with statin therapy in people at low risk of vascular disease: Meta-analysis of individual data from 27 randomised trials. Lancet. 2012;380(9841):581-590.

35. Finkelstein J, Cha E, Scharf SM. Chronic obstructive pulmonary disease as an independent risk factor for cardiovascular morbidity. Int J Chron Obstruct Pulmon Dis. 2009;4:337-349.

36. Alberts VP, Bos MJ, Koudstaal P, et al. Heart failure and the risk of stroke: The rotterdam study. Eur J Epidemiol. 2010;25(11):807-812. 
37. Lip GY, Skjoth F, Overvad K, Rasmussen LH, Larsen TB. Blood pressure and prognosis in patients with incident heart failure: The diet, cancer and health (DCH) cohort study. Clin Res Cardiol. 2015;104(12):1088-1096.

38. Odutayo A, Wong CX, Hsiao AJ, Hopewell S, Altman DG, Emdin CA. Atrial fibrillation and risks of cardiovascular disease, renal disease, and death: Systematic review and meta-analysis. BMJ. 2016;354:i4482.

39. Schiffrin EL, Lipman ML, Mann JF. Chronic kidney disease: Effects on the cardiovascular system. Circulation. 2007;116(1):85-97.

40. Adang EM, Gerritsma A, Nouwens E, van Lieshout J, Wensing M. Efficiency of the implementation of cardiovascular risk management in primary care practices: An observational study. Implement Sci. 2016;11:67-016-0434-2.

41. Kringos D, Boerma W, Bourgueil Y, et al. The strength of primary care in europe: An international comparative study. Br J Gen Pract. 2013;63(616):e742-50.

42. Groenewegen P, Heinemann S, Gress S, Schafer W. Primary care practice composition in 34 countries. Health Policy. 2015;119(12):1576-1583. 


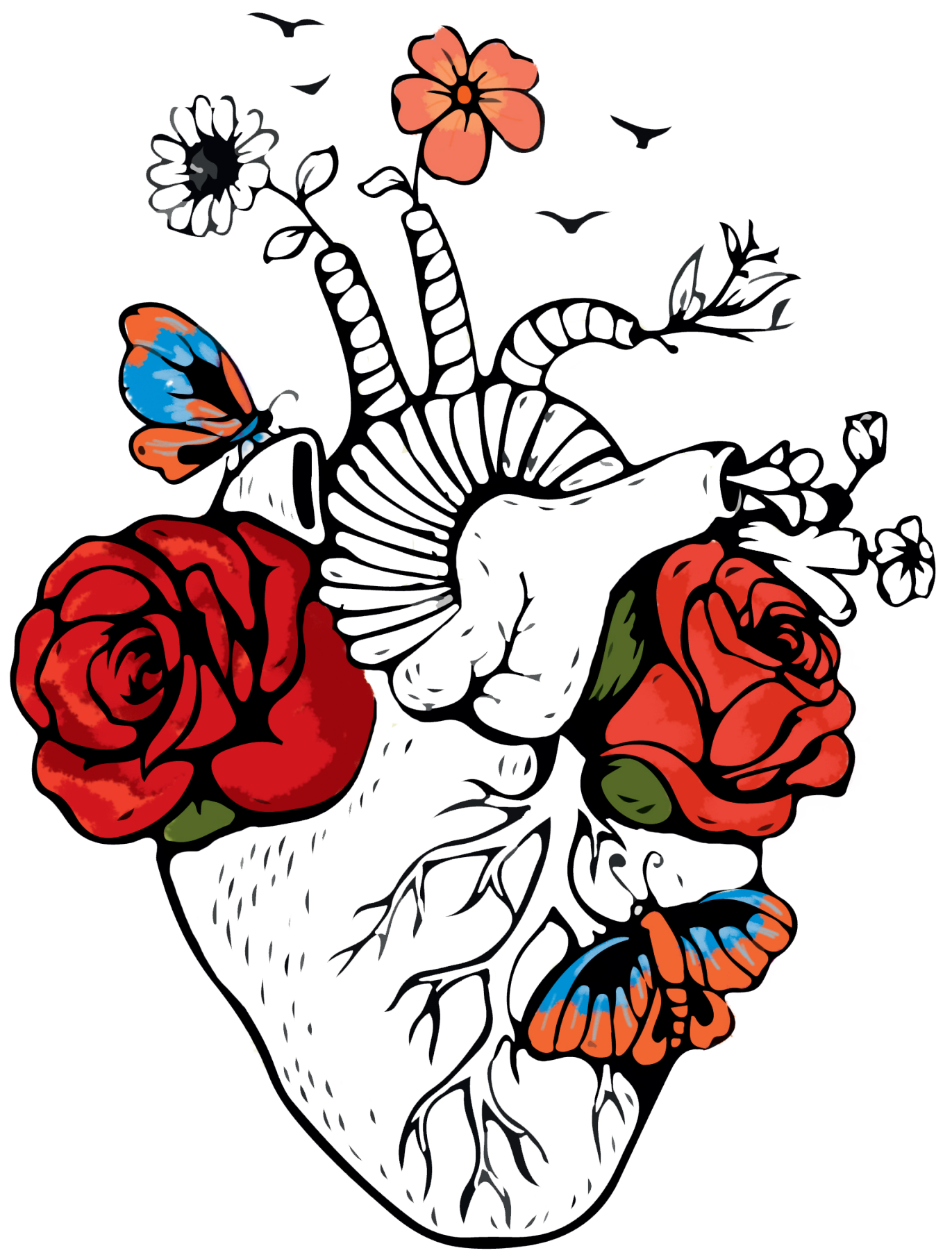




\section{CHAPTER 4}

\section{Integrated cardiovascular risk management programme versus usual care in high $\mathrm{CV}$ risk patients: an observational study in general practice}

Suzanne Marchal

Arnoud W.J. van 't Hof

Henk J.G. Bilo

Sander J. Deijns

Jan Evert Heeg

Marieke Schoenmakers

Michiel Schouwink

Olof Schwantje

Michiel L. Bots

Arno W. Hoes

Monika Hollander

British Journal of General Practice Open, 2021 


\section{ABSTRACT}

\section{Background}

Cardiovascular diseases (CVD) are the leading cause of death and cardiovascular (CV) risk factors are often insufficiently controlled in high risk patients. Recently, integrated multidisciplinary cardiovascular risk management (CVRM) programmes were introduced in primary care.

\section{Aim}

The present study investigates the effects of a CVRM programme on systolic blood pressure (SBP) and LDL-cholesterol.

\section{Design and setting}

A prospective observational study, in high CV risk patients aged $40-80$ years in general practice, comparing integrated CVRM care with usual care.

\section{Methods}

Intervention and usual care patients were matched at baseline on age, gender and presence of CVD. During one year of follow-up patients received integrated or usual CVRM care in general practice. Primary outcomes were SBP and LDL-cholesterol. Secondary outcomes included calculated 10-year CV risk, BMI, lifestyle (smoking, physical activity, dietary habits), medication use, patient satisfaction, health care consumption, morbidity, comorbidity and mortality. We used mixed-model analyses to assess the outcomes.

\section{Results}

We included 372 and 317 patients in the intervention and usual care group, respectively. Mean age at baseline was 65.1 and 66.2 years respectively and $42 \%$ were women in both groups. After one year, we observed no difference in SBP (137.2 $\mathrm{mmHg}$ vs $139.0 \mathrm{mmHg}$ in the intervention and usual care group, respectively) and LDL-cholesterol (2.6 mmol/L in both groups), nor in any of the secondary outcomes.

\section{Conclusion}

Integrated CVRM care in general practice did not lead to a lower SBP or LDLcholesterol in patients at high CV risk. Further research is needed to improve CVRM. 


\section{INTRODUCTION}

Cardiovascular diseases (CVD) remain the leading cause of mortality worldwide. ${ }^{1,2}$ The European Society of Cardiology recommends preventive, multidisciplinary programmes for cardiovascular risk management (CVRM), also in primary care. ${ }^{3}$ However, survey studies have shown that CVRM in primary care is suboptimally implemented, as control rates of cardiovascular risk factors are disappointing. ${ }^{4-6}$

In some European countries, integrated and multidisciplinary CVRM programmes were introduced in primary care in recent years. Core elements of these programmes include systematic selection, invitation, cardiovascular risk assessment, shared decision in treatment and follow-up of eligible patients, stimulation of self-management, registration of patient data in clinical information systems and yearly feedback to general practitioners (GPs) on delivered CVRM care. ${ }^{7}$ So far, studies on the effectiveness of CVRM programmes are scarce and the available evidence is inconsistent. ${ }^{8-10}$ Some studies showed a trend towards improved lifestyle, but did not show an effect on cardiovascular risk factors and cardiovascular outcomes. ${ }^{11-13}$ However, the studies were heterogeneous in design, target population and interventions tested and adequate comparison with usual care was often lacking.

The present ZWOT-CASE study (ZWOlle inTegrated care for CArdiovaScular risk managEment study) reports the effects of the implementation of an integrated CVRM care programme on systolic blood pressure (SBP) and LDL-cholesterol in general practice as compared to usual care.

\section{METHODS}

\section{Design}

A prospective observational study comparing integrated care for CVRM with usual care during 1 year of follow-up. The details of the study design have been described elsewhere. ${ }^{14}$

\section{Setting}

The study was performed in the Zwolle region in the Netherlands, including 56 general practices, affiliated to a care group 'Medrie'. All practices delivered usual 
care prior to the implementation of integrated care for CVRM. From January 2016, 37 general practices implemented integrated CVRM care and 19 general practices continued usual care. All practices were invited to participate in the study; 17 intervention and 9 usual care practices participated.

\section{Patients}

In total, we aimed to include 370 patients in each group consisting of respectively i) 185 patients with CVD and ii) 185 patients with a high ( $>10 \%)$ ten year risk of CVD morbidity and mortality based on the Dutch Guideline for CVRM and a modifiable risk factor (SBP > $140 \mathrm{mmHg}$, LDL-cholesterol > $2.5 \mathrm{mmol} / \mathrm{L}$, smoking or BMI > 30 $\mathrm{kg} / \mathrm{m} 2) .{ }^{15}$ We ensured that $50 \%$ was aged below 65 years and $50 \%$ over 65 years. In- and exclusion criteria are shown in box 1.

\section{Intervention}

Implementation of the integrated CVRM programme was coordinated by the care group 'Medrie' in accordance with the regional hospital and the regionally largest health care insurance company, based on the Dutch CVRM guideline and the practical manual for CVRM provided by the Dutch Society of General Practitioners. ${ }^{15,16}$ GPs screened their practice population for eligible patients and invited them for an intake consultation for the integrated CVRM programme, mostly done by PNs under supervision of the GP. ${ }^{17}$ During this consultation the researchers identified patients for the study. To prevent a Hawthorne effect, GPs and patients were not informed about the identification. Patients received the integrated CVRM programme as previously described. ${ }^{14}$ In short, prior to the intake, a blood sample was taken to measure lipids, renal function (MDRD), and glucose. The intake included assessment of cardiovascular complaints, lifestyle (smoking habits, diet, alcohol, physical activity), prescribed medication, measurement of blood pressure and BMI, estimation of the 10-year CV risk according to the Dutch CVRM guideline in patients without $\mathrm{CVD}^{15}$, and defining individual treatment goals in shared decision. Patients were monitored at least once a year for control of cardiovascular risk factors. If necessary, other disciplines were involved, including dieticians, physiotherapists and medical specialists. All disciplines had access to the patient data in the multidisciplinary information system, facilitating care coordination across organizations and ensuring a consistent policy in individual patients. After one year the study patients were revealed to the GP and received a 
letter from their GP to inform them about the study. After agreement to participate, written informed consent was obtained during the endpoint visit.

Box 1. In- and exclusion criteria

Inclusion criteria for patients with CVD:

- Patients with a history of atherosclerotic CVD, including angina pectoris, myocardial infarction, chronic ischemic heart disease, coronary sclerosis, transient ischaemic attack (TIA), cerebral infarction, intermittent claudication or aneurysm of the abdominal aorta and

- The patient is primarily managed by the general practitioner (GP) and

- Aged 40 to 80 years

Inclusion criteria for high $\mathrm{CV}$ risk patients:

- No previous CVD and

- Use of antihypertensive or lipid lowering drugs or

- A 10 -year CV risk > 10\%, based on the Dutch guideline for CVRM and i) either 1 strongly CV risk enhancing factor or 2 mildly CV risk enhancing factors (based on family history of CVD, physical activity, BMI and renal function) or ii) $>1 \mathrm{CV}$ risk factor (current smoking, SBP>140 mmHg, LDL $>2.5$ mmol/L, TC/HDL-ratio > 8, chronic renal impairment age < 65 years: eGFR $<60 \mathrm{ml} / \mathrm{min} / 1,73 \mathrm{~m} 2$; age $\geq 65$ years: eGFR $<45 \mathrm{ml} / \mathrm{min} / 1,73 \mathrm{~m} 2$, and/or (micro)albuminuria) or

- A 10 -year CV risk of $>20 \%$ and $>1 \mathrm{CV}$ risk factor, as mentioned above and

- At least one modifiable risk factor and

- The patient is primarily managed by the GP and

- Aged 40 to 80 years

Exclusion criteria for all patients:

- Diabetes mellitus (DM), as these patients receive CVRM in a DM programme

- Limited life expectancy

- Cognitive impairment

- No Dutch language proficiency

- Staying abroad $>3$ months

- Patient receives CVRM in the hospital or outpatient clinic from a medical specialist

\section{Usual care}

Practices in the usual care group continued usual care. Patients were consecutively matched with intervention patients at baseline, on the basis of age (5 years categories), gender and presence of CVD. Similar to the intervention group, the patients and their GPs were not informed about the identification. After one year, 
the matched patient was invited for a CVRM consultation if the corresponding intervention patient agreed to participate. Written informed consent was obtained and endpoints were measured during this consultation.

\section{Outcomes}

The primary outcomes were SBP and LDL-cholesterol. Secondary outcomes included diastolic blood pressure, achievement of treatment goals (blood pressure $<140 / 90$ $\mathrm{mmHg}$, LDL-cholesterol $\leq 2.5$ and $\leq 1.8 \mathrm{mmol} / \mathrm{L}$ for all patients and those with CVD, respectively), smoking status, BMI, 10-year cardiovascular morbidity or mortality risk (according to SMART and the Dutch guideline for patients with and without CVD, respectively) ${ }^{15,18}$, healthy food habits (according to Dutch guideline for CVRM ${ }^{15}$ and guideline Healthy Food of the Dutch Health Council ${ }^{19}$ ), alcohol consumption, physical activity ( squash questionnaire) ${ }^{20}$, medication use (antihypertensive drugs, lipid lowering drugs and anticoagulants), primary treating practitioner in CVRM (GP or medical specialist), total number of consultations in general practice, patient satisfaction regarding the provided care (Patient Reported Experience Measure (PREM)), quality of life (EQ-5D and SF-12), anxiety and depression (Hospital Anxiety and Depression Scale (HADS)), newly developed (co)morbidity and mortality.

\section{Data collection}

Prior to the endpoint visit, patients filled out a paper questionnaire (including the squash questionnaire, EQ-5D, SF-12, PREM, HADS and food habits) and a blood sample was taken for measurement of lipids, renal function, glucose and hs-CRP for CVD patients (to calculate SMART risk). During the endpoint visit practice nurses (PNs) assessed office blood pressure ${ }^{16}$, BMI, smoking status, alcohol consumption and primary treating practitioner. After the endpoint visit we manually scrutinized electronic medical records to assess baseline data, medication use, health care consumption, (co)morbidity and mortality, and whether a patient received previous CVRM care, defined as at least yearly visiting the general practice for a CVRM consultation, including measurement of lipids, renal function and blood pressure.

We pseudonymised all data relating to patients. The Isala hospital Review Board reviewed the study and exempted it from full assessment under the Medical Research Involving Human Subjects Act (reference number 16.06104). 


\section{Sample size}

The sample size was based on a $5 \mathrm{mmHg}$ (SD 15.9) absolute reduction in SBP and a $0.3 \mathrm{mmol} / \mathrm{L}$ (SD 1.0) reduction in LDL-cholesterol in the intervention group as compared to usual care after 1 year of follow-up, with an alpha of 0.05 , a power of $80 \%$ and an intra-cluster correlation coefficient of 0.05 for the general practice cluster level. This led to a need of 370 patients in both groups. Accounting for a response rate of $70 \%$ in the intervention group, we planned to invite 587 intervention patients. Anticipating a 50\% response rate in the usual care group, each intervention patient was matched to 2 usual care patients, resulting in 587 $\times 2=1,174$ patients in the usual care group.

\section{Statistical analyses}

We used generalized linear mixed-model analyses. For continuous, count and dichotomous outcomes we assumed a linear, poisson and logistic distribution, respectively. For skewely distributed continuous outcomes we conducted analyses with a logarithmic transformed variable if appropriate and calculated the reversed logarithm of the $\mathrm{B}$ values and confidence intervals resulting into a ratio (interpreted as a multiplication factor).

We used crude mixed model analyses with a random intercept to correct for clustering within practices and additionally corrected for a priori defined potential confounding baseline covariates (use of antihypertensive and lipid lowering drugs and anticoagulants, comorbidity (chronic obstructive pulmonary disease (COPD), heart failure, atrial fibrillation, renal failure) and practice characteristics (number of PNs, GPs, and patients)).

We examined potential effect modification of differences in practice characteristics (practice organization (solo/duo/group), availability of CVRM protocol and existence of other disease management programmes (COPD, DM) and CVRM usual care given prior to the intervention (yes or no), by adding them as interaction terms to the crude model. If an interaction term was statistically significant ( $p<$ 0.05), we conducted stratified analyses.

Statistical analyses were conducted in R studio (version 3.5.1, Copyright (C) 2018 The R Foundation for Statistical Computing). 


\section{RESULTS}

In total, 689 patients were included; 372 intervention and 317 usual care patients (figure 1). In the intervention and control group, 439 (54\%) and 384 (54\%) of the invited patients did not participate, respectively (50\% and $45 \%$ were women, mean age was 63.5 years and $39 \%$ had CVD in both groups).

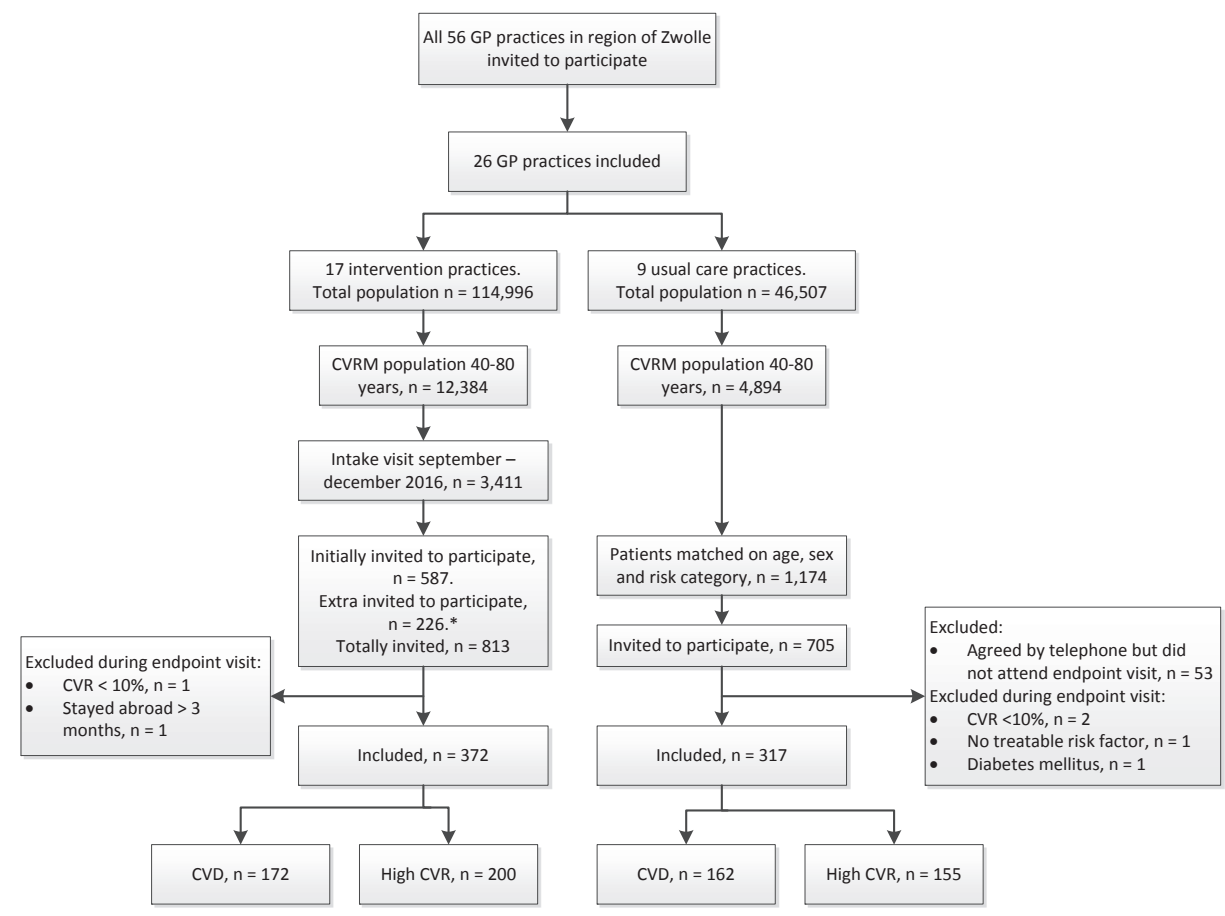

Figure 1. ZWOT-CASE study flow diagram

GP, general practitioner. CVRM, cardiovascular risk management. CVR, cardiovascular risk. CVD, cardiovascular disease. ${ }^{*}$ As the response rate in the intervention group was lower than the expected $70 \%$, we did not reach the required sample size after we invited 587 intervention patients. Therefore we had to invite 226 extra patients in the intervention group (totally invited $n=813$ ) and matched them retrospectively to the usual care group.

Mean age in included patients was 65.1 vs. 66.2 years, respectively and in both groups $42 \%$ were women (table 1). At baseline, we observed no differences in cardiovascular risk factors, CVD, comorbidities and medication use across the groups. Prior to the study, the proportion receiving CVRM care was higher in the intervention than in the usual care group (67\% vs 51\%, p < 0.001). 
Table 1. Baseline characteristics.

\begin{tabular}{|c|c|c|}
\hline Characteristics & $\begin{array}{l}\text { Intervention group } \\
(\mathrm{n}=372)\end{array}$ & $\begin{array}{l}\text { Usual care group } \\
(\mathrm{n}=317)\end{array}$ \\
\hline Mean age in years (SD) & $65.1(8.3)$ & $66.2(7.5)$ \\
\hline Age $<65$ & $175(47)$ & $132(42)$ \\
\hline Female & $158(42)$ & $132(42)$ \\
\hline Western & $358(99)$ & $295(99)$ \\
\hline \multicolumn{3}{|l|}{ Cardiovascular risk factors } \\
\hline Hypertension $^{a}$ & $280(77)$ & $234(75)$ \\
\hline Hypercholesterolemia ${ }^{a}$ & $91(25)$ & $91(29)$ \\
\hline Current smoking ${ }^{\mathrm{b}}$ & $43(12)$ & $32(11)$ \\
\hline Chronic kidney disease $^{c}$ & $40(11)$ & $51(16)$ \\
\hline Micro-albuminuria $^{c}$ & $15(4)$ & $10(3)$ \\
\hline Rheumatoid arthritis $^{\text {a }}$ & $4(1)$ & $10(3)$ \\
\hline Cardiovascular diseases ${ }^{\mathrm{a}, \mathrm{d}}$ & $172(46)$ & $162(51)$ \\
\hline Myocardial infarction & $41(11)$ & $48(15)$ \\
\hline Coronary sclerosis & $46(13)$ & $44(14)$ \\
\hline Angina pectoris & $44(12)$ & $39(12)$ \\
\hline Transient ischaemic attack & $33(9)$ & $31(10)$ \\
\hline Cerebral infarction & $35(10)$ & $17(5)$ \\
\hline Aneurysm aortae & $8(2)$ & $11(4)$ \\
\hline Intermittent claudication & $12(3)$ & $13(4)$ \\
\hline Atherosclerosis & $4(1)$ & $4(1)$ \\
\hline \multicolumn{3}{|l|}{ Comorbidities (including other CVD) ${ }^{\mathrm{a}}$} \\
\hline COPD & $9(2)$ & $14(4)$ \\
\hline Atrial fibrillation & $23(6)$ & $16(5)$ \\
\hline Heart failure & $1(0)$ & $3(1)$ \\
\hline \multicolumn{3}{|l|}{ Medication use ${ }^{b}$} \\
\hline Antihypertensive agents & 299 (83) & $251(81)$ \\
\hline Statins/lipid lowering agents & $190(52)$ & $167(54)$ \\
\hline Anticoagulants & $169(47)$ & $154(50)$ \\
\hline \multicolumn{3}{|l|}{ Measurements $^{e}$} \\
\hline Mean SBP in mmHg (SD) & $136.7(15.2)$ & \\
\hline Mean DBP in mmHg (SD) & $80.3(9.5)$ & \\
\hline Mean LDL-cholesterol in mmol/L (SD) & $2.8(0.9)$ & \\
\hline Mean BMI (SD) & $27.7(4.0)$ & \\
\hline
\end{tabular}

SD, standard deviation. CVD, cardiovascular diseases. COPD, chronic obstructive pulmonary disease. SBP, systolic blood pressure. DBP, diastolic blood pressure. LDL, low-density lipoprotein. BMI, body mass index.

Absolute numbers (\%) are presented unless stated otherwise.

${ }^{\text {a }}$ Based on International Classification of Primary Care (ICPC)-coded diagnoses.

${ }^{\mathrm{b}}$ Based on medical records.

${ }^{\mathrm{c}}$ Based on ICPC-coded diagnoses and/ or laboratory measurements. Micro-albuminuria: albumincreatinine ratio $>3 \mathrm{mg} / \mathrm{mmol}$. Chronic kidney disease: $\geq 3$ months impaired renal function (eGFR < $60 \mathrm{ml} / \mathrm{min} / 1.73 \mathrm{~m}^{2}$ ) and/ or micro-albuminuria.

${ }^{\mathrm{d}}$ Cardiovascular diseases as inclusion criteria for integrated CVRM care and for the study.

${ }^{\mathrm{e}}$ Baseline measurements of the control group at $\mathrm{t}=0$ are not presented, as there was no routine intake consultation. 
In the intervention and usual care group we were able to collect data on SBP in $96 \%$ and $94 \%$ of the patients and data on LDL-cholesterol in 93\% and $98 \%$ of the patients, respectively. We did not observe differences in both mean SBP and LDLcholesterol between the intervention and usual care group at the endpoint (137.2 mmHg vs. $139.0 \mathrm{mmHg}$, respectively and $2.6 \mathrm{mmol} / \mathrm{L}$ in both groups)) (table 2 and 3). None of the interaction terms for the primary outcomes were statistically significant (data not shown). Therefore, stratified analyses were not performed.

Table 2. Primary and secondary outcomes, descriptives

\begin{tabular}{|c|c|c|c|c|}
\hline \multirow{2}{*}{$\begin{array}{l}\text { Outcomes } \\
\text { Primary outcomes }\end{array}$} & \multicolumn{2}{|c|}{$\begin{array}{l}\text { Intervention group } \\
(n=372)\end{array}$} & \multicolumn{2}{|c|}{$\begin{array}{l}\text { Usual care group } \\
\qquad(n=317)\end{array}$} \\
\hline & $n$ & & $n$ & \\
\hline Mean systolic blood pressure in $\mathrm{mmHg}$ (SD) & $358^{a}$ & $137.2(16.2)$ & $298^{b}$ & $139.0(16.8)$ \\
\hline Mean LDL-cholesterol in mmol/L (SD) & $347^{c}$ & $2.6(0.8)$ & $310^{\mathrm{d}}$ & $2.6(1.0)$ \\
\hline \multicolumn{5}{|l|}{ Secondary outcomes } \\
\hline Mean diastolic blood pressure in mmHg (SD) & 358 & $80.3(10.2)$ & 298 & $80.6(10.1)$ \\
\hline Blood pressure $\leq 140 / 90 \mathrm{mmHg}(\%)$ & 358 & $214(60)$ & 298 & $175(59)$ \\
\hline LDL-cholesterol $\leq 2.5 \mathrm{mmol} / \mathrm{L} \mathrm{( \% )}$ & 347 & $178(51)$ & 310 & $168(54)$ \\
\hline LDL-cholesterol $\leq 1.8 \mathrm{mmol} / \mathrm{L} \mathrm{( \% )}{ }^{\mathrm{e}}$ & 166 & $45(27)$ & 163 & $58(36)$ \\
\hline Smoking (\%) & 363 & $31(9)$ & 311 & $30(10)$ \\
\hline Mean BMI (SD) & 349 & $27.3(5.2)$ & 300 & $27.7(4.8)$ \\
\hline \multicolumn{5}{|l|}{10 -year CVD morbidity or mortality risk in $\%$ f } \\
\hline All patients, median (IQR) & 317 & $22.0(11.7-36.4)$ & 267 & $24.0(13.7-38.0)$ \\
\hline Patients with CVD, median (IQR) & 159 & $26.2(17.9-38.5)$ & 144 & $27.8(18.7-39.5)$ \\
\hline Patients without CVD, median (IQR) & 158 & $15.5(5.4-31.9)$ & 123 & $18.7(8.4-34.3)$ \\
\hline \multicolumn{5}{|l|}{ Healthy food habits (\%) } \\
\hline Vegetables $\geq 150$ - 200 grams/ day & 360 & $142(39)$ & 294 & $99(34)$ \\
\hline Fruits $\geq 200$ grams/ day & 354 & $214(60)$ & 294 & $187(64)$ \\
\hline Red meat $\leq 300$ grams/ week & 356 & $207(58)$ & 286 & $155(54)$ \\
\hline Fatty fish $\geq 1 /$ week & 358 & $244(68)$ & 296 & $187(63)$ \\
\hline $\begin{array}{l}\text { Unhealthy fat products } \leq 3 \text { / week \& } \\
\text { healthy fat products }>3 \text { / week }\end{array}$ & 352 & $121(34)$ & 289 & $75(26)$ \\
\hline Sweet $\&$ salty snacks $\leq 3 /$ week & 357 & $196(55)$ & 295 & $157(53)$ \\
\hline Table salt $\leq 3 /$ week & 360 & $335(93)$ & 294 & $265(90)$ \\
\hline Alcohol consumption, units/week, median (IQR) & 311 & $3(0-7)$ & 292 & $2(0-7)$ \\
\hline Physically active (\%) ${ }^{\mathrm{g}}$ & 303 & $230(76)$ & 250 & $178(71)$ \\
\hline \multicolumn{5}{|l|}{ Medication use } \\
\hline \multicolumn{5}{|l|}{ Patients with CVD } \\
\hline Antihypertensive drugs (\%) & 174 & 137 (79) & 160 & $121(76)$ \\
\hline Lipid lowering drugs (\%) & 174 & $139(80)$ & 160 & $127(79)$ \\
\hline
\end{tabular}


Table 2. (Continued)

\begin{tabular}{|c|c|c|c|c|}
\hline \multirow{2}{*}{$\begin{array}{l}\text { Outcomes } \\
\text { Anticoagulants (\%) }\end{array}$} & \multicolumn{2}{|c|}{$\begin{array}{l}\text { Intervention group } \\
\qquad(\mathrm{n}=372)\end{array}$} & \multicolumn{2}{|c|}{$\begin{array}{l}\text { Usual care group } \\
\qquad(n=317)\end{array}$} \\
\hline & 174 & $160(92)$ & 160 & $146(91)$ \\
\hline \multicolumn{5}{|l|}{ Patients without CVD } \\
\hline Antihypertensive drugs (\%) & 187 & $167(89)$ & 149 & $126(85)$ \\
\hline Lipid lowering drugs (\%) & 188 & $52(28)$ & 149 & $46(31)$ \\
\hline GP as primary treating practitioner $(\%)^{\mathrm{h}}$ & 368 & 366 (99) & 314 & 307 (98) \\
\hline Consultations in general practice, median $(\mathrm{IQR})^{\mathrm{i}}$ & 361 & $6(3-10)$ & 311 & $6(3-10)$ \\
\hline Patient satisfaction (PREM) $(1-5)^{j}$, mean (SD) & 359 & $3.6(0.7)$ & 283 & $3.5(0.8)$ \\
\hline Recommendation score $(0-10)^{\mathrm{j}}$, mean (SD) & 352 & $8.3(1.3)$ & 275 & $8.2(1.3)$ \\
\hline EQ-5D-5L index score $(-0.45-1)^{j}$, mean (SD) & 353 & $0.9(0.1)$ & 290 & $0.8(0.1)$ \\
\hline SF-12 Mental component (7.9-72.0) ', mean (SD) & 353 & $53.9(7.5)$ & 290 & $52.3(9.3)$ \\
\hline $\begin{array}{l}\text { SF-12 Physical component }(5.2-64.7)^{j} \text {, mean } \\
\text { (SD) }\end{array}$ & 353 & $48.1(9.2)$ & 290 & $46.7(10.0)$ \\
\hline HADS Anxiety (0-7) ', mean (SD) & 342 & $4.1(3.3)$ & 286 & $4.5(3.7)$ \\
\hline HADS Depression $(0-7)^{j}$, mean (SD) & 347 & $3.2(3.0)$ & 283 & $3.9(3.3)$ \\
\hline Newly developed CVD (\%) ${ }^{\mathrm{k}}$ & 364 & $10(3)$ & 311 & $10(3)$ \\
\hline Newly developed comorbidity $(\%)^{1}$ & 363 & $13(4)$ & 311 & $12(4)$ \\
\hline Mortality (\%) & 372 & $5(1)$ & 318 & $3(1)$ \\
\hline
\end{tabular}

SD, standard deviation; LDL, low-density lipoprotein; BMI, body mass index; CV, cardiovascular; IQR, interquartile range; CVD, cardio vascular disease; GP, general practitioner; PREM, Patient Reported Experience Measure; EQ-5D, five-level EuroQoL-5 Dimensions; SF-12, Short Form-12 Health Survey; HADS, Hospital Anxiety and Depression Scale.

a Reasons for missing data: died before endpoint $(n=5)$, not measured $(n=7)$, data not available due to change of GP $(n=2)$

${ }^{\mathrm{b}}$ Reasons for missing data: died before endpoint $(\mathrm{n}=3)$, not measured $(\mathrm{n}=16)$

${ }^{c}$ Reasons for missing data: died before endpoint $(n=5)$, not measured $(n=16)$, data not available due to change of GP $(n=4)$

${ }^{d}$ Reasons for missing data: died before endpoint $(n=3)$, not measured $(n=3)$, data not available due to change of GP $(n=1)$

${ }^{\mathrm{e}}$ For patients with CVD, $\mathrm{n}=175$ in intervention group and $\mathrm{n}=164$ in usual care group.

${ }^{\mathrm{f}}$ For patient with known CVD the SMART-function was used to calculate the risk; for patients without CVD the risk was based on the risk chart in the Dutch guideline (based on the SCORE risk function).

${ }^{\mathrm{g}} \geq 5$ days a week moderate intense physical activity $\geq 30$ minutes/day.

${ }^{\text {h }}$ Primary treating practitioner could be the GP or a medical specialist.

${ }^{\mathrm{i}}$ Including all visits and telephone calls with the general practice for all reasons.

${ }^{j}$ Minimum and maximum possible values.

${ }^{\mathrm{k}}$ Including cardiovascular diseases as inclusion criteria for integrated CVRM care and for the study.

${ }^{1}$ Including diabetes mellitus, chronic obstructive pulmonary disease, heart failure, atrial fibrillation and chronic renal impairment. 


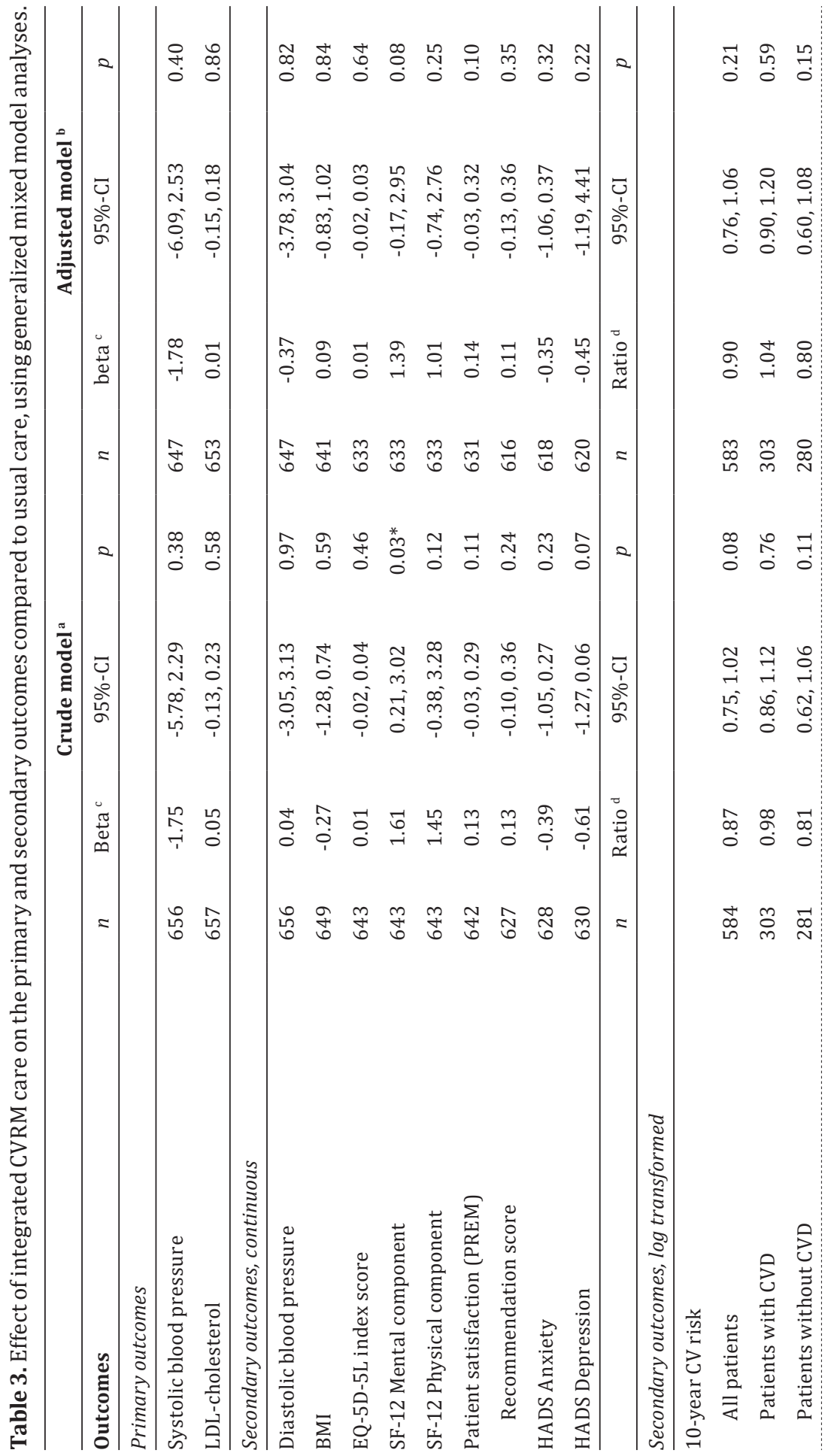




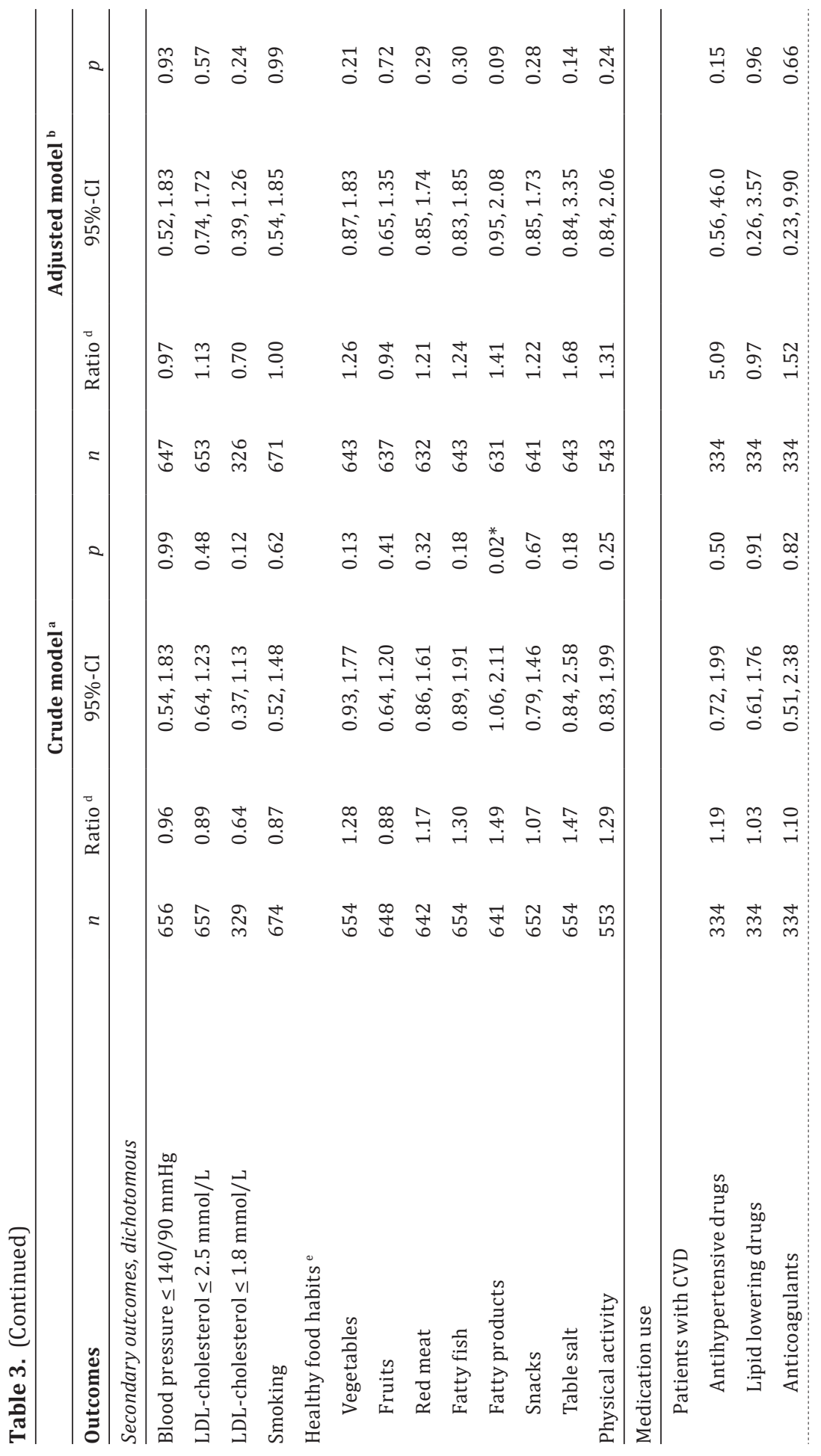




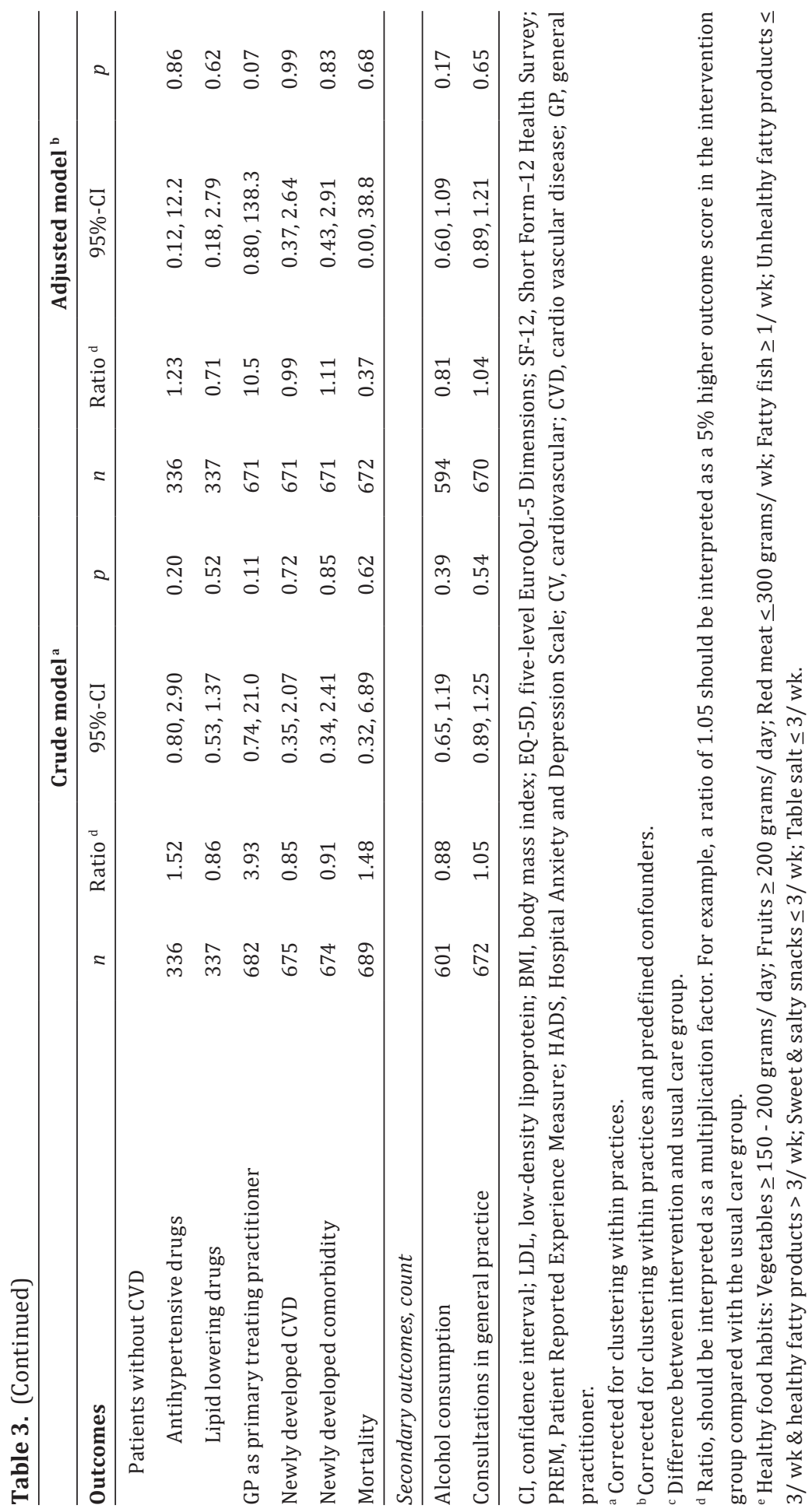


Treatment goals for blood pressure and LDL-cholesterol were achieved in slightly more than half of the patients in both groups (table 2); 60\% vs. 59\% reached a blood pressure target of $\leq 140 / 90 \mathrm{mmHg}$ and $51 \%$ vs. $54 \%$ achieved target of LDLcholesterol $\leq 2.5 \mathrm{mmol} / \mathrm{L}$. In CVD patients, $27 \%$ vs. $36 \%$ reached a LDL-cholesterol $<1.8 \mathrm{mmol} / \mathrm{L}$. Smoking rates were $9 \%$ vs $10 \%$, respectively. BMI, CV risk, physical activity, alcohol consumption and food habits did not differ between both groups. Approximately one-third of participants in both groups achieved healthy food habits regarding vegetables and fats and 50-60\% reported a healthy dietary pattern concerning intake of fruit, red meat, fatty fish and snacks. We observed no difference between the groups in medication use, number of consultations during follow-up (median 6), satisfaction with the delivered care (median 3.7 on a scale of 1 to 5 ) and recommendation scores to their GP (median 8 on a scale of 0 to 10). We observed similar results for quality of life and anxiety and depression scores.

\section{DISCUSSION}

In this observational study one year of integrated primary care for CVRM following usual care did not lead to better outcomes for SBP and LDL-cholesterol or any of the secondary outcomes of the study, as compared to usual care.

\section{Strengths and limitations}

Strengths of the ZWOT-CASE study are its prospective design, the real-world setting, the matched groups from the same environment and the reliably measurable outcomes and reasoned statistical methods. However, the lack of random allocation to the two study arms may have led to confounding bias. Ample measures have been taken (notably matching of patients, multivariable analyses) to prevent and correct for confounding and baseline characteristics were comparable between both groups. Also, we found that given care before implementation of integrated CVRM care did not affect the effect of the intervention. Although residual confounding is possible, we believe that the observational design of our study is of large value, as randomisation of regionally implemented complex interventions is hardly possible.

All the general practices in this study were from the region of Zwolle and affiliated to the care group 'Medrie'. Therefore, usual care may have changed in the direction of the intervention and consequently the effect of the intervention may have been 
underestimated. However, this setting reflects real practice as integrated CVRM care is always implemented regionally in the Netherlands.

Another limitation is the lower statistical power than calculated a priori due to the $14 \%$ lower participation rate in the usual care group. However, a post-hoc power analysis showed that we still would have been able to find a difference of 3.65 mmHg in SBP, which we consider as still clinically relevant.

In both groups, the response rates were lower than expected. We assume that reasons for (non) participation are similar in both groups but cannot rule out that this has led to some bias.

Finally, we had some missing outcome data in both groups. Since missing data were not extensively present in the primary outcomes and we did not observe important differences in missing endpoints between both groups, we expected that imputation would not change our results.

\section{Comparison with existing literature}

Our results are in line with previous studies, showing disappointing findings. ${ }^{9}$ One Dutch study on the effect of disease management programmes (DMPs) for CVRM in general practice, showed a trend towards improved lifestyle (physical activity, smoking) after 2 years. ${ }^{13}$ However, this study included a heterogeneous population (some DMPs targeted only CVD patients, some included high risk patients without CVD as well) and comparison with usual care and assessment of clinical outcomes (SBP, lipids) was lacking.

A cluster randomized controlled trial (RCT) compared a tailored implementation of CVRM in general practice to usual care and found a significant improvement in physical activity, but not in other outcomes (SBP, LDL-cholesterol, smoking status, BMI, and diet) after 6 months. ${ }^{12}$ However, this intervention is not easily comparable to ours as it focused on motivational interviewing, online education for PNs and e-health options for patients.

The follow-up time of the current study was shorter than the follow-up in a Dutch cluster RCT (1 vs 5.4 years). In that study, a CVRM programme in primary care significantly reduced SBP with $2.39 \mathrm{mmHg}$ in older adults (70 - 78 years) without 
CVD. However, this reduction was largely obtained in the first year of follow-up. ${ }^{21}$ This suggests that we would have been able to observe an effect after one year. However, it is known that it takes time to implement a new programme and to improve health care as practices have to adapt to new standards of quality and reorganize their practice. ${ }^{22}$ Therefore, we can't rule out that a longer follow-up time would have resulted in better outcomes.

Comparison with other studies is difficult, given the heterogeneity in study design, interventions tested, outcomes measured and target populations. Overall, most studies point towards no robust effect on cardiovascular risk factors or outcomes. . $^{93}$

Several reasons could explain the lack of effectiveness. First, the intervention itself could be ineffective due to insufficient intensity, lack of personalized health promotion or multidisciplinary collaboration. Possibly, PNs are insufficiently prepared, as their workload increases and patients become more complex. ${ }^{24}$

Besides, intensifying medication according to the guidelines if needed may have failed. ${ }^{25}$ Although GPs received yearly feedback on the state of cardiovascular risk factors of their CVRM population in the intervention group, not achieving treatment goals had no consequences. A reward system might enhance risk factor control and a continuous feedback system could improve CVRM in daily practice..$^{25}$ Further, patient-related factors, such as inadequate risk and lifestyle perception, nonadherence to lifestyle advice and medication could have played a role. More insight in the patient perspective of CVRM care could lead to better communication about CV risk, more patient empowerment and possibly, better adherence to the advised therapy. ${ }^{26}$ Moreover, the efforts of primary care need support from government and society regarding lifestyle improvement. ${ }^{9}$

A second reason could be that usual care was already of high quality, diminishing the contrast between the intervention and usual care. As more than half of the patients in both groups received usual CVRM care previous to our study, the largest reduction in SBP and LDL-cholesterol may already have been gained, leaving little room for further improvement. Still, there is room for improvement, as less than $60 \%$ reached blood pressure and LDL-targets. 


\section{Implications for research and practice}

Despite the lack of effect, we should not depreciate the potential of CVRM programmes to reduce $\mathrm{CV}$ risk, but look for potentials to improve their quality. To help reshaping CVRM in primary care, a process evaluation is needed to provide a deeper understanding of the lack of effectiveness of the intervention in the present study. For GPs participating in a programme for CVRM we would recommend to critically evaluate the process of care in their daily practice and to organize direct and adequate feedback regarding adherence to CVRM guidelines, if possible supported by information and communication technology.

Furthermore, the effect of CVRM programmes in countries with lower quality of CVRM in usual primary care should be evaluated, as they may be more effective there. ${ }^{27}$ Also, out-of-the-box strategies to organise CVRM care should be considered, e.g. other settings than general practice or a more multidisciplinary approach. Finally, modernisation of prevention programmes, for example by a more continuous telemetric risk factor control, may be promising. ${ }^{8}$ 


\section{REFERENCES}

1. GBD 2017 Causes of Death Collaborators. Global, regional, and national age-sexspecific mortality for 282 causes of death in 195 countries and territories, 1980 2017: A systematic analysis for the global burden of disease study 2017. Lancet. 2018;392(10159):1736-1788.

2. Timmis A, Townsend N, Gale CP, et al. European society of cardiology: Cardiovascular disease statistics 2019. Eur Heart J. 2020;41(1):12-85.

3. Piepoli MF, Hoes AW, Agewall S, et al. 2016 european guidelines on cardiovascular disease prevention in clinical practice: The sixth joint task force of the european society of cardiology and other societies on cardiovascular disease prevention in clinical practice (constituted by representatives of 10 societies and by invited experts): Developed with the special contribution of the european association for cardiovascular prevention \& rehabilitation (EACPR). Eur Heart J. 2016.

4. Kotseva K, De Backer G, De Bacquer D, et al. Lifestyle and impact on cardiovascular risk factor control in coronary patients across 27 countries: Results from the european society of cardiology ESC-EORP EUROASPIRE V registry. Eur J Prev Cardiol. 2019;26(8):824-835.

5. van der Ende, M Y, Hartman MH, Hagemeijer Y, et al. The LifeLines cohort study: Prevalence and treatment of cardiovascular disease and risk factors. Int J Cardiol. 2017;228:495-500.

6. NCD Risk Factor Collaboration (NCD-RisC). Long-term and recent trends in hypertension awareness, treatment, and control in 12 high-income countries: An analysis of 123 nationally representative surveys. Lancet. 2019.

7. Bodenheimer T, Wagner EH, Grumbach K. Improving primary care for patients with chronic illness: The chronic care model, part 2. JAMA. 2002;288(15):1909-1914.

8. Osteresch R, Fach A, Schmucker J, et al. Long-term risk factor control after myocardial infarction-A need for better prevention programmes.J Clin Med.2019;8(8):10.3390/ jcm8081114.

9. Ebrahim S, Taylor F, Ward K, Beswick A, Burke M, Davey Smith G. Multiple risk factor interventions for primary prevention of coronary heart disease. Cochrane Database Syst Rev. 2011;(1):CD001561. doi(1):CD001561.

10. Murphy AW, Cupples ME, Smith SM, et al. Effect of tailored practice and patient care plans on secondary prevention of heart disease in general practice: Cluster randomised controlled trial. BMJ. 2009;339:b4220. 
11. Lonnberg L, Ekblom-Bak E, Damberg M. Improved unhealthy lifestyle habits in patients with high cardiovascular risk: Results from a structured lifestyle programme in primary care. Ups J Med Sci. 2019;124(2):94-104.

12. van Lieshout J, Huntink E, Koetsenruijter J, Wensing M. Tailored implementation of cardiovascular risk management in general practice: A cluster randomized trial. Implement Sci. 2016;11:115-0.

13. Tsiachristas A, Burgers L, Rutten-van Molken MP. Cost-effectiveness of disease management programs for cardiovascular risk and COPD in the netherlands. Value Health. 2015;18(8):977-986.

14. Marchal S, Hollander M, Schoenmakers M, et al. Design of the ZWOT-CASE study: An observational study on the effectiveness of an integrated programme for cardiovascular risk management compared to usual care in general practice. $B M C$ Fam Pract. 2019;20(1):149-z.

15. Dutch College of General Practitioners Guideline Development Group. Guideline cardiovascular risk management (second revision). Huisarts Wet. 2012(55):14-28.

16. Den Boer, J. K. W. Protocollair CVRM. Nederlands Huisartsen Genootschap; 2016.

17. Freund T, Everett C, Griffiths P, Hudon C, Naccarella L, Laurant M. Skill mix, roles and remuneration in the primary care workforce: Who are the healthcare professionals in the primary care teams across the world? Int J Nurs Stud. 2015;52(3):727-743.

18. Dorresteijn JA, Visseren FL, Wassink AM, et al. Development and validation of a prediction rule for recurrent vascular events based on a cohort study of patients with arterial disease: The SMART risk score. Heart. 2013;99(12):866-872.

19. Gezondheidsraad. Richtlijnen goede voeding 2015.

20. de Hollander EL, Zwart L, de Vries SI, Wendel-Vos W. The SQUASH was a more valid tool than the OBiN for categorizing adults according to the dutch physical activity and the combined guideline. J Clin Epidemiol. 2012;65(1):73-81.

21. van Bussel EF, Hoevenaar-Blom MP, Busschers WB, et al. Effects of primary cardiovascular prevention on vascular risk in older adults. Am J Prev Med. 2018;55(3):368-375.

22. Willems N, Romeijnders ACM, Smits G. Verminderen van praktijkvariatie in de eerste lijn. Huisarts Wet 2017;11:580-583.

23. Murphy E, Vellinga A, Byrne M, et al. Primary care organisational interventions for secondary prevention of ischaemic heart disease: A systematic review and metaanalysis. Br J Gen Pract. 2015;65(636):460.

24. Heery S, Gibson I, Dunne D, Flaherty G. The role of public health nurses in risk factor modification within a high-risk cardiovascular disease population in ireland - a qualitative analysis. Eur J Cardiovasc Nurs. 2019;18(7):584-592. 
25. Phillips LS, Branch WT, Cook CB, et al. Clinical inertia. Ann Intern Med. 2001;135(9):825-834.

26. Ju I, Banks E, Calabria B, et al. General practitioners' perspectives on the prevention of cardiovascular disease: Systematic review and thematic synthesis of qualitative studies. BMJ Open. 2018;8(11):e021137-021137.

27. Uthman OA, Hartley L, Rees K, Taylor F, Ebrahim S, Clarke A. Multiple risk factor interventions for primary prevention of cardiovascular disease in low- and middleincome countries. Cochrane Database Syst Rev. 2015;(8):CD011163. 


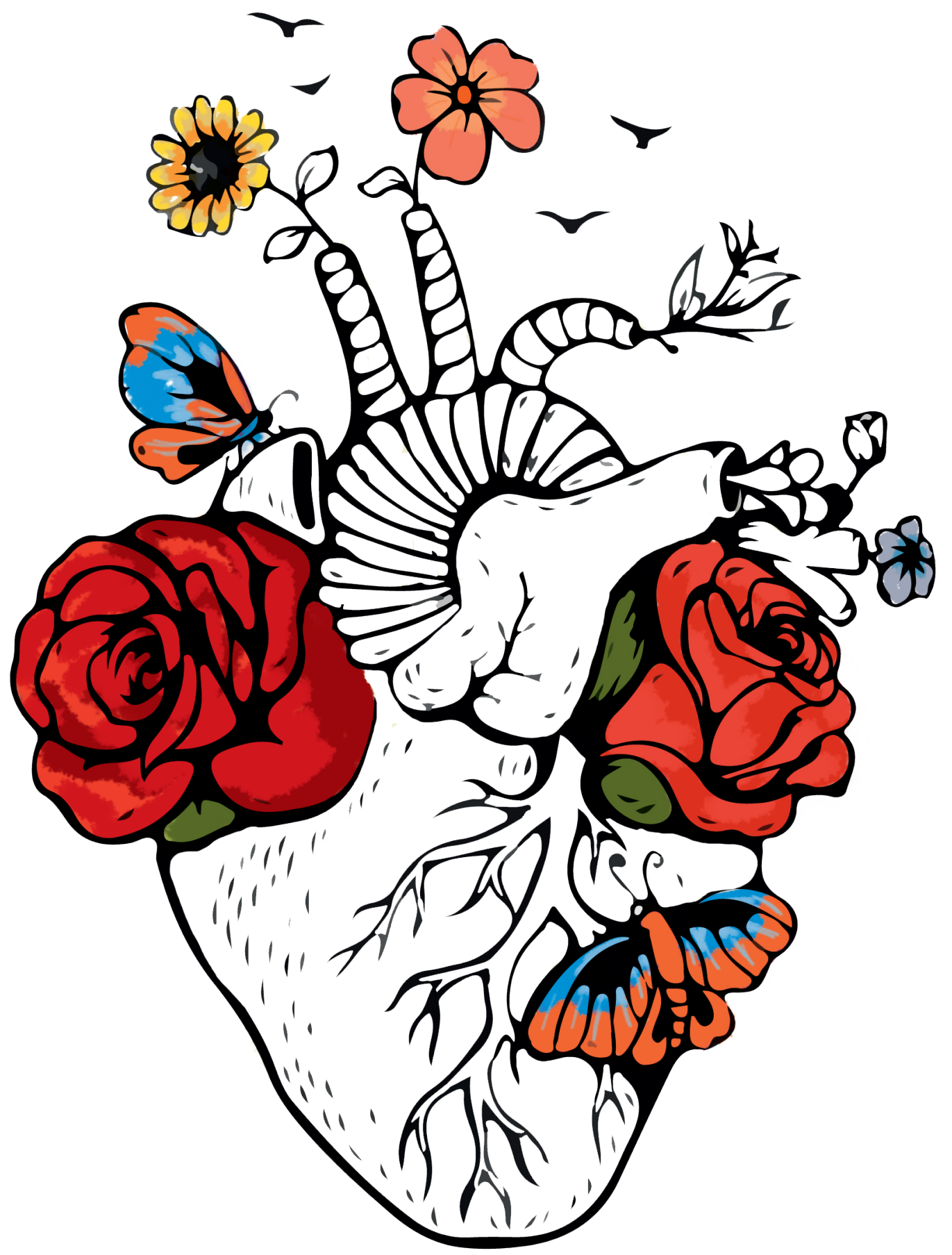




\title{
CHAPTER 5
}

Fidelity to a cardiovascular risk management programme in patients with a high cardiovascular risk in primary care; a process evaluation

\author{
Suzanne Marchal \\ Arnoud W.J. van 't Hof \\ Sander J. Deijns \\ Olof Schwantje \\ Michiel L. Bots \\ Arno W. Hoes \\ Monika Hollander
}

Submitted 


\section{ABSTRACT}

\section{Background}

Studies on the effectiveness of integrated cardiovascular risk management (CVRM) programmes show disappointing results. An underlying mechanism might be lack of fidelity to the programme. We aimed to assess the fidelity to such a programme.

\section{Methods}

We conducted a prospective observational study among high CV risk patients who received integrated CVRM (intervention) or usual care. Assessment of fidelity included adequacy of delivered CVRM care and patients' perception of CV risk (factors) and lifestyle (advice).

\section{Results}

In total, $85 \%$ and $32 \%$ intervention and usual care patients received at least one consultation, including measurements of blood pressure (BP), weight, LDLcholesterol and renal function.

In intervention patients with hypertension or hypercholesterolemia but not on BPor lipid lowering medication at baseline, medication was started in $57 \%$ vs $14 \%$ and $9 \%$ vs $3 \%$, in patients with an off- vs near-target systolic BP or LDL-cholesterol, respectively. In patients using such medication at baseline, the prescription was changed in $33 \%$ vs $19 \%$ and $28 \%$ vs $8 \%$, respectively.

In total, $12-14 \%$ of intervention and $13-22 \%$ of usual care patients correctly labelled their CV risk as intermediate to high. Adequacy of patient's perception of $\mathrm{CV}$ risk factors and lifestyle did not differ between the groups. Less than one-third of patients who received lifestyle advice reported having received the advice.

\section{Conclusion}

Integrated CVRM improved CV risk factor assessment. However, actions taken in patients with hypertension or hypercholesterolemia seem to be insufficient. Patients' perception of risk (factors) and lifestyle (advice) was poor. Further research is needed to improve risk awareness and therapeutic inertia. 


\section{INTRODUCTION}

Cardiovascular disease (CVD) is still the leading cause of death globally. ${ }^{1}$ Despite decreasing mortality rates in high-income countries, worrying trends in CVD risk factor prevalence have been observed. ${ }^{2}$ This underlines the importance of guideline-recommended prevention to further reduce CVD morbidity and mortality. ${ }^{3}$ However, studies, such as the EUROASPIRE surveys, have consistently shown that cardiovascular (CV) risk factors are insufficiently controlled, in primary care ${ }^{4,5}$ Therefore, effective cardiovascular risk management (CVRM) programmes are needed. ${ }^{6}$ General practitioners (GPs) play an important role in CVRM, as they have a longstanding relationship with their patients. To promote and structure implementation of CVRM in general practice, integrated and multidisciplinary CVRM programmes were introduced in recent years. ${ }^{7}$ However, studies investigating the effect of CVRM programmes on mortality, cardiovascular events, blood pressure (BP), cholesterol and life style show disappointing results. ${ }^{8-12}$ The reasons underlying these findings remain unclear. ${ }^{13}$ Inadequately addressing essential elements may play a role, including assessment of risk factors and lifestyle, therapeutic action, communication on risk factors and lifestyle, and patients' perception of risk (factors) and lifestyle. ${ }^{14-16}$ Further, to achieve fidelity to CVRM prevention programmes, a well organised practice is of particular relevance, including involvement of nurses in CVRM, cooperation among clinicians and feedback mechanisms for reporting. ${ }^{17-19}$ To guide future development of CVRM interventions, it is vital to gain a deeper understanding of to what extent the essential elements of integrated CVRM programmes are addressed. The aim of the present study was to assess the fidelity to the integrated care programme for CVRM. $^{20}$ 


\section{METHODS}

\section{Design}

We performed a process evaluation within the framework of the ZWOT-CASE study, a prospective observational study on the effectiveness of an integrated CVRM programme in general practice on systolic blood pressure (SBP) and low-density lipoprotein (LDL)-cholesterol as compared to usual care. It was performed in 689 primary care patients at high CVD risk in the Zwolle region in the Netherlands. Prior to the study all practices delivered usual care for CVRM. The design of the ZWOT-CASE study has been extensively described elsewhere and will be briefly summarized below. ${ }^{20}$ The Isala hospital Review Board reviewed the study and exempted it from full assessment under the Medical Research Involving Human Subjects Act (reference number 16.06104).

\section{Participants}

Patients at high CV risk (having CVD or a > 10\% 10-years CVD risk according to the Dutch CVRM guideline) ${ }^{21}$ were included. In total 372 patients were included in the intervention and 317 patients in the usual care group. Written informed consent was obtained from all participants.

\section{Intervention}

The intervention consisted of an integrated and multidisciplinary CVRM programme in general practice performed by practice nurses (PNs) and GPs. ${ }^{20} \mathrm{PNs}$ had at least 3-4 years of nursing education, including basic CVRM training, were supervised by the GP, and had access to the Dutch CVRM guideline and the practical manual for CVRM provided by the Dutch Society of General Practitioners. ${ }^{21-23}$ Some of the PNs followed a specialization course in CVRM, but this was not obligatory. General practices systematically scrutinized their practice population to identify patients eligible for the CVRM programme, who were subsequently invited to a face-to-face intake consultation. Prior to the intake consultation a blood sample was taken to measure lipids and renal function (glomular filtration rate (GFR) estimated by the formula based on the Modification of Diet in Renal Disease study (MDRD)). The intake consultation included assessment of (cardiovascular) complaints (angina, dyspnoea, painful cramping in lower leg muscles, limited walking distance, sexual disorder), family history of CVD, lifestyle (smoking habits, diet, alcohol, physical activity), medication, measurement of BP and calculation of 
the body mass index (BMI). ${ }^{21}$ Besides, estimation of the 10 -year CV risk according to the Dutch CVRM guideline in patients without CVD was an important part of the intake. In addition, individual treatment goals were defined applying shared decision making, taking into account the CV risk in communication with patients. All patients were given general lifestyle advice. Patients not achieving a healthy lifestyle according to the Dutch guideline could be referred to smoking cessation programmes, dieticians, exercise programmes or a physiotherapist to get support in changing their lifestyle. If treatment goals according to the Dutch guideline for CVRM (SBP < $140 \mathrm{mmHg}$, LDL-cholesterol $<2.6 \mathrm{mmol} / \mathrm{L}$ ), were not reached through life style changes, treatment with medication was indicated, including antihypertensive and/or lipid lowering drugs. ${ }^{21}$ After the intake consultation, patients were monitored on a regular base, depending on the control of cardiovascular risk factors and individual treatment goals, but at least once a year.

From the start of the intervention, all practices started to work with a multidisciplinary information system for integrated care (KIS, Portavita ${ }^{\circledR}$ ), in which they registered all patient data collected during the visits. All involved disciplines, including dieticians, physiotherapists and medical specialists, had access to the patient data in the multidisciplinary information system, facilitating care coordination across organizations and ensuring a consistent policy in individual patients. Besides, these data were used for yearly feedback to the GP on delivered CVRM, including comparison of mean SBP and LDL-cholesterol levels and smoking rates per practice with national data. Once a year, practices received a benchmark report and regional benchmark meetings were organized.

\section{Usual care}

Usual care was based on the Dutch CVRM guideline, describing how to calculate the $\mathrm{CV}$ risk and advice to lower this risk by lifestyle intervention and/or medication. ${ }^{21}$ However, scrutinizing the practice for and actively inviting eligible patients for a visit and regular follow-up was not formalized. Finally, data were not registered in a multidisciplinary information system, GPs did not receive feedback on delivered CVRM and care coordination across different disciplines was not facilitated.

\section{Data collection}

After 1 year of follow-up, patients in both the intervention and usual care group visited the general practice for the endpoint visit of the ZWOT-CASE study, during 
which an office BP, BMI, smoking status and alcohol consumption were assessed. Further, an up-to-date CV risk score was calculated (for patients without CVD the risk chart in the Dutch guideline was used, based on the SCORE risk function; ${ }^{21}$ for patients with known CVD the SMART-risk score was used). ${ }^{24}$ Prior to the endpoint visit, a blood sample was taken to measure lipids, renal function and hs-CRP for CVD patients (to calculate SMART risk) and patients were asked to fill out a questionnaire. The questionnaire included questions on perception of risk factors and lifestyle, such as "How high do you think your risk of cardiovascular disease is for the next ten years?" (answer options: low; medium; high) and "Is your physical activity sufficient?", "Do you have a healthy body weight?", "Do you have a high blood pressure?" (answer options: yes; no; I don't know) and questions on received lifestyle advice, such as "In the last year, did you receive advice to increase physical activity?", “... to lose weight?”, “... to eat healthier?”, “... to do something about your high blood pressure?" (answer options: yes; no; I don't know; not applicable). Further, physical activity was assessed by the questionnaire (the squash questionnaire). ${ }^{25}$ Also, the questionnaire included the level of education. After the follow-up visit we scrutinized electronic medical records to assess the number of consultations in the last year in the context of CVRM, measurements of BP, weight and/ or BMI, LDL-cholesterol and renal function, lifestyle advice given, including dietary habits, physical activity and smoking, and medication use (including antihypertensive and lipid lowering medication) and changes in medication. We pseudonymised all data relating to patients. As data from the endpoint visit and questionnaires were not available in patients who died during follow-up, they were excluded from the current process evaluation.

\section{Process evaluation measures}

The assessment of fidelity was twofold: 1) adequacy of delivered CVRM care, including assessment of risk factors, lifestyle advice as given by the PN or GP and start or intensification of targeted medication in patients with increased BP or cholesterol levels; and 2) adequacy of patients' perception of CV risk (factors) and lifestyle (advice).

We operationalized the adequacy of the delivered care by assessing the proportion of patients that had a consultation in the context of CVRM, whose BP, weight and/ or BMI, LDL-cholesterol and renal function were measured and in whom lifestyle advice was given on dietary habits, physical activity and smoking if indicated. 
Start or intensification of medication was only assessed in the intervention group as the usual care group did not have an intake consultation and no baseline measurements. Therefore, it was not possible to assess whether medication adjustment was needed in the usual care group. In the intervention group we assessed whether antihypertensive medication was changed during follow-up in patients who already used antihypertensive and in patients who did not use any antihypertensive at baseline and with a $\mathrm{BP} \geq 140 / 90 \mathrm{mmHg}$ and a near-target $(\geq 140$ and $<150 \mathrm{mmHg}$ ) or off-target SBP ( $\geq 150 \mathrm{mmHg}$ ) at baseline. This BP was based on a single office measurement. We did not have data on BP home measurements. Similarly we assessed whether lipid lowering medication was changed in patients who did or did not use lipid lowering drugs at baseline and with near-target $(\geq 2.6$ and $<3.5 \mathrm{mmol} / \mathrm{L}$ ) or off-target ( $\geq 3.5 \mathrm{mmol} / \mathrm{L}$ ) LDL-cholesterol at baseline. Lack of change in medication when indicated could suggest clinical inertia. ${ }^{14}$

To evaluate the extent to which the intervention and given advice reached the patient, we assessed the adequacy of the patient's perception regarding their cardiovascular risk (factors) and lifestyle at the endpoint in both groups. Perception was defined as adequate if: patients with CV risk $\geq 10 \%$ and $<20 \%$ (according to risk chart in Dutch CVRM guideline) considered their CV risk as intermediate or high and patients with CVD or CV risk $\geq 20 \%$ considered it as high; patients with $\mathrm{BP} \geq 140 / 90 \mathrm{mmHg}$ or antihypertensive drug use considered themselves to have hypertension; patients with a LDL-cholesterol $\geq 2.6$ or lipid lowering drug use considered themselves to have hypercholesterolemia; patients who were $<5$ days a week moderate intense physically active for $\geq 30$ minutes/ day considered physical activity as insufficient; patients with $\mathrm{BMI} \geq 30$ considered body weight as unhealthy; men consumed $>2$ alcohol units/ day and women $>1$ alcohol unit/ day considered their alcohol consumption as too much.

Further, lifestyle advice given by the GP or PN in the last year as reported by the patient was assessed and compared to reporting of lifestyle advice given by the $\mathrm{GP} / \mathrm{PN}$ in the patient's file during follow-up, including advice on diet, physical activity and smoking cessation.

\section{Statistical analyses}

To analyse the process data descriptive statistics were used. To test for statistical differences between the intervention group and the usual care group, Pearson $\chi 2$ 
test was used for dichotomous outcomes and Kruskal-Wallis test for categorical outcomes. To assess whether level of education influenced the adequacy of the patient's perception regarding their cardiovascular risk (factors) and lifestyle we did an exploratory analysis in subgroups of 3 different levels of education (low, intermediate, high). Statistical analyses were performed using R studio (version 3.5.1, Copyright (C) 2018 The R Foundation for Statistical Computing).

\section{RESULTS}

\section{Patient and practice characteristics}

In total, we obtained process measures of 367 (99\%) from the intervention and 314 (99\%) patients from the usual care group of the ZWOT-CASE study, as respectively $5(1 \%)$ and $3(1 \%)$ patients who died during follow-up were excluded. In both groups $42 \%$ were women and the mean age was 65.0 (SD 8.3) in the intervention and 66.2 (SD 7.5) in the usual care group (table 1).

The median number of GPs per practice was 3.5 vs 2.0 and $100 \%$ vs $78 \%$ worked with a PN in the intervention and usual care practices respectively (table 1). Most practices in both groups offered an integrated care programme for diabetes mellitus and Chronic Obstructive Pulmonary Disease (COPD).

Table 1. Baseline characteristics

\begin{tabular}{|c|c|c|}
\hline Patient characteristics & $\begin{array}{l}\text { Intervention group } \\
\quad(n=367)\end{array}$ & $\begin{array}{l}\text { Usual care group } \\
\quad(n=314)\end{array}$ \\
\hline Mean age in years (SD) & $65.0(8.3)$ & $66.2(7.5)$ \\
\hline Age $<65$ & $175(48)$ & $130(41)$ \\
\hline Female & $155(42)$ & $131(42)$ \\
\hline \multicolumn{3}{|l|}{ Level of education ${ }^{\text {a }}$} \\
\hline Low & $171(47)$ & $167(53)$ \\
\hline Intermediate & $100(27)$ & $69(22)$ \\
\hline High & $84(23)$ & $54(17)$ \\
\hline \multicolumn{3}{|l|}{ Cardiovascular risk factors } \\
\hline Hypertension ${ }^{\mathrm{b}}$ & $280(77)$ & $234(75)$ \\
\hline Hypercholesterolemia ${ }^{\text {b }}$ & $91(25)$ & $91(29)$ \\
\hline Current smoking ${ }^{c}$ & $43(12)$ & $32(11)$ \\
\hline Chronic kidney disease $^{d}$ & $40(11)$ & $51(16)$ \\
\hline
\end{tabular}


Table 1. (Continued)

\begin{tabular}{|c|c|c|}
\hline Patient characteristics & $\begin{array}{l}\text { Intervention group } \\
(\mathrm{n}=367)\end{array}$ & $\begin{array}{c}\text { Usual care group } \\
(\mathrm{n}=314)\end{array}$ \\
\hline Micro-albuminuria ${ }^{\mathrm{d}}$ & $15(4)$ & $10(3)$ \\
\hline Rheumatoid arthritis ${ }^{\mathrm{b}}$ & $4(1)$ & $10(3)$ \\
\hline Cardiovascular diseases ${ }^{\mathrm{b}, \mathrm{e}}$ & $170(46)$ & $159(51)$ \\
\hline Myocardial infarction & $40(11)$ & $48(15)$ \\
\hline Coronary sclerosis & $46(13)$ & $44(14)$ \\
\hline Angina pectoris & $44(12)$ & $39(13)$ \\
\hline Transient ischaemic attack & $33(9)$ & $31(10)$ \\
\hline Cerebral infarction & $35(10)$ & $16(5)$ \\
\hline Aneurysm aortae & $8(2)$ & $11(4)$ \\
\hline Intermittent claudication & $12(3)$ & $13(4)$ \\
\hline Atherosclerosis & $4(1)$ & $4(1)$ \\
\hline \multicolumn{3}{|l|}{ Comorbidities (including other CVD) ${ }^{\mathrm{b}}$} \\
\hline COPD & $9(2)$ & $14(5)$ \\
\hline Atrial fibrillation & $23(6)$ & $15(5)$ \\
\hline Heart failure & $1(0)$ & $3(1)$ \\
\hline \multicolumn{3}{|l|}{ Medication use ${ }^{c}$} \\
\hline Antihypertensive agents & $298(83)$ & $250(81)$ \\
\hline Statins/lipid lowering agents & $189(52)$ & $166(54)$ \\
\hline Anticoagulants & $168(47)$ & $153(50)$ \\
\hline \multicolumn{3}{|l|}{ Measurements ${ }^{f}$} \\
\hline Mean SBP in mmHg (SD) & $136.8(15.2)$ & \\
\hline Mean DBP in mmHg (SD) & $80.3(9.6)$ & \\
\hline Mean LDL-cholesterol in mmol/L (SD) & $2.8(0.9)$ & \\
\hline Mean BMI (SD) & $27.7(4.0)$ & \\
\hline Uncontrolled RR ( $\geq 140 / 90$ ) & $166(45)$ & \\
\hline Uncontrolled LDL- cholesterol ( $\geq 2.6 \mathrm{mmol} / \mathrm{L})$ & $214(59)$ & \\
\hline Practice characteristics & $(n=16)$ & $(\mathrm{n}=9)$ \\
\hline Median number of GPs (IQR) & $3.5(2-4)$ & $2(2-3)$ \\
\hline Solo & $1(6)$ & $2(22)$ \\
\hline Duo & $5(31)$ & $3(33)$ \\
\hline Group & $10(63)$ & $4(44)$ \\
\hline \multicolumn{3}{|l|}{ Practice location } \\
\hline Urban & $8(50)$ & $5(56)$ \\
\hline Rural & $8(50)$ & $4(44)$ \\
\hline Availability of practice nurse & $16(100)$ & $7(78)$ \\
\hline
\end{tabular}


Table 1. (Continued)

\begin{tabular}{lcc}
\hline Practice characteristics & (n = 16) & (n= 9) \\
\hline Practice nurse followed CVRM training & $16(100)$ & $3(33)$ \\
Median number of PNs (IQR) & $2(1.8-3)$ & $2(1-2)$ \\
Integrated care diabetes mellitus & $16(100)$ & $8(89)$ \\
Integrated care COPD & $14(88)$ & $8(89)$ \\
\hline
\end{tabular}

$\mathrm{SD}$, standard deviation. CVD, cardiovascular diseases. COPD, chronic obstructive pulmonary disease. SBP, systolic blood pressure. DBP, diastolic blood pressure. LDL, low-density lipoprotein. BMI, body mass index.

Absolute numbers (\%) are presented unless stated otherwise.

${ }^{\text {a }}$ Low level: no education, (pre-)primary education, pre-vocational secondary education, first 3 years of senior general secondary education, first 3 years of pre-university education. Intermediate level: senior general secondary education, pre-university education, senior secondary vocational education and training. High level: associate degree, bachelor's degree, master's degree, doctoral degree.

${ }^{\mathrm{b}}$ Based on International Classification of Primary Care (ICPC)-coded diagnoses.

${ }^{\mathrm{c}}$ Based on medical records.

${ }^{\mathrm{d}}$ Based on ICPC-coded diagnoses and/ or laboratory measurements. Micro-albuminuria: albumincreatinine ratio $>3 \mathrm{mg} / \mathrm{mmol}$. Chronic kidney disease: $\geq 3$ months impaired renal function (eGFR < $60 \mathrm{ml} / \mathrm{min} / 1.73 \mathrm{~m}^{2}$ ) and/ or micro-albuminuria.

${ }^{\text {e }}$ Cardiovascular diseases as inclusion criteria for integrated CVRM care and for the ZWOT-CASE study.

${ }^{\mathrm{f}}$ Baseline measurements of the usual care group at $\mathrm{t}=0$ are not presented, as there was no routine intake consultation.

\section{Adequacy of delivered CVRM care - assessment of risk factors and given lifestyle advice}

In one year, all intervention patients compared to $79 \%$ of patients in the usual care group had at least one consultation and in $85 \%$ and $32 \% \mathrm{BP}$, body weight, LDL-cholesterol and renal function were all measured (table 2). The median number of consultations was 2 (IQR 1 - 3) in both groups. In a higher proportion of intervention patients BP (99\% vs 74\%), body weight (95\% vs 46\%), LDLcholesterol (94\% vs 57\%) and renal function (93\% vs 65\%) was measured as compared to usual care patients during the 1-year follow-up period. Likewise, a higher proportion of intervention patients received advice on diet (59\% vs 19\%), physical activity ( $85 \%$ vs $22 \%$ ) and smoking cessation in smokers (71\% vs $20 \%$ ). All these differences were statistically significant $(p<0.001)$. 


\section{Adequacy of delivered CVRM care - start or intensification of medi- cation}

In the intervention group, $63(17 \%)$ patients did not use antihypertensive medication at baseline and among them 14 (23\%) and 7 (12\%) had an off- and near-target SBP, respectively. During follow-up, medication was started more often in patients with an off-target SBP as compared to near-target SBP (57\% vs 14\%, respectively) (figure S1). Among 298 (83\%) patients who used antihypertensive medication at baseline 54 (19\%) and 72 (25\%) had an off- and near-target SBP, respectively. Antihypertensive medication was more often changed in patients with off-target SBP as compared to near-target SBP (33\% vs 19\%, respectively). This concerned starting additional medication in 12 (22\%) vs 3 (4\%), uptitration in $8(15 \%)$ vs $4(6 \%)$ and replacement in $1(2 \%)$ vs $5(7 \%)$.

In total 172 (48\%) intervention patients did not use lipid-lowering drugs at baseline and among these, 70 (41\%) and 76 (44\%) had an off- and near-target LDL-cholesterol. Lipid-lowering medication was started in 9\% and 3\% (figure S2). Among 189 (52\%) patients who used lipid-lowering drugs at baseline 18 (10\%) and $50(27 \%)$ had an off- and near-target LDL-cholesterol. Lipid-lowering medication was changed more often in patients with an off-target as compared to near-target LDL-cholesterol (28\% vs 8\%, respectively).

\section{Adequacy of patients' perception of risk (factors) and lifestyle (advice)}

Overall, adequacy of patients' perception of risk (factors) and lifestyle (advice) did not statistically differ between intervention and control patients (table 3). Among patients without CVD, $14 \%$ vs $22 \%$ correctly classified themselves as having an intermediate or high risk of CVD and among CVD patients $12 \%$ vs $13 \%$ correctly classified themselves as having a high CV risk. In hypertensive patients $51 \%$ correctly labelled themselves as having hypertension in both groups and in patients with hypercholesterolemia $25 \%$ vs $28 \%$ correctly classified themselves as having hypercholesterolemia.

Regarding lifestyle, $73 \%$ vs $65 \%$ correctly classified themselves as being physically active and $88 \%$ vs $86 \%$ as drinking not too much alcohol in respectively the intervention and usual care group and $70 \%$ as having a healthy weight in both groups. 


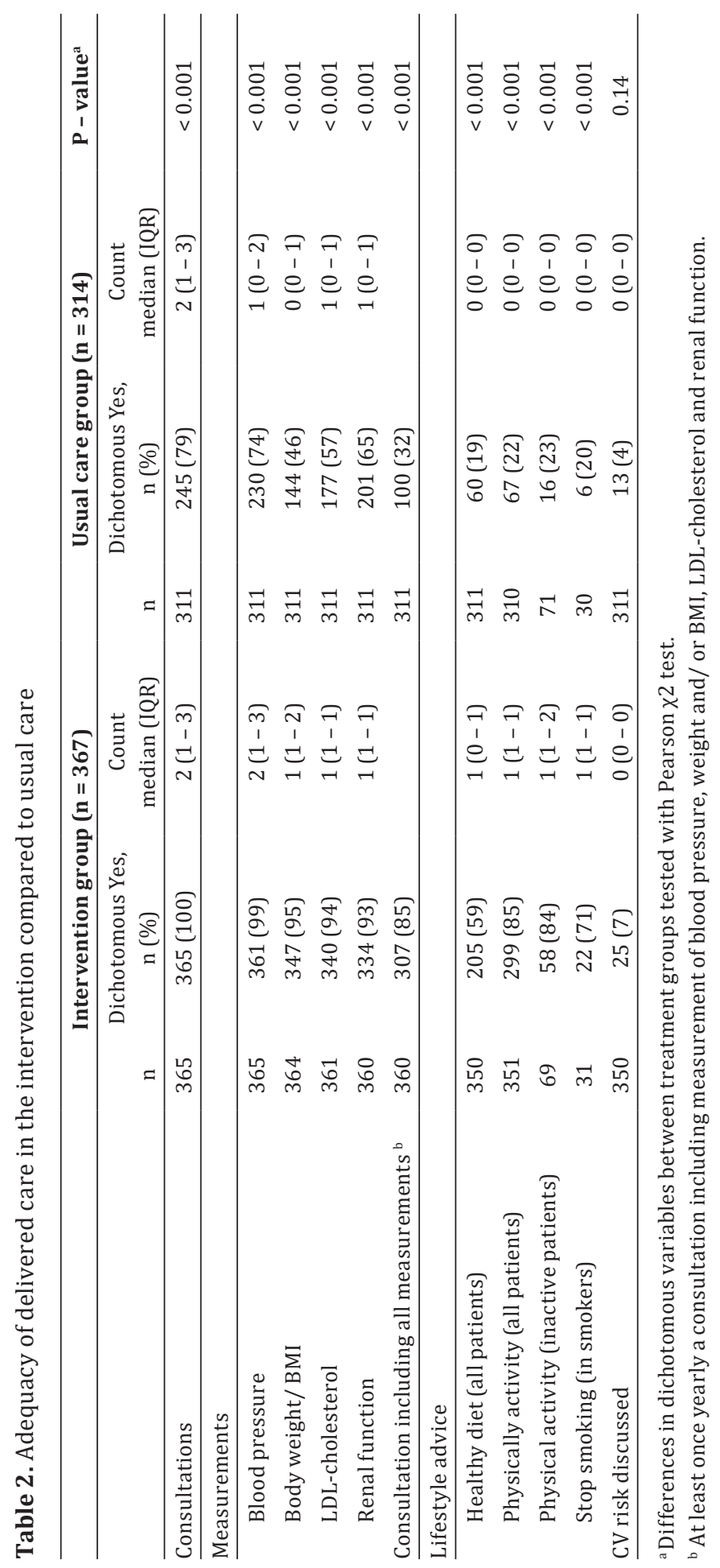


Overall, level of education did not influence the adequacy of patients' perception of risk (factors) and lifestyle, except for physical activity. Patients with a high level of education classified themselves more often correctly as being physically active ( $85 \%$ and $76 \%$ ) than patients with an intermediate $(66 \%$ and $68 \%$ ) or low level of education $(71 \%$ and $59 \%)$ in the intervention and control group respectively.

In both groups, the proportion of lifestyle advice given as reported by the GP or PN in medical records was much higher than "lifestyle advice received" reported by patients. In patients who filled out the questionnaire, in 299 (82\%) intervention and $64(22 \%)$ usual care patients advice by the GP or PN to stay physically active was given, but among them only 67 (22\%) vs 19 (30\%) patients reported having received such advice. Similarly, in 205 (56\%) and 56 (19\%) patients advice to maintain a healthy diet was given and $30(16 \%)$ vs $10(19 \%)$ reported having received the advice. The proportion of smokers that reported to have received a smoking cessation advice was higher, 13 of 22 (59\%) intervention patients vs 5 of $6(83 \%)$ usual care patients. 


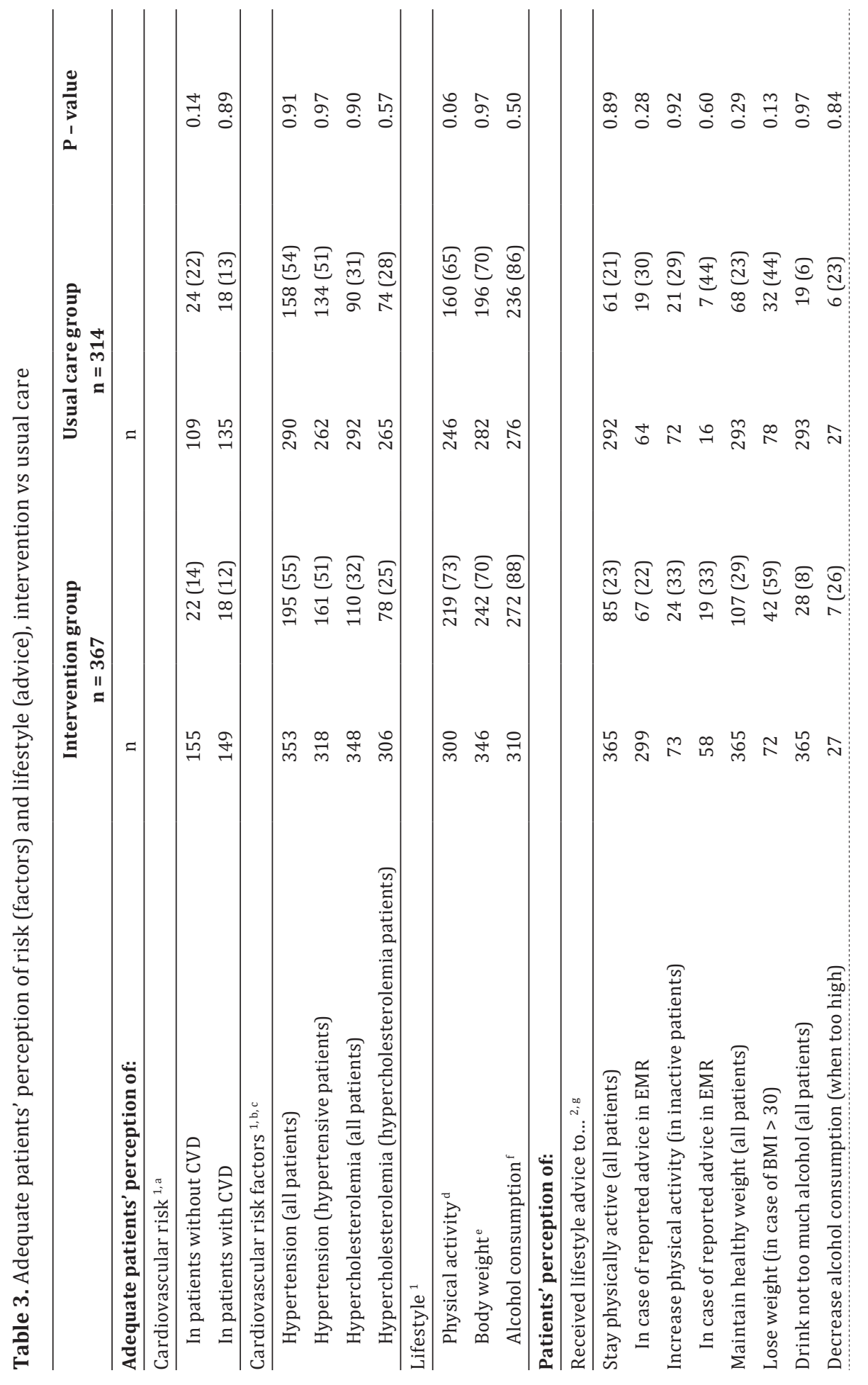




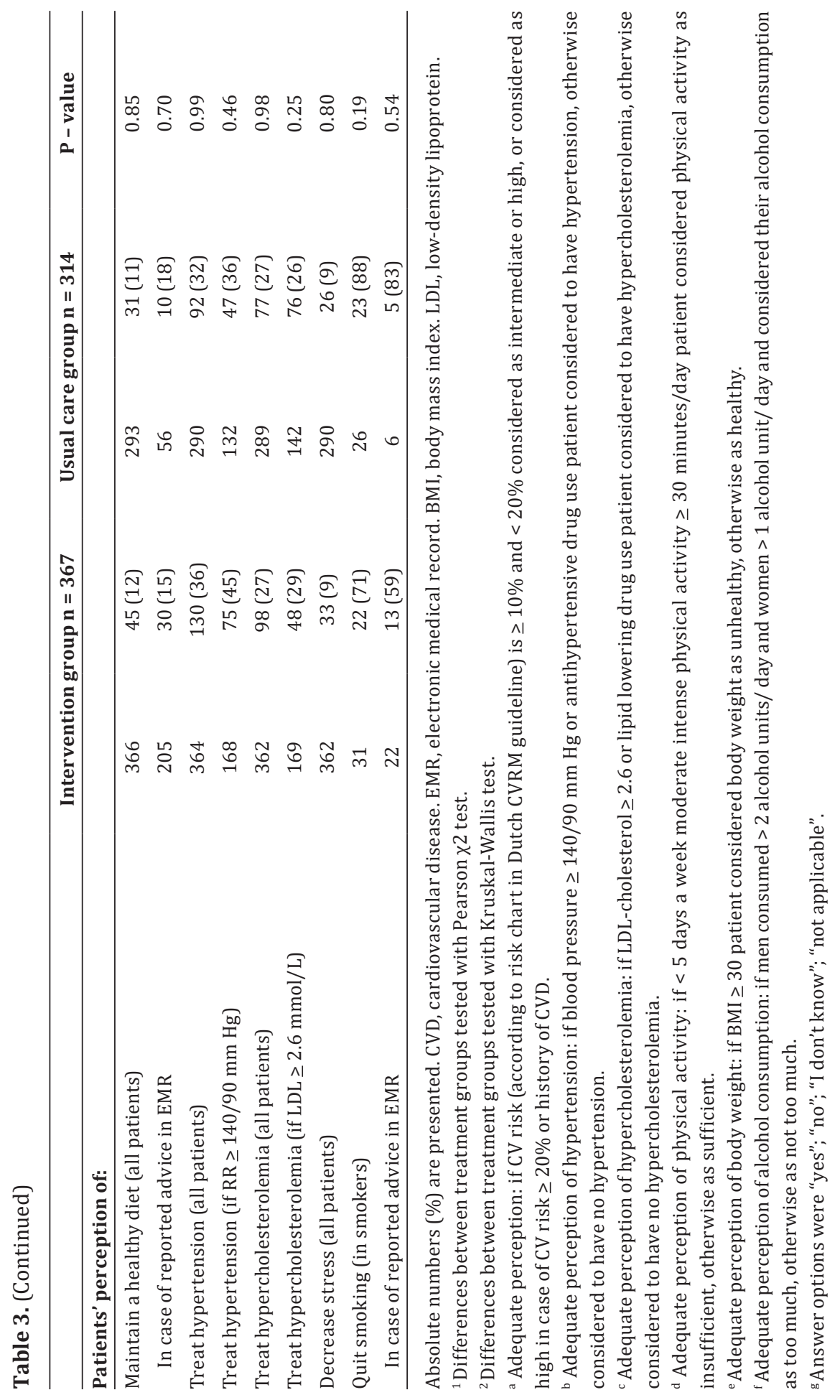




\section{DISCUSSION}

In patients receiving integrated care for CVRM in general practice, $\mathrm{CV}$ risk factors and lifestyle advice were more often assessed and discussed as compared to usual care. However, in patients receiving CVRM care, antihypertensive medication often remained unchanged and in particular lipid-lowering drugs were seldom started or uptitrated when indicated. The CV risk and risk factor awareness in patients was poor; only one out of eight intervention patients with a high risk or CVD correctly labelled themselves as having a high risk. No more than a half and a quarter of patients correctly indicated themselves as having hypertension or hypercholesterolemia, respectively. The adequacy of patient's perception of CV risk (factors) and lifestyle (advice) did not differ between the groups and there was a huge gap between lifestyle advice documented in the medical files and that what was reported by patients.

\section{Strengths and limitations}

This process evaluation is among the first to evaluate the fidelity to an integrated care programme for CVRM in general practice. It adds to a deeper understanding of what elements need to be addressed to improve the outcomes of such programmes. A strength is that this study was conducted in a clinical context that reflects reality, making the results applicable in daily practice. Another strength is the complete data on adequacy of the delivered care; we were able to collect data from more than $95 \%$ of patients.

Bias cannot be entirely eliminated. First, the usual care group included less group practices compared to the intervention group. However, as we did not observe differences in outcomes between practices in the ZWOT-CASE study, we expect that the difference in group practices would not have influenced the differences in fidelity. Second, data on lifestyle and perceived CV risk could suffer from 'socialdesirability bias'. Third, the prevalence of received lifestyle advice in according to the patient could be subject to recall bias, leading to considerable underreporting.

Another limitation is the difference in registration of patient data between both groups. In intervention practices patient data were registered in a multidisciplinary information system for integrated care (KIS, Portavita ${ }^{\circledR}$ ) with boxes to enter predefined data and prompts to give lifestyle advice. In usual care, a general 
information system with free text fields was used without any encouragement to register data on lifestyle advice given to the patient. Therefore, the number of given lifestyle advice could be underreported in the usual care group. We were not able to analyse the quality of the lifestyle advices in depth.

Further, the lack of qualitative data in our study may have limited complete assessment of the organization of CVRM care, including interdisciplinary collaboration.

Finally, misclassification of hypertension may have occurred as the analyses were based on a single office blood pressure measurement and repeated office BP measurements, home or 24-hour BP measurements were not available. This could partly explain the low uptake of BP lowering drugs in those with 'increased BP levels'.

\section{Interpretation of the results and comparison with existing literature}

Integrated CVRM care improved the assessment of CV risk factors and lifestyle counselling compared to usual care, also when compared to the findings from the EPA-cardio study. That large European observational study on CVRM in high risk patients without CVD in primary care, reported lower assessment rates of BP (92.5\%), cholesterol (83.9\%) and weight/ BMI (66.4\%) and lifestyle counselling on diet (42.9\%), physical activity (38.8\%) and smoking (65.6\%) compared to the intervention group in our study. ${ }^{26}$

In our study, medication was added or up-titrated in less than one-third of patients using antihypertensive or lipid-lowering medication who had an off-target SBP or LDL-cholesterol. This is in line with previous studies, reporting clinical inertia rates between $37 \%$ and $88 \%$ in patients with an uncontrolled BP in general practice. ${ }^{14,27-29}$ However, in more than half of patients with an off-target SBP who were not already on antihypertensive medication, antihypertensive medication was started. The corresponding percentage for lipid-lowering medication was much lower (9\%). At one hand, clinical inertia could play a role. ${ }^{14,30}$ On the other hand GPs and patients may have primarily tried to achieve targets by lifestyle change as specifically recommended in cardiovascular prevention guidelines. ${ }^{21}$ Also, patient-related factors may have limited adequate therapeutic interventions, such as reluctance to take medication due to various reasons. Especially, reluctance 
to taking lipid-lowering drugs is widespread. ${ }^{31,32}$ Unfortunately we did not collect detailed information on why therapy was not initiated. Further, inadequate risk factor awareness that we observed in our study may have played a role; a finding in line with previous research. ${ }^{15,33}$ Since risk factor awareness is related to medication adherence, this is of major concern. ${ }^{34,35}$

Consistent with our results, an earlier Dutch primary care study reported CV risk to be perceived inappropriately by nearly 4 out of 5 high-risk patients, suggesting incorrect optimism. ${ }^{15}$ Suboptimal communication between the PN/ GP and patients may explain the gap between communicated and perceived risk factor levels and lifestyle advice by patients. ${ }^{36}$ Possibly, the attention of PNs and GPs focused more on checking boxes than on providing tailored lifestyle counselling. Further, variation in health literacy and numeracy of patients could make risk communication challenging. ${ }^{37}$ Adequate counselling takes time and effort and as their workload increases and patients become more complex PNs may have been insufficiently prepared. ${ }^{38}$ PNs and GPs might need support and tools to communicate about CV risk and how to empower patients to change their lifestyle. ${ }^{39-42}$ For example, a short e-learning course has shown to improve risk communication skills of health care providers. ${ }^{43}$

An observational study showed that local variations between primary care practices with regard to implementation of a CVRM programme (resources, programme compliance to the planned regional clinical process, internal coordination of the health team, and programme experience) had no positive effect on SBP and physical activity. ${ }^{44}$ Another observational study concluded that a favourable perception by team members regarding interdisciplinary collaboration (nurse, nutritionist, kinesiologist, pharmacist, social worker and GP) was associated with better patient outcomes (SBP, diet, quality of life) and less patient withdrawal from the programme, whereas the frequency of clinical information sharing was similar. ${ }^{45}$ This suggests that the qualitative aspect of the interaction between interdisciplinary teams and GPs is of great importance. It raises the question to what extent the CVRM programme in our study, while on paper describing interdisciplinary collaboration, involved genuine collaboration across interdisciplinary teams. Instead of integrated care, referring patients from one to the other discipline may have occurred, lacking high qualitative communication 
and cohesive information sharing with patients. Such a fragmented approach may hinder a more holistic, patient-centred response and, hence, effective CVRM.

\section{Future considerations}

In summary, implementation of integrated CVRM care in general practice leads to a higher proportion of patients in whom CV risk, risk factors, and lifestyle advice are registered and discussed. However, clinical action by primary care workers and risk (factor) and lifestyle awareness in patients remain problematic. This is in line with other studies that consistently have shown that adherence to guidelines and adequate lifestyle counselling is a challenge. ${ }^{4,5,33}$ Possibly, a learning healthcare system including reminders and targeted feedback on performance might enhance risk factor control. ${ }^{14}$ Future studies should focus on improvement of the communication between GP/PN and the patient, including the use of modern risk reduction tools, such as lifetime risk and the absolute risk reduction tool, and CVD free survival (available at https://u-prevent.com). ${ }^{46}$ Also, greater collaborative efforts from various relevant stakeholders and additional financial support may be required to adequately manage $\mathrm{CV}$ risk. ${ }^{47}$ Further, qualitative data could give more insight into the real content of interdisciplinary collaboration in primary care and explore what is needed for a more holistic approach. Finally, studies with longer follow-up should be considered, to assess whether improvement in process measures leads to improvement in (intermediate) outcomes in the longer term. ${ }^{48}$ 


\section{REFERENCES}

1. GBD 2016 Causes of Death Collaborators. Global, regional, and national age-sex specific mortality for 264 causes of death, 1980-2016: A systematic analysis for the global burden of disease study 2016. Lancet. 2017;390(10100):1151-1210.

2. Townsend N, Wilson L, Bhatnagar P, Wickramasinghe K, Rayner M, Nichols M. Cardiovascular disease in europe: Epidemiological update 2016. Eur Heart J. 2016;37(42):3232-3245.

3. Piepoli MF, Hoes AW, Agewall S, et al. 2016 european guidelines on cardiovascular disease prevention in clinical practice: The sixth joint task force of the european society of cardiology and other societies on cardiovascular disease prevention in clinical practice (constituted by representatives of 10 societies and by invited experts): Developed with the special contribution of the european association for cardiovascular prevention \& rehabilitation (EACPR). Eur Heart J. 2016.

4. Kotseva K, De Bacquer D, De Backer G, et al. Lifestyle and risk factor management in people at high risk of cardiovascular disease. A report from the european society of cardiology european action on secondary and primary prevention by intervention to reduce events (EUROASPIRE) IV cross-sectional survey in 14 european regions. Eur J Prev Cardiol. 2016;23(18):2007-2018.

5. Kotseva K, Wood D, De Backer G, et al. EUROASPIRE III. management of cardiovascular risk factors in asymptomatic high-risk patients in general practice: Cross-sectional survey in 12 european countries. Eur J Cardiovasc Prev Rehabil. 2010;17(5):530-540.

6. Osteresch R, Fach A, Schmucker J, et al. Long-term risk factor control after myocardial infarction-A need for better prevention programmes. J Clin Med. 2019;8(8):10.3390/ jcm8081114.

7. Transparante ketenzorg rapportage 2017 zorggroepen diabetes mellitus, VRM, COPD en astma.

8. Ebrahim S, Taylor F, Ward K, Beswick A, Burke M, Davey Smith G. Multiple risk factor interventions for primary prevention of coronary heart disease. Cochrane Database Syst Rev. 2011;(1):CD001561. doi(1):CD001561.

9. van Lieshout J, Huntink E, Koetsenruijter J, Wensing M. Tailored implementation of cardiovascular risk management in general practice: A cluster randomized trial. Implement Sci. 2016;11:115-0.

10. van Bussel EF, Hoevenaar-Blom MP, Busschers WB, et al. Effects of primary cardiovascular prevention on vascular risk in older adults. Am J Prev Med. 2018;55(3):368-375. 
11. Murphy E, Vellinga A, Byrne M, et al. Primary care organisational interventions for secondary prevention of ischaemic heart disease: A systematic review and metaanalysis. Br J Gen Pract. 2015;65(636):460.

12. Goldstein MG, Whitlock EP, DePue J, Planning Committee of the Addressing Multiple Behavioral Risk Factors in Primary Care Project. Multiple behavioral risk factor interventions in primary care. summary of research evidence. Am J Prev Med. 2004;27(2 Suppl):61-79.

13. Alageel S, Gulliford MC, McDermott L, Wright AJ. Multiple health behaviour change interventions for primary prevention of cardiovascular disease in primary care: Systematic review and meta-analysis. BMJ Open. 2017;7(6):e015375-015375.

14. Phillips LS, Branch WT, Cook CB, et al. Clinical inertia. Ann Intern Med. 2001;135(9):825834.

15. van der Weijden T, van Steenkiste B, Stoffers HE, Timmermans DR, Grol R. Primary prevention of cardiovascular diseases in general practice: Mismatch between cardiovascular risk and patients' risk perceptions. Med Decis Making. 2007;27(6):754761.

16. Alageel S, Gulliford MC, McDermott L, Wright AJ. Implementing multiple health behaviour change interventions for cardiovascular risk reduction in primary care: A qualitative study. BMC Fam Pract. 2018;19(1):171-0.

17. Nutting PA, Dickinson WP, Dickinson LM, et al. Use of chronic care model elements is associated with higher-quality care for diabetes. Ann Fam Med. 2007;5(1):14-20.

18. Wagner EH, Austin BT, Davis C, Hindmarsh M, Schaefer J, Bonomi A. Improving chronic illness care: Translating evidence into action. Health Aff (Millwood). 2001;20(6):64-78.

19. Nouwens E, van Lieshout J, van den Hombergh P, Laurant M, Wensing M. Shifting cardiovascular care to nurses results in structured chronic care. Am J Manag Care. 2014;20(7):278.

20. Marchal S, Hollander M, Schoenmakers M, et al. Design of the ZWOT-CASE study: An observational study on the effectiveness of an integrated programme for cardiovascular risk management compared to usual care in general practice. BMC Fam Pract. 2019;20(1):149-z.

21. Dutch College of General Practitioners Guideline Development Group. Guideline cardiovascular risk management (second revision). Huisarts Wet. 2012(55):14-28.

22. Freund T, Everett C, Griffiths P, Hudon C, Naccarella L, Laurant M. Skill mix, roles and remuneration in the primary care workforce: Who are the healthcare professionals in the primary care teams across the world? Int J Nurs Stud. 2015;52(3):727-743.

23. Den Boer, J. K. W. Protocollair CVRM. Nederlands Huisartsen Genootschap; 2016. 
24. Dorresteijn JA, Visseren FL, Wassink AM, et al. Development and validation of a prediction rule for recurrent vascular events based on a cohort study of patients with arterial disease: The SMART risk score. Heart. 2013;99(12):866-872.

25. de Hollander EL, Zwart L, de Vries SI, Wendel-Vos W. The SQUASH was a more valid tool than the OBiN for categorizing adults according to the dutch physical activity and the combined guideline. J Clin Epidemiol. 2012;65(1):73-81.

26. Cruz I, Serna C, Real J, Galindo G, Gasco E, Galvan L. Ischemic heart disease and primary care: Identifying gender-related differences. an observational study. BMC Fam Pract. 2008;9:60-60.

27. Escobar C, Barrios V, Alonso-Moreno FJ, et al. Evolution of therapy inertia in primary care setting in spain during 2002-2010. J Hypertens. 2014;32(5):1138-45; discussion 1145.

28. Hoepfner C, Franco SC. Therapeutic inertia and control of high blood pressure in primary health care units. Arq Bras Cardiol. 2010;95(2):223-228.

29. Gil-Guillen V, Orozco-Beltran D, Perez RP, et al. Clinical inertia in diagnosis and treatment of hypertension in primary care: Quantification and associated factors. Blood Press. 2010;19(1):3-10.

30. Allen JD, Curtiss FR, Fairman KA. Nonadherence, clinical inertia, or therapeutic inertia? J Manag Care Pharm. 2009;15(8):690-695.

31. Naderi SH, Bestwick JP, Wald DS. Adherence to drugs that prevent cardiovascular disease: Meta-analysis on 376,162 patients. Am J Med.2012;125(9):882-7.e1.

32. Ju A, Hanson CS, Banks E, et al. Patient beliefs and attitudes to taking statins: Systematic review of qualitative studies. Br J Gen Pract. 2018;68(671):e408-e419.

33. Kotseva K, De Backer G, De Bacquer D, et al. Primary prevention efforts are poorly developed in people at high cardiovascular risk: A report from the european society of cardiology EURObservational research programme EUROASPIRE V survey in 16 european countries. Eur J Prev Cardiol. 2020:2047487320908698.

34. Rajpura J, Nayak R. Medication adherence in a sample of elderly suffering from hypertension: Evaluating the influence of illness perceptions, treatment beliefs, and illness burden. J Manag Care Pharm. 2014;20(1):58-65.

35. Horne R, Chapman SC, Parham R, Freemantle N, Forbes A, Cooper V. Understanding patients' adherence-related beliefs about medicines prescribed for long-term conditions: A meta-analytic review of the necessity-concerns framework. PLoS One. 2013;8(12):e80633.

36. Tiffe T, Morbach C, Malsch C, et al. Physicians' lifestyle advice on primary and secondary cardiovascular disease prevention in germany: A comparison between the STAAB cohort study and the german subset of EUROASPIRE IV. Eur J Prev Cardiol. 2019:2047487319838218. 
37. Recchia G, Freeman A. Communicating risks and benefits to cardiology patients. Heart. 2020;106(23):1862-1863.

38. Heery S, Gibson I, Dunne D, Flaherty G. The role of public health nurses in risk factor modification within a high-risk cardiovascular disease population in ireland - a qualitative analysis. Eur J Cardiovasc Nurs. 2019;18(7):584-592.

39. Marshall IJ, Wolfe CDA, McKevitt C. 'People like you?': How people with hypertension make sense of future cardiovascular risk-a qualitative study. BMJ Open. 2018;8(11):e023726-023726.

40. Damman OC, Timmermans DR. Educating health consumers about cardio-metabolic health risk: What can we learn from lay mental models of risk? Patient Educ Couns. 2012;89(2):300-308.

41. Ju I, Banks E, Calabria B, et al. General practitioners' perspectives on the prevention of cardiovascular disease: Systematic review and thematic synthesis of qualitative studies. BMJ Open. 2018;8(11):e021137-021137.

42. Brick C, McDowell M, Freeman ALJ. Risk communication in tables versus text: A registered report randomized trial on 'fact boxes'. R Soc Open Sci. 2020;7(3):190876.

43. Hoffmann TC, Del Mar C, Santhirapala R, Freeman A. Teaching clinicians shared decision making and risk communication online: An evaluation study. BMJ Evid Based Med. 2020.

44. Beauregard ME, Provost S, Pineault R, Grimard D, Perez J, Fournier M. Effects on patients of variations in the implementation of a cardiometabolic risk intervention program in montreal. Health Promot Chronic Dis Prev Can. 2018;38(2):64-77.

45. Provost S, Pineault R, Grimard D, et al. Implementation of an integrated primary care cardiometabolic risk prevention and management network in montreal: Does greater coordination of care with primary care physicians have an impact on health outcomes? Health Promot Chronic Dis Prev Can. 2017;37(4):105-113.

46. Stam-Slob MC, Visseren FL, Wouter Jukema J, et al. Personalized absolute benefit of statin treatment for primary or secondary prevention of vascular disease in individual elderly patients. Clin Res Cardiol. 2017;106(1):58-68.

47. Yeoh EK, Wong MCS, Wong ELY, et al. Benefits and limitations of implementing chronic care model (CCM) in primary care programs: A systematic review. Int J Cardiol. 2018;258:279-288.

48. Chin MH, Cook S, Drum ML, et al. Improving diabetes care in midwest community health centers with the health disparities collaborative. Diabetes Care. 2004;27(1):2-8. 


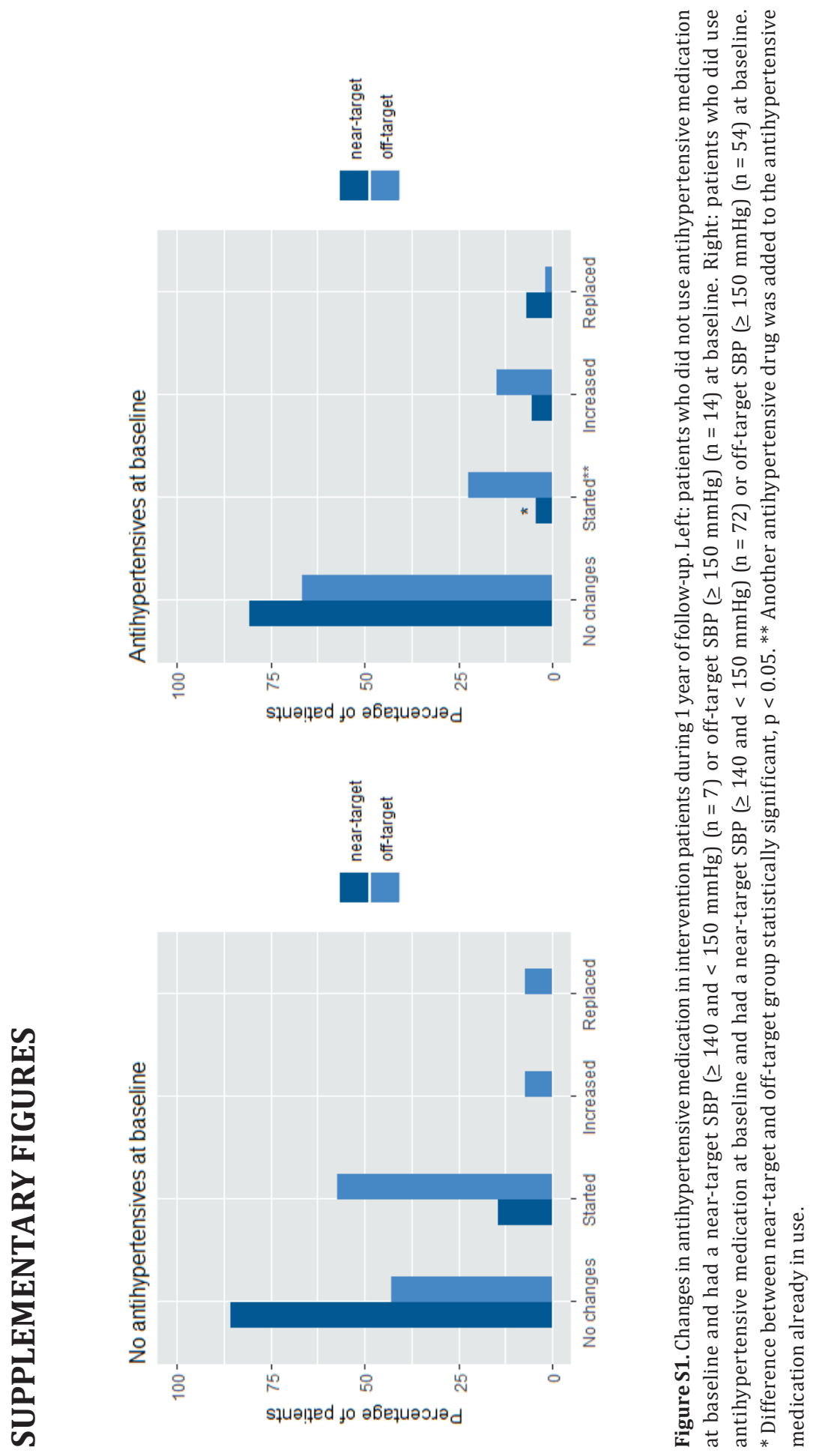



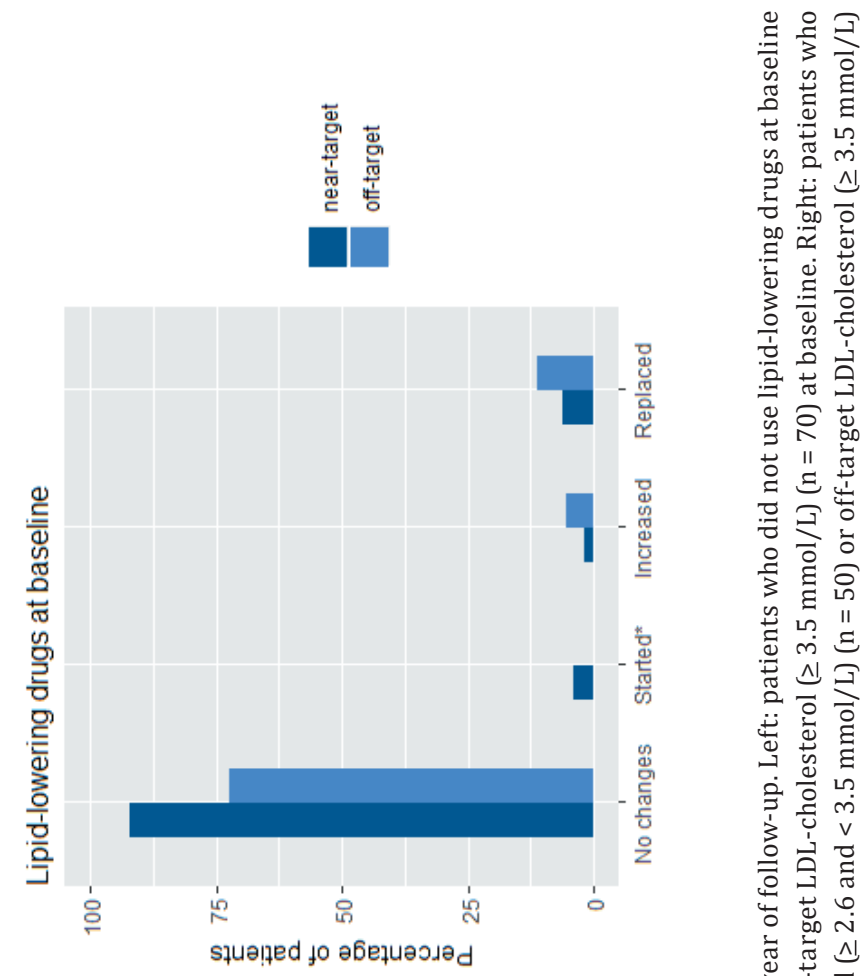

용

궁

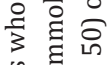

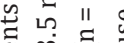

粉

$\stackrel{2}{2} \stackrel{2}{2}$

䒕选

ㄴ. 눙

3 i $v$

응 뭉

范

휴 시 시

¿

b :

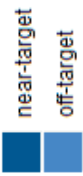

艺 $0 \div$

先

링

苛苛

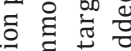

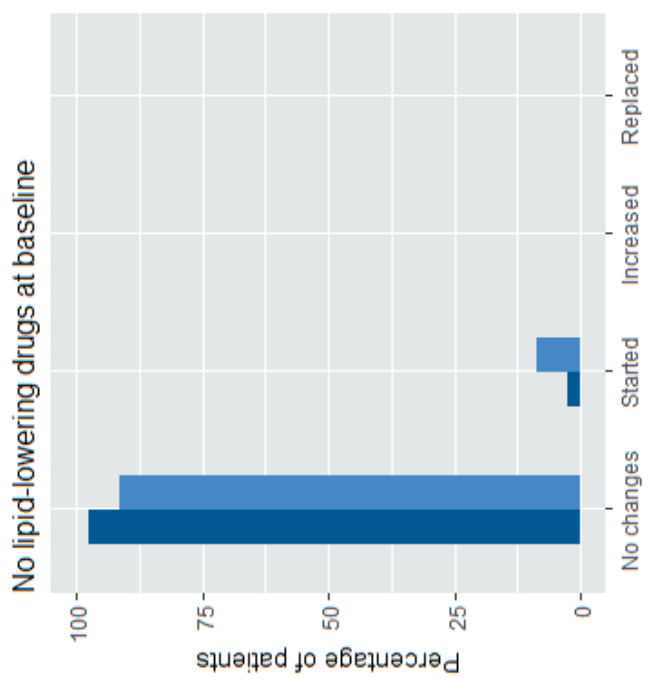




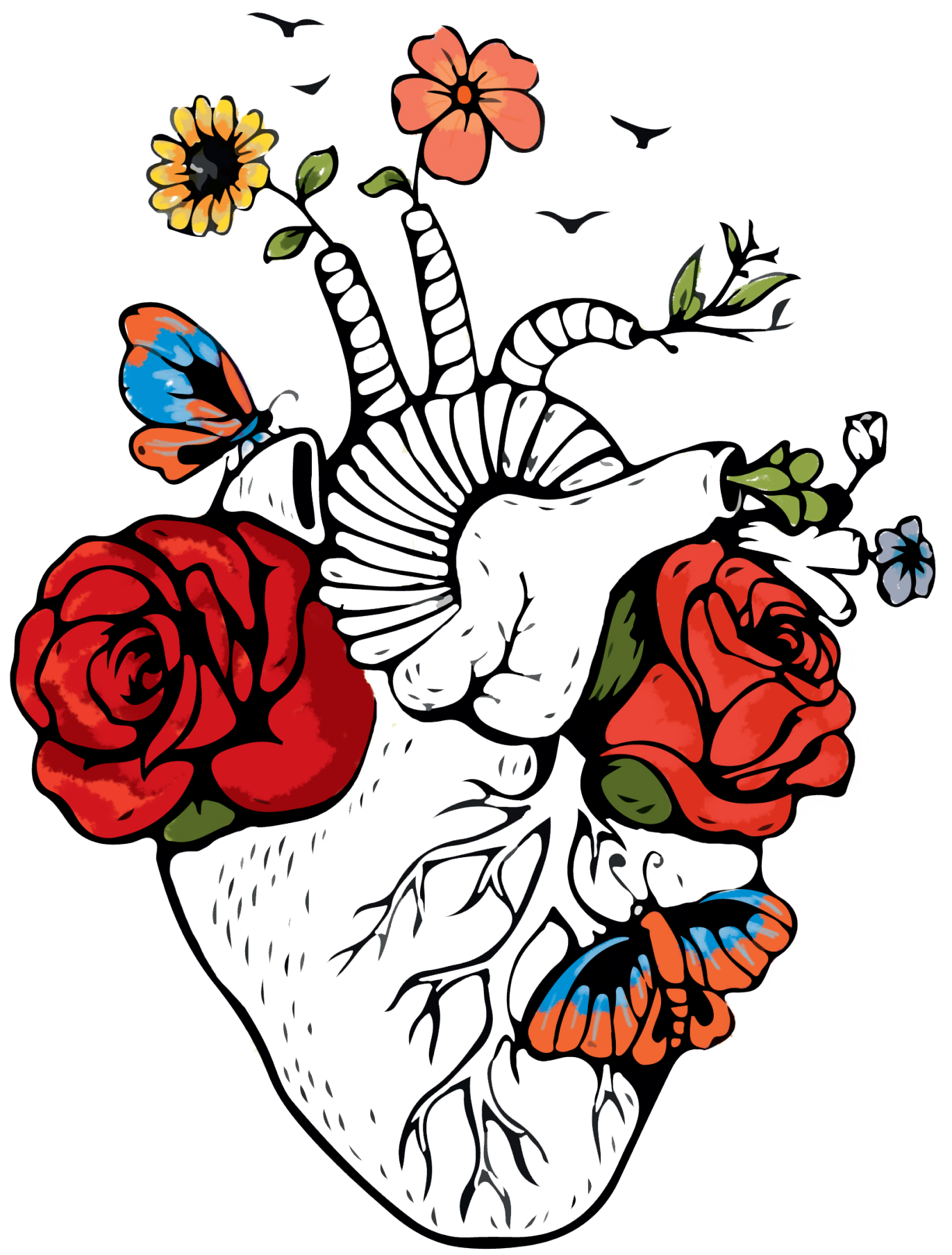




\title{
CHAPTER 6
}

Unravelling the impact of integrated care for cardiovascular risk management on hospital care and costs; a retrospective cohort study among patients with cardiovascular disease

\author{
Suzanne Marchal \\ Willem Keusters \\ Geert W.J. Frederix \\ Arno W. Hoes \\ Henk J.G. Bilo \\ Arnoud W.J. van 't Hof \\ Monika Hollander
}

Submitted 


\section{ABSTRACT}

\section{Background}

Hospital and outpatient care for patients with cardiovascular disease (CVD) constitutes a large part of the health care budget. Integrated care for cardiovascular risk management (CVRM) could reduce costs by substitution of hospital care by care in primary care.

\section{Aim}

To assess costs for hospital care over time and to evaluate whether an integrated care programme for CVRM reduces hospital care and subsequent costs.

\section{Methods}

A retrospective cohort study among patients enlisted in the Isala hospital with atherosclerotic CVD. We assessed patient-level data on diagnoses and care activities from the Isala hospital between January $1^{\text {st }}, 2014$ and January $1^{\text {st }}$, 2018. From January $1^{\text {st }}, 2016$ onwards, an integrated primary care programme for CVRM was implemented in the adherent region. We compared duration of hospital care, number of care activities and corresponding costs prior and after starting integrated CVRM care and used descriptive statistics to assess differences between the two periods.

\section{Results}

We included respectively 5,215 and 5,449 CVD patients, (mean age 70 years, 35\% female), in the period before and after 01-01-2016. The median length of treatment at the hospital decreased from 149 (IQR 12-389) to 128 (IQR 10-386) days and the total median costs of CVRM related hospital care per patient decreased by $13 \%$ from 583 euros (IQR 272 - 2586) the period before to 507 euros (IQR 262 - 2119) during the period after implementation of the programme.

\section{Conclusion}

Real-world hospital data can be an efficient method to evaluate the cost impact of healthcare interventions over time. After introduction of an integrated CVRM programme in primary care, length of treatment decreased slightly and the total costs of CVRM related hospital care decreased by more than $10 \%$. 


\section{INTRODUCTION}

Cardiovascular disease (CVD) is the most common cause of death in Europe. ${ }^{1}$ Between 2015 and 2019, the prevalence of CVD in the Netherlands increased by 150,000 patients to 1,55 million, due to ageing, smoking and increase in prevalence of obesity. ${ }^{2}$ In 2016, CVD accounted for more than $10 \%$ of health expenditure and was at the top of hospital spending. ${ }^{3}$ Due to ageing and an increase in the prevalence of chronic diseases, expenditures are expected to increase further in the near future. ${ }^{4}$ Therefore, policymakers look for solutions to control health care costs, with programmes such as 'right care in the right place'. ${ }^{4}$ This policy aims to reduce health care costs, by relocating care from hospitals closer to people's homes without reducing and preferably improving quality of care. This approach is based on the Triple Aim principle that pursuits the following aims: improving both the quality of care and the health of the population, while reducing the increase of health-care costs. ${ }^{5}$ Integrated multidisciplinary care programmes, such as for cardiovascular risk management (CVRM) in primary care, correspond to this policy by aiming to improve health of patients and reduce costs by substitution of, expensive, hospital care by cheaper care in primary care ${ }^{6}$ General practitioners (GPs) are the key persons to deliver CVRM, as they have a longstanding relationship with their patients. ${ }^{7}$ In addition, GPs in the Netherlands have a gatekeeping role, which means that hospital care is only accessible through GP referral. ${ }^{8}$ However, it is unknown whether an integrated and multidisciplinary CVRM programme indeed leads to substitution of hospital care by care in the primary care and to reduction of costs. ${ }^{9}$ In theory, improved CVRM in general practice could lead to less referrals to a medical specialist at the hospital. ${ }^{10}$ It may also trigger medical specialists to refer patients back to the GP. Therefore, it composes a promising intervention to support substitution and to slow down the increase in expenditures.

The aim of the current study is to compare hospital care and costs related to CVRM in the period before and after implementation of an integrated care programme for CVRM in primary care among patients with established CVD. 


\section{METHODS}

\section{Design}

We performed a retrospective cohort study among patients enlisted in the Isala hospital with an atherosclerotic CVD. An integrated and multidisciplinary CVRM programme in primary care was implemented in the region of Zwolle on January $1^{\text {st }}, 2016$. We assessed the effect of the programme on CVRM related care at the hospital, including length of hospital care, number of care activities and associated costs by comparing patient-level data from the Isala hospital on diagnoses and care activities, including associated costs, during 2 years before and 2 years after January $1^{\text {st }}, 2016$. The study was conducted following the privacy legislation of the Netherlands. A trusted third party anonymized the data.

\section{Setting}

The study was conducted in the region of Zwolle, including the Isala hospital, a large general hospital in the Netherlands, and 56 surrounding general practices affiliated to a care group 'Medrie' and who collaborated with the Isala hospital. From January 2016, integrated care for CVRM was implemented in 39 general practices (70\%, including 115 general practitioners) in this region and coordinated by this care group. The medical specialists of the Isala hospital were involved in organizing integrated care for CVRM together with the GPS.

\section{Study population}

Inclusion criteria for patients were:

- History of atherosclerotic CVD defined as angina pectoris, myocardial infarction, chronic ischemic heart disease, coronary sclerosis, transient ischaemic attack (TIA), cerebral infarction, intermittent claudication or aneurysm of the aorta

- Treatment for atherosclerotic CVD by a medical specialist in the Isala hospital

- At least one care activity at the hospital in the context of CVRM during the period 2014-2018

- Registered with a GP who participated in the integrated CVRM programme

History of atherosclerotic CVD of patients was based on diagnosis codes used in the hospital (table S1). "Treatment by a medical specialist" was defined as having 
at least one care activity at the hospital related to CVRM during the period 20142018. To be able to select patients of GPs participating in the integrated CVRM programme, we used the personal code of the GPs registered at the hospital file for each patient. We asked the GPs for permission to use this personal code.

We compared two periods: the 2 years before January $1^{\text {st }}, 2016$ (control period) and 2 years after January $1^{\text {st }}, 2016$ (intervention period). Information on hospital care and associated costs for CVD patients treated in the Isala hospital during this period was included in the analysis. Patients treated at the hospital in both periods contributed information to both periods.

\section{Intervention}

The intervention under study was an integrated and multidisciplinary programme for CVRM in primary care. ${ }^{11}$ Core elements of this programme include systematic selection and invitation, cardiovascular risk assessment, shared decision in treatment and follow-up of eligible patients, stimulation of self-management, registration of patient data in a multidisciplinary information system and yearly feedback to GPs on delivered CVRM care. GPs collaborated with several health care professionals in the health care chain, including dieticians, physiotherapists and medical specialists. All involved health care professionals had access to the patient data in the multidisciplinary information system. This system also facilitated online consultation between health care professionals.

The aim of the integrated care programme for CVRM was to enhance chronic care and management of cardiovascular risk factors in primary care. Besides, the programme aimed to substitute hospital care by CVRM care in primary care. This substitution can be achieved by several mechanisms. First, improving CVRM in primary care may result in prevention of new cardiovascular events and reduce the need for referral to the hospital. Second, the possibility of an online consultation of a medical specialist can make hospital referral unnecessary. Third, referral from the hospital back to the GP is encouraged by adhering to regional agreements pertaining to some specific patient groups ${ }^{12}$, including patients:

- 6 months after myocardial infarction (MI)

- 1 month after percutaneous coronary intervention (PCI) (no MI)

- 6 months after uncomplicated coronary artery bypass grafting (CABG)

- 12 months after established stable coronary artery disease 
According to the regional agreements, substitution of hospital care by CVRM care in primary care was only possible in case of stable complaints and adequate medication use. In case of residual ischemia after an intervention, clinically manifest heart failure or an ejection fraction of less than $30 \%$ patients remained under control of a medical specialist.

In patients with other CVDs, it was decided on a case-by-case basis whether substitution of hospital care by CVRM care in primary care was possible. At the start of the integrated care programme for CVRM, GPs invited all patients with CVD for an intake visit. If a patient was under control for a CVD at the hospital, the GP considered ending this hospital care after agreeing on this with the medical specialist and the patient.

\section{Data collection}

We used patient-level data on diagnoses and care activities at the Isala hospital. In the Netherlands, diagnoses and care activities are currently coded using a national system adopted by all hospitals and are primarily for financial reimbursement. ${ }^{13}$ Each diagnosis code consists of a specialism code and a more specific diagnosis code. For the current study, we extracted all coded diagnoses of included patients from the electronic medical hospital file. We selected 50 coded diagnoses concerning atherosclerotic CVD of five medical specialties (cardiology, neurology, internal medicine, surgery and cardiothoracic surgery) (table S1).

Besides, we extracted all care activities belonging to the diagnoses, including the date of the activity. We divided activities related to CVRM in 3 main groups: diagnostic activities, paramedical care and consultation activities (table S2). Besides, we extracted outpatient visits, day-care admissions and hospital admissions (number of admission days) related to CVD.

Further, the dataset encompasses information on patient characteristics, including gender and age.

Data were extracted from 2 years before (January $1^{\text {st }}$, 2014) until 2 years after (January $1^{\text {st }}, 2018$ ) implementation of the integrated CVRM programme on January $1^{\text {st }}, 2016$. The dataset was anonymised by a third party. 


\section{Outcome measures}

The outcomes of the study included:

- Duration of CVD care at the hospital in days

- Number of CVRM related care activities during treatment at the hospital

- Costs of CVRM related care at the hospital

First, duration of CVD care at the hospital was based on dates of all care activities related to the $50 \mathrm{CVD}$ diagnoses. The date of the first care activity was defined as the start of treatment at the hospital; the date of the last care activity was defined as the end of treatment at the hospital. To calculate the length of duration of care at the hospital, we calculated the number of days between these two dates.

Second, we counted the number of CVRM related activities during the treatment at the hospital within the 50 CVD diagnoses, including outpatient visits, day-care admissions, hospital admissions, diagnostics, paramedical care activities and consultations (table S2).

Lastly, we assessed the costs of CVRM related care at the hospital, both for the total group and per patient within the 50 CVD diagnoses. Costs were based on CVRM related care activities (table S2). We calculated the costs of each activity by multiplying the actual number of care activities delivered during treatment at the hospital with standardized national prices for the specific activities. ${ }^{14}$ To avoid price difference over time, we used 2018 unit prices and did not apply a discount rate. In case a standardized national unit price was not available, we estimated the price of an activity. If possible, we estimated the price by taking the price of a very similar activity. Otherwise, we estimated the price by estimating and multiplying the duration of the activity in hours by the salary per hour of the health care worker who delivered the activity. ${ }^{14}$

To check whether other factors may have influenced the outcome measures, such as an ageing population or changed hospital policy, we assessed the number of outpatient visits and hospital admissions and corresponding costs of all other diagnoses excluding the 50 atherosclerotic CVD diagnoses (non-CVD care) between January $1^{\text {st }}, 2014$ and January $1^{\text {st }}, 2018$ within the same study population. 


\section{Statistical analyses}

To describe the prevalence of different atherosclerotic CVD in the study population, we used the 50 coded diagnoses of atherosclerotic CVD. The aim of the main analysis was to compare the duration of CVD care at the hospital, number of CVRM related care activities at the hospital and corresponding costs between the 2 years before and the 2 years after implementation of the integrated programme for CVRM on January $1^{\text {st }}, 2016$. For this analysis, we used descriptive statistics. To assess the impact of uncertainties in estimated prices on the robustness of the results concerning total costs a sensitivity analysis was done, using a standard error of $10 \%$ for the estimated prices. Analyses were performed using R studio (version 3.5.1, Copyright (C) 2018 The R Foundation for Statistical Computing).

\section{RESULTS}

In total, 82 of 115 general practitioners agreed to participate in the study. From these participating general practices, we included 5,215 and 5,449 patients in, respectively, the 2 years before and after implementation of the integrated care for CVRM on January 1 1t, 2016 (figure 1).

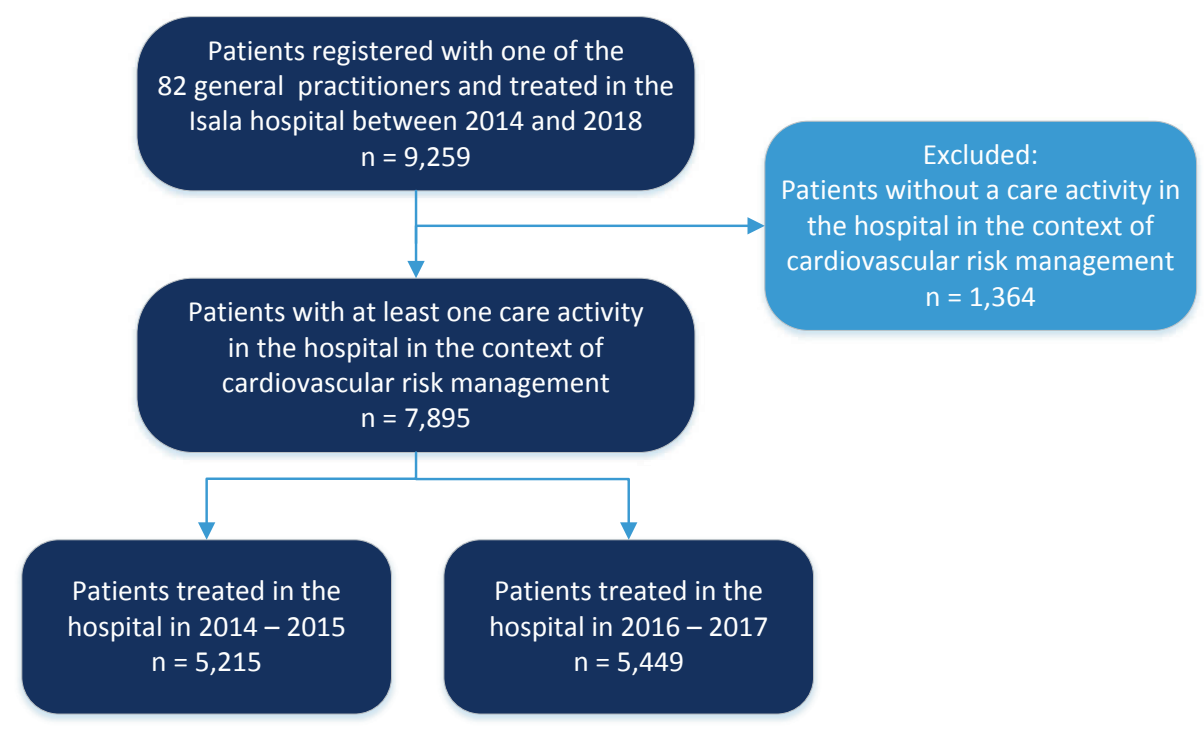

Figure 1. Flowchart selection of study population 
Mean age in included patients was 70.2 (SD 11.5) and 70.6 (SD 11.5) years, on July $1^{\text {st }}, 2016$ and on July $1^{\text {st }}, 2018$ respectively (table 1). In both periods, 35\% were female. The most common CVD diagnosis codes were 'follow-up after percutaneous coronary angioplasty and/or coronary artery bypass graft' (35\% and 33\%), 'angina pectoris' (31\% and 30\%), 'cerebrovascular accident/stroke or transient ischemic attack' (21\% and 20\%) and 'peripheral atherosclerotic disease' (12\% during both periods), in respectively the period before and after January $1^{\text {st }}, 2016$. We observed no clear differences in CVD diagnosis codes between both periods.

Table 1. Patient characteristics

\begin{tabular}{lcc}
\hline Characteristics & $\begin{array}{c}\text { Before (2014 - 2015) } \\
\mathbf{n = 5 , 2 1 5}\end{array}$ & $\begin{array}{c}\text { After (2016 - 2017) } \\
\mathbf{n}=\mathbf{5 , 4 4 9}\end{array}$ \\
\hline Mean age in years (SD) & $70.2(11.5)$ & $70.6(11.5)$ \\
Female (\%) & $1,827(35)$ & $1,893(35)$ \\
\hline Diagnoses* & & $1,622(30)$ \\
\hline Angina pectoris & $1,634(31)$ & $473(9)$ \\
Myocardial infarction & $482(9)$ & $4(0)$ \\
Other ischemic heart disease & $4(0)$ & $321(6)$ \\
CABG & $311(6)$ & $403(7)$ \\
Aortic aneurysm & $341(7)$ & $1,105(20)$ \\
Cerebrovascular accident /TIA & $1,088(21)$ & $659(12)$ \\
Peripheral atherosclerotic disease & $643(12)$ & $205(4)$ \\
Other atherosclerotic CVD & $152(3)$ & $40(1)$ \\
Follow-up after acute coronary syndrome & $36(1)$ & $1,790(33)$ \\
Follow-up after PTCA and/or CABG & $1,819(35)$ & $23(0)$ \\
Follow-up after vascular operation & $23(0)$ & $865(16)$ \\
Cardiac rehabilitation & $919(18)$ & \\
\hline
\end{tabular}

* Diagnoses were based on 50 coded diagnoses of atherosclerotic cardiovascular diseases.

CABG, coronary artery bypass graft. PTCA, percutaneous coronary angioplasty. SD, standard deviation. TIA, transient ischemic attack.

Absolute numbers (\%) are presented unless stated otherwise.

The median length of CVD care at the hospital decreased from 149 days (IQR 12 - 389) to 128 days (IQR 10 - 386) per patient in the period before versus after implementation of integrated CVRM care, respectively (table 2). 
Table 2. Outcome measures per patient

\begin{tabular}{lccc}
\hline & $\begin{array}{c}\text { Before (2014- } \\
\mathbf{2 0 1 5} \\
\mathbf{n = 5 , 2 1 5}\end{array}$ & $\begin{array}{c}\text { After (2016) } \\
\mathbf{n = 5 , 4 4 9}\end{array}$ & \\
\hline Outcomes & & $\begin{array}{c}\text { Change in } \\
\text { costs }\end{array}$ \\
\hline Length of hospital care in days, mean (SD) & $216(211)$ & $212(210)$ & \\
Length of hospital care in days, median (IQR) & $149(12-389)$ & $128(10-386)$ & \\
\hline Median number of activities (IQR) & & & \\
\hline Outpatient visits & $2(1-4)$ & $2(1-3)$ & \\
Hospital admissions & $0(0-4)$ & $0(0-3)$ & \\
Day care & $0(0-0)$ & $0(0-0)$ & \\
Diagnostic activities & $6(2-12)$ & $6(2-12)$ & \\
Paramedical care & $0(0-1)$ & $0(0-1)$ & \\
Consultations & $0(0-0)$ & $0(0-0)$ & \\
Sum of all activities & $9(4-23)$ & $9(4-21)$ & \\
\hline Median costs (IQR) & \multicolumn{3}{c}{$0 \%$} \\
\hline Outpatient visits & $167(83-260)$ & $167(83-250)$ & \\
Hospital admissions & $0(0-1,844)$ & $0(0-1,383)$ & $0 \%$ \\
Day care & $0(0-0)$ & $0(0-0)$ & $0 \%$ \\
Diagnostic activities & $188(61-385)$ & $187(61-348)$ & $-0.5 \%$ \\
Paramedical care & $0(0-66)$ & $0(0-34)$ & $0 \%$ \\
Consultations & $0(0-0)$ & $0(0-0)$ & $0 \%$ \\
Sum of all activities & $583(272-2,586)$ & $507(262-2,119)$ & $-13.0 \%$ \\
\hline
\end{tabular}

SD, standard deviation. IQR, interquartile range.

The median number of the sum of all CVRM related activities per patient was 9 (IQR 4 - 23) and 9 (IQR 4 - 21) in respectively the period before and after implementation of integrated CVRM (table 2). At the group level, the sum of all CVRM related care activities during the treatment in the hospital decreased from 98,924 to 95,439 , whereas the total number of patients with at least one CVRM related care activity increased from 5,199 to 5,413 (table 3). 
Table 3. Total costs per group

\begin{tabular}{|c|c|c|c|c|c|c|c|}
\hline \multirow[b]{2}{*}{ Outcomes } & \multicolumn{3}{|c|}{$\begin{array}{c}\text { Before }(2014-2015) \\
n=5,215\end{array}$} & \multicolumn{3}{|c|}{$\begin{array}{c}\text { After }(2016-2017) \\
n=5,449\end{array}$} & \multirow[b]{2}{*}{$\begin{array}{l}\text { Change } \\
\text { in costs }\end{array}$} \\
\hline & $\begin{array}{c}\text { Patients } \\
\text { n }\end{array}$ & $\begin{array}{c}\text { Activities } \\
\mathbf{n}\end{array}$ & & $\begin{array}{c}\text { Patients } \\
\text { n }\end{array}$ & $\begin{array}{c}\text { Activities } \\
\text { n }\end{array}$ & & \\
\hline \multicolumn{8}{|l|}{$\begin{array}{l}\text { Total costs of hospital } \\
\text { care }\end{array}$} \\
\hline Outpatient visits & 4,980 & 14,364 & $1,112,595$ & 4,850 & 13,695 & $1,064,286$ & $-4.3 \%$ \\
\hline $\begin{array}{l}\text { Hospital } \\
\text { admissions }\end{array}$ & 1,818 & 16,462 & $7,589,068$ & 1,773 & 14,738 & $6,794,295$ & $-10.5 \%$ \\
\hline Day care & 1,224 & 1,596 & 245,254 & 1,142 & 14,68 & 225,585 & $-8.0 \%$ \\
\hline $\begin{array}{l}\text { Diagnostic } \\
\text { activities }\end{array}$ & 4,987 & 58,262 & $1,468,803$ & 5,235 & 57,652 & $1,441,669$ & $-1.8 \%$ \\
\hline Paramedical care & 1,589 & 7,206 & 278,228 & 1,407 & 6,808 & 248,496 & $-10.7 \%$ \\
\hline Consultations & 457 & 1,034 & 36,414 & 235 & 1,078 & 32,813 & $-9.9 \%$ \\
\hline Sum of all activities & 5,199 & 98,924 & $10,730,365$ & 5,413 & 95,439 & $9,807,146$ & $-8.6 \%$ \\
\hline
\end{tabular}

The median costs per patient of the sum of all CVRM related care activities decreased by 13.0\% from 583 euros (IQR 272 - 2,586) to 507 euros (IQR 262 - 2,119) (table 2). At the group level, the total costs of CVRM related care at the hospital decreased by $8.6 \%$, from $10,730,365$ euros in the period before to $9,807,146$ euros in the period after implementation of the programme (table 3). This included a decrease in the costs of outpatient visits by $4.3 \%$ (from 1,112,595 to $1,064,286$ euros), hospital admissions by $10.5 \%$ (from 7,589.068 to $6,794,295$ euros), day care admissions by $8.0 \%$ (from 245,254 to 225,585 euros), diagnostics activities by $1.8 \%$ (from $1,468.803$ to $1,441,669$ euros), paramedical care by $10.7 \%$ (from 278,228 to 248,496 euros) and consultations by $9.9 \%$ (from 36,414 to 32,813 ) (table 3 and figure S1).

The sensitivity analysis showed that uncertainties in estimated prices did not influence the results concerning total costs.

The hospital costs related to other diagnoses than CVD for the CVD patients also decreased, but to a much lower extent from 2014-2015 to the 2016-2017 period; the costs of non-CVD related outpatient visits even slightly increased (table S3). 


\section{DISCUSSION}

In this study, we analysed costs of CVRM related care in the hospital over time and evaluated the effect of an integrated and multidisciplinary CVRM programme in primary care on CVRM related care in the hospital. The median length of treatment in the hospital decreased slightly from 149 days (IQR 12 - 389) to 128 days (IQR 10 - 386). Further, the median costs per patient of CVRM related care at the hospital decreased by $13.0 \%$, from 583 euros (IQR 272 - 2,586) to 507 euros (IQR 262 $2,119)$, mainly due to a decrease in the costs of hospital admissions.

\section{Strengths and limitations}

This study is among the first to evaluate the effect of an integrated care programme for CVRM on hospital care, including costs. A strength is that we had access to a large and complete dataset of delivered healthcare in one hospital. Further, the Isala hospital is the only hospital in the region, minimizing the chance that patients were referred to another hospital. Another strength is that we were able to compare relative long periods ( 2 years each) before and after the introduction of the integrated CVRM care programme. Substitution initiatives require enough time for professionals to adapt to the new policy. ${ }^{15}$ We believe that a follow-up of 2 years after implementation was long enough to demonstrate an effect on hospital care.

Unfortunately, we had no access to data from the general practices, but only to hospital data. Therefore, we were not able to estimate the effects on care activities or costs in primary care and thus to describe the "true substitution" for this patient cohort, but only assessed the effects on hospital care. We also cannot be sure whether CVRM care was started in primary care when care at the hospital ended. However, it is known that a decreased use of hospital care is associated with increased use of primary care. ${ }^{16}$

As this study had a before-after design without a parallel group, we cannot rule out that the observed effects on costs and length of hospital care are due to time dependent trends or other interventions. However, the trend analysis of non-CVD care showed a much smaller decrease in the costs of hospital admissions and even a small increase in the total costs of outpatient visits suggesting that any effect of such time dependent trends is likely to be small. 
The before-after study design is, by design, a non-randomised comparison. Hence, the samples may not have been completely comparable in their characteristics. However, we did not observe any relevant differences in age, gender and type of CVD diagnoses between the two periods.

Lastly, generalisability of the results to countries with other healthcare and referral systems may be limited.

\section{Interpretation of the results and comparison with existing literature}

The mechanism behind the reduction in the number of care activities and corresponding costs in the current study is uncertain. We assume that our findings may be explained by a decrease in referrals from primary care to the hospital due to both intensifying of CVRM care in primary care as improved accessibility of consultation of a medical specialist in primary care as part of the integrated CVRM programme. Further, medical specialists were probably more compliant with regional agreements on substitution for some specific patient groups, leading to an increase in referral from the hospital back to the GP.

Comparison with existing literature is limited, as previous studies on the effect of integrated care for CVRM on hospital care and substitution are very scarce and differ considerably in study aim and design. In line with our results, an Australian study showed that a chronic disease management programme for patients with CVD or diabetes successfully reduced the frequency and duration of hospital admissions..$^{17}$ The magnitude of the effect increased over time and persisted after 4 years, demonstrating the importance of a sustained programme to maximise its impact. ${ }^{17,18}$

Several reviews evaluating other integrated care programmes or substitution initiatives also showed beneficial effects on hospital care. A meta-review of 27 reviews comparing integrated care interventions with usual care, found effects in favour of integrated care on hospital admissions and re-admissions, but no reduction in costs. ${ }^{19}$ Further, a scoping review concluded that transfer of services from secondary to primary care and strategies aimed at changing referral behaviour of primary care clinicians can be effective in reducing outpatient referrals..$^{20}$ Also, a systematic review of Faulkner et al. suggested that a diverse range of interventions to improve health care at the primary-secondary interface 
could suppress referral rates from primary to secondary care. ${ }^{21}$ However, there was little evidence available on cost consequences. ${ }^{20}$

\section{Future considerations}

Substitution of hospital care by primary care for selected patients should be encouraged, as general practitioners are able to deliver care of equal quality against lower costs for several patient groups. ${ }^{22,23}$ However, more evidence is needed on the effect of such interventions to stimulate such substitution. For example, longitudinal research comparing a regional intervention with national trends on a population level should be conducted to assess the effect of a regional substitution initiative. ${ }^{15}$ Further research is also needed to clarify whether such interventions are cost-effective, taking into account the health of the population, quality of care and costs across the whole health system. ${ }^{20,24}$ Such evidence is also needed to ensure that the enthusiasm surrounding substitution intervention does not lead to overly optimistic, essentially uncontrolled, experiments, without first evaluating whether these interventions negatively affect quality of care, health care outcomes or costs.

Ideally, reductions in healthcare expenditure are based on a decrease in the claims burden for health insurers. ${ }^{15}$ However, our research shows that financial hospital data, despite their inherent limitations, can be an efficient method to evaluate the cost impact of healthcare implementations over time. If performed properly, cost analysis on big cohorts can support decision makers in evaluating healthcare patterns. We propose that such analyses could be used more often to evaluate the impact of healthcare interventions.

Besides further research on substitution, the continuity of care between the hospital and general practice should receive more attention, as a collaborative and multidisciplinary approach is crucial to ensure high quality cardiovascular care after substitution..$^{25,26}$

In conclusion, real world hospital data can be an efficient method to evaluate the cost impact of healthcare interventions over time. After introduction of an integrated CVRM programme in primary care, length of treatment decreased slightly and the total costs of CVRM related hospital care decreased by more than $10 \%$. 


\section{REFERENCES}

1. Timmis A, Townsend N, Gale CP, et al. European society of cardiology: Cardiovascular disease statistics 2019. Eur Heart J. 2020;41(1):12-85.

2. de Boer AR, van Dis I, Visseren F, Vaartjes I, Bots ML. Hart- en vaatziekten in nederland 2019, cijfers over incidentie, prevalentie, ziekte en sterfte. Hartstichting. 2019.

3. OECD. Expenditure by disease, age and gender-focus on health spending. 2016. https://www.oecd.org/els/health-systems/estimating-expenditure-by-dis ease-ageand-gender.htm. Updated 2019.

4. Van den Dungen, B. E., Bindels PJE, De Boer, W. F. H., et al. De juiste zorg op de juiste plek. 2019.

5. Whittington JW, Nolan K, Lewis N, Torres T. Pursuing the triple aim: The first 7 years. Milbank Q. 2015;93(2):263-300.

6. Bodenheimer T, Wagner EH, Grumbach K. Improving primary care for patients with chronic illness: The chronic care model, part 2. JAMA. 2002;288(15):1909-1914.

7. Piepoli MF, Abreu A, Albus C, et al. Update on cardiovascular prevention in clinical practice: A position paper of the european association of preventive cardiology of the european society of cardiology. Eur J Prev Cardiol. 2020;27(2):181-205.

8. van Ginneken E. Perennial health care reform--the long dutch quest for cost control and quality improvement. N Engl J Med. 2015;373(10):885-889.

9. Jong J, Korevaar J, Kroneman M, Dijk C, Bouwhuis S, Bakker D. Substitutiepotentieel tussen eerste en tweedelijns zorg: Communicerende vaten of gescheiden circuits? 2016.

10. Freund T, Campbell SM, Geissler S, et al. Strategies for reducing potentially avoidable hospitalizations for ambulatory care-sensitive conditions. Ann Fam Med. 2013;11(4):363-370.

11. Marchal S, Hollander M, Schoenmakers M, et al. Design of the ZWOT-CASE study: An observational study on the effectiveness of an integrated programme for cardiovascular risk management compared to usual care in general practice. $B M C$ Fam Pract. 2019;20(1):149-z.

12. Medisch Coördinerend Centrum (MCC) Klik. Regional agreements Cardiovascular risk management. https://mcc-klik.nl/documenten.

13. Krabbe-Alkemade YJ, Groot TL, Lindeboom M. Competition in the dutch hospital sector: An analysis of health care volume and cost. Eur J Health Econ. 2017;18(2):139-153.

14. Hakkaart-van Roijen L, Van der Linden N, Bouwmans C, Kanters T, Swan Tan S. Kostenhandleiding: Methodologie van kostenonderzoek en referentieprijzen voor economische evaluaties in de gezondheidszorg. Institute for Medical Technology Assessment Erasmus Universiteit Rotterdam. 2010:195. 
15. Westra D, Kroese M and Ruwaard D. Substitutie van zorg. wat weten we, wat moeten we weten en wat moeten we doen? Ned Tijdschr Geneesk. 2017;161(D1354).

16. Atun R. What are the advantages and disadvantages of restructuring a health care system to be more focused on primary care services? . World Health Organisation Regional Office for Europe (Health Evidence Network). 2004.

17. Hamar GB, Rula EY, Wells A, Coberley C, Pope JE, Larkin S. Impact of a chronic disease management program on hospital admissions and readmissions in an australian population with heart disease or diabetes. Popul Health Manag. 2013;16(2):125-131.

18. Hamar GB, Rula EY, Coberley C, Pope JE, Larkin S. Long-term impact of a chronic disease management program on hospital utilization and cost in an australian population with heart disease or diabetes. BMC Health Serv Res. 2015;15:174-z.

19. Martinez-Gonzalez NA, Berchtold P, Ullman K, Busato A, Egger M. Integrated care programmes for adults with chronic conditions: A meta-review. Int J Qual Health Care. 2014;26(5):561-570.

20. Winpenny EM, Miani C, Pitchforth E, King S, Roland M. Improving the effectiveness and efficiency of outpatient services: A scoping review of interventions at the primary-secondary care interface. J Health Serv Res Policy. 2017;22(1):53-64.

21. Faulkner A, Mills N, Bainton D, et al. A systematic review of the effect of primary carebased service innovations on quality and patterns of referral to specialist secondary care. Br J Gen Pract. 2003;53(496):878-884.

22. Franks P, Clancy CM, Nutting PA. Gatekeeping revisited--protecting patients from overtreatment. N Engl J Med. 1992;327(6):424-429.

23. Singh BM, Holland MR, Thorn PA. Metabolic control of diabetes in general practice clinics: Comparison with a hospital clinic. Br Med J (Clin Res Ed). 1984;289(6447):726728.

24. van Hoof, S J M, Quanjel TCC, Kroese, M E A L, Spreeuwenberg MD, Ruwaard D. Substitution of outpatient hospital care with specialist care in the primary care setting: A systematic review on quality of care, health and costs. PLoS One. 2019;14(8):e0219957.

25. Kripalani S, LeFevre F, Phillips CO, Williams MV, Basaviah P, Baker DW. Deficits in communication and information transfer between hospital-based and primary care physicians: Implications for patient safety and continuity of care. JAMA. 2007;297(8):831-841.

26. Price E, Baker R, Krause J, Keen C. Organisation of services for people with cardiovascular disorders in primary care: Transfer to primary care or to specialistgeneralist multidisciplinary teams? BMC Fam Pract. 2014;15:158-158. 


\section{SUPPLEMENTARY TABLES AND FIGURES}

Table S1. 50 coded diagnoses used for selection of study population

\begin{tabular}{|c|c|c|}
\hline Specialism & Diagnosis code & Diagnosis \\
\hline Surgery & $0303 \mid 402$ & Carotid pathology \\
\hline Surgery & $0303 \mid 403$ & Thoracic aortic aneurysm \\
\hline Surgery & $0303 \mid 405$ & Iliac artery aneurysm \\
\hline Surgery & $0303 \mid 406$ & Abdominal aortic aneurysm \\
\hline Surgery & $0303 \mid 408$ & Renal artery stenosis \\
\hline Surgery & $0303 \mid 418$ & P.A.O.D. ${ }^{\text {a }} 2$, intermittent claudication \\
\hline Surgery & $0303 \mid 419$ & P.A.O.D. ${ }^{\mathrm{a}} 3$, rest pain \\
\hline Surgery & $0303 \mid 420$ & P.A.O.D. 4 , gangrene \\
\hline Internal medicine & $0313 \mid 101$ & $\begin{array}{l}\text { Symptomatic ischemic heart disease, not diagnosis } \\
0313 \mid 102\end{array}$ \\
\hline Internal medicine & $0313 \mid 102$ & Unstable angina pectoris, myocardial infarction \\
\hline Internal medicine & $0313 \mid 121$ & Cerebrovascular accident / TIA $^{\mathrm{b}}$ \\
\hline Internal medicine & $0313 \mid 124$ & $\begin{array}{l}\text { Atherosclerosis of the extremities /peripheral } \\
\text { vascular disease }\end{array}$ \\
\hline Internal medicine & $0313 \mid 129$ & Aneurysm and other arterial vascular disorders \\
\hline Cardiology & $0320 \mid 202$ & Angina pectoris, stable \\
\hline Cardiology & $0320 \mid 203$ & Angina pectoris, unstable \\
\hline Cardiology & $0320 \mid 204$ & ST-elevation myocardial infarction \\
\hline Cardiology & $0320 \mid 205$ & Non ST-elevation myocardial infarction \\
\hline Cardiology & $0320 \mid 601$ & Arterial vascular defect / stenosis \\
\hline Cardiology & $0320 \mid 801$ & Follow-up after acute coronary syndrome \\
\hline Cardiology & $0320 \mid 802$ & Follow-up after PTCA $^{\mathrm{c}}$ and/or $\mathrm{CABG}^{\mathrm{d}}$ \\
\hline Cardiology & $0320 \mid 808$ & $\begin{array}{l}\text { Follow-up after vascular operation (arterial/ } \\
\text { venous) }\end{array}$ \\
\hline Cardiology & $0320 \mid 821$ & Cardiac rehabilitation \\
\hline Cardiothoracic surgery & $0328 \mid 2320$ & CABG ${ }^{\mathrm{d}}$, venous grafts and max. 1 arterial graft \\
\hline Cardiothoracic surgery & $0328 \mid 2400$ & $\mathrm{CABG}^{\mathrm{d}}(>=2$ arterial grafts $)$ \\
\hline Cardiothoracic surgery & $0328 \mid 2415$ & $\mathrm{CABG}^{\mathrm{d}}(1$ arterial graft $)+\mathrm{MVR}^{\mathrm{e}}$ \\
\hline Cardiothoracic surgery & $0328 \mid 2425$ & $\mathrm{CABG}^{\mathrm{d}}(1$ arterial graft $)+\mathrm{AVR}^{\mathrm{f}}$ \\
\hline Cardiothoracic surgery & $0328 \mid 2470$ & Left ventricular plasty $+\mathrm{CABG}^{\mathrm{d}}$ \\
\hline Cardiothoracic surgery & $0328 \mid 2550$ & $\mathrm{CABG}^{\mathrm{d}}+\mathrm{MPL}^{\mathrm{g}}+/-\mathrm{TPL}^{\mathrm{h}}$ \\
\hline Cardiothoracic surgery & $0328 \mid 2555$ & $\mathrm{CABG}^{\mathrm{d}}(2$ arterial grafts$)+\mathrm{MVR}^{\mathrm{e}}$ \\
\hline Cardiothoracic surgery & $0328 \mid 2560$ & $\mathrm{CABG}^{\mathrm{d}}($ 1arterial graft $)+\mathrm{AVR}^{\mathrm{f}}+\mathrm{MVR}^{\mathrm{e}}$ \\
\hline Cardiothoracic surgery & $0328 \mid 2570$ & $\mathrm{CABG}^{\mathrm{d}}(2$ arterial grafts $)+\mathrm{AVR}^{\mathrm{f}}$ \\
\hline Cardiothoracic surgery & $0328 \mid 2585$ & $\mathrm{CABG}^{\mathrm{d}}+\mathrm{HOCM}^{\mathrm{i}}$ \\
\hline Cardiothoracic surgery & $0328 \mid 2630$ & $\mathrm{VT}^{\mathrm{j}}+\mathrm{CABG}^{\mathrm{d}}$ \\
\hline Cardiothoracic surgery & $0328 \mid 2635$ & Maze $+\mathrm{CABG}^{\mathrm{d}}$ \\
\hline
\end{tabular}


Table S1. (Continued)

\begin{tabular}{|c|c|c|}
\hline Specialism & Diagnosis code & Diagnosis \\
\hline Cardiothoracic surgery & $0328 \mid 2640$ & $\mathrm{VSR}^{\mathrm{k}}+\mathrm{CABG}^{\mathrm{d}}$ \\
\hline Cardiothoracic surgery & $0328 \mid 2645$ & $\mathrm{MPL}^{\mathrm{g}}+\mathrm{AVR}^{\mathrm{f}}+\mathrm{CABG}^{\mathrm{d}}$ \\
\hline Cardiothoracic surgery & $0328 \mid 2650$ & $\mathrm{MPL}^{\mathrm{g}}+\mathrm{CABG}^{\mathrm{d}}(2$ arterial grafts $)$ \\
\hline Cardiothoracic surgery & $0328 \mid 2655$ & $\mathrm{AVR}^{\mathrm{f}}+\mathrm{CABG}^{\mathrm{d}}+\mathrm{HOCM}^{\mathrm{i}}$ \\
\hline Cardiothoracic surgery & $0328 \mid 2665$ & Aortic root $+\mathrm{CABG}^{\mathrm{d}}$ \\
\hline Cardiothoracic surgery & $0328 \mid 2720$ & Aortic dissection +/- CABG ${ }^{\mathrm{d}}$ \\
\hline Cardiothoracic surgery & $0328 \mid 2740$ & Ascending aorta $+\mathrm{CABG}^{\mathrm{d}}$ \\
\hline Cardiothoracic surgery & $0328 \mid 2770$ & Aortic root $+\mathrm{CABG}^{\mathrm{d}}+\mathrm{MPL}^{\mathrm{g}} / \mathrm{MVR}^{\mathrm{e}}$ \\
\hline Cardiothoracic surgery & $0328 \mid 2785$ & $\mathrm{Maze}+\mathrm{CABG}^{\mathrm{d}}$ or $\mathrm{AVR}^{\mathrm{f}}+\mathrm{MPL}^{\mathrm{g}}+/-\mathrm{TPL}^{\mathrm{h}}$ \\
\hline Cardiothoracic surgery & $0328 \mid 2810$ & Thoracic-abdominal aneurysm \\
\hline Cardiothoracic surgery & $0328 \mid 3210$ & Carotid endarterectomy \\
\hline Cardiothoracic surgery & $0328 \mid 3310$ & Carotid endarterectomy, both sides \\
\hline Cardiothoracic surgery & $0328 \mid 3320$ & Abdominal aortic aneurysms \\
\hline Cardiothoracic surgery & $0328 \mid 3340$ & Endoprosthesis \\
\hline Neurology & $0330 \mid 1111$ & Ischeamic stroke \\
\hline Neurology & $0330 \mid 1112$ & TIA $^{\mathrm{b}}$ (including amaurosis fugax) \\
\hline
\end{tabular}

a P.A.O.D.: Peripheral Arterial Occlusive Disease. ${ }^{\mathrm{b}}$ TIA: Transient Ischaemic Attack. ${ }^{\mathrm{c}}$ PTCA: Percutaneous Transluminal Coronary Angioplasty. ${ }^{d}$ CABG: Coronary Artery Bypass Graft. ${ }^{e}$ MVR: Mitral Valve Replacement. ${ }^{\mathrm{f}}$ AVR: Aortic Valve Replacement. ${ }^{\mathrm{g}}$ MPL: Mitral valve Plasty. ${ }^{\mathrm{h}}$ TPL: Thoracoplasty. ${ }^{1}$ HOCM: Hypertrophic Obstructive Cardiomyopathy. ${ }^{j}$ VT: Ventricular Tachycardia. ${ }^{k}$ VSR: Ventricular Septal Rupture.

Table S2. CVRM related activities

\begin{tabular}{|c|c|c|c|}
\hline Group & Short description & Details & Price in euros \\
\hline Outpatient visits & Outpatient visit & & 83 \\
\hline Outpatient visits & Consultation by telephone & & 83 \\
\hline Outpatient visits & Short teleconsultation & & 10 \\
\hline $\begin{array}{l}\text { Day-care } \\
\text { admissions }\end{array}$ & Day-care admission & & 154 \\
\hline $\begin{array}{l}\text { Hospital } \\
\text { admissions }\end{array}$ & Hospitalization day & & 461 \\
\hline Diagnostics & Ultrasound of the heart & Ultrasound of the heart & 139 \\
\hline Diagnostics & Ultrasound of the heart & $\begin{array}{l}\text { Ultrasound of the heart and/ or } \\
\text { thorax }\end{array}$ & 123 \\
\hline Diagnostics & Ultrasound of the heart & $\begin{array}{l}\text { Ejection fraction left and / or } \\
\text { right ventricle with wall motion } \\
\text { analysis }\end{array}$ & 287 \\
\hline Diagnostics & Cardiac stress test & Simple & 145 \\
\hline Diagnostics & Cardiac stress test & Comprehensive & 185 \\
\hline
\end{tabular}


Table S2. (Continued)

\begin{tabular}{|c|c|c|c|}
\hline Group & Short description & Details & Price in euros \\
\hline Diagnostics & $\begin{array}{l}\text { 24-hour blood pressure } \\
\text { measurement }\end{array}$ & & 125 \\
\hline Diagnostics & $\begin{array}{l}\text { Duplex blood vessels in } \\
\text { extremities }\end{array}$ & & 108 \\
\hline Diagnostics & $\begin{array}{l}\text { Examination of arterial } \\
\text { obstructions of extremities }\end{array}$ & $\begin{array}{l}\text { Including blood pressure } \\
\text { measurement of arms and } \\
\text { / or legs or penis with } \\
\text { continuous wave doppler or } \\
\text { plethysmography }\end{array}$ & 93 \\
\hline Diagnostics & Electrocardiogram & & 48 \\
\hline Diagnostics & Laboratory measurement & Creatinine clearance & 5 \\
\hline Diagnostics & Laboratory measurement & Microalbumin in urine & 3 \\
\hline Diagnostics & Laboratory measurement & Triglycerides & 2 \\
\hline Diagnostics & Laboratory measurement & $\begin{array}{l}\text { High-density lipoprotein } \\
\text { cholesterol }\end{array}$ & 2 \\
\hline Diagnostics & Laboratory measurement & Total cholesterol & 2 \\
\hline Diagnostics & Laboratory measurement & Glucose Galactose tolerance test & 2 \\
\hline Diagnostics & Laboratory measurement & Creatinine & 2 \\
\hline Diagnostics & Telemonitoring & & 30 \\
\hline Paramedical care & Dietician, consultation & & 17 \\
\hline Paramedical care & $\begin{array}{l}\text { Physiotherapist, } \\
\text { consultation }\end{array}$ & & 34 \\
\hline Paramedical care & Psychologist, consultation & & 67 \\
\hline Paramedical care & $\begin{array}{l}\text { Psychologist, peer } \\
\text { consultation }\end{array}$ & & 17 \\
\hline Paramedical care & $\begin{array}{l}\text { Nurse practitioner, } \\
\text { consultation }\end{array}$ & & 30 \\
\hline Consultations & $\begin{array}{l}\text { Multidisciplinary } \\
\text { consultation }\end{array}$ & & 30 \\
\hline Consultations & $\begin{array}{l}\text { Multidisciplinary } \\
\text { consultation }\end{array}$ & Heart team & 40 \\
\hline
\end{tabular}


Table S3. Costs of outpatient visits and hospital admissions for non-CVD care

\begin{tabular}{|c|c|c|c|c|c|c|c|}
\hline \multirow{3}{*}{ Outcomes } & \multicolumn{3}{|c|}{$\begin{array}{c}\text { Before }(2014-2015) \\
n=5,215\end{array}$} & \multicolumn{3}{|c|}{$\begin{array}{l}\text { After }(2016-2017) \\
\qquad n=5,449\end{array}$} & \multirow{3}{*}{$\begin{array}{l}\text { Change } \\
\text { in costs }\end{array}$} \\
\hline & Patients & Activities & & Patients & Activities & & \\
\hline & $\mathbf{n}$ & $\mathbf{n}$ & & $\mathbf{n}$ & $\mathbf{n}$ & & \\
\hline $\begin{array}{l}\text { Median costs per } \\
\text { patient (IQR) }\end{array}$ & & & $500(88-2,177)$ & & & $500(83-2,069)$ & $0 \%$ \\
\hline Outpatient visits & & & $343(83-759)$ & & & $343(83-759)$ & $0 \%$ \\
\hline Hospital admissions & & & $0(0-1,383)$ & & & $0(0-1,383)$ & $0 \%$ \\
\hline Total costs & 4,265 & 58,550 & $11,469,584$ & 4,426 & 58,718 & $11,393,398$ & $-1 \%$ \\
\hline Outpatient visits & 4,243 & 40,012 & $2,923,469$ & 4,401 & 40,422 & $2,958,846$ & $+1 \%$ \\
\hline Hospital admissions & 1,703 & 18,538 & $8,546,115$ & 1,710 & 18,296 & $8,434,551$ & $-1 \%$ \\
\hline
\end{tabular}

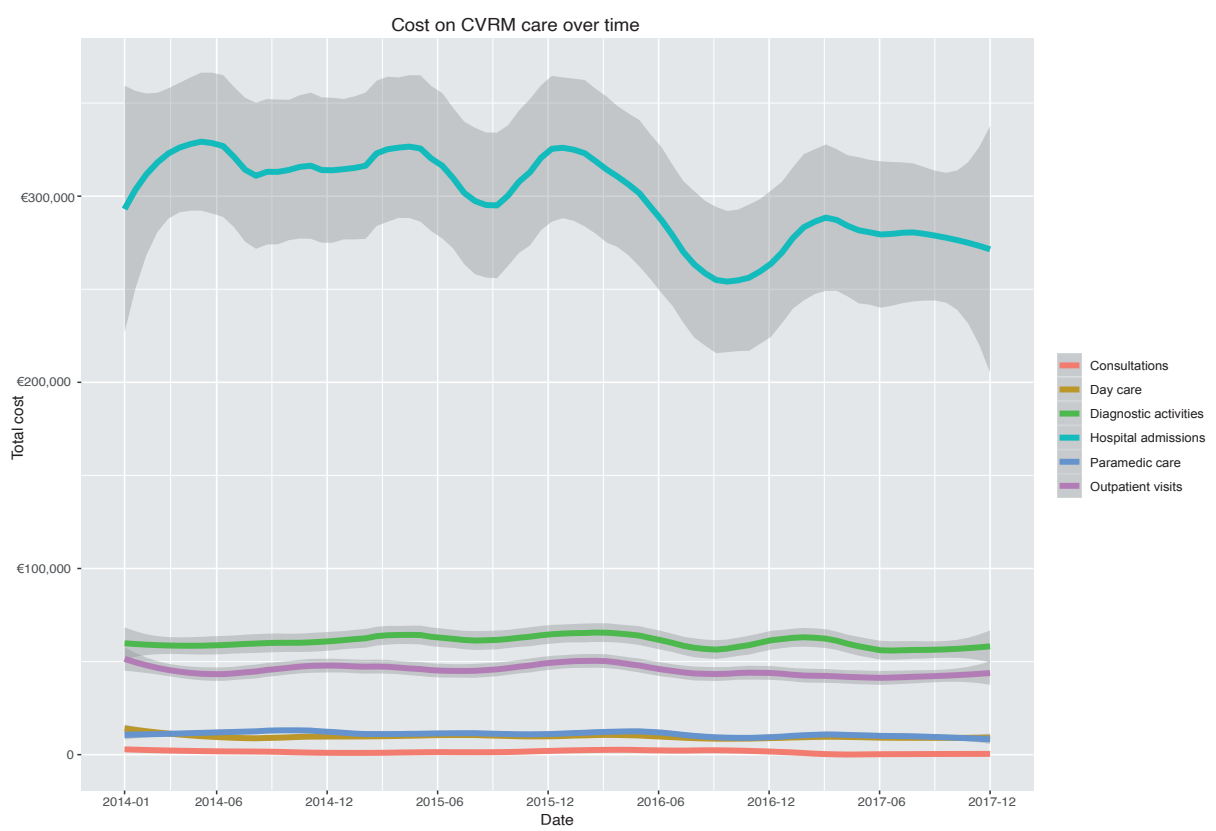

Figure S1. Costs of care activities 


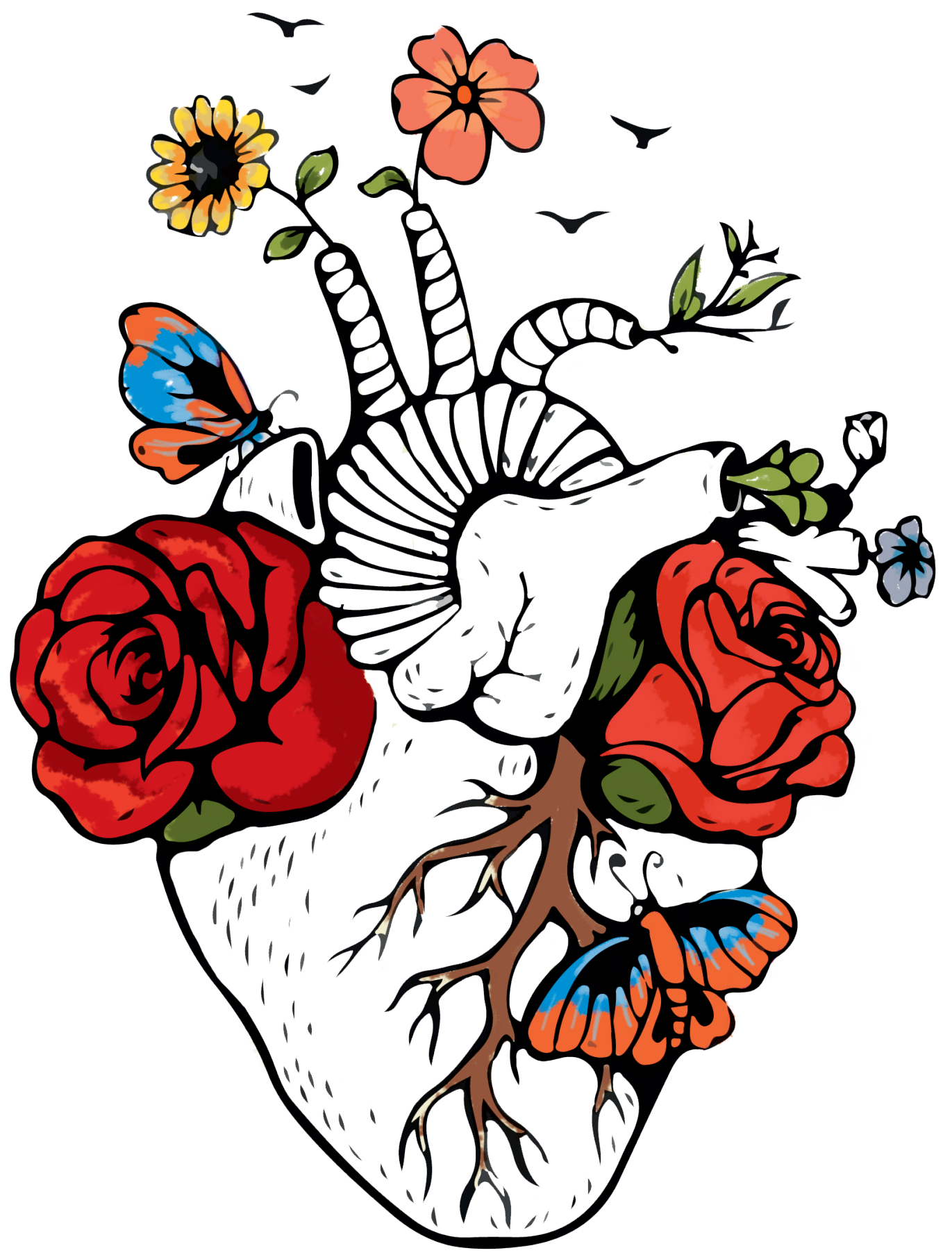




\section{CHAPTER 7}

\section{Inadequate management of dyslipidaemia in primary care}

Suzanne Marchal

Frans H. Rutten

Arnoud W.J. van 't Hof

Michiel L. Bots

Jan Westerink

Arno W. Hoes

Monika Hollander 


\section{ABSTRACT}

\section{Background}

The management of dyslipidaemia in primary care remains suboptimal. Therapeutic inertia may be a possible explanation.

\section{Aim}

To assess characteristics associated with therapeutic inertia in general practitioner's lipid-management.

\section{Design and setting}

An observational study in patients labelled (ICPC coded) for dyslipidaemia, atherosclerotic cardiovascular disease (CVD) or diabetes mellitus (DM) in general practice.

\section{Methods}

Electronic health record data of patients registered in the Julius General Practitioners' Network $(n=530,564)$ were used. We selected patients with dyslipidaemia, CVD or DM, and with a recently measured uncontrolled LDLcholesterol level (> $2.5 \mathrm{mmol} / \mathrm{L})$. Therapeutic inertia was defined as absence of lipid-lowering drug adjustment within three months after the LDL-cholesterol measurement. We used logistic-regression analyses to identify characteristics associated with therapeutic inertia.

\section{Results}

Out of 21,310 patients with dyslipidaemia, atherosclerotic CVD and/or DM with a recently measured LDL-cholesterol we identified 6,854 (32\%) patients with a LDL-cholesterol $>2.5 \mathrm{mmol} / \mathrm{L}$. Mean age was 68 (SD 12.2) years and $57 \%$ were women. The median LDL-cholesterol was $3.1 \mathrm{mmol} / \mathrm{L}$ (IQR 2.8 - 3.7) and 45\% used a lipid-lowering drug in the 6 months prior to the measurement. Therapeutic inertia was present in 93\% and did not differ between patients with a CVD, DM or dyslipidaemia. Age (OR per year 1.01, 95\%-CI 1.01 to 1.02) was positively, while LDL-cholesterol level (OR per mmol/L $0.63,95 \%$-CI 0.56 to 0.70 ) and being a current or past smoker (OR $0.66,95 \%$-CI 0.54 to 0.80 ) were inversely associated with therapeutic inertia. 


\section{Conclusion}

Therapeutic inertia was seen in nearly all patients in whom lipid-lowering treatment was indicated. This huge gap between guidelines and daily practice warrants further attention and action.

\section{INTRODUCTION}

Cardiovascular diseases (CVD) are the leading cause of death worldwide. ${ }^{1,2}$ There is convincing evidence for a log-linear relationship between plasma LDL-cholesterol levels and the risk of CVD. ${ }^{3,4}$ Lowering LDL-cholesterol with statins reduces the risk of vascular events by about $20 \%$ per one mmol/L reduction. ${ }^{5}$ More intensive lowering of LDL-cholesterol further reduces major vascular events. ${ }^{6}$ The Dutch College of General Practitioners guidelines 'Cardiovascular Risk Management' (CVRM) for the management of dyslipidaemia valid from 2012 to May 2019 recommends to achieve a LDL-cholesterol of $\leq 2.5 \mathrm{mmol} / \mathrm{L}$ for patients at moderate or high risk of CVD. ${ }^{7}$ The guideline of the European Society of Cardiology for the management of dyslipidaemias and the new CVRM guidelines for the Netherlands (based on this European guideline) from May 2019, recommend stricter target values, and the latter is currently being implemented. ${ }^{8,9}$

To achieve LDL-cholesterol goals, uptitration of existing therapy, switching to another more effective statin or combining another lipid-lowering agent with a statin has been proven to be effective. ${ }^{10-13}$ However, studies such as the EUROASPIRE surveys, have consistently shown that management of dyslipidaemia remains suboptimal, especially in primary care. ${ }^{14-16}$ In the most recent survey, among treated patients with dyslipidaemia less than $50 \%$ attained the LDLcholesterol target of $<2.6 \mathrm{mmol} / \mathrm{L} .{ }^{16}$ Furthermore, only $38 \%$ of patients with diabetes mellitus (DM) type 2 irrespective of the presence of CVD were on statins at all. ${ }^{16}$ This marks the considerable gap between evidence and daily practice.

A possible explanation for the disappointing findings on lipid management in everyday practice is therapeutic inertia, as has been reported in several high-risk groups. ${ }^{17-20}$ Inertia is defined as failure to initiate or intensify therapy in patients who have not yet reached their target. ${ }^{17}$ Limited knowledge exists on determinants of therapeutic inertia in dyslipidaemia, especially in primary care. One primary care study has shown that higher LDL-cholesterol levels were inversely associated 
with therapeutic inertia and older age and diabetes were positively associated with therapeutic inertia. ${ }^{21}$

More insight in modifiable characteristics associated with therapeutic inertia is crucial to improve the treatment and prognosis of patients with dyslipidaemia. The current study aims to assess characteristics associated with therapeutic inertia in lipid-management in primary care.

\section{METHODS}

\section{Study design and data source}

We conducted a cohort study with data from the Julius General Practitioner Network (JGPN). The JGPN database consists of routine care data extracted from electronic health records (EHR) of 72 general practices in the vicinity of Utrecht, the Netherlands. JGPN covers approximately 530,000 registered community people and is considered an adequate representation of the population in the Netherlands. ${ }^{22}$ Data available include diagnostic measurements, laboratory test results, diagnoses recorded with the International Classification of Primary Care (ICPC) codes and prescriptions based on the Anatomical Therapeutic Chemical (ATC) codes. The last date of data extraction differed per practice, ranging from December 2017 up to August 2019.

Research in JGPN is conducted following the privacy legislation of the Netherlands. All JGPN practices informed their patients on the JGPN database and provided information on the opt-out procedure. ${ }^{22}$

\section{Population selection}

Information was extracted from patients $\geq 18$ years with a clinical indication for lipid-lowering treatment (based on ICPC codes), i.e.; dyslipidaemia, atherosclerotic CVD (angina pectoris, coronary heart disease, ischemic stroke, transient ischemic attack (TIA), aortic aneurysm, peripheral artery disease), or DM (type I or II) (table S1). We selected patients with a measured LDL-cholesterol level > 2.5 $\mathrm{mmol} / \mathrm{L}$, within the 12 months before the date of data extraction. LDL-cholesterol measurements within three months before the last date of extraction were excluded, as we considered at least three months necessary for GPs to adjust lipid-lowering medication after the index high LDL-cholesterol measurement. We 
excluded patients without a LDL-cholesterol measurement in the study period. Poorly controlled dyslipidaemia, defined as LDL-cholesterol $>2.5 \mathrm{mmol} / \mathrm{L}$ in patients with established atherosclerotic CVD or a high CVD risk, including DM, was based on the Dutch College of General Practitioners guidelines 'Cardiovascular Risk Management' (CVRM) for the management of dyslipidaemia valid from 2012 to May $2019 .^{7}$

We excluded patients registered with a new diagnosis of dyslipidaemia, CVD or DM less than six months before the index LDL-cholesterol measurement to allow a period of 6 months to achieve the treatment goal after initiating lipid-lowering therapy.

In order to focus on patients in whom uptitration or change of medication was evidently needed, we only included patients with dyslipidaemia, but without CVD or DM, in case they used lipid-lowering $\operatorname{drug}(\mathrm{s})$ in the year before the measurement. We excluded these patients if they were not on lipid-lowering drugs since they might have not completed the steps prior to initiating pharmacological therapy. Patients were also excluded when the GP prescribed new drugs or intensified the dose of prescribed drugs less than six weeks before the LDL-cholesterol measurement because their effect may not yet be set.

\section{Definition of therapeutic inertia}

Therapeutic inertia was defined as no drug change or adjustment within three months after the LDL-cholesterol measurement with the aim to decrease LDLcholesterol. Therapeutic inertia was deemed absent in case of: (i) start of lipidlowering drugs, (ii) addition of a different class of lipid-lowering drug, (iii) change to a same class lipid-lowering drug and (iv) uptitration within three months after the measurement.

Classes of lipid-lowering drugs were categorized according to ATC codes into statins, fibrates, bile acid sequestrants, nicotinic acid and derivatives and other lipid-lowering drugs (including ezetimibe). PCSK9 inhibitors were not considered, as these drugs are not prescribed by GPs in the Netherlands.

To assess medication adjustments, we compared prescription records up to three months after the LDL-cholesterol measurement to prescription records of up to 
one year before cholesterol measurements. If the drug had already been prescribed previously, this was not registered as a new drug.

\section{Variables}

We explored which characteristics were associated with therapeutic inertia in univariable logistic regression models. Characteristics included age, sex, LDLcholesterol level, near-target LDL (defined as LDL-cholesterol $>2.5$ and $<3.5$ $\mathrm{mmol} / \mathrm{L}$ ), atherosclerotic CVD, DM, dyslipidaemia, hypertension, smoking, obesity, renal insufficiency, heart failure, atrial fibrillation, family history of dyslipidaemia or CVD, muscle pain and use of a lipid-lowering drug in the previous six months. All characteristics were considered present when the date of registration was prior to the LDL-cholesterol measurement. Definitions are given in Supplementary Table 1.

In a multivariable model, we considered a priori defined characteristics potentially associated with therapeutic inertia, based on theory and literature..$^{20,21,23-25}$ For this model, we selected age, sex, LDL-cholesterol level, CVD, DM, hypertension, smoking, obesity and renal insufficiency. We did not select 'family history of CVD' for this model as the prevalence in our database was very low and it is known to be poorly reported in EHR.

\section{Data analyses}

To assess therapeutic inertia we used descriptive statistics for the total group and for different subgroups, as the indication for lipid-lowering drugs may vary among these groups, including patients with CVD, DM, dyslipidaemia and aged $\leq$ 70 years old. We used univariable and multivariable logistic regression models to study characteristics potentially associated with therapeutic inertia in the total group. The results were reported as odds ratios (OR) and corresponding 95\% confidence intervals (CI). Two-sided P-values $<0.05$ indicated statistical significance. Statistical analyses were performed using R studio (version 3.5.1, Copyright (C) 2018 The R Foundation for Statistical Computing). 


\section{RESULTS}

\section{Patient characteristics}

In the JGPN database, 78,952 patients with a history of CVD, DM or dyslipidaemia were identified (figure 1). In 21,310 (27\%) of these patients LDL-cholesterol was measured in the past 12 months. Among these 6,854 (32\%) patients had uncontrolled LDL-cholesterol (> $2.5 \mathrm{mmol} / \mathrm{L})$ and were included in our study.

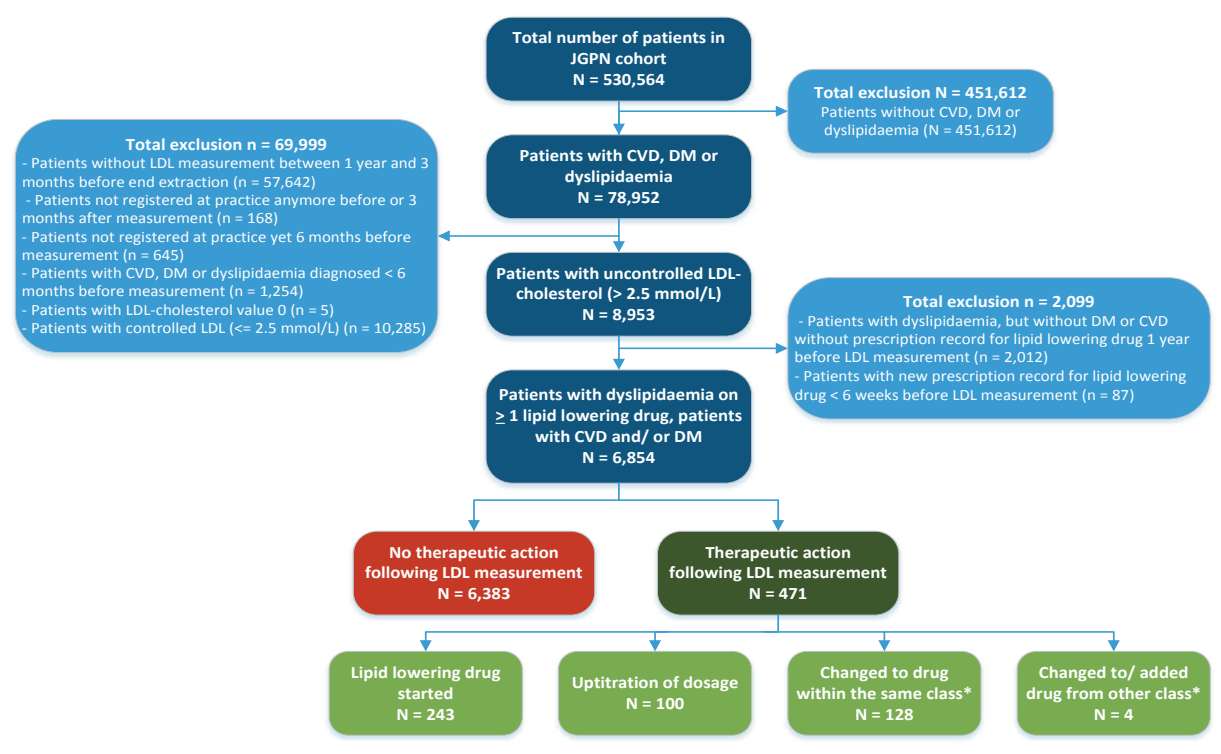

Figure 1. Flowchart of the selection of patients with dyslipidaemia, cardiovascular disease and/or diabetes mellitus within the Julius General Practitioners' Network cohort, divided in those with or without therapeutic inertia.

BP, blood pressure; DBP, diastolic blood pressure; GP, general practitioner; JGPN, Julius General Practitioners' Network; LDL, low density lipoprotein.

* Classes of lipid-lowering drugs included statins, fibrates, bile acid sequestrants and nicotinic acid and derivatives.

Mean age of these patients with uncontrolled LDL was 68 (SD 12.2) years and 57\% were women (table 1). The median LDL-cholesterol level was $3.1 \mathrm{mmol} / \mathrm{L}$ (IQR 2.8 - 3.7). A history of CVD was present in 44\%, DM in 45\% and dyslipidaemia in $74 \%$. Thirty percent were either a past or current smoker, $38 \%$ were obese and $62 \%$ had hypertension. Less than half of the patients (45\%) used a lipid-lowering drug in the 6 months prior to the uncontrolled LDL-cholesterol measurement. Muscle pain was recorded in $9 \%$ of the patients. 
Table 1. Patient characteristics

\begin{tabular}{lllll}
\hline Characteristics & $\begin{array}{l}\text { Total group } \\
\mathbf{n = 6 , 8 5 4}\end{array}$ & $\begin{array}{l}\text { CVD } \\
\mathbf{n = 3 , 0 4 0}\end{array}$ & $\begin{array}{l}\text { DM } \\
\mathbf{n = 3 , 0 8 7}\end{array}$ & $\begin{array}{l}\text { Dyslipidaemia } \\
\mathbf{n = 5 , 0 9 8}\end{array}$ \\
\hline Age in years, mean (SD) & $68(12.2)$ & $71(11.4)$ & $67(12.9)$ & $68(11.4)$ \\
Women (\%) & $3,900(57)$ & $1,685(55)$ & $1,720(56)$ & $2,920(57)$ \\
LDL-cholesterol in mmol/L, median & $3.1(2.8-3.7)$ & $3.2(2.8-3.8)$ & $3.1(2.8-3.6)$ & $3.1(2.8-3.7)$ \\
(IQR) & & & & \\
Near-target LDL-cholesterol*(\%) & $4,566(67)$ & $1,916(63)$ & $2,132(69)$ & $3,456(68)$ \\
Cardiovascular disease (\%) & $3,040(44)$ & $3,040(100)$ & $816(26)$ & $2,142(42)$ \\
Diabetes mellitus (\%) & $3,087(45)$ & $816(27)$ & $3,087(100)$ & $2,091(41)$ \\
Dyslipidaemia (\%) & $5,098(74)$ & $2,142(70)$ & $2,091(68)$ & $5,098(100)$ \\
Current or past smoker (\%) & $2,053(30)$ & $1,014(33)$ & $831(27)$ & $1,637(32)$ \\
Obesity, BMI>30 kg/m² (\%) & $2,615(38)$ & $944(31)$ & $1,687(55)$ & $1,960(38)$ \\
Hypertension (\%) & $4,221(62)$ & $1,998(66)$ & $1,826(59)$ & $3,257(64)$ \\
Muscle pain (\%) & $647(9)$ & $290(10)$ & $304(10)$ & $514(10)$ \\
Use of lipid lowering drug (\%) & $3,072(45)$ & $1,044(34)$ & $1,040(34)$ & $3,028(59)$ \\
\hline
\end{tabular}

* Near-target LDL-cholesterol was defined as LDL-cholesterol > 2.5 and $<3.5 \mathrm{mmol} / \mathrm{L}$. BMI, body mass index. CVD, cardiovascular disease. LDL, low-density lipoprotein.

\section{Therapeutic inertia}

In 471 (7\%) patients with uncontrolled LDL-cholesterol medication was adjusted within three months after the LDL-cholesterol measurement; (i) in 243 (52\%) of these patients a lipid-lowering drug was started, (ii) 4 (1\%) patients received a lipid-lowering drug from another class, (iii) 128 (27\%) patients were prescribed a lipid-lowering drug within the same class and (iv) in 100 (21\%) patients lipidlowering drugs were uptitrated (figure 1). In 6,383 patients (93\%), medication was not adjusted (table 2). Therapeutic inertia increased with age (figure 2). In patients at younger age $(\leq 70$ years) therapeutic inertia was slightly less prevalent compared to older patients (>70 years); $92 \%$ vs $95 \%$ respectively. Therapeutic inertia was more commonly observed in patients with a near-target LDL-cholesterol $(>2.5$ and $<3.5 \mathrm{mmol} / \mathrm{L}$ ) than in patients with an off-target LDL-cholesterol ( $\geq 3.5 \mathrm{mmol} / \mathrm{L})$; $95 \%$ vs $90 \%$ respectively. Therapeutic inertia did not differ between patients with a history of CVD, DM and dyslipidaemia (93\%) and in younger patients ( $\leq 70$ years) in these subgroups, therapeutic inertia was common as well $(92 \%, 91 \%$ and $91 \%$ respectively). In patients with hypertension, in smokers (past or current) and patients with obesity, therapeutic inertia was present in 94\%, 91\% and 92\%, respectively. 
Table 2. Presence of therapeutic inertia in different subgroups

\begin{tabular}{llll}
\hline Group & N & $\begin{array}{l}\text { Therapeutic } \\
\text { inertia }\end{array}$ & $\begin{array}{l}\text { No therapeutic } \\
\text { inertia }\end{array}$ \\
\hline Total & 6,854 & $6,383(93)$ & $471(7)$ \\
Age $\leq 70$ years & 3,961 & $3,634(92)$ & $327(8)$ \\
Age > 70 years & 2,893 & $2,749(95)$ & $152(5)$ \\
Women & 3,900 & $3,651(94)$ & $249(6)$ \\
Men & 2,954 & $2,732(92)$ & $222(8)$ \\
LDL-cholesterol near-target* & 4,566 & $4,317(95)$ & $249(5)$ \\
LDL-cholesterol off-target** & 2,288 & $2,066(90)$ & $222(10)$ \\
Cardiovascular disease & 3,040 & $2,838(93)$ & $202(7)$ \\
$\quad$ Age $\leq 70$ years & 1,456 & $1,344(92)$ & $112(8)$ \\
Diabetes mellitus & 3,087 & $2,868(93)$ & $219(7)$ \\
$\quad$ Age $\leq 70$ years & 1,819 & $1,662(91)$ & $157(9)$ \\
Dyslipidaemia & 5,098 & $4,734(93)$ & $364(7)$ \\
$\quad$ Age $\leq 70$ years & 2,933 & $2,682(91)$ & $251(9)$ \\
Hypertension & 4,221 & $3,957(94)$ & $264(6)$ \\
Current or past smokers & 2,053 & $1,868(91)$ & $185(9)$ \\
Obesity (BMI>30 kg/m $\left.{ }^{2}\right)$ & 2,615 & $2,414(92)$ & $201(8)$ \\
Renal insufficiency & 659 & $628(95)$ & $31(5)$ \\
Heart failure & 286 & $278(97)$ & $8(3)$ \\
Atrial fibrillation & 496 & $471(95)$ & $5(25)$ \\
Family history of dyslipidaemia & 28 & $26(93)$ & $2(7)$ \\
Family history of CVD & 178 & $164(92)$ & $14(8)$ \\
Muscle pain & 647 & $595(92)$ & $52(8)$ \\
Use of lipid-lowering drug & 3,072 & $2,873(96)$ & $199(4)$ \\
No use of lipid-lowering drug & 3,782 & $3,510(93)$ & $272(7)$ \\
\hline
\end{tabular}

Values are presented as numbers (\%).

* Near-target LDL-cholesterol was defined as LDL-cholesterol $>2.5$ and $<3.5 \mathrm{mmol} / \mathrm{L}$.

** Off-target LDL-cholesterol was defined as LDL-cholesterol $\geq 3.5 \mathrm{mmol} / \mathrm{L}$

BMI, body mass index. CVD, cardiovascular disease. LDL, low-density lipoprotein. 


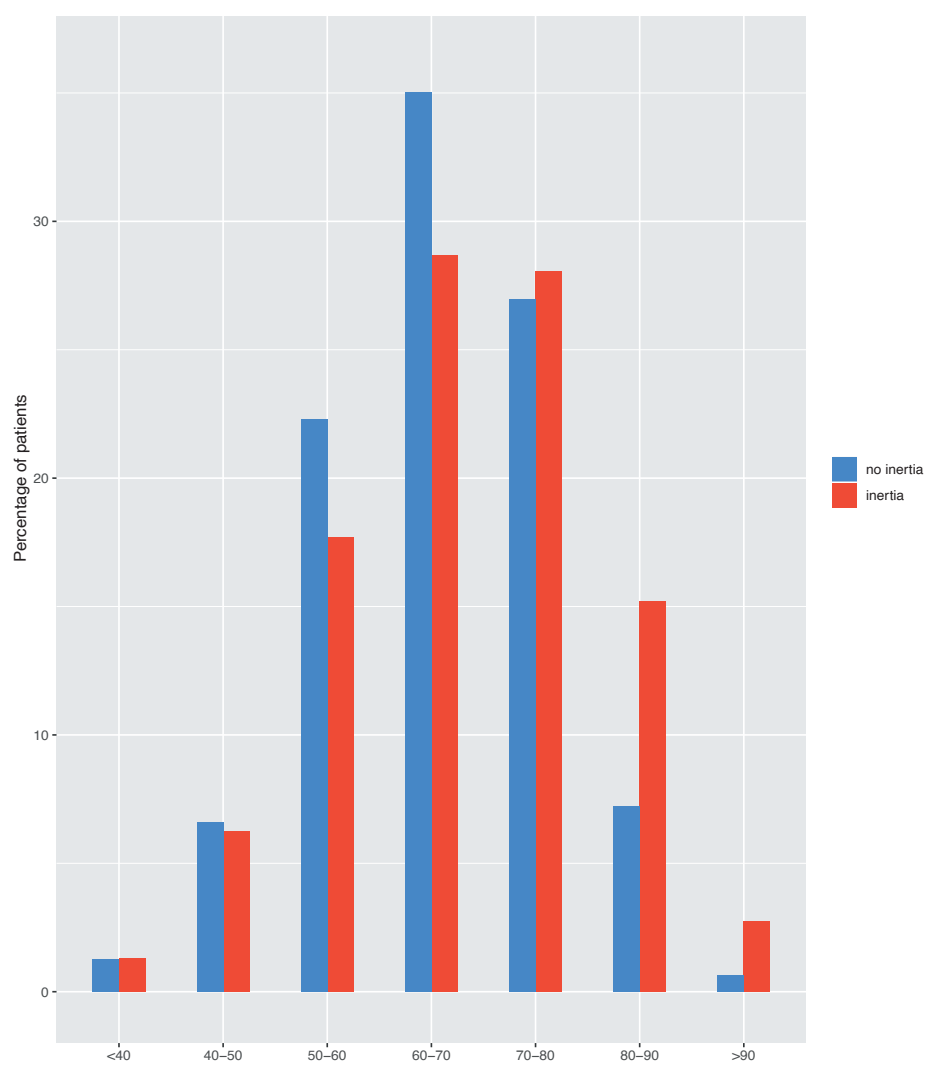

Figure 2. Distribution of age groups in patients with poorly controlled LDL-cholesterol, with and without inertia in the Julius General Practitioners' Network cohort.

\section{Characteristics associated with therapeutic inertia}

Univariable regression analyses showed that older age (OR per year 1.02, 95\%-CI 1.01 to 1.03 ), near-target LDL-cholesterol (OR 1.86, 95\%-CI 1.54 to 2.25), a history of hypertension (OR 1.28, 95\%-CI 1.06 to 1.54), renal insufficiency (OR $1.55,95 \%$-CI 1.08 to 2.29 ) and heart failure (OR 2.64, 95\%-CI 1.39 to 5.84 ) were positively associated with therapeutic inertia (table 3). The LDL-cholesterol level (OR per mmol/L 0.63, 95\% CI 0.56 to 0.70 ), being a current or past smoker (OR 0.64, 95\%-CI 0.53 to 0.78 ), and having obesity (OR 0.82, 95\%-CI 0.68 to 0.99 ) showed an inverse association.

Multivariable regression showed that older age (OR per year 1.01, 95\%-CI 1.01 to 1.02 ) was positively and independently associated with therapeutic inertia. 
The LDL-cholesterol level (OR per mmol/L 0.63, 95\%-CI 0.56 to 0.70 ) and being a current or past smoker (OR $0.66,95 \%$-CI 0.54 to 0.80 ) were inversely and independently associated with therapeutic inertia.

Table 3. Univariable and multivariable logistic regression of variables and their association with therapeutic inertia

\begin{tabular}{|c|c|c|c|c|}
\hline & Univariable & & Multivariable & \\
\hline Factor & OR $(95 \% \mathrm{CI})$ & $p$-value & OR $(95 \% \mathrm{CI})$ & $p$-value \\
\hline Age per year & $1.02(1.01,1.03)$ & $<0.001$ & $1.01(1.01,1.02)$ & 0.002 \\
\hline Women & $1.19(0.99,1.44)$ & 0.067 & $1.16(0.95,1.40)$ & 0.14 \\
\hline LDL cholesterol per mmol/L & $0.63(0.56,0.70)$ & $<0.001$ & $0.63(0.56,0.70)$ & $<0.001$ \\
\hline Near-target LDL* & $1.86(1.54,2.25)$ & $<0.001$ & & \\
\hline Cardiovascular disease & $1.07(0.88,1.29)$ & 0.51 & $0.99(0.80,1.22)$ & 0.92 \\
\hline Angina pectoris & $1.15(0.89,1.50)$ & 0.31 & & \\
\hline Coronary heart disease & $1.05(0.78,1.44)$ & 0.76 & & \\
\hline Ischemic stroke and/or TIA & $0.97(0.76,1.27)$ & 0.84 & & \\
\hline Aortic aneurysm & $1.18(0.61,2.65)$ & 0.65 & & \\
\hline Peripheral artery disease & $0.94(0.69,1.30)$ & 0.70 & & \\
\hline Diabetes mellitus & $0.94(0.78,1.13)$ & 0.51 & $0.95(0.77,1.18)$ & 0.66 \\
\hline Dyslipidaemia & $0.84(0.67,1.05)$ & 0.14 & & \\
\hline Hypertension & $1.28(1.06,1.54)$ & 0.012 & $1.12(0.91,1.37)$ & 0.27 \\
\hline Smoker (current or past) & $0.64(0.53,0.78)$ & $<0.001$ & $0.66(0.54,0.80)$ & $<0.001$ \\
\hline Obesity $\left(\mathrm{BMI}>30 \mathrm{~kg} / \mathrm{m}^{2}\right)$ & $0.82(0.68,0.99)$ & 0.037 & $0.83(0.68,1.02)$ & 0.078 \\
\hline Renal insufficiency & $1.55(1.08,2.29)$ & 0.022 & $1.31(0.90,1.98)$ & 0.17 \\
\hline Heart failure & $2.64(1.39,5.84)$ & 0.007 & & \\
\hline Atrial fibrillation & $1.42(0.96,2.20)$ & 0.096 & & \\
\hline Family history of dyslipidaemia & $0.96(0.29,5.96)$ & 0.96 & & \\
\hline Family history of CVD & $0.86(0.51,1.57)$ & 0.60 & & \\
\hline Muscle pain & $0.83(0.62,1.13)$ & 0.22 & & \\
\hline Use of lipid-lowering drug & $1.12(0.93,1.35)$ & 0.25 & & \\
\hline
\end{tabular}

* Near-target LDL was defined as LDL-cholesterol $>2.5$ and $<3.5 \mathrm{mmol} / \mathrm{L}$.

BMI, body mass index. CVD, cardiovascular disease. LDL, low-density lipoprotein. TIA, transient ischemic attack.

\section{DISCUSSION}

In this cohort study, we showed that there is a gap between recommended lipidlowering prescription and what is seen in daily primary care practice. In patients with a CVD, DM or dyslipidaemia in whom LDL-cholesterol was measured in the 
last year, 32\% had uncontrolled LDL-cholesterol levels (> $2.5 \mathrm{mmol} / \mathrm{L}$ ) and less than half of these patients had a prescription for lipid-lowering drugs in the 6 months prior to an elevated LDL-cholesterol measurement, also in patients with a CVD. In 93\% there was therapeutic inertia, i.e. LDL-lowering medication was not started or uptitrated. In different subgroups, rates of therapeutic inertia were high as well. Younger age, a higher LDL-cholesterol level and current/past smokers were independent determinants of intensified lipid-lowering medication.

\section{Strengths and limitations}

A strength is that we had access to a large dataset resembling real-world general practice in the Netherlands. However, as is common with routine care data, we had to depend on the information registered in the EHRs. Diagnoses were therefore considered present if recorded by GPs, and absent if not. This may have led to an underestimation of the prevalence of comorbidities.

Another strength is that we defined therapeutic inertia in 'favour of the GP', i.e. defined such that the number of false-positives was low. First, we selected a wide time window to enable adjustments of medication. Second, we excluded patients with a new, recent diagnosis of dyslipidaemia, CVD or DM, to allow enough time to achieve the treatment goals with lipid-lowering therapy. Third, we used a rather lenient LDL-cholesterol target of $\leq 2.5 \mathrm{mmol} / \mathrm{L}$ for all patients, following the Dutch guidelines on CVRM valid at that time, ${ }^{7}$ while more recent guidelines apply stricter target levels. ${ }^{9}$ All these choices reduced the risk of overestimation of therapeutic inertia.

A limitation of the study was the lack of data on the CV risk score, for patients without established CVD, making it less certain whether lipid-lowering drugs were definitely indicated in patients labelled as dyslipidaemia or DM. However, in patients with dyslipidaemia their CV risk was elevated and considered large enough by the GP to have initiated lipid-lowering medication, given their LDL-level $>2.5 \mathrm{mmol} / \mathrm{L}$ while on lipid-lowering treatment (our inclusion criterion). In the majority of patients with DM, it was very likely that their CV risk was large enough as the mean age of this group was 67 years and according to the guideline fifteen years should be added to their age to calculate their CV risk. 
We could not further classify patients above the age of 70 years into frailty categories, and thus were unable to assess whether a more lenient LDL-cholesterol target should indeed be considered., ${ }^{7,26}$ However, we assumed that the GP would not measure a LDL-cholesterol in frail patients.

\section{Comparison with existing literature}

Our study expands the scarcely available evidence on therapeutic inertia in lipidmanagement in primary care. We showed that the management of dyslipidaemia could be improved, as we found low levels of lipid-lowering drug use (45\%) and high levels of therapeutic inertia (93\%) in patients with an uncontrolled LDLcholesterol. The high level of therapeutic inertia was in line with some previous studies in primary care $(80 \% \text { to } 86 \%)^{27,28}$, whereas others reported lower rates, ranging from $44 \%$ to $70 \% .^{20,29,30}$ The evidence on use of lipid-lowering drugs is more consistent across studies; most studies report rates between $31 \%$ and 69\% in patients with elevated cholesterol levels, CVD or DM. ${ }^{16,31-34}$ One study focusing on patients with established CVD in primary care reported higher rates $(80 \%){ }^{35}$

It is speculative why we found such high levels of inertia compared to other studies. One explanation may be that rates of therapeutic inertia vary among studies because of different treatment goals and time windows. ${ }^{36}$ Further, therapeutic inertia may partly be explained by certain patient characteristics. We assessed the association between a large number of patient characteristics and therapeutic inertia and found that patients at older age and with lower LDL-cholesterol levels had higher risk of therapeutic inertia, consistent with other studies. ${ }^{21,25}$ Likely, reduced life expectancy, frailty and comorbidity may affect the clinical decision between GPs and patients not to increase or start treatment in older patients. ${ }^{37,38}$ However, as this is allowed according to the Dutch CVRM guideline it should not be assigned as therapeutic inertia and this may have artificially increased our therapeutic inertia estimastes. ${ }^{7}$ In contrast, the tendency for GPs to consider higher LDL-cholesterol values as adequately controlled is worrisome. ${ }^{17}$ Probably, GPs are not convinced of the importance of attaining the LDL-cholesterol treatment goal. However, a qualitative study reported that most GPs (89\%) agreed with the content of lipid treatment guidelines and reported to apply these in daily practice (81\%). ${ }^{39}$ Barriers to the implementation of guidelines seem to be of more importance, including lack of time and the complexity of guidelines. ${ }^{39}$ 
The patient characteristics that we assessed do not sufficiently explain the high rate of therapeutic inertia. Other reasons should be considered, including physician factors, patient factors and office system factors.

First, physician factors that contribute substantially to inertia include (i) physicians overestimating their adherence to guidelines, (ii) 'soft' reasons to avoid intensifying treatment, such as the perception that control was improving over time and (iii) physicians' lack of training on how to achieve goals (e.g. optimal dosages, how to deal with polypharmacy and statin intolerance). ${ }^{17,36}$ It is unknown to what extent practice nurses contribute to inertia. However, studies have shown that in chronic care practice nurses probably provide equal or possibly even better quality of care compared to primary care doctors. ${ }^{40}$

Second, patient factors such as reluctance to taking lipid-lowering drugs, for example due to scepticism about statins or fear for side effects such as muscle pain, may have hindered adequate LDL-cholesterol control. ${ }^{18,41,42}$ In some cases GPs may be incorrectly considered as reacting inadequately whereas it may be an appropriate shared decision with the patient to set an individual target, try lifestyle interventions first or to use no medication if patients are well informed about the benefits and risks.

Third, office system factors that may influence prescription include the "style of practice" (reactive or more proactive concerning prevention) and the primary care setting with variation in health care professionals involved in delivering chronic disease care, including practice nurses. ${ }^{36,43}$

Lastly, suboptimal communication between GPs and patients may be an important key to therapeutic inertia. ${ }^{44}$

\section{Implications for research and practice}

Guidelines become more complex and their complexity hinders adequate implementation. ${ }^{45,46}$ The gap between evidence and practice is expected to increase further with the even stricter LDL-cholesterol target values for high-risk patients in the new guidelines. ${ }^{9,47}$ Therefore, there is an urgent need for interventions to overcome inertia, including training of health care providers. Interventions that simultaneously target various factors contributing to clinical inertia (physician 
factors, patient factors, and office system factors) seem promising. ${ }^{36,48}$ Future studies should focus on improvement of the communication between GP and the patient, including the use of modern risk reduction tools, such as lifetime risk and the absolute risk reduction tool, and CVD free survival (available at https://uprevent.com). ${ }^{44,49-51}$ In such a patient-centred and lifetime benefit-based approach shared decision-making is crucial. ${ }^{52}$ Importantly, a low awareness of CV risk in patients should be taken into account in the physician-patient discussion. ${ }^{53}$ Enhancement of patients' involvement in their goal setting and achievement may be beneficial. ${ }^{46}$ For example, feedback on care directly to patients may work synergistically by activating both the patient and the patient's physician to intensify treatment. ${ }^{36}$ However, we have to consider that shared decisionmaking may also result in deliberate deviation from the guidelines if patients have their reasons not to adhere. At least, in order to further study therapeutic inertia, the efforts taken by the GP to discuss the treatment goals and reasons not to adhere should be recorded. Lastly, a decision support program in the EHR, including reminders and targeted feedback on performance, might facilitate lipidmanagement. . $^{17,36}$

\section{Conclusion}

The management of dyslipidaemia in primary care was suboptimal. In patients with dyslipidaemia, CVD or DM and an uncontrolled LDL-cholesterol only 45\% used a lipid-lowering drug and in 93\% therapeutic inertia was observed. There is an urgent need for effective interventions to overcome therapeutic inertia in primary care. 


\section{REFERENCES}

1. Timmis A, Townsend N, Gale CP, et al. European society of cardiology: Cardiovascular disease statistics 2019. Eur Heart J. 2020;41(1):12-85.

2. Roth GA, Abate D, Abate KH, Abay SM, Abbafati C, Abbasi N. Global, regional, and national age-sex-specific mortality for 282 causes of death in 195 countries and territories, 1980-2017: A systematic analysis for the global burden of disease study 2017. Lancet. 2018;392(10159):1736-1788.

3. Chen Z, Peto R, Collins R, MacMahon S, Lu J, Li W. Serum cholesterol concentration and coronary heart disease in population with low cholesterol concentrations. BMJ. 1991;303(6797):276-282.

4. Stamler J, Vaccaro 0, Neaton JD, Wentworth D. Diabetes, other risk factors, and 12-yr cardiovascular mortality for men screened in the multiple risk factor intervention trial. Diabetes Care. 1993;16(2):434-444.

5. Baigent C, Keech A, Kearney PM, et al. Efficacy and safety of cholesterol-lowering treatment: Prospective meta-analysis of data from 90,056 participants in 14 randomised trials of statins. Lancet. 2005;366(9493):1267-1278.

6. Baigent C, Blackwell L, Emberson J, et al. Efficacy and safety of more intensive lowering of LDL cholesterol: A meta-analysis of data from 170,000 participants in 26 randomised trials. Lancet. 2010;376(9753):1670-1681.

7. Dutch College of General Practitioners Guideline Development Group. Guideline cardiovascular risk management (second revision). Huisarts Wet. 2012(55):14-28.

8. Mach F, Baigent C, Catapano AL, et al. 2019 ESC/EAS guidelines for the management of dyslipidaemias: Lipid modification to reduce cardiovascular risk. Eur Heart J. 2019.

9. Dutch College of General Practitioners Guideline Development Group. Guideline cardiovascular risk management (third revision). Huisarts Wet. 2019:62: 55-7.

10. Cannon CP, Blazing MA, Giugliano RP, et al. Ezetimibe added to statin therapy after acute coronary syndromes. N Engl J Med. 2015;372(25):2387-2397.

11. Yogo M, Sasaki M, Ayaori M, et al. Intensive lipid lowering therapy with titrated rosuvastatin yields greater atherosclerotic aortic plaque regression: Serial magnetic resonance imaging observations from RAPID study. Atherosclerosis. 2014;232(1):31-39.

12. Baigent C, Landray MJ, Reith C, et al. The effects of lowering LDL cholesterol with simvastatin plus ezetimibe in patients with chronic kidney disease (study of heart and renal protection): A randomised placebo-controlled trial. Lancet. 2011;377(9784):2181-2192.

13. LaRosa JC, Grundy SM, Waters DD, et al. Intensive lipid lowering with atorvastatin in patients with stable coronary disease. N Engl J Med. 2005;352(14):1425-1435. 
14. Kotseva K, Wood D, De Backer G, et al. EUROASPIRE III. management of cardiovascular risk factors in asymptomatic high-risk patients in general practice: Cross-sectional survey in 12 european countries. Eur J Cardiovasc Prev Rehabil. 2010;17(5):530-540.

15. Kotseva K, De Bacquer D, De Backer G, et al. Lifestyle and risk factor management in people at high risk of cardiovascular disease. A report from the european society of cardiology european action on secondary and primary prevention by intervention to reduce events (EUROASPIRE) IV cross-sectional survey in 14 european regions. Eur J Prev Cardiol. 2016;23(18):2007-2018.

16. Kotseva K, De Backer G, De Bacquer D, et al. Primary prevention efforts are poorly developed in people at high cardiovascular risk: A report from the european society of cardiology EURObservational research programme EUROASPIRE V survey in 16 european countries. Eur J Prev Cardiol. 2020:2047487320908698.

17. Phillips LS, Branch WT, Cook CB, et al. Clinical inertia. Ann Intern Med. 2001;135(9):825-834.

18. Allen JD, Curtiss FR, Fairman KA. Nonadherence, clinical inertia, or therapeutic inertia? J Manag Care Pharm. 2009;15(8):690-695.

19. Whitford DL, Al-Anjawi HA, Al-Baharna MM. Impact of clinical inertia on cardiovascular risk factors in patients with diabetes. Prim Care Diabetes. 2014;8(2):133-138.

20. Wang KF, Wu CH, Chang CC, et al. Determinants of treatment modification in hypercholesterolemic patients. Acta Cardiol Sin. 2017;33(2):156-164.

21. Goldberg KC, Melnyk SD, Simel DL. Overcoming inertia: Improvement in achieving target low-density lipoprotein cholesterol. Am J Manag Care. 2007;13(9):530-534.

22. Smeets HM, Kortekaas MF, Rutten FH, et al. Routine primary care data for scientific research, quality of care programs and educational purposes: The julius general practitioners' network (JGPN). BMC Health Serv Res. 2018;18(1):735-5.

23. Groenhof TKJ, Kofink D, Bots ML, et al. Low-density lipoprotein cholesterol target attainment in patients with established cardiovascular disease: Analysis of routine care data. JMIR Med Inform. 2020;8(4):e16400.

24. Roa L, Monreal M, Carmona JA, et al. Treatment inertia in secondary prevention of cardiovascular disease. FRENA registry. Med Clin (Barc). 2010;134(2):57-63.

25. Lazaro P, Murga N, Aguilar D, Hernandez-Presa MA, INERTIA Study Investigators. Therapeutic inertia in the outpatient management of dyslipidemia in patients with ischemic heart disease. the inertia study. Rev Esp Cardiol. 2010;63(12):1428-1437.

26. Odesjo H, Bjorck S, Franzen S, et al. Adherence to lipid-lowering guidelines for secondary prevention and potential reduction in CVD events in swedish primary care: A cross-sectional study. BMJ Open. 2020;10(10):e036920-036920. 
27. Whitford DL, Al-Anjawi HA, Al-Baharna MM. Impact of clinical inertia on cardiovascular risk factors in patients with diabetes. Prim Care Diabetes. 2014;8(2):133-138.

28. Lopez-Simarro F, Brotons C, Moral I, et al. Inertia and treatment compliance in patients with type 2 diabetes in primary care. Med Clin (Barc). 2012;138(9):377-384.

29. Diaz Rodriguez A, Murga N, Camafort-Babkowski M, et al. Therapeutic inertia in hypercholesterolaemia is associated with ischaemic events in primary care patients. A case-control study. Int J Clin Pract. 2014;68(8):1001-1009.

30. Rodondi N, Peng T, Karter AJ, et al. Therapy modifications in response to poorly controlled hypertension, dyslipidemia, and diabetes mellitus. Ann Intern Med. 2006;144(7):475-484.

31. Guallar-Castillon P, Gil-Montero M, Leon-Munoz LM, et al. Magnitude and management of hypercholesterolemia in the adult population of spain, 2008-2010: The ENRICA study. Rev Esp Cardiol (Engl Ed). 2012;65(6):551-558.

32. Fuke D, Hunt J, Siemienczuk J, et al. Cholesterol management of patients with diabetes in a primary care practice-based research network. Am J Manag Care. 2004;10(2 Pt 2):130-136.

33. Kleipool EEF, Nielen MMJ, Korevaar JC, et al. Prescription patterns of lipid lowering agents among older patients in general practice: An analysis from a national database in the netherlands. Age Ageing. 2019;48(4):577-582.

34. Hespe CM, Campain A, Webster R, et al. Implementing cardiovascular disease preventive care guidelines in general practice: An opportunity missed. Med J Aust. 2020;213(7):327-328.

35. Kotseva K, De Backer G, De Bacquer D, et al. Lifestyle and impact on cardiovascular risk factor control in coronary patients across 27 countries: Results from the european society of cardiology ESC-EORP EUROASPIRE V registry. Eur J Prev Cardiol. 2019;26(8):824-835.

36. O'Connor PJ, Sperl-Hillen JAM, Johnson PE, Rush WA, Biltz G. Clinical inertia and outpatient medical errors. In: Henriksen K, Battles JB, Marks ES, Lewin DI, eds. Advances in patient safety: From research to implementation (volume 2: Concepts and methodology). Rockville (MD): ; 2005. NBK20513 [bookaccession].

37. Kleipool EEF, Nielen MMJ, Korevaar JC, et al. Prescription patterns of lipid lowering agents among older patients in general practice: An analysis from a national database in the netherlands. Age Ageing. 2019;48(4):577-582.

38. Kleipool EE, Dorresteijn JA, Smulders YM, Visseren FL, Peters MJ, Muller M. Treatment of hypercholesterolaemia in older adults calls for a patient-centred approach. Heart. 2020;106(4):261-266. 
39. Hobbs FD, Erhardt L. Acceptance of guideline recommendations and perceived implementation of coronary heart disease prevention among primary care physicians in five european countries: The reassessing european attitudes about cardiovascular treatment (REACT) survey. Fam Pract. 2002;19(6):596-604.

40. Laurant M, van der Biezen M, Wijers N, Watananirun K, Kontopantelis E, van Vught AJ. Nurses as substitutes for doctors in primary care. Cochrane Database Syst Rev. 2018;7:CD001271.

41. Ju I, Banks E, Calabria B, et al. General practitioners' perspectives on the prevention of cardiovascular disease: Systematic review and thematic synthesis of qualitative studies. BMJ Open. 2018;8(11):e021137-021137.

42. Tanner RM, Safford MM, Monda KL, et al. Primary care physician perspectives on barriers to statin treatment. Cardiovasc Drugs Ther. 2017;31(3):303-309.

43. Shah BR, Hux JE, Laupacis A, Zinman B, van Walraven C. Clinical inertia in response to inadequate glycemic control: Do specialists differ from primary care physicians? Diabetes Care. 2005;28(3):600-606.

44. Carratala-Munuera C, Gil-Guillen VF, Orozco-Beltran D, et al. Barriers to improved dyslipidemia control: Delphi survey of a multidisciplinary panel. Fam Pract. 2015;32(6):672-680.

45. Campbell NC, Murchie P. Treating hypertension with guidelines in general practice. BMJ. 2004;329(7465):523-524.

46. Parker DR, Gramling R, Goldman RE, et al. Physicians' perceptions of barriers and facilitators regarding adoption of the national cholesterol education program guidelines. Prev Cardiol. 2008;11(1):29-35.

47. Mach F, Baigent C, Catapano AL, et al. 2019 ESC/EAS guidelines for the management of dyslipidaemias: Lipid modification to reduce cardiovascular risk. Eur Heart J. 2020;41(1):111-188.

48. Bodenheimer T, Wagner EH, Grumbach K. Improving primary care for patients with chronic illness: The chronic care model, part 2. JAMA. 2002;288(15):1909-1914.

49. Stam-Slob MC, Visseren FL, Wouter Jukema J, et al. Personalized absolute benefit of statin treatment for primary or secondary prevention of vascular disease in individual elderly patients. Clin Res Cardiol. 2017;106(1):58-68.

50. Kaasenbrood L, Bhatt DL, Dorresteijn JAN, et al. Estimated life expectancy without recurrent cardiovascular events in patients with vascular disease: The SMARTREACH model. J Am Heart Assoc. 2018;7(16):e009217. 
51. Berkelmans GFN, Gudbjornsdottir S, Visseren FLJ, et al. Prediction of individual lifeyears gained without cardiovascular events from lipid, blood pressure, glucose, and aspirin treatment based on data of more than 500000 patients with type 2 diabetes mellitus. Eur Heart J. 2019;40(34):2899-2906.

52. Kleipool EE, Dorresteijn JA, Smulders YM, Visseren FL, Peters MJ, Muller M. Treatment of hypercholesterolaemia in older adults calls for a patient-centred approach. Heart. 2020;106(4):261-266.

53. van der Weijden T, van Steenkiste B, Stoffers HE, Timmermans DR, Grol R. Primary prevention of cardiovascular diseases in general practice: Mismatch between cardiovascular risk and patients' risk perceptions. Med Decis Making. 2007;27(6):754761. 


\section{SUPPLEMENTARY TABLES AND FIGURES}

Table S1. ICPC codes of medical diagnoses used in our study.

\begin{tabular}{llc}
\hline Variable & ICPC codes* & $\begin{array}{c}\text { Used for selection } \\
\text { of population }\end{array}$ \\
\hline Dyslipidaemia & T93, T93.01, T93.02, T93.03, T93.04 & $\mathrm{X}$ \\
or use of lipid-lowering drug & $\mathrm{X}$ \\
Diabetes mellitus & T90, T90.01, T90.02 & $\mathrm{X}$ \\
Angina pectoris & K74, K74.01, K74.02 & $\mathrm{X}$ \\
Coronary heart disease & K75, K76, K76.01, K76.02 & $\mathrm{X}$ \\
Ischemic stroke and/or TIA & K89, K90, K90.03 & $\mathrm{X}$ \\
Peripheral artery disease & K91, K92, K92.01 & $\mathrm{X}$ \\
Aortic aneurysm & K99.01 & \\
Hypertension & K86, K87 & \\
Smoker (current or past) & P17 or pack years mentioned in EHR & \\
Obesity & T82 or BMI $>30$ kg/m 2 & \\
Renal insufficiency & U99.01 & \\
Heart failure & K77 & \\
Atrial fibrillation & K78 & \\
Family history of CVD & A29.01 & \\
Family history of hyperlipidaemia & A29.06 & \\
\hline
\end{tabular}

BMI, body mass index; CVD, cardiovascular diseases; EHR, electronic health record; TIA, transient ischaemic attack, *All medical diagnoses are based on International Classification of Primary Care (ICPC) codes. As described, additional information was used for obesity, smoking and dyslipidaemia. 


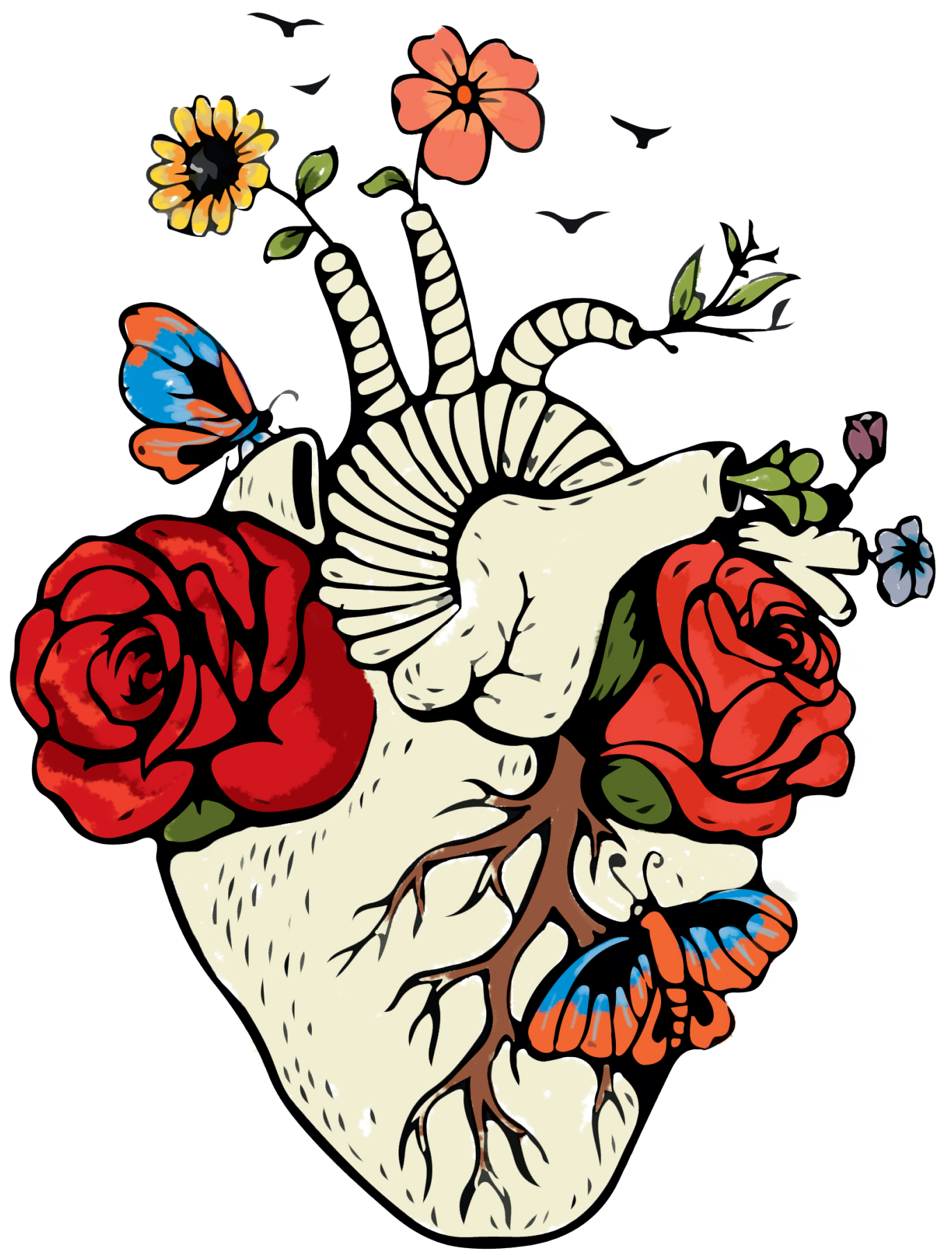




\section{CHAPTER 8}

General Discussion 


\section{MAIN FINDINGS OF THIS THESIS}

This thesis aims to provide insight in the effectiveness of an integrated and multidisciplinary programme for cardiovascular risk management (CVRM) in primary care in a real-world setting and to describe the challenges of the implementation of CVRM in daily practice.

The main findings of the studies included in this thesis are as follows:

- In patients receiving integrated care for CVRM in general practice, blood pressure, body weight, low-density lipoprotein (LDL)-cholesterol and renal function were more often measured compared to usual care. In addition, in a higher proportion of patients in the CVRM programme dietary habits, physical activity and smoking cessation were discussed.

- One year of integrated primary care for CVRM following usual care did not result in better outcomes for systolic blood pressure (SBP) and LDLcholesterol compared to usual care. Moreover, no differences were observed in cardiovascular (CV) risk, smoking rates, body mass index (BMI), physical activity, alcohol consumption, dietary habits, medication use, number of consultations during follow-up, satisfaction with delivered care, quality of life, anxiety and depression scores, morbidity and mortality.

- In patients with hypertension or hypercholesterolemia, receiving integrated CVRM in general practice, actions to optimize drug treatment seemed to be insufficient; antihypertensive medication often remained unchanged and in particular lipid-lowering drugs were seldom initiated or uptitrated when indicated.

- The CV risk and risk factor awareness in patients was poor, both in patients participating in the integrated CVRM programme and in patients receiving usual care. The adequacy of patient's perception of CV risk (factors) and lifestyle (advice) did not differ between the groups and there was a huge gap between lifestyle advice documented in the medical files and what was reported by patients.

- In patients with dyslipidaemia, known cardiovascular disease (CVD), or diabetes mellitus (DM) and uncontrolled LDL-cholesterol therapeutic inertia was very common ( $>90 \%)$. 
- The integrated and multidisciplinary CVRM programme in primary care may have some effect on cardiovascular disease (CVD) related hospital care. After introduction of the programme, length of treatment at the hospital slightly decreased and the costs of hospital care decreased considerably, mainly caused by a decrease in the costs of hospital admissions. Importantly, non-CVD hospital care showed a much smaller decrease in the total costs of hospital admissions and even a small increase in the total costs of outpatient visits.

These findings indicate that the current integrated CVRM programme in the Netherlands is not effective in a real-world setting, during the first year after the start of the programme and that implementation of CVRM in daily practice according to the guidelines is insufficient.

It raises the question whether this integrated CVRM programme should be implemented and advocated further. Before these future considerations are discussed, the RE-AIM model, developed to evaluate preventive intervention, will be applied to assess the potential impact of integrated multidisciplinary CVRM programmes in daily practice, in the light of the results of studies included in this thesis and available evidence from earlier studies.

\section{THE RE-AIM MODEL}

A structural method to evaluate preventive interventions is the RE-AIM model, developed in 1999 by Glasgow et al. ${ }^{1}$ It conceptualizes how well a programme works in the complex setting of the real world by addressing five dimensions: Reach, Efficacy/Effectiveness, Adoption, Implementation, and Maintenance. The RE-AIM model is summarized in Box 1. The idea behind RE-AIM is that efficacybased research (typically randomised controlled trials within a selected patient population) oversimplifies reality by testing an intervention under controlled conditions; the results are not automatically applicable to daily practice. Many interventions that prove efficacious in randomized trials are much less effective in the real-world setting. The effectiveness of an intervention in daily practice is influenced by the interaction of the five dimensions of the RE-AIM model. Therefore, this model is a useful method to evaluate the impact of an intervention 
and therefore provides a framework to determine whether an intervention should be continued in daily practice or not.

The first character of the acronym RE-AIM stands for Reach and concerns the extent to which the target population participates in the intervention and whether participants are representative. It gives an idea of the degree to which the intervention reaches the intended patients/ those who need it.

The second character stands for Efficacy/Effectiveness. Efficacy refers to the success of an intervention when it is implemented according to the guidelines under optimal conditions. Effectiveness reflects the success of an intervention when implemented in daily practice.

The third character stands for Adoption, the degree of acceptance of the intervention within the intended settings, including the health care staff. Assessment of adoption should include barriers for settings or staff to participate and adopt the intervention.

The fourth character stands for Implementation and concerns the extent to which a programme is delivered as intended and relates to adherence to guidelines within the intervention/ the intervention protocol.

The last character stands for Maintenance and describes whether an intervention becomes part of regular daily practice (institutionalized), reflecting long-term effects of the intervention.

Box 1. The RE-AIM model

\begin{tabular}{|l|l|}
\hline Reach & $\begin{array}{l}\text { Proportion of the target population that participated in the } \\
\text { intervention }\end{array}$ \\
\hline Efficacy/ Effectiveness & $\begin{array}{l}\text { Success rate if implemented as in guidelines/ if implemented in daily } \\
\text { practice }\end{array}$ \\
\hline Adoption & $\begin{array}{l}\text { Proportion of settings, practices, and plans that will adopt this } \\
\text { intervention }\end{array}$ \\
\hline Implementation & $\begin{array}{l}\text { Extent to which the intervention is implemented as intended in the } \\
\text { real world }\end{array}$ \\
\hline Maintenance & Extent to which a programme is sustained over time \\
\hline
\end{tabular}




\section{Reach}

Ideally, when a programme is implemented, all indicated patients should be reached. Broad implementation is crucial for a programme to be successful. In the Netherlands, implementation of integrated CVRM is organized regionally. General practitioners (GPs) are member of one of the 115 regional care groups that coordinate the implementation of the programme. In the region of our study, the Zwolle region, approximately two third of the general practices chose to participate, the others continued usual care. For us, this provided the opportunity to compare integrated care for CVRM with usual care. However, apart from the research potential, it limited the degree to which the programme reached the intended patients. National participation rates are even lower; just 55\% of the GPs participate in a CVRM programme coordinated by a regional care group. ${ }^{2}$ Among GPs in Europe, $49 \%$ to $74 \%$ participate in a disease management programme for patients with risk factors for cardio metabolic disease. ${ }^{3}$ It is not known why practices decide to participate or not. In the literature, limited time and access to appropriate resources in primary care, the lack of evidence of effectiveness/ efficacy of interventions and the difficulty to achieve sustained behavioural change in patients are mentioned as barriers for healthcare professionals to deliver interventions aimed at changing patient behaviour in primary care. ${ }^{4,5}$ It may be more attractive for GPs to participate in a more lean CVRM programme in primary care.

If a general practice participates in integrated care for CVRM this does not guarantee patient participation in the programme. In the ZWOT-CASE study, we did not assess the participation rate of patients in the CVRM programme. A report on CVRM programmes in the Netherlands in 2019 reported that almost $10 \%$ of the patients with CVD and 25\% of the patients with a high CVD risk did not participate, despite implementation of an integrated CVRM programme by their GPs. ${ }^{6}$ Reasons for patients at high CVD risk not to participate in the programme (anymore) included: significantly improved lifestyle habits, presence of dominant co-morbidity and insufficient motivation. In addition, limitations on inclusion rates installed by the health care insurer can be a reason not to include patients in the programme. ${ }^{6}$ The same report disclosed that only $68 \%$ of CVD patients received CVRM by their GP while $23 \%$ was treated in the hospital, suggesting enough room for (additional) substitution from secondary to primary care. ${ }^{6}$ CVRM requires 
a lifelong, holistic and multidisciplinary approach. As GPs have a longstanding relationship with their patients, they are well suited to deliver this care.

Evidence for non-participation of patients and room for further substitution of secondary by primary CVRM care raises the question how patients are invited and motivated to participate in the programme. In Europe, 71\% of GPs invite their patients to attend cardio metabolic disease risk assessments; less than half of these GPs use an active approach to invite their patients, while the others used an opportunistic approach. ${ }^{3}$ Encouragement of patients to attend preventive programmes can feel as a waste of time when patients lack motivation and GPs might feel unable to deliver adequate preventive care to their patients. ${ }^{7}$ Lack of time and resources make this task even more challenging and GPs increasingly question their role and obligation in preventive care. ${ }^{7}$

\section{Efficacy/Effectiveness}

Multidisciplinary integrated CVRM is a heterogeneous concept. An overall assessment of studies on the efficacy and effectiveness of integrated programmes for CVRM is hindered by heterogeneity in intervention strategies, target populations and outcomes. Unsurprisingly, the overall findings of studies on the effects of disease management programmes for CVRM are inconclusive. ${ }^{8,9}$

In the ZWOT-CASE study (chapter 4), one year of an integrated programme for CVRM did not improve blood pressure, cholesterol levels, lifestyle, quality of life and morbidity and mortality in a real-world setting. Some other studies showed similar disappointing results of CVRM programmes, while others found beneficial effects. Evidence published during the preceding 10 years, on the effect of multifactorial interventions to prevent CVD in primary care is summarized in supplementary table 1 . We focused on systematic reviews and an individual study was only included if it was not already included in one of the systematic reviews. It is important to note that this overview itself is not a systematic review. We should be cautious to draw conclusions as most of the reviews reported extensive heterogeneity in results. Outcomes evaluated in the studies included lifestyle, intermediate outcomes such as CV risk factors, clinical outcomes (CVD events and mortality) and quality of life. Unfortunately, improvements in lifestyle, including smoking cessation, physical activity and dietary habits, were only reported in 
a minority of the studies.-11 This is disappointing as especially smoking and insufficient physical activity are clearly associated with CVD events and mortality.

Some studies found beneficial effects on weight/BMI. ${ }^{12}$ The effect on weight/BMI is less important, as it is not sure whether (small) reductions in weight/BMI translate into decreased CVD events and/or mortality from CVD. ${ }^{13}$ Clinical significance of changes in weight/BMI should primarily be based on accompanying changes in lipid, blood pressure, and glucose metabolism.

Studies reporting positive findings of integrated CVRM care mainly found an effect on intermediate outcomes. Several reviews showed a small effect on blood pressure (figure 1). 10,12,14-17 These small effects on blood pressure are of value, as it is known that small reductions may result in longer-term reduction in CVD morbidity and mortality. Even a $2 \mathrm{~mm} \mathrm{Hg}$ lower 'usual' SBP would confer a 10\% lower risk of stroke mortality and 7\% lower mortality from ischemic heart disease or other vascular causes. ${ }^{18}$ LDL-cholesterol was less often reported as an outcome and the effects were less clear. The review of Snaterse et al. reported a small reduction in LDL-cholesterol of $0.23 \mathrm{mmol} / \mathrm{L}$ (95\%-CI $0.10-0.36$ ) in patients with coronary heart disease ${ }^{9}$, whereas Lin et al. found no effect on LDL-cholesterol $(-0.09 \mathrm{mmol} / \mathrm{L}$ (95\% CI -0.14 to -0.04)) in CVD-free patients with at least one CV risk factor. ${ }^{10}$

The changes in intermediate outcomes were not reflected in reductions in CVD events and mortality in the findings of most studies that reported on these outcomes. ${ }^{9,10,14,15}$ Possibly, the lack of an effect on clinical outcomes is due to (heterogeneity in) study designs, including selected study populations, a short follow-up period and small sample sizes, resulting in limited power to detect effects on these outcomes. Thus, the possibility of beneficial effect on these clinical outcomes cannot be ruled out.

As integrated care for CVRM is a multicomponent intervention, it would be interesting to define which components are associated with effectiveness. The benefits of drug treatments for lowering blood pressure and cholesterol are well known. It may explain the lack of positive findings in the ZWOT-CASE study, as therapeutic inertia was common. Alageel et al. argued that reductions in blood pressure and total cholesterol might be mediated by pharmacological treatment instead of the multiple health behavioural change (MHBC) interventions. ${ }^{12}$ In 
contrast, Álvarez-Bueno et al. reported that advice on nutrition and physical activity was the most effective intervention in producing risk factor modifications. ${ }^{14} \mathrm{Glynn}$ et al. assessed different interventions to reduce blood pressure and concluded that an organized system of regular follow-up had the greatest impact. ${ }^{17}$ These heterogeneous conclusions indicate that it is very difficult to assign the most effective components of complex interventions. Moreover, we should be cautious to evaluate the contribution of individual components, as it does not take into account the synergistic effects of combining these components of complex interventions. Lin et al. showed that benefits on intermediate health outcomes are most robust for combined lifestyle counselling compared to interventions focused on diet or physical activity alone. ${ }^{10}$

Besides the different components, effectiveness may depend on the intensity of the intervention. Probably, the intensity of the integrated CVRM programme in the ZWOT-CASE study was too low with a median number of consultations of 2 (IQR 1 - 3) during 12 months. One study in the review of Álvarez-Bueno et al. associated the decrease in blood pressure and total cholesterol with high-intensity interventions. ${ }^{14}$ In contrast, in the review of Alageel et al. no association was observed between intervention intensity (number of sessions and intervention duration) and intervention outcomes. ${ }^{12}$ Lin et al. found that both medium- and high-intensity interventions were effective. ${ }^{10}$ However, the intensity of the ZWOT-CASE study could still be too low, as it is not comparable with medium(median of 5 contacts) and high-intensity (median of 16 contacts) interventions. ${ }^{10}$ Regardless of whether interventions that are more intensive produce better effects, the question is whether such interventions are feasible in routine practice. In addition, adherence rates might decrease in case of higher intensity. Adherence, and therefore effectiveness, in trials may be higher than in real-world practice, especially for higher-intensity interventions. There is no evidence available on a minimum threshold of time/intensity of integrated CVRM care that is effective.

Lastly, only certain populations might benefit from integrated care for CVRM. Interventions in high-risk individuals have shown to be more effective than in lower-risk populations. ${ }^{15}$ Patients are much more motivated to change their behaviours following a CVD event. Another explanation might be a "ceiling effect", whereby it becomes more difficult to show benefits once a certain baseline level of care has been reached. ${ }^{19}$ Strong associations have been observed between baseline 
levels of risk factors and effectiveness, suggesting that interventions may be more effective in populations with particularly adverse risk-factor profiles. ${ }^{15}$ Therefore, resources and time in primary care might be better spent on patients at higher risk of CVD. ${ }^{20}$

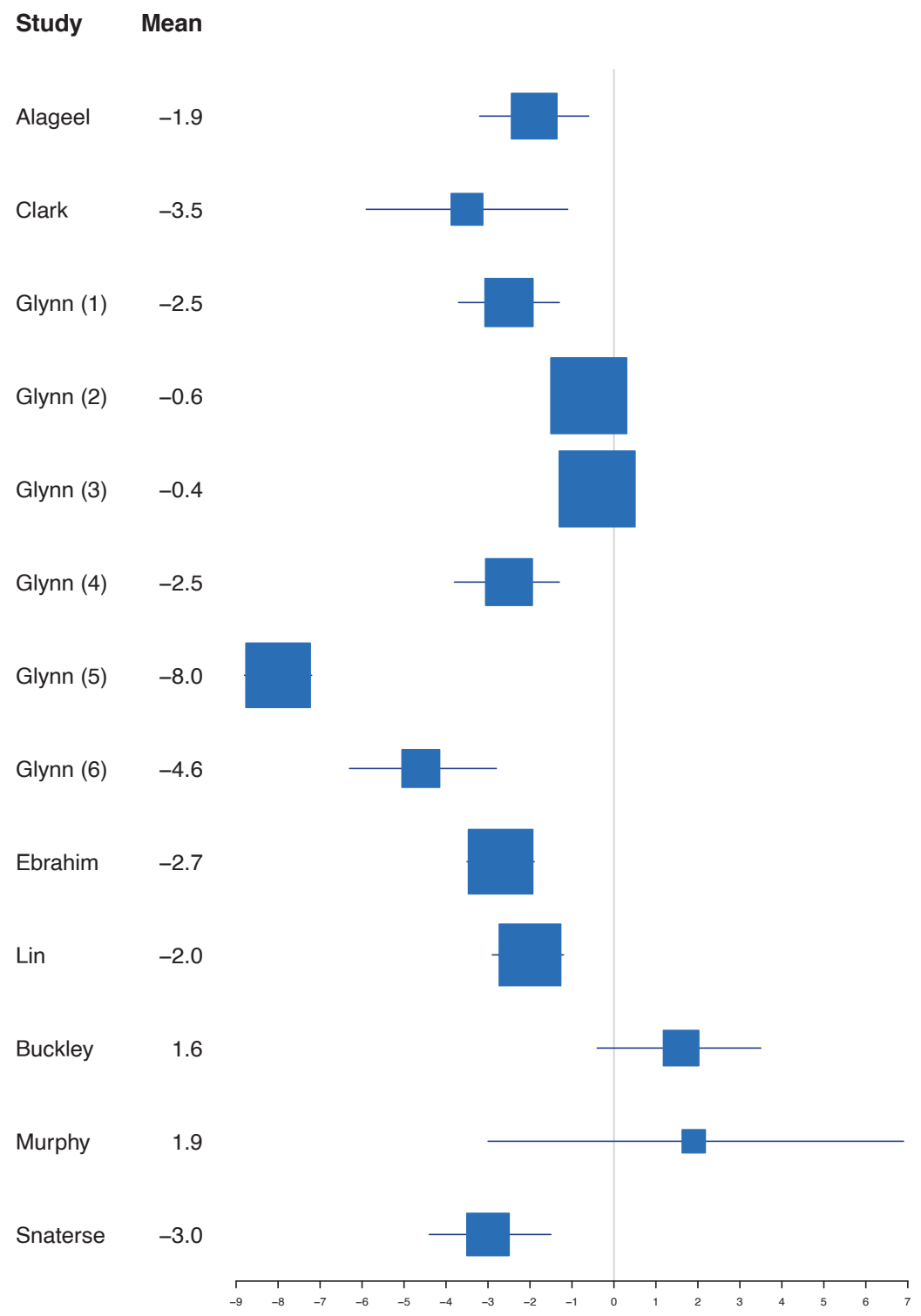

Figure 1. Overview of study findings. Mean difference in systolic blood pressure, including $95 \%$ CI 


\section{Adoption}

The studies in this thesis did not focus on the degree of uptake of the integrated programme for CVRM. During the recruitment of general practices for the ZWOTCASE study, I discussed arguments of GPs in favour and against participation in the programme during some informal conversations, reflecting the degree of acceptance of the programme by the GP. Interestingly, financial profit was often mentioned as argument to participate. Furthermore, some GPs participated because they expected no efforts were required to implement the programme as their CVRM care was already well organized. Others decided to participate based on the motivation to structure and improve CVRM in their practice. Some GPs who continued usual care argued that they expected no benefit from the intervention beyond usual care, as they already considered their CVRM care as very good. Other reasons not to participate in the programme included the increase in workload, requirements for reorganization of the practice, registration of data in an extra information system, and lack of evidence.

These various arguments suggest that the degree of uptake is influenced by a wide variety of factors such as team composition and engagement and organizational structures. ${ }^{21}$ Accordingly, barriers and facilitators to adopt complex interventions in primary care are diverse as summarized by Lau et al. in a comprehensive review. ${ }^{22}$ These barriers and facilitators concern (1) the external context in which implementation was taking place, (2) organizational features, (3) characteristics of health professionals involved and (4) characteristics of the intervention (figure 2).

Ad (1). At the level of external context, especially the 'fit' between the intervention and the context seems to be of great importance for successful implementation. For example, access to appropriate resources, including well-integrated clinical software, enough time and adequate funding are necessary. ${ }^{4,23}$

Ad (2). At the organizational level, a bottom-up interdisciplinary collaboration approach across the health care system seems to be essential for integration of health care. ${ }^{24}$ Diverse health care professionals must be strongly connected to disease management programmes to provide effective, holistic care that embraces all facets of the Chronic Care Model, including high quality of communication and task integration. ${ }^{25} \mathrm{~A}$ high degree of perceived integration by all stakeholders is associated with effectiveness. ${ }^{24}$ In an observational study, a favourable perception 
by team members regarding interdisciplinary collaboration (nurse, nutritionist, kinesiologist, pharmacist, social worker and GP) was associated with better patient outcomes (SBP, diet, quality of life) and less patient withdrawal from the CVRM programme. ${ }^{26}$ At the same time, the multidisciplinary character of CVRM programmes make a successful implementation more complex and challenging, as all involved disciplines together are responsible for its success. ${ }^{27}$ In the process evaluation of the ZWOT-CASE study we had no data to analyse multidisciplinary collaboration. However, the lack of effectiveness of integrated CVRM in our study raises the question whether the programme involved genuine collaboration across interdisciplinary teams. Instead of integrated care, referring patients from one to the other discipline may have occurred. Such a fragmented approach may hinder a more holistic, patient-centred response and, hence, effective CVRM.

Ad (3). At the level of the health care professional, the knowledge of and attitude towards integrated CVRM care of involved health care providers plays an important role. Although health care professionals generally believe that prevention of CVD is important, they do not always feel competent to deliver CVRM. ${ }^{7,28,29}$ Furthermore, the engagement of health care professionals in CVRM varies according to the level of interest in CVD prevention..$^{23} \mathrm{~A}$ strong interest in CVD prevention by one particular staff member can lead to a high level of engagement with the intervention. ${ }^{23}$

The process evaluation of the ZWOT-CASE study (chapter 5) showed that CV risk factors and lifestyle were more often assessed and discussed. At the same time, therapeutic inertia was very common and CV risk and risk factor awareness in patients was very poor. It is known that CVD prevention is experienced as a difficult task. ${ }^{23}$ It might be that PNs and GPs were able to adopt 'the easiest part' of the programme, checking boxes of $\mathrm{CV}$ risk factors and lifestyle. Following the guidelines and a real conversation with patients about their $\mathrm{CV}$ risk requires training, experience and enough time. Therefore, continuous professional development, using training tailored to the different needs of individual health care professionals and practices, is necessary to build the competence of the team. In addition, effective interdisciplinary collaboration between health care professionals should be supported by training relational competence. ${ }^{25}$ This may increase their ability to visualize the larger process and recognize their 
interconnectedness in accomplishing their shared goal: prevention of CVD in patients at high risk.

Ad (4). Characteristics of the intervention that affect adoption include the complexity of the intervention, evidence of benefit, applicability and relevance, clarity, practicality and utility of intervention, customisation of intervention and compatibility with the currently used information system. ${ }^{22}$ Interventions with a complex nature are associated with lower adoption rates. ${ }^{22}$ This may also apply to CVRM programmes. Guidelines for CVRM are experienced as complex and their complexity hinders adequate implementation. ${ }^{30,31}$ It may be one of the explanations why we found high levels of therapeutic inertia in our studies. Furthermore, lack of evidence on effectiveness can impede adoption of an intervention, as was mentioned by GPs in the ZWOT-CASE study. Implementation of an intervention can be facilitated by a good fit between intervention characteristics and the practice organization and provider needs. ${ }^{22}$

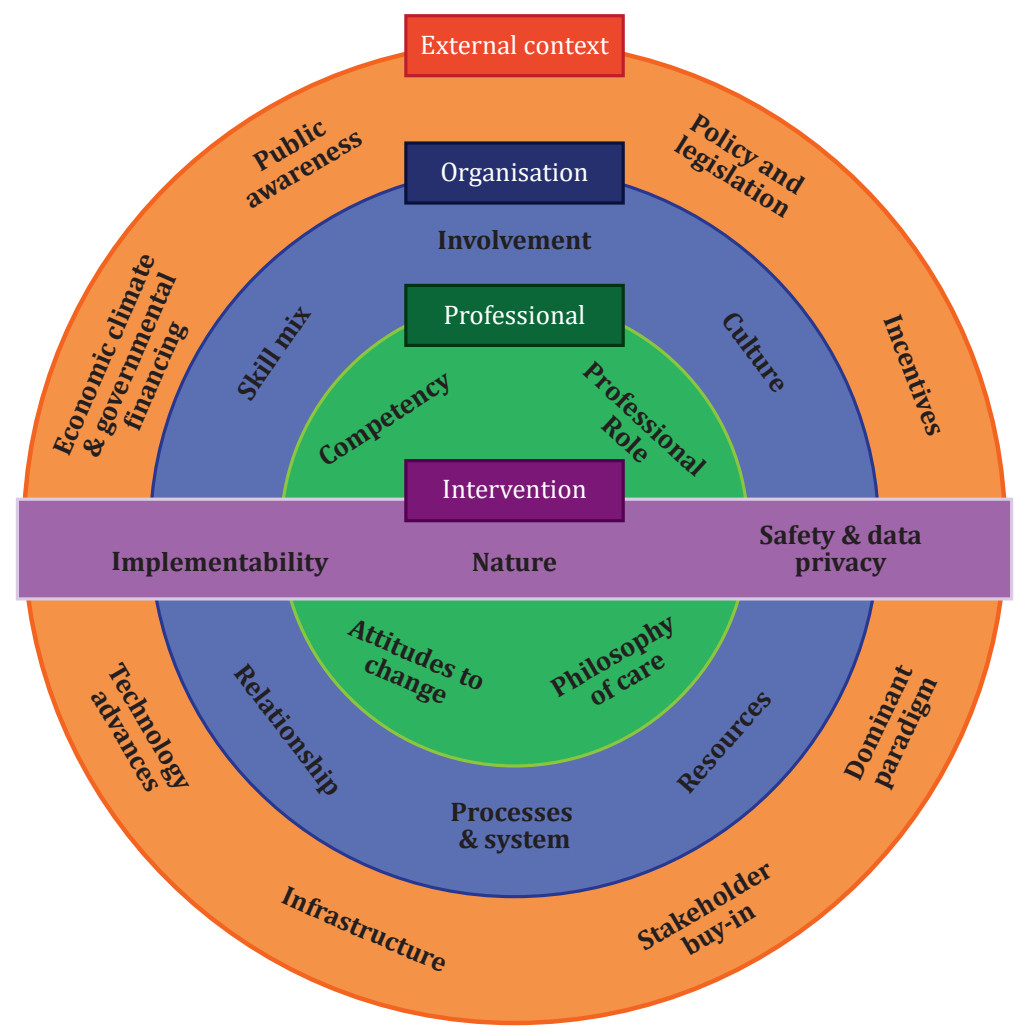

Figure 2. Barriers and facilitators to adopt complex interventions in primary care. ${ }^{22}$ 


\section{Implementation}

The success of CVRM programmes largely depends on the degree of implementation of the programme in the real world. In chapter 5 of this thesis, we found that some aspects of care improved in the integrated care programme for CVRM (CV risk factors were more often measured and lifestyle advice was more often discussed), which may suggest that the programme was well implemented. However, despite these improvements in process measures, a clinical benefit or an increased CV risk and risk factor awareness in patients was not achieved. Moreover, therapeutic inertia was a common phenomenon, both in the ZWOT-CASE study as well as in patients registered in the Julius General Practitioners' Network (chapter 7). It makes clear that guidelines are insufficiently implemented in daily practice, also when integrated care programmes for CVRM are initiated.

Although most GPs are aware of current guidelines, only 54\% to $81 \%$ of GPs report frequent use of one of the CVD prevention guidelines. ${ }^{32,33}$ Besides, only $18 \%$ of GPs across five European countries believe that guidelines are implemented to a major extent. ${ }^{33}$ In chapter 2 of this thesis, we commented on the new European guideline on CVD prevention. Key messages in the guideline included that CVD prevention asks for a personalized approach and that estimation of the CV risk and assessment of lifestyle factors should regularly be repeated. ${ }^{34}$ We stated that implementation of all recommendations in this new guideline would be challenging and requires more guidance for GPs as well as enough consultation time, ICT support, adequate reimbursement, a trained multidisciplinary team and support by concordant actions of surrounding organizations, insurance companies and government. Many of these requirements are mentioned in the literature as barriers to the implementation of guidelines..$^{27,32,33,35-37}$ One may wonder whether barriers to implementation of the integrated CVRM programme in the region of Zwolle were considered and whether measures to overcome these were taken. Prior to the implementation of the programme, GPs had to declare that they act in accordance with the most recent relevant national care standards. Furthermore, the care group provided a multidisciplinary information system for integrated care (KIS, Portavita $®$ ) and participating GPs agreed to register patient data in the KIS. Based on the data in this KIS GPs received yearly feedback on the state of cardiovascular risk factors of their CVRM population, but not achieving treatment goals had no consequences. It is very likely that barriers were still present during implementation of the integrated care programme. It may be that the programme 
was implemented too much top-down, not taking into account the needs of individual practices. Alternatively, the programme could be still in the startingphase of implementation and its evaluation (the ZWOT-CASE study) was timed too early. The process of developing an implementation strategy may take up to several years to complete and should consist of certain basic steps. ${ }^{27}$ One may doubt whether these steps were taken prior to and during the implementation of the integrated CVRM programme. These steps pertain to several important questions; were GPs and PNs sufficiently trained or did they lack adequate knowledge and skills?; were guidelines clear enough or were they too comprehensive and should they be simplified for use in daily practice?; was there enough consultation time or were patients too complex, requiring more time and effort to be adequately counsel?; was the KIS supportive in daily practice or was it too time consuming to register all the data, without providing decision support and reminders in return? It would be useful to evaluate these steps in depth to improve the implementation of the CVRM programme.

\section{Maintenance}

Evidence of the long-term effects of an integrated programme for CVRM are crucial to decide whether the programme should be continued or not. The follow-up times of the studies in this thesis were relatively short. However, other studies in primary care had a longer follow-up and many of these showed that CVRM programmes were not successful in the long term either ${ }^{38-40}$, whereas in a simulation study a primary care lifestyle intervention appeared to be (cost-)effective up to lifelong. ${ }^{41}$

Interestingly, some large Swedish studies, comparing regions with and without CVD prevention programmes in primary care, have shown positive results with regard to their ability to reduce CVD risk. In the 1980s, a regional prevention programme in the community and primary care led to significantly decreased CVD mortality compared to the whole of Sweden after 8 years. ${ }^{42}$ Another CVD prevention programme (the Vasterbotten Intervention Programme) in Sweden between 1990 and 2006 was able to reduce all cause and CVD mortality for people aged 40-70 years. ${ }^{43}$ More recently, another Swedish study showed that a CVD prevention programme (The Sollentuna Prevention Program) in primary care for patients with at least one CV risk factor but no established CVD, focusing on promotion of physical activity and healthy lifestyle, was associated with lower risk of CV events (12\%), CV deaths (21\%) and all-cause deaths (17\%) after two 
decades. ${ }^{44}$ Importantly, the interventions in these studies combined an individual approach in primary care with community prevention strategies. This might be a successful combination, as the increased awareness of the need for CVD prevention in the entire population may very well facilitate CVRM care in general practice. ${ }^{43}$

To achieve effects over a longer period, sustained interventions seem important, preferably by using an integrated approach across the community and primary care. Behavioural changes are difficult to persist without continuation or intermittent exposure to interventions. A short (one-time) intervention is not likely to be effective on the longer-term, ${ }^{45}$ and several studies have shown an increasing programme effect over time. ${ }^{46}$ It may take time to improve quality of care and outcomes of CVRM. Intensive targeted feedback to general practices participating in an integrated care programme for CVRM has been shown to improve this process. ${ }^{47}$ Possibly, a learning healthcare system, including a continuous cycle of targeted feedback based on real-time clinical data, taking into account patient preferences, and followed by implementation of potential improvements, might enhance and sustain cardiovascular risk factor control. ${ }^{48}$ Further, a stable government policy and long-term agreements with health care insurers are important to improve CVRM programmes and let these become part of daily practice.

\section{The RE-AIM model and integrated CVRM care programmes: conclu- sions}

Although CVRM programmes have been implemented in many regions in the Netherlands, the evidence for their effectiveness in the real world shows disappointing short-term results. Some randomized controlled trials indicate a small positive effect on blood pressure and cholesterol levels. However, these findings are usually not accompanied by evidence of reductions in CVD events and mortality in the short- and long-term. Possible explanations for the lack of clear effectiveness may be poor guideline adherence, as shown by the prevalence of therapeutic inertia in high-risk populations. Further, lack of time and resources, insufficient training of involved health care professionals and inadequate multidisciplinary collaboration across the health care chain may have hindered effective CVRM. 
Interventions that are more intensive are expected to improve the effectiveness of CVRM programmes. However, given the existing barriers to adequate implementation of the programme, increasing the intensity of the CVRM programme does not seem feasible in daily practice. Rather, a more lean CVRM programme in primary care with a focus on motivated and high-risk patients could be more promising.

Currently, by participating in a CVRM programme, GPs take responsibility for CVD prevention in a large group of patients at risk. The question is whether GPs are faced with an unfeasible task. Is primary care the right place for screening for patients at increased CV risk and implementing a comprehensive CVRM programme for all patients with increased risk of CVD?

\section{POSSIBLE SOLUTIONS}

\section{'Right care in the right place'}

Given the lack of effect, further implementation of the current CVRM programme in its current form is questionable. However, we should not depreciate the potential of CVRM programmes to reduce CV risk, but look for possible solutions to improve their impact. Currently, primary care plays a central role in CVRM programmes. The question is which tasks of CVRM, including screening, belong within the scope of primary care. Last year, Dutch GP discussed their core values during the "Woudschoten conference". Only 15\% of GPs consider prevention in patients without established disease as one of their core tasks. A survey amongst patients showed that they agree that prevention should not be the primary task of the GP. Certain parts of CVRM may be better conducted in settings other than primary care. Therefore, collaborative efforts from various organisations beyond general practice are needed, including public health services and governmental organisations, to optimise CVRM.

I will discuss several options to reshape CVRM, considering both interventions beyond the limits of general practice as well as interventions to increase the quality of CVRM care in primary care. 


\section{Public health services and general practice}

The efforts of general practices could be supported by involvement of Municipal Health Services in the prevention of CVD. General practices and Municipal Health Services have different qualities and competencies. Therefore, an integrated CVRM programme across these settings might be promising.

In the Netherlands, Municipal Health Services perform a number of public health tasks, including youth health care, infectious disease control and, most, vaccinations. Public health nurses and physicians in social medicine provide this care. Each Municipal Health Service is responsible for on average 600,000 residents. Besides, the network of Municipal Health Services includes many organizations in the municipality, creating opportunities for widely implemented interventions. In this way, the reach of citizens is optimal, in contrast to primary care CVRM programmes where reach of patients is dependent on participation of the general practice. Thus, Municipal Health Services are the designated organizations to apply prevention strategies at the population level. Further, Municipal Health Services are very well aware of problems in their different regions and districts and trained to reach people who live on the fringes of society, a population with a high prevalence of CV risk factors. Moreover, they have ample experience in the assessment of social problems, an important barrier to lifestyle changes. Physicians in social medicine are obviously less experienced in curative care, but CVRM interventions, including preventive medications, in individual men and women, might be considered an additional task.

General practitioners have a longstanding relationship with their patients, which gives them insight in their medical history, family structure and living circumstances. Thereby, guiding patients in the light of all above-mentioned factors is the key quality of general practice. In addition, medical specialists are easily accessible by GPs.

Given the different qualities of general practices and Municipal Health Services, some aspects of CVRM may be better performed by one and other parts by the other. I will give some currently non-evidence-based, suggestions for such a division of tasks pertaining to cardiovascular risk assessment, lifestyle modification and treatment of high-risk patients. 


\section{Outsourcing cardiovascular risk assessment}

Systematic cardiovascular risk assessment in primary care in patients not yet known with risk factors is not cost-effective in the short- and long-term. ${ }^{49}$ Therefore, primary care seems not to be the best setting for cardiovascular risk assessment. However, the European Guideline on cardiovascular disease prevention states that systematic $\mathrm{CV}$ risk assessment may be considered in men $>40$ years of age and in women $>50$ years of age or post-menopausal with no known $\mathrm{CV}$ risk factors. ${ }^{34}$ It is recommended to repeat CV risk assessment every 5 years, and more often for individuals with risks close to thresholds mandating treatment. Besides, the Dutch CVRM guideline recommends a mixture of opportunistic and systematic screening. ${ }^{50}$ This poses the question who should be responsible for such screening activities.

Given their broad experience in public health, Municipal Health Services could play an important role in systematic screening. Similar to the health checks in children, Municipal Health Services could offer health checks to the population of an age of 40 years and older. These health checks should include an assessment of CV risk factors and lifestyle, but also assessment of social welfare and someone's financial situation, known as important barriers to a healthy lifestyle. Public health nurses could play a crucial role in these health checks. For healthy individuals this screening should be repeated every 5 years. Further research needs to be carried out to establish the value of repeated screening and the optimal time frame.

The GP can continue with opportunistic screening during consultations for some other reason in the primary care practice. Therefore, the GP is the key person to identify patients who will not be identified by systematic screening, for example younger patients or patients who avoid screening. Sufficient time and financial resources are needed to stimulate GPs to provide this opportunistic screening.

\section{Lifestyle modification and treatment of high-risk patients: capacity issues}

If GPs adhere to the guidelines, they would identify too many patients at risk of CVD who need further lifestyle advice or pharmacotherapy. Surprisingly, in many regions in the Netherlands, GPs are confronted with the limitation of, unjustified, inclusion rates for patients in the CVRM programme imposed by health care insurers. Consequently, not all patients who are eligible and may benefit from it 
can be included in reimbursed CVRM programme. Further, lifestyle modification is a difficult and time-consuming task for $\mathrm{GPs} .{ }^{23}$ This poses the question whether general practice is the optimal place to treat all patients who need lifestyle modification or pharmacotherapy. With regard to lifestyle modification, Dutch general practices already have the opportunity to refer patients at high risk of CVD to a combined lifestyle intervention with coaches who can advise patients about healthy dietary habits, physical activity and other lifestyle factors such as stress. However, not all practices have access to or are aware of such combined lifestyle interventions, as is reflected by a Dutch monitor that reported that just over 7,000 people participated in this lifestyle intervention between October 2019 and April 2020, despite the intervention being reimbursed by health care insurance companies. ${ }^{51} \mathrm{GP}$ 's access to and awareness of this combined lifestyle intervention option could be improved.

Alternatively, Municipal Health Services could be involved in lifestyle modification, after they identified patients who need further lifestyle advice during the systematic screening. This lifestyle counselling could be part of the screening visit. If more intense lifestyle modification is needed, Municipal Health Services could refer patients to lifestyle interventions, such as the combined lifestyle intervention. This could increase participation in such interventions.

Besides, Municipal Health Services could play a role in pharmacological therapy in individual patients. For example, patients without established CVD but at increased risk of CVD could be managed by physicians in social medicine, including prescription of preventive medication such a blood pressure and lipid lowering drugs and smoking cessation therapies. Physicians in social medicine could spend more time on high quality communication on risk factors and lifestyle. This may increase patients' awareness of their CV risk, adherence to medication and improve outcomes of CVRM.

Treatment of patients with established CVD and complex patients should continue in primary care, including patients with comorbidities and polypharmacy and young patients with a high absolute CV risk. In this way, the CVRM programme in primary care will be a lean variant of the current programme. 


\section{Quality improvement}

A few measures may lead to a better quality of CVRM in primary care.

First, a lean CVRM programme in primary care, focused on patients with the highest CVD risk will give more room for improvement in quality of care. Fewer patients will be included in such a programme, making it manageable for the general practice to keep an overview. An important condition is that CVRM patients with lower CVD risk are managed adequately elsewhere.

Second, according to a learning healthcare system, continuous data collection and analyses could guide primary care in optimizing performance at the practice level. To support this, a continuous targeted feedback on performance regarding adherence to CVRM guidelines should be implemented. For example, a builtin feedback program in the electronic health system could send reminders or warnings when targets are not achieved and offer suggestions for adjustment of treatment. Such programs already exist, but could be more sophisticated and better suited to a patients' individual situation. In addition, continuous professional development in the context of CVRM for primary care health care providers, tailored to their personal needs, should get more attention.

Third, general practices could offer optimal versus regular CVRM care dependent on the motivation of a patient. A discount on health insurance costs could be used to motivate patients to participate in the optimal programme. In case of a lack of motivation in patients, targets will not be achieved. However, the responsibility of GPs for the health of their patients has its limits. If a patient is motivated, a contract could be signed that both GP/PN and patient will put optimal effort in optimizing CVRM care. Monitoring the adherence to lifestyle advices and medication could be considered to check whether patients' motivation actually translates into action, but is notoriously difficult and poses huge privacy and ethical issues. Continuous telemetric risk factor control, for example by devices such as step counters or activity trackers, could be provided to patients, including data transmission to their electronic health record.$^{52}$ However, adherence to a healthy diet or medication are more difficult to monitor. We should find a balance between trusting and monitoring patients. 
Lastly, the process of the CVRM programme in primary care should be critically evaluated on a regular base, including actions taken by health care providers. This may increase the sense of ownership of the programme. ${ }^{53}$ To stimulate this further, financial rewards could be made dependent on the performance of a general practice. The quality of performance should not be based on outcomes such as blood pressure or LDL-cholesterol targets, as these measures are not only dependent on actions taken by health care providers, but also on patients' motivation and compliance. However, process measures, such as delivered care and therapeutic inertia, could be good indicators of the quality of performance. For example, health care providers could report the given lifestyle advice and treatment recommendations to patients in the electronic health record, including the efforts that are taken to motivate patients. By reporting these actions, it could be assessed whether general practices have taken all steps as recommended in the guidelines. If so, the quality of performance should be considered as an indicator of success, independent of achieved treatment targets. This quality of performance could be used to assign a quality mark to well-performing practices.

\section{Promotion of CVD prevention by governmental organisations}

The efforts of primary care to prevent CVD require support from governments and society. Recently, the government has shown to be able to promote, install and finance preventive interventions during the urgent coronavirus pandemic. It has become clear that unhealthy lifestyle factors are related to worse COVID outcomes. ${ }^{54}$ However, in the pandemic of lifestyle-associated diseases such as CVD the government has lacked a sense of urgency in the past decades. This is of major concern, as the burden of lifestyle diseases is huge, especially in the long-term. The coronavirus and its economic consequences have worsened the problem, as people became less physically active and experienced more stress. ${ }^{55}$ At the same time, lifestyle diseases are risk factors for covid-19 and a healthy lifestyle protects against the coronavirus disease. ${ }^{56,57}$ Therefore, the covid-19 pandemic emphasizes the importance of a healthy lifestyle and the need to tackle the pandemic of lifestyle diseases, including CVD.

As for most people it is very difficult to change their behaviour, the government could implement policies that nudge people into a healthy lifestyle. ${ }^{58}$ Health protection through national fiscal and legislative changes that aim to reduce smoking, encourage a healthy diet, and increase facilities and opportunities for 
physical activity, should have high priority to deal with the increasing burden of CVD. Basic health insurance should include reimbursement for lifestyle interventions. Lastly, the government must take back control of CVD prevention. Policies on prevention of CVD should aim at integrated care across the entire health care chain.

\section{Future research}

Although randomized trials to assess the long-term effects of CVRM integrated care programmes are needed, it is unlikely that such, logistically challenging and very expensive trials, will be performed in the near future. Non-experimental comparisons using before-after designs or external control groups are more feasible, but do have, other, inherent limitations, as was shown in the ZWOTCASE study. Qualitative studies could provide additional information, by giving more insight into the 'black box' of complex interventions for CVD prevention. For example, it would be interesting to examine how health care providers communicate treatment advice and how patients perceive and respond to the advice. Further, better understanding the multidisciplinary cooperation could be very helpful in improving integration of future interventions. Finally, the consequences of strategies such as pay-for-performance should be evaluated.

\section{CONCLUDING REMARKS}

General practitioners should reconsider what role they want to play in CVD prevention, as the CVRM programme in its current form is not effective enough. My vision regarding future CVRM programmes is that general practices will continue to play a key role, but with an increased focus on high-risk, complex and motivated patients and more attention being payed to the quality of performance in primary care. To make this possible, Municipal Health Services could be involved more closely in cardiovascular risk assessment, lifestyle modification and treatment of individual, typically, low-risk patients. Moreover, it is time that the government recognises the urgency of the pandemic of lifestyle-associated diseases and much more actively stimulates a healthy lifestyle across the population. All these concordant actions could work synergistically and increase the success of CVRM. 


\section{REFERENCES}

1. Glasgow RE, Vogt TM, Boles SM. Evaluating the public health impact of health promotion interventions: The RE-AIM framework. Am J Public Health. 1999;89(9):1322-1327.

2. Zaat J. De kern van het vak (4): Huisarts en netwerk. Huisarts Wet. 2018;61:17-23.

3. de Waard AM, Hollander M, Korevaar JC, et al. Selective prevention of cardiometabolic diseases: Activities and attitudes of general practitioners across europe. Eur J Public Health. 2019;29(1):88-93.

4. Alageel S, Gulliford MC, McDermott L, Wright AJ. Implementing multiple health behaviour change interventions for cardiovascular risk reduction in primary care: A qualitative study. BMC Fam Pract. 2018;19(1):171-0.

5. Yeoh EK, Wong MCS, Wong ELY, et al. Benefits and limitations of implementing chronic care model (CCM) in primary care programs: A systematic review. Int J Cardiol. 2018;258:279-288.

6. InEen. Transparante ketenzorg rapportage 2019.

7. Ju I, Banks E, Calabria B, et al. General practitioners' perspectives on the prevention of cardiovascular disease: Systematic review and thematic synthesis of qualitative studies. BMJ Open. 2018;8(11):e021137-021137.

8. Martinez-Gonzalez NA, Berchtold P, Ullman K, Busato A, Egger M. Integrated care programmes for adults with chronic conditions: A meta-review. Int J Qual Health Care. 2014;26(5):561-570.

9. Snaterse M, Dobber J, Jepma P, et al. Effective components of nurse-coordinated care to prevent recurrent coronary events: A systematic review and meta-analysis. Heart. 2016;102(1):50-56.

10. Lin JS, O'Connor EA, Evans CV, Senger CA, Rowland MG, Groom HC. Behavioral counseling to promote a healthy lifestyle for cardiovascular disease prevention in persons with cardiovascular risk factors: An updated systematic evidence review for the U.S. preventive services task force. In: Rockville (MD): ; 2014 . NBK241537 [bookaccession].

11. van Lieshout J, Huntink E, Koetsenruijter J, Wensing M. Tailored implementation of cardiovascular risk management in general practice: A cluster randomized trial. Implement Sci. 2016;11:115-0.

12. Alageel S, Gulliford MC, McDermott L, Wright AJ. Multiple health behaviour change interventions for primary prevention of cardiovascular disease in primary care: Systematic review and meta-analysis. BMJ Open. 2017;7(6):e015375-015375. 
13. Danaei G, Ding EL, Mozaffarian D, et al. The preventable causes of death in the united states: Comparative risk assessment of dietary, lifestyle, and metabolic risk factors. PLoS Med. 2009;6(4):e1000058.

14. Alvarez-Bueno C, Cavero-Redondo I, Martinez-Andres M, Arias-Palencia N, RamosBlanes R, Salcedo-Aguilar F. Effectiveness of multifactorial interventions in primary health care settings for primary prevention of cardiovascular disease: A systematic review of systematic reviews. Prev Med. 2015;76 Suppl:68.

15. Ebrahim S, Taylor F, Ward K, Beswick A, Burke M, Davey Smith G. Multiple risk factor interventions for primary prevention of coronary heart disease. Cochrane Database Syst Rev. 2011;(1):CD001561. doi(1):CD001561.

16. Clark CE, Smith LF, Taylor RS, Campbell JL. Nurse led interventions to improve control of blood pressure in people with hypertension: Systematic review and meta-analysis. BMJ. 2010;341:c3995.

17. Glynn LG, Murphy AW, Smith SM, Schroeder K, Fahey T. Interventions used to improve control of blood pressure in patients with hypertension. Cochrane Database Syst Rev. 2010;(3):CD005182. doi(3):CD005182.

18. Lewington S, Clarke R, Qizilbash N, Peto R, Collins R, Prospective Studies Collaboration. Age-specific relevance of usual blood pressure to vascular mortality: A meta-analysis of individual data for one million adults in 61 prospective studies. Lancet. 2002;360(9349):1903-1913.

19. Buckley BS, Byrne MC, Smith SM. Service organisation for the secondary prevention of ischaemic heart disease in primary care. Cochrane Database Syst Rev. 2010;(3):CD006772. doi(3):CD006772.

20. Fleming P, Godwin M. Lifestyle interventions in primary care: Systematic review of randomized controlled trials. Can Fam Physician. 2008;54(12):1706-1713.

21. Russell G, Lane R, Parker S, et al. Preventive evidence into practice: What factors matter in a facilitation intervention to prevent vascular disease in family practice? BMC Fam Pract. 2019;20(1):113-7.

22. Lau R, Stevenson F, Ong BN, et al. Achieving change in primary care--causes of the evidence to practice gap: Systematic reviews of reviews. Implement Sci. 2016;11:40-4.

23. Volker N, Williams LT, Davey RC, Cochrane T, Clancy T. Implementation of cardiovascular disease prevention in primary health care: Enhancing understanding using normalisation process theory. BMC Fam Pract. 2017;18(1):28-x.

24. Valentijn PP, Ruwaard D, Vrijhoef HJ, de Bont A, Arends RY, Bruijnzeels MA. Collaboration processes and perceived effectiveness of integrated care projects in primary care: A longitudinal mixed-methods study. BMC Health Serv Res. 2015;15:4634. 
25. Cramm JM, Nieboer AP. In the netherlands, rich interaction among professionals conducting disease management led to better chronic care. Health Aff (Millwood). 2012;31(11):2493-2500.

26. Provost $\mathrm{S}$, Pineault $\mathrm{R}$, Grimard D, et al. Implementation of an integrated primary care cardiometabolic risk prevention and management network in montreal: Does greater coordination of care with primary care physicians have an impact on health outcomes? Health Promot Chronic Dis Prev Can. 2017;37(4):105-113.

27. Uchmanowicz I, Hoes A, Perk J, et al. Optimising implementation of european guidelines on cardiovascular disease prevention in clinical practice: What is needed? Eur J Prev Cardiol. 2020:2047487320926776.

28. Heery S, Gibson I, Dunne D, Flaherty G. The role of public health nurses in risk factor modification within a high-risk cardiovascular disease population in ireland - a qualitative analysis. Eur J Cardiovasc Nurs. 2019;18(7):584-592.

29. Jansen J, McKinn S, Bonner C, et al. General practitioners' decision making about primary prevention of cardiovascular disease in older adults: A qualitative study. PLoS One. 2017;12(1):e0170228.

30. Campbell NC, Murchie P. Treating hypertension with guidelines in general practice. BMJ. 2004;329(7465):523-524.

31. Parker DR, Gramling R, Goldman RE, et al. Physicians' perceptions of barriers and facilitators regarding adoption of the national cholesterol education program guidelines. Prev Cardiol. 2008;11(1):29-35.

32. Byrne D, O'Connor L, Jennings S, Bennett K, Murphy AW. A survey of GPs awareness and use of risk assessment tools and cardiovascular disease prevention guidelines. Ir Med J. 2015;108(7):204-207.

33. Hobbs FD, Erhardt L. Acceptance of guideline recommendations and perceived implementation of coronary heart disease prevention among primary care physicians in five european countries: The reassessing european attitudes about cardiovascular treatment (REACT) survey. Fam Pract. 2002;19(6):596-604.

34. Piepoli MF, Hoes AW, Agewall S, et al. 2016 european guidelines on cardiovascular disease prevention in clinical practice: The sixth joint task force of the european society of cardiology and other societies on cardiovascular disease prevention in clinical practice (constituted by representatives of 10 societies and by invited experts): Developed with the special contribution of the european association for cardiovascular prevention \& rehabilitation (EACPR). Eur HeartJ. 2016.

35. Dallongeville J, Banegas JR, Tubach F, et al. Survey of physicians' practices in the control of cardiovascular risk factors: The EURIKA study. Eur J Prev Cardiol. 2012;19(3):541-550. 
36. Huntink E, Wensing M, Klomp MA, van Lieshout J. Perceived determinants of cardiovascular risk management in primary care: Disconnections between patient behaviours, practice organisation and healthcare system. BMC Fam Pract. 2015;16:179-y.

37. Huntink E, Wensing M, Timmers IM, van Lieshout J. Process evaluation of a tailored intervention programme of cardiovascular risk management in general practices. Implement Sci. 2016;11(1):164-z.

38. Pajak A, Wolfshaut-Wolak R, Dorynska A, et al. Longitudinal effects of a nursemanaged comprehensive cardiovascular disease prevention programme for hospitalized coronary heart disease patients and primary care high-risk patients. Kardiol Pol. 2020.

39. Jorgensen T, Jacobsen RK, Toft U, Aadahl M, Glumer C, Pisinger C. Effect of screening and lifestyle counselling on incidence of ischaemic heart disease in general population: Inter99 randomised trial. BMJ. 2014;348:g3617.

40. Murphy AW, Cupples ME, Murphy E, et al. Six-year follow-up of the SPHERE RCT: Secondary prevention of heart disease in general practice. BMJ Open. 2015;5(11):e007807-007807.

41. Saha S, Carlsson KS, Gerdtham UG, et al. Are lifestyle interventions in primary care cost-effective?--an analysis based on a markov model, differences-in-differences approach and the swedish bjorknas study. PLoS One. 2013;8(11):e80672.

42. Lingfors H, Persson LG, Lindstrom K, Ljungquist B, Bengtsson C. Time for a "vision zero" concerning premature death from ischaemic heart disease? Scand J Prim Health Care. 2002;20(1):28-32.

43. Blomstedt Y, Norberg M, Stenlund H, et al. Impact of a combined community and primary care prevention strategy on all-cause and cardiovascular mortality: A cohort analysis based on 1 million person-years of follow-up in vasterbotten county, sweden, during 1990-2006. BMJ Open. 2015;5(12):e009651-009651.

44. Journath G, Hammar N, Vikstrom M, et al. A swedish primary healthcare prevention programme focusing on promotion of physical activity and a healthy lifestyle reduced cardiovascular events and mortality: 22-year follow-up of 5761 study participants and a reference group. Br J Sports Med. 2020.

45. van Weel C, Bakx C, van den Hoogen $H$, Thien T, van den Bosch W. Long-term outcome of cardiovascular prevention: A nijmegen academic family practices network study. J Am Board Fam Med. 2006;19(1):62-68.

46. Hamar GB, Rula EY, Coberley C, Pope JE, Larkin S. Long-term impact of a chronic disease management program on hospital utilization and cost in an australian population with heart disease or diabetes. BMC Health Serv Res. 2015;15:174-z. 
47. Willems N, Romeijnders ACM, Smits G. Verminderen van praktijkvariatie in de eerste lijn. 2017;11:580-583.

48. Maddox TM, Albert NM, Borden WB, et al. The learning healthcare system and cardiovascular care: A scientific statement from the american heart association. Circulation. 2017;135(14):e826-e857.

49. Stol DM. Cost-effectiveness of selective cardiometabolic disease prevention in primary care. Utrecht University, the Netherlands; 2020.

50. Dutch College of General Practitioners Guideline Development Group. Guideline cardiovascular risk management (third revision). Huisarts Wet. 2019:62: 55-7.

51. Mohnen S, Feenstra T, Wendel-Vos W, De Wit A. Gecombineerde leefstijlinterventie 2020: Ontwikkeling in volle gang. Rijksinstituut voor Volksgezondheid en Milieu. 2020.

52. Wienbergen H, Fach A, Meyer S, et al. Effects of an intensive long-term prevention programme after myocardial infarction - a randomized trial. Eur J Prev Cardiol. 2019;26(5):522-530.

53. Davy C, Bleasel J, Liu H, Tchan M, Ponniah S, Brown A. Factors influencing the implementation of chronic care models: A systematic literature review. BMC Fam Pract. 2015;16:102-5.

54. Hamer M, Kivimaki M, Gale CR, Batty GD. Lifestyle risk factors, inflammatory mechanisms, and COVID-19 hospitalization: A community-based cohort study of 387,109 adults in UK. Brain Behav Immun. 2020;87:184-187.

55. Ammar A, Brach M, Trabelsi K, et al. Effects of COVID-19 home confinement on eating behaviour and physical activity: Results of the ECLB-COVID19 international online survey. Nutrients. 2020;12(6):10.3390/nu12061583.

56. McKeigue PM, Weir A, Bishop J, et al. Rapid epidemiological analysis of comorbidities and treatments as risk factors for COVID-19 in scotland (REACT-SCOT): A populationbased case-control study. PLoS Med. 2020;17(10):e1003374.

57. Anderson MR, Geleris J, Anderson DR, et al. Body mass index and risk for intubation or death in SARS-CoV-2 infection : A retrospective cohort study. Ann Intern Med. 2020;173(10):782-790.

58. Lonnberg L, Damberg M, Revenas A. "It's up to me": The experience of patients at high risk of cardiovascular disease of lifestyle change. Scand J Prim Health Care. 2020:1-12. 
Supplementary table 1. Evidence on the effect of multifactorial interventions to prevent cardiovascular disease in primary care

\begin{tabular}{|c|c|c|c|c|c|}
\hline $\begin{array}{l}\text { First author } \\
\text { (year of } \\
\text { publication) }\end{array}$ & Design & $\begin{array}{l}\text { Target } \\
\text { population }\end{array}$ & Intervention & $\begin{array}{l}\text { Mode of intervention } \\
\text { delivery }\end{array}$ & $\begin{array}{l}\text { Density of the } \\
\text { intervention }\end{array}$ \\
\hline $\begin{array}{l}\text { Álvarez-Bueno } \\
(2014)\end{array}$ & $\begin{array}{l}\text { Systematic } \\
\text { review of } \\
8 \text { reviews } \\
\text { including } 219 \\
\text { studies (mainly } \\
\text { RCTs) }\end{array}$ & $\begin{array}{l}\text { CVD-free adults, } \\
\text { aged } 18-75 \\
\text { years }\end{array}$ & $\begin{array}{l}\text { Multifactorial } \\
\text { interventions, targeting } \\
\geq 1 \mathrm{CV} \text { risk factor, } \\
\text { and implementing } \geq 1 \\
\text { type of intervention } \\
\text { (education, behavioural } \\
\text { strategies, psychological } \\
\text { interventions) and may } \\
\text { be combined with drug } \\
\text { therapy }\end{array}$ & $\begin{array}{l}\text { Individual sessions; } \\
\text { Group sessions; } \\
\text { Use of written or audio- } \\
\text { visual educational } \\
\text { materials; } \\
\text { Follow-up e-mail and } \\
\text { telephone contact; } \\
\text { Use of mass media }\end{array}$ & NA \\
\hline Alageel (2017) & $\begin{array}{l}\text { Systematic } \\
\text { review of } 31 \\
\text { RCTs }\end{array}$ & $\begin{array}{l}\text { CVD-free adults, } \\
\text { aged }>18 \text { years } \\
\text { old }\end{array}$ & $\begin{array}{l}\text { Multiple health behaviour } \\
\text { change (MHBC) } \\
\text { interventions, aimed at } \\
\text { reducing CVD risk by } \\
\text { intervening on two or } \\
\text { more risk behaviours } \\
\text { (physical activity, diet, } \\
\text { alcohol consumption, use } \\
\text { of stress management and } \\
\text { smoking). Comparators } \\
\text { were usual care or less } \\
\text { intensive interventions. }\end{array}$ & $\begin{array}{l}\text { Individual sessions; } \\
\text { Group sessions; } \\
\text { Telephone sessions; } \\
\text { Written materials } \\
\\
\end{array}$ & $\begin{array}{l}\text { Number of } \\
\text { sessions: } \\
3 \text { - } 56 \\
\text { (median 6) } \\
\text { Time: } 45 \text { min } \\
\text { to } 2.5 \text { hours } \\
\text { (median=300 } \\
\text { min) }\end{array}$ \\
\hline Clark (2010) & $\begin{array}{l}\text { Systematic } \\
\text { review of } 14 \\
\text { RCTs }\end{array}$ & $\begin{array}{l}\text { Adults aged > } \\
18 \text { years with } \\
\text { hypertension } \\
\text { with or without } \\
\text { antihyperten- } \\
\text { sive drugs }\end{array}$ & $\begin{array}{l}\text { Nurse led interventions } \\
\text { designed to improve } \\
\text { blood pressure }\end{array}$ & Face to face visits & NA \\
\hline
\end{tabular}




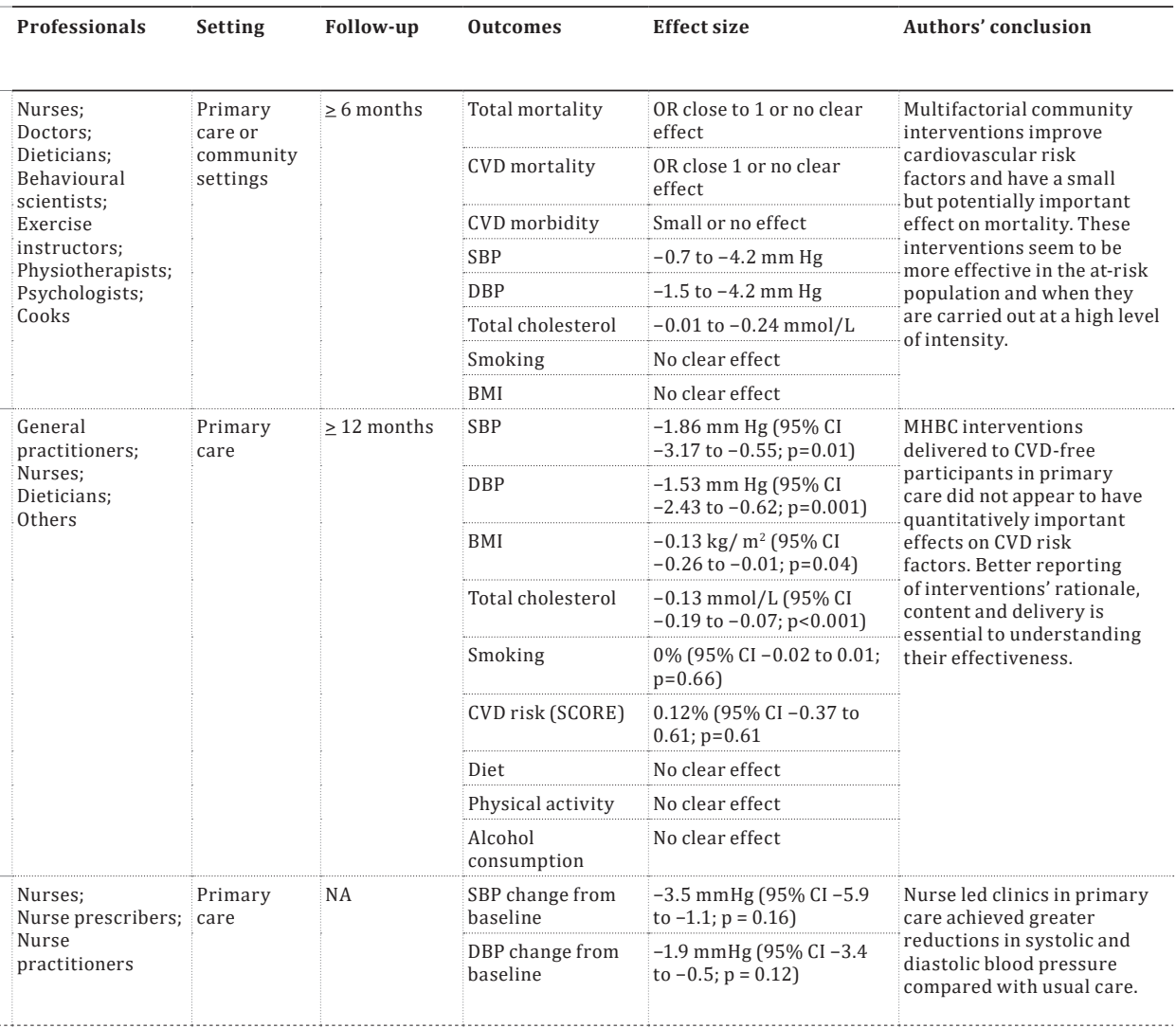


Supplementary table 1. (Continued)

\begin{tabular}{|c|c|c|c|c|c|}
\hline $\begin{array}{l}\text { First author } \\
\text { (year of } \\
\text { publication) }\end{array}$ & Design & $\begin{array}{l}\text { Target } \\
\text { population }\end{array}$ & Intervention & $\begin{array}{l}\text { Mode of intervention } \\
\text { delivery }\end{array}$ & $\begin{array}{l}\text { Density of the } \\
\text { intervention }\end{array}$ \\
\hline \multirow[t]{7}{*}{ Glynn (2010) } & \multirow[t]{7}{*}{$\begin{array}{l}\text { Cochrane } \\
\text { review of } 72 \\
\text { RCTS }\end{array}$} & \multirow[t]{7}{*}{$\begin{array}{l}\text { Patients with } \\
\text { hypertension }\end{array}$} & $\begin{array}{l}\text { Interventions aimed to } \\
\text { improve the control of } \\
\text { high blood pressure: }\end{array}$ & \multirow[t]{7}{*}{ NA } & \multirow[t]{7}{*}{ NA } \\
\hline & & & (1) self-monitoring & & \\
\hline & & & $\begin{array}{l}\text { (2) educational } \\
\text { interventions directed to } \\
\text { the patient }\end{array}$ & & \\
\hline & & & $\begin{array}{l}\text { (3) educational } \\
\text { interventions directed to } \\
\text { the health professional }\end{array}$ & & \\
\hline & & & $\begin{array}{l}\text { (4) health professional } \\
\text { (nurse or pharmacist) } \\
\text { led care }\end{array}$ & & \\
\hline & & & $\begin{array}{l}\text { (5) organisational } \\
\text { interventions that aimed } \\
\text { to improve the delivery } \\
\text { of care }\end{array}$ & & \\
\hline & & & $\begin{array}{l}\text { (6) appointment } \\
\text { reminder systems }\end{array}$ & & \\
\hline Ebrahim (2011) & $\begin{array}{l}\text { Cochrane } \\
\text { review of } 55 \\
\text { RCTs }\end{array}$ & $\begin{array}{l}\text { CVD-free adults } \\
\text { with or without a } \\
\text { high risk of CVD }\end{array}$ & $\begin{array}{l}\text { A health promotion } \\
\text { activity to achieve } \\
\text { behaviour change; more } \\
\text { specifically counselling } \\
\text { or educational } \\
\text { interventions, with or } \\
\text { without pharmacological } \\
\text { treatments, which aim } \\
\text { to alter more than one } \\
\text { cardiovascular risk } \\
\text { factor (i.e. diet, reduce } \\
\text { blood pressure, smoking, } \\
\text { total blood cholesterol } \\
\text { or increase physical } \\
\text { activity). }\end{array}$ & $\begin{array}{l}\text { Workshops; Lectures; } \\
\text { Individual sessions; } \\
\text { Personal counselling; } \\
\text { Provision of written } \\
\text { material; Assignments; } \\
\text { Shopping tours and } \\
\text { cooking sessions }\end{array}$ & $\begin{array}{l}4 \text { to } 54 \\
\text { sessions over } \\
\text { periods of } \\
\text { two weeks to } \\
\text { three years }\end{array}$ \\
\hline
\end{tabular}


Supplementary table 1. (Continued)

\begin{tabular}{|c|c|c|c|c|c|}
\hline $\begin{array}{l}\text { First author } \\
\text { (year of } \\
\text { publication) }\end{array}$ & Design & $\begin{array}{l}\text { Target } \\
\text { population }\end{array}$ & Intervention & $\begin{array}{l}\text { Mode of intervention } \\
\text { delivery }\end{array}$ & $\begin{array}{l}\text { Density of the } \\
\text { intervention }\end{array}$ \\
\hline Lin (2014) & $\begin{array}{l}\text { Systematic } \\
\text { review of } 74 \\
\text { controlled trials }\end{array}$ & $\begin{array}{l}\text { CVD-free adults } \\
\text { with known CV } \\
\text { risk factors (e.g., } \\
\text { hypertension, } \\
\text { dyslipidaemia, } \\
\text { impaired } \\
\text { fasting glucose } \\
\text { or glucose } \\
\text { tolerance, } \\
\text { metabolic } \\
\text { syndrome) }\end{array}$ & $\begin{array}{l}\text { Behaviourally-based } \\
\text { counselling interventions } \\
\text { to improve diet and } \\
\text { physical activity - } \\
\text { alone or as part of } \\
\text { a multicomponent } \\
\text { intervention. }\end{array}$ & $\begin{array}{l}\text { Face-to-face sessions, } \\
\text { either in individual or } \\
\text { group sessions; } \\
\text { Telephone and mail } \\
\text { contacts }\end{array}$ & $\begin{array}{l}\text { Medium- } \\
\text { intensity: } \\
\text { median of } \\
5 \text { contacts, } \\
\text { median } \\
\text { duration of } 9 \\
\text { months } \\
\text { High- } \\
\text { intensity: } \\
\text { median of } \\
16 \text { contacts, } \\
\text { median } \\
\text { duration of } 12 \\
\text { months }\end{array}$ \\
\hline Buckley (2010) & $\begin{array}{l}\text { Cochrane } \\
\text { review of } 11 \\
\text { RCTs }\end{array}$ & $\begin{array}{l}\text { Patients with } \\
\text { established IHD }\end{array}$ & $\begin{array}{l}\text { Service organisation } \\
\text { interventions whose main } \\
\text { elements are specific } \\
\text { planned changes in } \\
\text { existing care provision } \\
\text { in primary care and } \\
\text { community settings } \\
\text { and which are aimed at } \\
\text { improved patient and } \\
\text { clinician adherence with } \\
\text { recommendations on } \\
\text { secondary prevention } \\
\text { of IHD. }\end{array}$ & $\begin{array}{l}\text { Individual consultations; } \\
\text { Leaflets posted to } \\
\text { patients; } \\
\text { Reminders/ distribution } \\
\text { of guidelines to GP; } \\
\text { Learning seminars/ } \\
\text { training for staff; } \\
\text { Feedback to GPs }\end{array}$ & NA \\
\hline
\end{tabular}




\begin{tabular}{|c|c|c|c|c|c|}
\hline Professionals & Setting & Follow-up & Outcomes & Effect size & Authors' conclusion \\
\hline \multirow{12}{*}{$\begin{array}{l}\text { Dieticians; } \\
\text { Physiotherapists } \\
\text { or exercise } \\
\text { professionals; } \\
\text { Trained } \\
\text { interventionists } \\
\text { (e.g., health } \\
\text { educators, } \\
\text { psychologists, } \\
\text { nurses, case } \\
\text { managers, life } \\
\text { coaches) }\end{array}$} & \multirow{12}{*}{$\begin{array}{l}\text { Primary } \\
\text { care }\end{array}$} & \multirow[t]{12}{*}{$\geq 6$ months } & CVD events & No effect & \multirow{12}{*}{$\begin{array}{l}\text { Medium- and high-intensity } \\
\text { diet and physical activity } \\
\text { behavioural counselling } \\
\text { in overweight or obese } \\
\text { persons with CVD risk } \\
\text { factors resulted in consistent } \\
\text { improvements across } \\
\text { a variety of important } \\
\text { cardiovascular intermediate } \\
\text { health outcomes up to } \\
2 \text { years. High-intensity } \\
\text { combined lifestyle } \\
\text { counselling reduced diabetes } \\
\text { incidence in the longer term. } \\
\text { The applicability of these } \\
\text { findings depends largely on } \\
\text { the availability of intensive } \\
\text { counselling in practice } \\
\text { and real-world fidelity } \\
\text { and adherence to these } \\
\text { interventions. }\end{array}$} \\
\hline & & & Mortality & No effect & \\
\hline & & & QoL & Increased or no effect & \\
\hline & & & Depression & No effect & \\
\hline & & & Total cholesterol & $\begin{array}{l}-0.12 \mathrm{mmol} / \mathrm{L}(95 \% \mathrm{CI} \\
-0.16 \text { to } \\
-0.07)\end{array}$ & \\
\hline & & & LDL-cholesterol & $\begin{array}{l}-0.09 \mathrm{mmol} / \mathrm{L}(95 \% \mathrm{CI} \\
-0.14 \text { to }-0.04)\end{array}$ & \\
\hline & & & SBP & $\begin{array}{l}-2.03 \mathrm{mmHg}(95 \% \mathrm{CI}-2.91 \\
\text { to }-1.15)\end{array}$ & \\
\hline & & & DBP & $\begin{array}{l}-1.38 \mathrm{~mm} H \mathrm{~g}(95 \% \mathrm{CI}-1.92 \\
\text { to }-0.84)\end{array}$ & \\
\hline & & & Fasting glucose & $\begin{array}{l}-0.05 \mathrm{mmol} / \mathrm{L}(95 \% \mathrm{CI} \\
-0.09 \text { to }-0.02)\end{array}$ & \\
\hline & & & Diabetes incidence & $\begin{array}{l}\text { RR of } 0.58(95 \% \mathrm{CI}, 0.37 \\
\text { to } 0.89)\end{array}$ & \\
\hline & & & Physical activity & Increased & \\
\hline & & & Dietary habits & Improved & \\
\hline \multirow{11}{*}{$\begin{array}{l}\text { Primary care } \\
\text { clinicians; } \\
\text { Nurses; } \\
\text { Dieticians; } \\
\text { Occupational } \\
\text { therapists; } \\
\text { Physiotherapists; }\end{array}$} & \multirow{11}{*}{$\begin{array}{l}\text { Primary } \\
\text { care or } \\
\text { community } \\
\text { setting }\end{array}$} & \multirow[t]{11}{*}{$\geq 12$ months } & BP control & $\begin{array}{l}\text { OR } 1.50 \text { (95\% CI } 0.96 \text { to } \\
2.35)\end{array}$ & \multirow{11}{*}{$\begin{array}{l}\text { There is weak evidence that } \\
\text { regular planned recall of } \\
\text { patients for appointments, } \\
\text { structured monitoring of } \\
\text { risk factors and prescribing, } \\
\text { and education for patients } \\
\text { can be effective in increasing } \\
\text { the proportions of patients } \\
\text { within target levels for } \\
\text { cholesterol control and blood } \\
\text { pressure. Further research } \\
\text { in this area would benefit } \\
\text { from greater standardisation } \\
\text { of the outcomes measured. }\end{array}$} \\
\hline & & & SBP & $\begin{array}{l}1.55 \mathrm{mmHg}(95 \% \mathrm{CI}-0.35 \\
\text { to } 3.46)\end{array}$ & \\
\hline & & & DBP & $\begin{array}{l}0.70 \mathrm{mmHg}(95 \% \mathrm{CI}-0.35 \\
\text { to } 1.76)\end{array}$ & \\
\hline & & & $\begin{array}{l}\text { Total cholesterol } \\
\text { control }\end{array}$ & $\begin{array}{l}\text { OR } 1.37 \text { (95\% CI } 0.63 \text { to } \\
3.01 \text { ) }\end{array}$ & \\
\hline & & & Total cholesterol & $\begin{array}{l}0.06 \mathrm{mmol} / \mathrm{L}(95 \% \mathrm{CI}-0.05 \\
\text { to } 0.17)\end{array}$ & \\
\hline & & & $\begin{array}{l}\text { Prescribed lipid } \\
\text { lowering drugs }\end{array}$ & $\begin{array}{l}\text { OR } 0.97(95 \% \text { CI } 0.79 \text { to } \\
1.19)\end{array}$ & \\
\hline & & & $\begin{array}{l}\text { Prescribed } \\
B \text {-blockers }\end{array}$ & $\begin{array}{l}\text { OR } 0.86 \text { (95\% CI } 0.67 \text { to } \\
1.10)\end{array}$ & \\
\hline & & & Prescribed ACE-i & $\begin{array}{l}\text { OR } 0.86(95 \% \text { CI } 0.63 \text { to } \\
1.18)\end{array}$ & \\
\hline & & & $\begin{array}{l}\text { Prescribed } \\
\text { antiplatelets }\end{array}$ & $\begin{array}{l}\text { OR } 1.16 \text { (95\% CI } 0.86 \text { to } \\
1.57)\end{array}$ & \\
\hline & & & $\begin{array}{l}\text { Exercise at target } \\
\text { level }\end{array}$ & $\begin{array}{l}\text { OR } 1.11 \text { (95\% CI } 0.95 \text { to } \\
1.29)\end{array}$ & \\
\hline & & & Smoking cessation & $\begin{array}{l}\text { OR } 1.06(95 \% \text { CI } 0.89 \text { to } \\
1.25 \text { ) }\end{array}$ & \\
\hline
\end{tabular}


Supplementary table 1. (Continued)

\begin{tabular}{|c|c|c|c|c|c|}
\hline $\begin{array}{l}\text { First author } \\
\text { (year of } \\
\text { publication) }\end{array}$ & Design & $\begin{array}{l}\text { Target } \\
\text { population }\end{array}$ & Intervention & $\begin{array}{l}\text { Mode of intervention } \\
\text { delivery }\end{array}$ & $\begin{array}{l}\text { Density of the } \\
\text { intervention }\end{array}$ \\
\hline Cole (2010) & $\begin{array}{l}\text { Systematic } \\
\text { review of } 21 \\
\text { RCTs }\end{array}$ & $\begin{array}{l}\text { Adults aged }> \\
18 \text { years with a } \\
\text { diagnosis of CHD }\end{array}$ & $\begin{array}{l}\text { Interventions with a } \\
\text { lifestyle and/or } \\
\text { behaviour change focus, } \\
\text { incorporating one or a } \\
\text { combination of exercise } \\
\text { and diet. Interventions } \\
\text { may be categorized as } \\
\text { follows: } \\
\text { (1) Dietary. } \\
\text { (2) Exercise. } \\
\text { (3) Psychological. } \\
\text { (4) Educational. } \\
\text { (5) Multifactorial. } \\
\text { (6) Organisational. }\end{array}$ & $\begin{array}{l}\text { Individual sessions; } \\
\text { Group sessions; } \\
\text { Follow-up by telephone } \\
\text { or e-mail; } \\
\text { Educational material }\end{array}$ & $\begin{array}{l}\text { Varying from } \\
\text { intensive } \\
\text { (for example } \\
16 \text { lectures } \\
+8 \text { group } \\
\text { meetings + } \\
6 \text { exercise } \\
\text { sessions + } 3 \\
\text { social events } \\
\text { within } 16 \\
\text { months) to } \\
\text { less intensive } \\
\text { ( } 3 \text { education } \\
\text { sessions in } 1 \\
\text { year) }\end{array}$ \\
\hline Murphy (2015) & $\begin{array}{l}\text { Systematic } \\
\text { review of } 5 \text { RCTs }\end{array}$ & $\begin{array}{l}\text { Patients with } \\
\text { established IHD }\end{array}$ & $\begin{array}{l}\text { Interventions targeted } \\
\text { at organizational change, } \\
\text { aimed at improved } \\
\text { clinician and patient } \\
\text { adherence with } \\
\text { recommendations on } \\
\text { secondary prevention } \\
\text { of IHD. }\end{array}$ & $\begin{array}{l}\text { Individual consultations; } \\
\text { Patient education; } \\
\text { Clinician education }\end{array}$ & $\begin{array}{l}\text { Length of } \\
\text { intervention: } \\
1-3 \text { years }\end{array}$ \\
\hline Snaterse (2016) & $\begin{array}{l}\text { Systematic } \\
\text { review of } 18 \\
\text { RCTs }\end{array}$ & $\begin{array}{l}\text { Patients with } \\
\text { CHD }\end{array}$ & $\begin{array}{l}\text { Nurse-coordinated care } \\
\text { (NCC) including : (1) } \\
\text { risk factor management } \\
\text { (for example, lifestyle } \\
\text { counselling, blood } \\
\text { pressure and } \\
\text { lipid control), (2) } \\
\text { multidisciplinary } \\
\text { consultation (for } \\
\text { example, consultation } \\
\text { and referral) and/ or (3) } \\
\text { shared decision making } \\
\text { (for example, goal setting } \\
\text { and family support) }\end{array}$ & $\begin{array}{l}\text { Visits; } \\
\text { Home visits; } \\
\text { Telephone follow-up }\end{array}$ & $\begin{array}{l}\text { High: }>4 \text { visits } \\
\text { plus more } \\
\text { than one NCC } \\
\text { strategy used. } \\
\text { Intermediate: } \\
3-4 \text { visits. } \\
\text { Low: } 1-2 \\
\text { visits. }\end{array}$ \\
\hline
\end{tabular}




\begin{tabular}{|c|c|c|c|c|c|}
\hline Professionals & Setting & Follow-up & Outcomes & Effect size & Authors' conclusion \\
\hline \multirow{12}{*}{$\begin{array}{l}\text { General } \\
\text { practitioners; } \\
\text { Practice nurses; } \\
\text { Community } \\
\text { Pharmacists; } \\
\text { Community and } \\
\text { public health } \\
\text { nurses; } \\
\text { Dieticians; } \\
\text { Occupational } \\
\text { therapists; } \\
\text { Physiotherapists; } \\
\text { Psychologists; } \\
\text { Social workers }\end{array}$} & \multirow{12}{*}{$\begin{array}{l}\text { Primary } \\
\text { care or } \\
\text { community } \\
\text { settings }\end{array}$} & \multirow[t]{12}{*}{$\geq 3$ months } & All-cause mortality & $\begin{array}{l}\text { RR } 0.75 \text { (95\% CI } 0.65 \text { to } \\
0.87)\end{array}$ & \multirow{12}{*}{$\begin{array}{l}\text { The review indicates } \\
\text { that lifestyle interventions } \\
\text { have mixed effects with some } \\
\text { benefits in relation to total } \\
\text { mortality, CV mortality, and } \\
\text { nonfatal CV events as well as } \\
\text { PA, diet, blood pressure, } \\
\text { cholesterol, QOL, and } \\
\text { medication adherence. The } \\
\text { heterogeneity between trials } \\
\text { and generally poor quality } \\
\text { of trials make any concrete } \\
\text { conclusions difficult. } \\
\text { However, the beneficial } \\
\text { effects observed in this } \\
\text { review are encouraging and } \\
\text { should stimulate further } \\
\text { research. }\end{array}$} \\
\hline & & & CV mortality & $\begin{array}{l}\text { RR } 0.63 \text { (95\% CI } 0.47 \text { to } \\
0.84)\end{array}$ & \\
\hline & & & $\begin{array}{l}\text { Nonfatal cardiac } \\
\text { events }\end{array}$ & RR $0.68(0.55,0.84)$ & \\
\hline & & & $\begin{array}{l}\text { Hospital } \\
\text { admissions }\end{array}$ & $\begin{array}{l}\text { Trend to reduction, not } \\
\text { significant }\end{array}$ & \\
\hline & & & Diet & No clear effect & \\
\hline & & & Physical activity & No clear effect & \\
\hline & & & Smoking & No effect & \\
\hline & & & BP & No effect & \\
\hline & & & Total cholesterol & No clear effect & \\
\hline & & & LDL-cholesterol & Significant effect & \\
\hline & & & QoL & No effect & \\
\hline & & & Medication & No clear effect & \\
\hline \multirow[t]{10}{*}{ NA } & \multirow{10}{*}{$\begin{array}{l}\text { Primary or } \\
\text { community } \\
\text { care settings }\end{array}$} & \multirow{10}{*}{$\geq 24$ months } & All-cause mortality & $\begin{array}{l}\text { RR } 0.79 \text { (95\% CI } 0.66 \text { to } \\
0.93)\end{array}$ & \multirow{10}{*}{$\begin{array}{l}\text { Cardiac secondary } \\
\text { prevention programmes } \\
\text { targeting organisational } \\
\text { change are associated } \\
\text { with a reduced risk of death } \\
\text { for at least } \\
4-6 \text { years. There is } \\
\text { insufficient evidence to } \\
\text { conclude whether this } \\
\text { beneficial effect is } \\
\text { maintained indefinitely }\end{array}$} \\
\hline & & & $\begin{array}{l}\text { Cardiac-related } \\
\text { mortality }\end{array}$ & $\begin{array}{l}\text { RR } 0.74(95 \% \mathrm{CI}=0.58 \\
\text { to } 0.94)\end{array}$ & \\
\hline & & & $\begin{array}{l}\text { Hospital } \\
\text { admissions }\end{array}$ & No effect & \\
\hline & & & BP control & $\begin{array}{l}\text { RR } 0.95 \text { ( } 95 \% \\
\text { CI } 0.83 \text { to } 1.09 \text { ) }\end{array}$ & \\
\hline & & & $\begin{array}{l}\text { Total cholesterol } \\
\text { control }\end{array}$ & $\begin{array}{l}\text { RR } 0.98 \text { (95\% CI } 0.89 \text { to } \\
1.07)\end{array}$ & \\
\hline & & & SBP & $1.94 \mathrm{mmHg}(-3.02$ to 6.91$)$ & \\
\hline & & & Total cholesterol & $0.03 \mathrm{mmHg}(-0.12$ to 0.18$)$ & \\
\hline & & & Smoking & No effect & \\
\hline & & & Aspirin prescribed & $\begin{array}{l}\text { RR } 1.06 \text { (95\% CI } 1.00 \text { to } \\
1.12)\end{array}$ & \\
\hline & & & Statins prescribed & $\begin{array}{l}\text { RR } 1.09 \text { (95\% CI } 0.77 \text { to } \\
1.53)\end{array}$ & \\
\hline \multirow{6}{*}{$\begin{array}{l}\text { Nurses; } \\
\text { General } \\
\text { practitioners; } \\
\text { Cardiologists; } \\
\text { Dieticians; } \\
\text { Physiotherapists }\end{array}$} & \multirow{6}{*}{$\begin{array}{l}\text { Primary } \\
\text { care and } \\
\text { hospital }\end{array}$} & \multirow[t]{6}{*}{ 3-24 months } & SBP & $\begin{array}{l}-2.96 \mathrm{~mm} \mathrm{Hg}(95 \% \mathrm{CI}- \\
4.40 \mathrm{~mm} \mathrm{Hg} \text { to }-1.53)\end{array}$ & \multirow{6}{*}{$\begin{array}{l}\text { NCC demonstrated to } \\
\text { have an effect on a small } \\
\text { number of outcomes. NCC } \\
\text { that incorporated blood } \\
\text { pressure monitoring, } \\
\text { cholesterol control and } \\
\text { smoking cessation has an } \\
\text { impact on the improvement } \\
\text { of secondary prevention. } \\
\text { Additionally, NCC is a } \\
\text { heterogeneous concept. A } \\
\text { shared definition of NCC may } \\
\text { facilitate better comparisons } \\
\text { of NCC content and outcomes. }\end{array}$} \\
\hline & & & LDL-cholesterol & $\begin{array}{l}-0.23 \mathrm{mmol} / \mathrm{L}(95 \% \mathrm{CI}- \\
0.36 \text { to } \\
-0.10)\end{array}$ & \\
\hline & & & $\begin{array}{l}\text { Smoking cessation } \\
\text { rates }\end{array}$ & $\begin{array}{l}\text { risk ratio } 1.25(95 \% \mathrm{CI} \\
1.08 \text { to } 1.43)\end{array}$ & \\
\hline & & & Weight & No effect & \\
\hline & & & Event free survival & No effect & \\
\hline & & & All-cause mortality & No effect & \\
\hline
\end{tabular}


Supplementary table 1. (Continued)

\begin{tabular}{|c|c|c|c|c|c|}
\hline $\begin{array}{l}\text { First author } \\
\text { (year of } \\
\text { publication) }\end{array}$ & Design & $\begin{array}{l}\text { Target } \\
\text { population }\end{array}$ & Intervention & $\begin{array}{l}\text { Mode of intervention } \\
\text { delivery }\end{array}$ & $\begin{array}{l}\text { Density of the } \\
\text { intervention }\end{array}$ \\
\hline $\begin{array}{l}\text { Van Lieshout } \\
\text { (2016) }\end{array}$ & Cluster RCT & $\begin{array}{l}\text { Adults aged }> \\
18 \text { years with } \\
\text { recorded CVD } \\
\text { or high CV risk } \\
\text { (estimated } 10- \\
\text { year risk score of } \\
20 \% \text { or higher } \\
\text { for morbidity and } \\
\text { mortality due to } \\
\text { CVD) }\end{array}$ & $\begin{array}{l}\text { A tailored } \\
\text { implementation program, } \\
\text { including communication } \\
\text { skills training to practice } \\
\text { nurses, online patient } \\
\text { information, and a } \\
\text { clinical protocol for } \\
\text { managing depressive } \\
\text { symptoms. }\end{array}$ & Visits & NA \\
\hline
\end{tabular}

BMI, body mass index. BP, blood pressure. CHD, coronary heart disease.

$\mathrm{CV}$, cardiovascular. CVD, cardiovascular disease. DBP, diastolic blood pressure.

GP, general practitioner. IHD, intracoronary heart disease. QoL, quality of life.

$\mathrm{RCT}$, randomized controlled trial. SBP, systolic blood pressure. 


\begin{tabular}{|c|c|c|c|c|c|}
\hline Professionals & Setting & Follow-up & Outcomes & Effect size & Authors' conclusion \\
\hline \multirow[t]{7}{*}{$\begin{array}{l}\text { Practice nurses; } \\
\text { General } \\
\text { practitioner }\end{array}$} & \multirow[t]{7}{*}{$\begin{array}{l}\text { Primary } \\
\text { care }\end{array}$} & \multirow[t]{7}{*}{6 months } & $\begin{array}{l}\text { Adequate } \\
\text { performance } \\
\text { practice nurse }\end{array}$ & No effect & \multirow{7}{*}{$\begin{array}{l}\text { The tailored improvement } \\
\text { program showed no effect on } \\
\text { the primary outcome. This } \\
\text { challenges the methodology } \\
\text { of tailoring. More } \\
\text { involvement of the targeted } \\
\text { health care professionals } \\
\text { might offer ways to } \\
\text { develop more effective } \\
\text { implementation programs. } \\
\text { Physical activity might be } \\
\text { the lifestyle issue that can } \\
\text { be more easily changed than } \\
\text { smoking or dietary habits. }\end{array}$} \\
\hline & & & $\mathrm{SBP}<140 \mathrm{mmHg}$ & $\begin{array}{l}\text { OR } 1.03(95 \% \text { CI } \\
0.72-1.48)\end{array}$ & \\
\hline & & & $\mathrm{LDL}<2.5 \mathrm{mmol} / \mathrm{L}$ & $\begin{array}{l}\text { OR } 0.85 \text { (95\% CI } \\
0.53-1.38)\end{array}$ & \\
\hline & & & $\mathrm{BMI}<25 \mathrm{~kg} / \mathrm{m}^{2}$ & $\begin{array}{l}\text { OR } 0.84(95 \% \text { CI } \\
0.48-1.46)\end{array}$ & \\
\hline & & & Smoking & $\begin{array}{l}\text { OR } 1.11(95 \% \text { CI } \\
0.68-1.82)\end{array}$ & \\
\hline & & & Physical exercise & $\begin{array}{l}B 0.18 \text { (95\%CI 0.02-0.35; } \\
\mathrm{p}<0.05 \text { ) }\end{array}$ & \\
\hline & & & Diet & $B 0.03(0.00-0.07)$ & \\
\hline
\end{tabular}




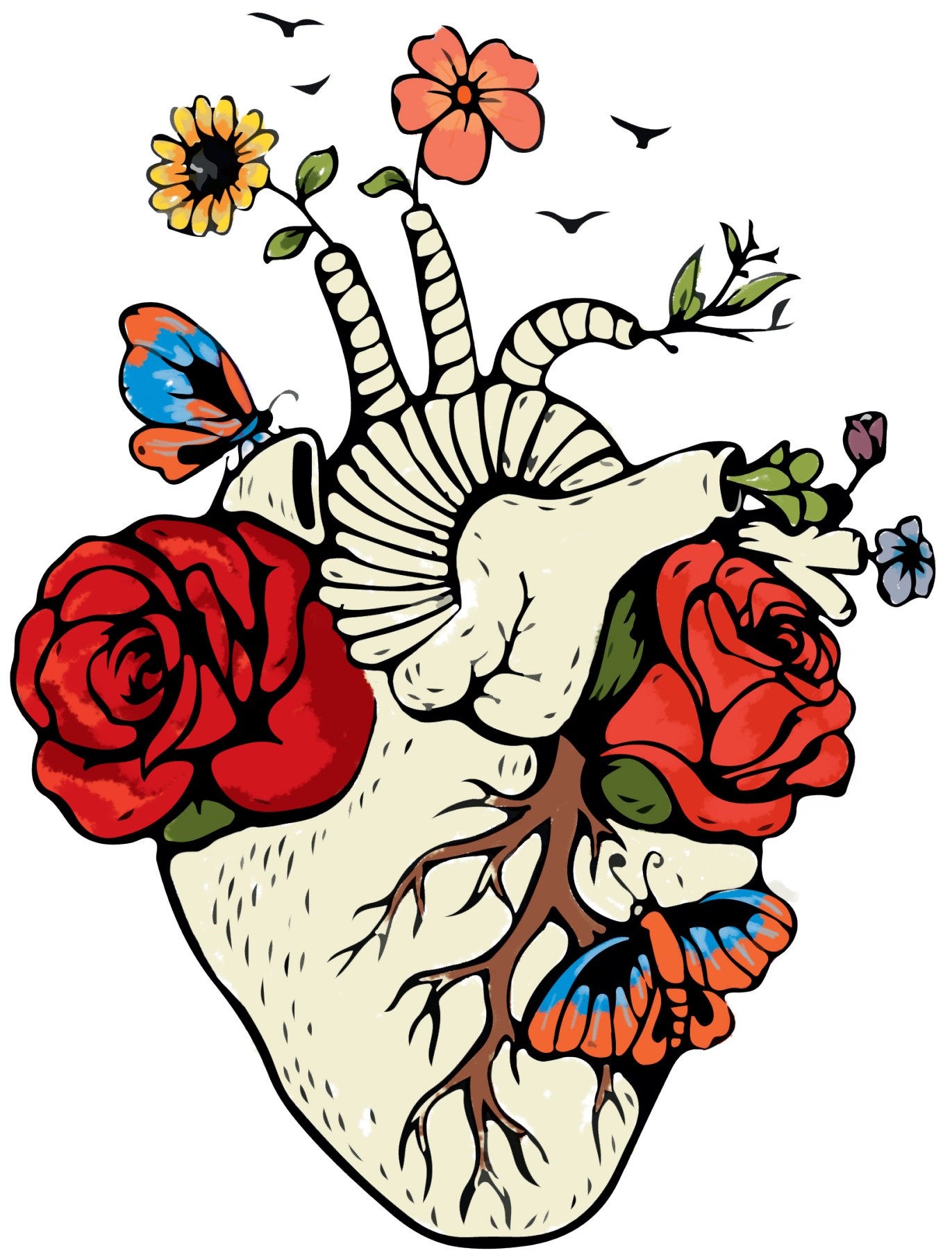


$\underline{\text { SUMMARY }}$ 
Cardiovascular disease (CVD) has remained the leading cause of death worldwide and also in Europe. ${ }^{1,2}$ There is concern about the prevalence of cardiovascular risk factors. In Europe, the prevalence of obesity has more than doubled in the last 36 years, 1 in 3 adults is insufficiently physically active and the downward trend in prevalence of elevated blood pressure appears to be minimal. ${ }^{1}$ The occurrence of CVD can be reduced by adequate treatment of cardiovascular risk factors, including high blood pressure, elevated blood lipids, smoking, physical inactivity, obesity and an unhealthy diet. However, primary care survey studies have shown that control rates of cardiovascular risk factors are disappointing. ${ }^{3,4}$ It underlines the need for effective multifactorial and multidisciplinary cardiovascular risk factor management (CVRM) interventions, as also recommended by the European guidelines on cardiovascular disease prevention. ${ }^{5}$ Integrated multidisciplinary CVRM programmes in primary care offer a potentially effective way to improve the implementation of CVD guideline recommendations and thereby the quality of CVD prevention. Most of these programmes are based on the chronic care model (CCM) and include systematic selection, invitation, cardiovascular risk assessment, shared decision in treatment and follow-up of eligible patients, stimulation of selfmanagement, registration of patient data in clinical information systems and yearly feedback to general practitioners (GPs) on delivered CVRM care. ${ }^{6}$ So far, studies on the effectiveness of CVRM programmes are scarce and the available evidence is inconsistent, partly due to the heterogeneity in study designs. ${ }^{7-11}$ Importantly, most evidence on integrated CVRM programmes is based on randomized controlled trials (RCTs), presenting the effect of the intervention when carefully implemented according to the existing guidelines under optimal conditions. ${ }^{12}$ However, RCTs oversimplify reality and the results are not automatically applicable in daily practice. Therefore, more real-world evidence is needed.

This thesis aims to provide insight in the effectiveness of an integrated and multidisciplinary programme for cardiovascular risk management (CVRM) in primary care in a real-world setting and to describe the challenges of the implementation of CVRM in daily practice.

In Chapter 2 of this thesis, we comment on the new European guideline on cardiovascular disease prevention. Key messages in the guideline include that CVD prevention asks for a personalized approach and that estimation of the CV risk and assessment of lifestyle factors should be repeated regularly. ${ }^{5}$ We stated 
that implementation of all recommendations in this new guideline would be challenging and requires more guidance for GPs as well as enough consultation time, ICT support, adequate reimbursement, a trained multidisciplinary team and support by concordant actions of surrounding organizations, insurance companies and government.

In the Netherlands an integrated programme for cardiovascular risk management (CVRM), based on the Chronic Care Model (CCM), has been introduced in primary care in many regions in recent years. In the ZWOT-CASE study (ZWOlle inTegrated care for CArdiovaScular risk managEment study), we investigated the effect of integrated care for CVRM compared to usual care within general practices in the region of Zwolle in the eastern part of the Netherlands. The design of the study is described in Chapter 3. We designed a prospective pragmatic observational study, performed among patients with known CVD or at high CVD risk in general practice. After one year of follow-up, integrated care for CVRM was compared with usual care. Patients in the usual care group were matched with patients in the intervention group according to age, gender and risk group (high CV risk or CVD). Primary outcomes included levels of systolic blood pressure and LDLcholesterol. Secondary outcomes included calculated 10-year CV risk, BMI, lifestyle (smoking, physical activity, dietary habits), medication use, patient satisfaction, health care consumption, morbidity, comorbidity and mortality. We used mixedmodel analyses to assess the outcomes.

In Chapter 4 we describe the results of the ZWOT-CASE study. We included 372 patients in the intervention group and 317 patients in the usual care group. Mean age at baseline was 65.1 and 66.2 years respectively and $42 \%$ were women in both groups. After one year, we observed no difference in systolic blood pressure (137.2 $\mathrm{mmHg}$ vs $139.0 \mathrm{mmHg}$ in the intervention and usual care group, respectively) and LDL-cholesterol (2.6 mmol/L in both groups), nor in any of the secondary outcomes.

In Chapter 5 we describe a process evaluation of the ZWOT-CASE study. We aimed to gain a deeper understanding of the disappointing results of the study by assessing fidelity to the CVRM programme. Assessment of fidelity includes adequacy of delivered CVRM care and patients' perception of CV risk, risk factors, lifestyle and lifestyle advice. The results of this study show that in total, $85 \%$ 
intervention and and 32\% usual care patients received at least one consultation, including measurements of blood pressure (BP), weight, LDL-cholesterol and renal function. In intervention patients with hypertension that are not on blood pressure lowering medication at baseline, medication was started in $57 \%$ of patients with an off-target BP and in 14\% of patients with an near-target BP. In intervention patients with hypercholesterolemia that are not on lipid lowering medication at baseline, medication was started in 9\% of patients with an off-target LDL-cholesterol and in $3 \%$ of patients with a near-target LDL-cholesterol. In patients using blood pressure lowering medication at baseline, the prescription was changed in 33\% of patients with an off-target BP and in 19\% of patients with an near-target BP. In patients using lipid lowering medication at baseline, the prescription was changed in $28 \%$ of patients with an off-target LDL-cholesterol and in $8 \%$ of patients with an near-target LDL-cholesterol. Among patients without CVD, 14\% of intervention patients vs $22 \%$ of the usual care group correctly classified themselves as having an intermediate or high risk of CVD. Among CVD patients $12 \%$ of the intervention group vs $13 \%$ of the usual care group correctly classified themselves as having a high CV risk. Adequacy of patient's perception of CV risk factors and lifestyle did not differ between the groups. Less than one-third of patients who received lifestyle advice reported having received the advice.

Chapter 6 describes a retrospective cohort study in which we evaluated whether an integrated care programme for CVRM reduced hospital care and subsequent costs. We included patients enlisted in the Isala hospital with atherosclerotic CVD and assessed patient-level data on diagnoses and care activities from the Isala hospital between January $1^{\text {st }}, 2014$ and January $1^{\text {st }}, 2018$. From January $1^{\text {st }}, 2016$ onwards, an integrated primary care programme for CVRM was implemented in the adherent region. We compared duration of hospital care, number of care activities and corresponding costs prior and after starting integrated CVRM care, and used descriptive statistics to assess differences between the two periods. We included respectively 5,215 and 5,449 CVD patients, (mean age 70 years, 35\% female) in the period before and after 01-01-2016. The median length of treatment at the hospital decreased from 149 (IQR 12-389) to 128 (IQR 10-386) days and the total median costs of CVRM related hospital care per patient decreased by $13 \%$ from 583 euros (IQR 272 - 2586) the period before to 507 euros (IQR 262 - 2119) during the period after implementation of the programme. 
In Chapter 7 we describe an observational study in which we assessed therapeutic inertia and characteristics associated with therapeutic inertia in patients with dyslipidaemia, CVD or diabetes mellitus in primary care. Electronic health record data of patients registered in the Julius General Practitioners' Network ( $n=530,564$ ) were used. We selected patients with dyslipidaemia, CVD or DM, and with a recently measured uncontrolled LDL-cholesterol level (> $2.5 \mathrm{mmol} / \mathrm{L})$. Therapeutic inertia was defined as absence of lipid-lowering drug adjustment within three months after the LDL-cholesterol measurement. We used logistic-regression analyses to identify patient characteristics associated with therapeutic inertia. The results of this study showed that out of 21,310 patients with dyslipidaemia, atherosclerotic CVD and/or DM with a recently measured LDL-cholesterol we identified 6,854 (32\%) patients with a LDL-cholesterol > $2.5 \mathrm{mmol} / \mathrm{L}$. Mean age was 68 (SD 12.2) years and 57\% were women. The median LDL-cholesterol was $3.1 \mathrm{mmol} / \mathrm{L}$ (IQR 2.8 - 3.7) and 45\% used a lipid-lowering drug in the 6 months prior to the measurement. Therapeutic inertia was present in $93 \%$ and did not differ between patients with a CVD, DM or dyslipidaemia. Age (OR per year 1.01, 95\%-CI 1.01 to 1.02 ) was positively associated with therapeutic inertia, while both LDL-cholesterol level (OR per mmol/L 0.63, 95\%-CI 0.56 to 0.70 ) and being a current or past smoker (OR $0.66,95 \%$-CI 0.54 to 0.80 ) were inversely associated with therapeutic inertia.

In Chapter 8 the main results of this thesis are summarized and interpreted. Furthermore, the potential impact of the integrated multidisciplinary CVRM programme in daily practice is discussed by using the RE-AIM model. Last, considerations are provided about the future of CVRM programmes in primary care. 


\section{REFERENCES}

1. Timmis A, Townsend N, Gale CP, et al. European society of cardiology: Cardiovascular disease statistics 2019. Eur Heart J. 2020;41(1):12-85. doi: 10.1093/eurheartj/ehz859 [doi].

2. Roth GA, Abate D, Abate KH, Abay SM, Abbafati C, Abbasi N. Global, regional, and national age-sex-specific mortality for 282 causes of death in 195 countries and territories, 1980-2017: A systematic analysis for the global burden of disease study 2017. Lancet. 2018;392(10159):1736-1788. doi: S0140-6736(18)32203-7 [pii].

3. Kotseva K, De Backer G, De Bacquer D, et al. Primary prevention efforts are poorly developed in people at high cardiovascular risk: A report from the european society of cardiology EURObservational research programme EUROASPIRE V survey in 16 european countries. Eur J Prev Cardiol. 2020:2047487320908698. doi: 10.1177/2047487320908698 [doi].

4. Kotseva K, De Bacquer D, De Backer G, et al. Lifestyle and risk factor management in people at high risk of cardiovascular disease. A report from the european society of cardiology european action on secondary and primary prevention by intervention to reduce events (EUROASPIRE) IV cross-sectional survey in 14 european regions. Eur J Prev Cardiol. 2016;23(18):2007-2018. doi: 10.1177/2047487316667784 [doi].

5. Piepoli MF, Hoes AW, Agewall S, et al. 2016 european guidelines on cardiovascular disease prevention in clinical practice: The sixth joint task force of the european society of cardiology and other societies on cardiovascular disease prevention in clinical practice (constituted by representatives of 10 societies and by invited experts): Developed with the special contribution of the european association for cardiovascular prevention \& rehabilitation (EACPR). Eur Heart J. 2016. doi: ehw106 [pii].

6. Bodenheimer T, Wagner EH, Grumbach K. Improving primary care for patients with chronic illness: The chronic care model, part 2. JAMA. 2002;288(15):1909-1914. doi: jip21005 [pii].

7. Alageel S, Gulliford MC, McDermott L, Wright AJ. Multiple health behaviour change interventions for primary prevention of cardiovascular disease in primary care: Systematic review and meta-analysis. BMJ Open. 2017;7(6):e015375-015375. doi: 10.1136/bmjopen-2016-015375 [doi].

8. Martinez-Gonzalez NA, Berchtold P, Ullman K, Busato A, Egger M. Integrated care programmes for adults with chronic conditions: A meta-review. Int J Qual Health Care. 2014;26(5):561-570. doi: 10.1093/intqhc/mzu071 [doi]. 
9. Ebrahim S, Taylor F, Ward K, Beswick A, Burke M, Davey Smith G. Multiple risk factor interventions for primary prevention of coronary heart disease. Cochrane Database Syst Rev. 2011;(1):CD001561. doi(1):CD001561. doi: 10.1002/14651858.CD001561. pub3 [doi].

10. Buckley BS, Byrne MC, Smith SM. Service organisation for the secondary prevention of ischaemic heart disease in primary care. Cochrane Database Syst Rev. 2010;(3):CD006772. doi(3):CD006772. doi: 10.1002/14651858.CD006772.pub2 [doi].

11. Snaterse M, Dobber J, Jepma P, et al. Effective components of nurse-coordinated care to prevent recurrent coronary events: A systematic review and meta-analysis. Heart. 2016;102(1):50-56. doi: 10.1136/heartjnl-2015-308050 [doi].

12. Minary L, Trompette J, Kivits J, Cambon L, Tarquinio C, Alla F. Which design to evaluate complex interventions? toward a methodological framework through a systematic review. BMC Med Res Methodol. 2019;19(1):92-6. doi: 10.1186/s12874019-0736-6 [doi]. 


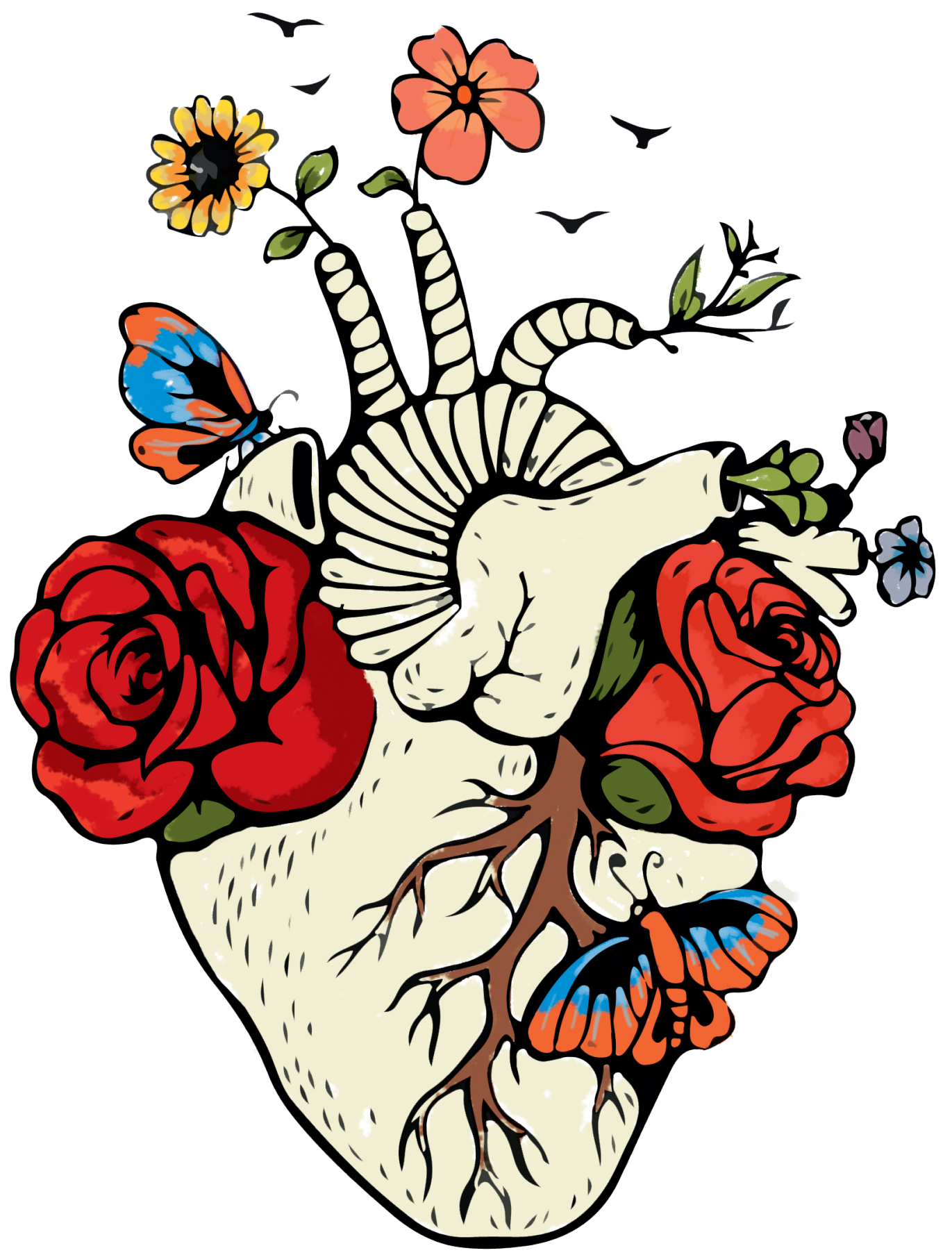


SAMENVATTING 
Hart- en vaatziekten (HVZ) is zowel wereldwijd als in Europa de belangrijkste doodsoorzaak. Daarom zijn er zorgen over de prevalentie van risicofactoren voor HVZ. Zo is in Europa het aantal mensen met obesitas in de afgelopen 36 jaar meer dan verdubbeld, beweegt 1 op de 3 volwassenen beweegt te weinig en neemt het aantal mensen met een verhoogde bloeddruk niet verder af. HVZ kunnen worden voorkomen door behandeling van risicofactoren voor HVZ, zoals hoge bloeddruk, verhoogd cholesterol, roken, te weinig bewegen, obesitas en een ongezond voedingspatroon. Onderzoeken in de eerstelijnszorg hebben echter aangetoond dat risicofactoren voor HVZ onvoldoende onder controle zijn. Dit benadrukt dat effectieve multifactoriële en multidisciplinaire interventies voor cardiovasculair risicomanagement (CVRM) nodig zijn, zoals ook wordt aanbevolen door de Europese richtlijnen voor de preventie van HVZ. In de gehele zorgketen geïntegreerde, multidisciplinaire CVRM-programma's in de eerste lijn zouden de implementatie van de richtlijnen en daarmee de kwaliteit van HVZ-preventie mogelijk kunnen verbeteren. Deze programma's zijn meestal gebaseerd op het chronische zorgmodel en omvatten het systematisch selecteren en uitnodigen van patiënten, het maken van een cardiovasculaire risicoschatting, een gedeelde beslissing in behandeling en follow-up van in aanmerking komende patiënten en stimulering van zelfmanagement. Daarnaast worden patiëntgegevens geregistreerd in klinische informatiesystemen en wordt jaarlijks feedback gegeven aan huisartsen over de door hun geleverde CVRM-zorg. Tot dusver zijn studies naar de effectiviteit van CVRM-programma's schaars en is het beschikbare bewijs niet eenduidig, onder andere vanwege de verscheidenheid in de onderzoeksopzet. De meeste studies zijn gerandomiseerde gecontroleerde studies (randomized controlled trials; RCT's). In een RCT wordt het effect van het CVRM-programma onderzocht onder optimale omstandigheden, waarbij het programma wordt geïmplementeerd volgens de richtlijnen. Echter, de omstandigheden in RCT's komen niet overeen met de complexiteit van de werkelijkheid. Daarom zijn de resultaten van deze studies niet automatisch toepasbaar in de dagelijkse praktijk. Daarom zijn er meer studies nodig onder realistischere omstandigheden.

Dit proefschrift heeft als doel om inzicht te verschaffen in de effectiviteit van een geïntegreerd en multidisciplinair programma voor CVRM in de eerstelijnszorg in de dagelijkse praktijk. Daarnaast worden in dit proefschrift de uitdagingen van de implementatie van CVRM in de dagelijkse praktijk beschreven. 
In Hoofdstuk 2 van dit proefschrift geven we commentaar op de nieuwe Europese richtlijn voor het voorkomen van HVZ. Kernboodschappen in de richtlijn zijn onder meer dat HVZ-preventie een gepersonaliseerde aanpak vereist en dat het inschatten van het risico op HVZ en de beoordeling van leefstijlfactoren regelmatig herhaald moeten worden. De implementatie van alle aanbevelingen in deze nieuwe richtlijn is een uitdaging en vereist meer begeleiding voor huisartsen evenals voldoende consulttijd, ICT-ondersteuning, adequate financiële vergoeding, een opgeleid multidisciplinair team en overeenstemming met beleid van omliggende organisaties, verzekeraars en de overheid.

In de afgelopen jaren is in veel regio's in Nederland een geïntegreerd programma voor CVRM geïntroduceerd in de eerste lijn, gebaseerd op het chronisch zorgmodel. In de ZWOT-CASE studie (ZWOlse Transmurale CArdiovaSculaire risicomanagEment ketenzorg studie) onderzochten wij het effect van zo'n geïntegreerd programma voor CVRM (interventie) in vergelijking met gebruikelijke zorg in huisartspraktijken in de regio Zwolle. De opzet van de studie wordt beschreven in Hoofdstuk 3. De ZWOT-CASE studie is een prospectieve pragmatische observationele studie in de huisartspraktijk, uitgevoerd onder patiënten met bekende HVZ of met een hoog risico op HVZ. Na een jaar follow-up werd de geïntegreerde zorg voor CVRM vergeleken met een groep die gebruikelijke zorg ontving. Patiënten in de interventiegroep werden gekoppeld aan patiënten in de gebruikelijke zorggroep op basis van leeftijd, geslacht en risicogroep (HVZ of hoog risico op HVZ). Primaire uitkomsten waren systolische bloeddruk en LDLcholesterol. Secundaire uitkomsten waren onder meer berekend 10-jaarsrisico op ziekte of sterfte door HVZ, BMI, leefstijl (roken, lichamelijke activiteit, voedingsgewoonten), medicatiegebruik, patiënttevredenheid, zorggebruik, nieuw ontwikkelde HVZ en sterfte door HVZ of een andere oorzaak. We gebruikten mixed-model analyses om de uitkomsten te beoordelen.

In Hoofdstuk 4 beschrijven we de resultaten van de ZWOT-CASE studie. In de interventiegroep deden 372 patiënten mee en in de groep die gebruikelijke zorg ontving deden 317 patiënten mee. De gemiddelde leeftijd aan het begin van het onderzoek was respectievelijk 65,1 en 66,2 jaar en in beide groepen was $42 \%$ vrouw. Na een jaar zagen we geen verschil in systolische bloeddruk $(137,2 \mathrm{mmHg}$ versus 139,0 mmHg in respectievelijk de interventie- en gebruikelijke zorggroep) 
en LDL-cholesterol (2,6 mmol / L in beide groepen), noch in een van de secundaire uitkomsten.

Om beter inzicht te krijgen in de tegenvallende resultaten van het CVRMprogramma, onderzochten wij of het CVRM-programma zorgvuldig was uitgevoerd door middel van een procesevaluatie. Dit wordt beschreven in Hoofdstuk 5. Hiervoor gingen wij na welke CVRM-zorg precies was geleverd. Daarnaast onderzochten wij of de patiënt zijn of haar risico op HVZ, de eigen risicofactoren en leefstijl juist beoordeelt en of leefstijladviezen bij de patiënt zijn aangekomen.

De resultaten van deze evaluatie laten zien dat in totaal $85 \%$ van de patiënten in het CVRM-programma minimaal één keer op het spreekuur kwam voor CVRM, inclusief een bloeddrukmeting en bepaling van gewicht, LDL-cholesterol en nierfunctie, tegenover $32 \%$ van de patiënten die gebruikelijke zorg ontvingen.

Bij interventiepatiënten met een bekende hoge bloeddruk die bij aanvang van de studie geen bloeddrukverlagende medicatie gebruikten, werd medicatie gestart bij $57 \%$ van de patiënten met een bloeddruk boven de streefwaarde en bij 14\% van de patiënten met een bloeddruk nabij de streefwaarde. Bij interventiepatiënten met een te hoog cholesterol die bij aanvang van de studie geen cholesterolverlagende medicatie gebruikten, werd medicatie gestart bij $9 \%$ van de patiënten met een LDL-cholesterol boven de streefwaarde en bij 3\% van de patiënten met een LDL-cholesterol nabij de streefwaarde. Bij patiënten die bij aanvang al bloeddrukverlagende medicatie gebruikten, werd de medicatie gewijzigd bij $33 \%$ van de patiënten met bloeddruk boven de streefwaarde en bij 19\% van de patiënten met bloeddruk nabij de streefwaarde. Bij patiënten die bij aanvang al cholesterolverlagende medicatie gebruikten, werd het recept gewijzigd bij $28 \%$ van de patiënten met een LDL-cholesterol boven de streefwaarde en bij $8 \%$ van de patiënten met een LDL-cholesterol nabij de streefwaarde.

Van de patiënten zonder HVZ beoordeelde 14\% van de interventiepatiënten versus $22 \%$ van de gebruikelijke zorggroep het eigen risico op HVZ correct. Van de patiënten met een HVZ beoordeelde $12 \%$ van de interventiegroep versus $13 \%$ van de gebruikelijke zorggroep het eigen risico op HVZ correct. Er was geen verschil tussen de groepen in het aantal patiënten dat de eigen risicofactoren en 
leefstijl juist inschatte. Tot slot gaf minder dan een derde van de patiënten die leefstijladvies kregen aan het advies te hebben ontvangen.

Hoofdstuk 6 beschrijft een retrospectieve cohortstudie waarin we evalueerden of het geïntegreerde zorgprogramma voor CVRM leidt tot minder ziekenhuiszorg en een daling van de daaruit voortvloeiende kosten. Het geïntegreerde eerstelijnszorgprogramma voor CVRM werd vanaf 1 januari 2016 geïmplementeerd in de regio Zwolle. We includeerden patiënten die tussen 1 januari 2014 en 1 januari 2018 in het Isala ziekenhuis waren opgenomen met atherosclerotische HVZ en beoordeelden gegevens op patiëntniveau over diagnoses en zorgactiviteiten van het Isala-ziekenhuis. We vergeleken de perioden voor en na het starten van geïntegreerde CVRM-zorg, en keken hierbij naar de duur van de ziekenhuiszorg, het aantal zorgactiviteiten en de bijbehorende kosten. Beschrijvende statistieken werden gebruikt om de verschillen tussen de twee perioden te beoordelen. In de periode voor en na 01-01-2016 includeerden we respectievelijk 5.215 en 5.449 patiënten met HVZ (gemiddelde leeftijd 70 jaar, 35\% vrouw). De mediane duur van de behandeling in het ziekenhuis daalde van 149 dagen (IQR 12-389) naar 128 dagen (IQR 10-386). De totale mediane kosten van CVRM-gerelateerde ziekenhuiszorg per patiënt daalden met 13\%, namelijk van 583 euro (IQR 2722586) in de periode voor tot 507 euro (IQR 262 - 2119) gedurende de periode na invoer van het programma.

Om de uitdagingen van CVRM-zorg in de dagelijkse praktijk verder te onderzoeken deden wij een studie naar therapeutische inertie. In Hoofdstuk 7 wordt deze studie beschreven. Het betreft een observationele studie in de eerste lijn waarin we therapeutische inertie en patiëntkenmerken geassocieerd met therapeutische inertie onderzochten. Hiervoor gebruikten we elektronische patiëntendossiers van patiënten geregistreerd in het Julius Huisartsennetwerk ( $n=530.564)$. We selecteerden patiënten met hypercholesterolemie, HVZ of diabetes mellitus (DM), en met een recent gemeten ongecontroleerd LDL-cholesterolgehalte $(>2,5 \mathrm{mmol}$ / L). Therapeutische inertie werd gedefinieerd als de afwezigheid van een aanpassing in cholesterolverlagende medicatie door de huisarts binnen drie maanden na de LDL-cholesterolmeting. We gebruikten logistische regressieanalyses om patiëntkenmerken op te sporen die samenhangen met therapeutische inertie. Van de 21.310 patiënten met hypercholesterolemie, atherosclerotische HVZ en / of DM met een recent gemeten LDL-cholesterol, hadden 6.854 (32\%) patiënten 
een LDL-cholesterol> 2,5 mmol / L. De gemiddelde leeftijd van deze patiënten was 68 (SD 12,2) jaar en 57\% was vrouw. Het mediane LDL-cholesterol was 3,1 mmol / l (IQR 2,8 - 3,7) en 45\% gebruikte een cholesterolverlagend medicijn in de 6 maanden voorafgaand aan de meting. In 93\% van de patiënten was er sprake van therapeutische inertie en dit verschilde niet tussen patiënten met HVZ, DM of hypercholesterolemie. De leeftijd van de patiënt hing positief samen met therapeutische inertie (OR per jaar 1,01, 95\% - CI 1,01 tot 1,02). Tussen zowel de hoogte van het LDL-cholesterol (OR per mmol / L 0,63, 95\% -CI 0,56 tot 0,70) als roken (OR 0,66, 95\% -CI 0,54 tot 0,80) en therapeutisch inertie was er een negatief verband.

In Hoofdstuk 8 worden de belangrijkste resultaten van dit proefschrift samengevat en geduid. Verder wordt de mogelijke impact van het geïntegreerde multidisciplinaire CVRM-programma in de dagelijkse praktijk besproken aan de hand van het RE-AIM-model. We eindigen met ideeën voor de toekomst van CVRMprogramma's in de eerste lijn. 


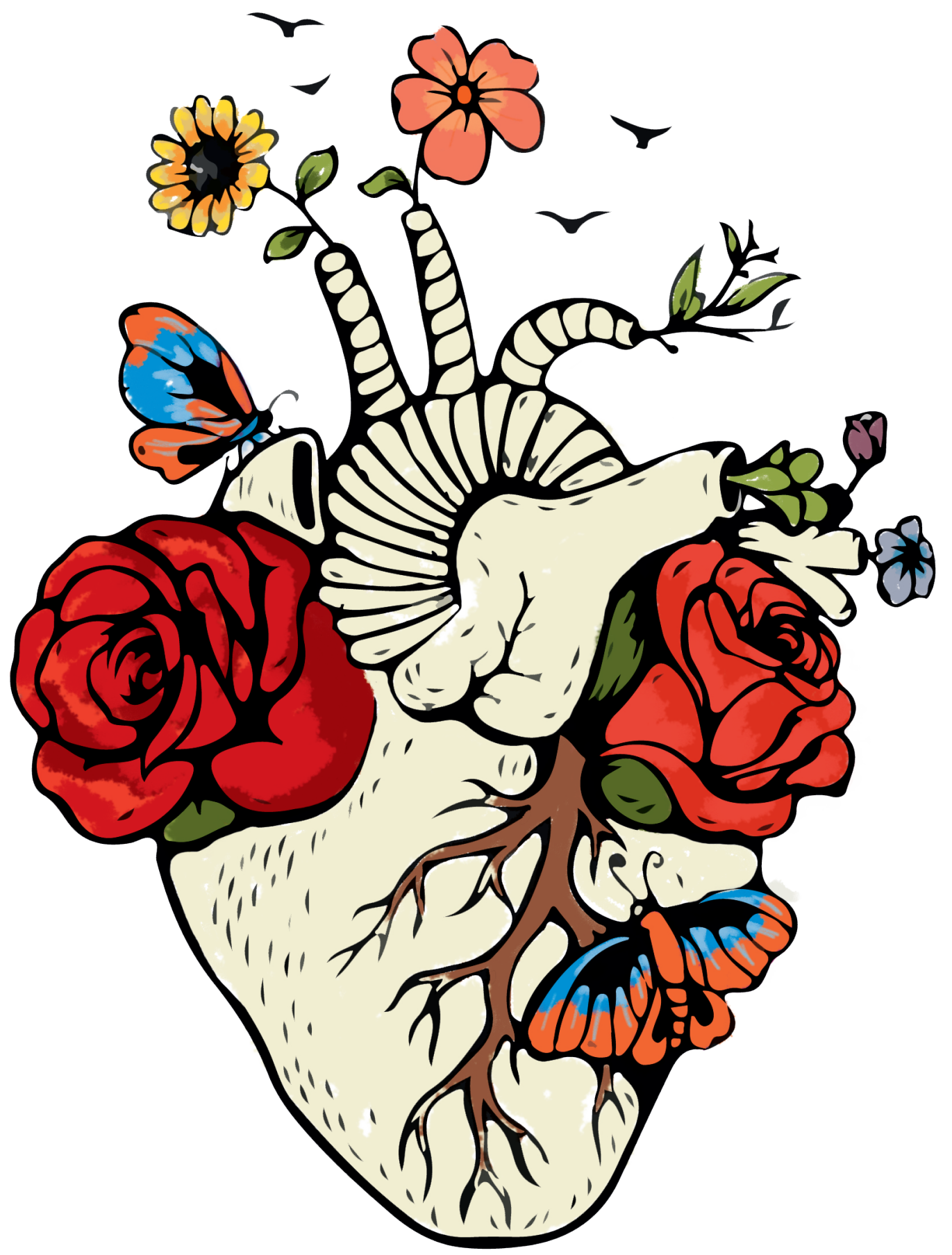


DANKWOORD 
In vijf jaar tijd Groningen verlaten, dan nog eens vier keer verhuizen, studeren om een goede huisarts te worden, de liefde ontmoeten en als kroon op alles moeder worden op de dag nadat ik mijn proefschrift indiende ter beoordeling. Daar tussendoor werd dit proefschrift in drie jaar tijd geschreven. Het behoeft denk ik geen verdere uitleg dat ik dit niet alleen heb kunnen doen. Mijn dank gaat uit naar vele collega's, vrienden en familie die betrokken waren. Een aantal mensen wil ik in het bijzonder noemen.

Allereerst wil ik mijn promotieteam bedanken. De eindsprint die we met zijn vieren gemaakt hebben was zeer efficiënt, waardoor alles precies op tijd af was.

Beste prof. dr. A.W. Hoes, beste Arno, bedankt voor jouw altijd scherpe blik. Jij wist precies de punten aan te stippen die verbetering verdienden. Beslissingen werden altijd snel, maar zeer zorgvuldig genomen. Het heeft mij veel inzichten opgeleverd en mij een kritischer onderzoeker gemaakt. Ondanks de tijdsdruk heb ik de overleggen altijd als ontspannen ervaren. Jouw humor heeft hier zeker aan bijgedragen.

Beste prof. dr. A.W.J. van 't Hof, beste Arnoud, jij was een verbindende factor tussen ons team en de regio Zwolle. Ook was jouw blik als clinicus in de tweede lijn erg waardevol voor de interpretatie van de resultaten van de onderzoeken. Onze overleggen in Zwolle gingen niet alleen over het onderzoek, maar ook over de bergen en persoonlijke ontwikkelingen. Bedankt voor die gezellige momenten.

Beste dr. M. Hollander, beste Monika, alle lof voor jouw rol in mijn promotietraject! Als enige co-promotor in het team heb jij heel veel werk verzet. Dat het tot zo'n mooi proefschrift heeft geleid zegt veel over jouw kwaliteiten. Je bent een praktisch ingestelde onderzoeker en weet als geen ander de bruggen te slaan, zowel tussen de wetenschap en de huisartspraktijk, als tussen verschillende onderzoeksgroepen. Je was ook een goede coach. Als ik het even niet meer zag zitten, wist jij mij met jouw enthousiasme steeds weer te motiveren en de mooie kanten van het onderzoek te laten inzien. Tot slot was je open over je eigen ontwikkelingen als huisarts en wetenschapper. Het was heel leerzaam om te zien welke kanten je allemaal op kunt groeien. Bedankt voor alles wat je mij geleerd hebt, bedankt voor de fijne samenwerking en we blijven natuurlijk collega's. 
Graag wil ik ook de leden van de beoordelingscommissie, prof. dr. H.A.H. Kaasjager, prof. dr. E.P. Moll van Charante, prof dr. W.M.M. Verschuren, prof. dr. M.L. Bouvy, en prof. dr. J.S. Burgers, bedanken voor het kritisch beoordelen van mijn proefschrift.

Naast mijn promotieteam zijn er nog heel wat andere onderzoekers die hebben meegewerkt aan de hoofdstukken in dit proefschrift. Het was inspirerend om met deze onderzoekers samen te werken.

Beste Prof. H.J.G. Bilo, beste Henk, bedankt voor het meewerken aan de ZWOT-CASE studie en het opzetten van het onderzoek naar het effect van geïntegreerde CVRM zorg op de ziekenhuiszorg in het Isala. Mede dankzij jou waren deze onderzoeken mogelijk. We hebben veel aan jou en het kenniscentrum te danken. Dank voor de goede samenwerking.

Beste Dr. M. Schoenmakers, beste Marieke, bedankt voor het meewerken aan de ZWOT-CASE studie. Jij zorgde er altijd heel terecht voor dat wij als onderzoekers de huisartsen uit de regio Zwolle en hun patiënten niet uit het oog verloren.

Beste Prof. dr. M.L. Bots, beste Michiel, bedankt voor het meedenken over de resultaten van de ZWOT-CASE studie en het onderzoek naar therapeutische inertie. Dankzij jouw kritische feedback werd het onderzoek naar een hoger niveau getild.

Beste Prof. dr. F.H. Rutten, beste Frans, bedankt voor je betrokkenheid bij het onderzoek naar therapeutische inertie. Het was leuk en nuttig om met jou te sparren over de resultaten.

Beste Drs. S.J. Deijns, beste Sander, bedankt voor al het werk dat jij hebt verzet tijdens jouw wetenschappelijke stage. De dagen waarop we data verzamelden waren lang en taai, maar werden dankzij jouw inzet een stuk productiever. Je bleek ook een goede schrijver te zijn. Dat heeft enorm geholpen bij het schrijven van de resultatenpaper.

Beste Drs. W.R. Keusters, beste Willem, bedankt voor al je analysewerk. Onze samenwerking verliep altijd efficiënt. Wijzigingen in de analyses waren voor jou nooit een probleem. 
Beste Dr. G.W.J. Frederix, beste Geert, bedankt voor jouw betrokkenheid bij het onderzoek naar het effect van CVRM zorg op de ziekenhuiszorg in het Isala. Jouw optimistische blik gaf een goede draai aan dit hoofdstuk. Het was prettig samenwerken met de collega's van HTA.

Wie ik ook zeker niet wil vergeten in dit rijtje is Peter Zuithoff. Beste Peter, bedankt voor het meedenken over de statistische analyses, voor het meekijken met mijn R-codes en voor de uitleg over wat die R-codes nou eigenlijk precies doen. Als stelde ik steeds weer dezelfde vragen, jij was altijd bereid het nog eens uit te leggen. Zo werd statistiek een stuk leuker!

Voor de opzet van de ZWOT-CASE studie valt veel te danken aan de collega's van Medrie en de aangesloten huisartsen uit de regio Zwolle.

In het bijzonder wil ik Olof Schwantje bedanken. Bedankt voor jouw inzet voor het creëren van draagvlak onder de huisartsen in de regio Zwolle voor het uitvoeren van de ZWOT-CASE studie.

Dank aan alle leden van het CVRM kwaliteitsteam van Medrie, onder andere Marieke Schoenmakers en Michiel Schouwink. Het was altijd zeer nuttig om de ontwikkelingen omtrent het CVRM ketenzorgprogramma op de voet te volgen. Het heeft mij veel inzicht gegeven in de uitdagingen waar huisartspraktijken mee te maken krijgen bij het invoeren van zo'n programma.

Ingeborg, Carla en Geanne bedankt voor jullie praktische hulp bij het opzetten en uitvoeren van de ZWOT-CASE studie. Geanne, jouw humor was hilarisch en maakte het werken in de kantoortuin bij Medrie altijd erg gezellig. Aly, bedankt voor het bellen van alle patiënten, dankzij jou hebben we de inclusie flink op kunnen schroeven. Rita, Thea en Bernadette, bedankt voor het inplannen van afspraken en publiceren van nieuwsberichten over de ZWOT-CASE studie.

Graag wil ik alle huisartsen, praktijkondersteuners, praktijkverpleegkundigen en praktijkassistentes bedanken die hebben meegedaan aan het onderzoek. Praktijk de Hoogstraat, de praktijk van collega's Appel en Hutter, de praktijk van collega's Takens en Zuidwijk, praktijk Westenhage, Medisch Centrum de Steenpoort, praktijk Molenweg, praktijk Blerckweg, praktijk Berkenhove, praktijk 
Hof van Blom, praktijk Van Haersoltelaan, Hanzepraktijk, praktijk Assendorp, praktijk Vilstersestraat, praktijk Berkum, de praktijk van collega's De Maat en Trum, praktijk De Vrijheid, praktijk De Trommel, praktijk 't Veen, praktijk Berent Avercamp, praktijk Ruitenborghstraat, praktijk Heerde, praktijk Geert Groote, praktijk IJsselmuiden, praktijk Munnikenhof, praktijk Zwolse tulp, en praktijk De Fenix. Het was leuk om in zoveel praktijken een inkijkje te krijgen. De huisartspraktijken in de regio Zwolle hebben bij mij een positieve indruk achter gelaten.

De ZWOT-CASE studie was nooit mogelijk geweest zonder de deelname van alle patiënten. Dank aan al deze patiënten voor de bereidheid om deel te nemen, voor het invullen van die ellenlange vragenlijst en voor de toestemming om jullie data te mogen gebruiken voor het onderzoek.

De eerste jaren van mijn promotietraject waren erg gezellig dankzij de kamergenoten van kamer 6.104 in het Stratenum. Romin, Carline, AnneKarien, Pauline, Kevin, Valentijn, Nicole en Saskia: bedankt voor de gezellige koffiemomentjes, borrels, etentjes en boulderavonden.

Door de coronacrisis was mijn tijd in het van Geuns niet zo lang, maar ook daar was het gezellig. Lisanne, Femke, Nicole en Ietje bedankt voor de fijne tijd.

Tussen de onderzoeksjaren door leerde ik de fijne kneepjes van het huisartsenvak. Beste Henriëtte en Cees en alle praktijkondersteuners en assistentes van Medisch Centrum Drielanden, bedankt voor de fijne en leerzame tijd in jullie praktijk, ik kijk er nog steeds met plezier op terug!

En dan waren er veel mensen in mijn privéleven die belangrijk zijn geweest de afgelopen 5 jaar.

Lieve Roos en Remco, het was fijn om jullie zo dichtbij te hebben in de flat. Roos, tijdens het wandelen heb je regelmatig mijn geklaag over mijn onderzoek aangehoord, bedankt voor je luisterend oor. Naast wandelmaatje ben je nu ook een klankbord voor allerlei vragen over het ouderschap, heel waardevol. Andere subclubbers, Mienke, Geer en Buufje, heel gezellig dat we elkaar zo nu en dan 
nog zien en mooie herinneringen kunnen ophalen, dat moeten we zeker in stand houden.

Dear Romin, you know you have played an important role for me and Loan. And you are still a good friend! The evenings in Het Muzieklokaal and Tivoli were very gezellig. We have both moved, we have been very busy, but hopefully we will catch up soon and drink another beer!

Lieve Lys en Vin, tijdens een reisje naar het Noorden wip ik altijd graag bij jullie langs en met onze twee kleintjes zo dicht op elkaar wordt dat alleen maar leuker. Nog beter zou zijn als jullie dichterbij komen wonen.

Lieve Maaike en Ruben, goede vrienden gaan nooit verloren. Jullie hebben mij gesteund op de juiste momenten, dat was heel bijzonder voor mij. Ik kijk ernaar uit weer eens een goede wijn met jullie te drinken.

Lieve Erik, je kent mij als geen ander, het blijft net zo vertrouwd als vroeger. Dank je dat je er nog steeds voor mij bent.

Lieve Siets, jij hebt een belangrijke rol gespeeld, nu wat meer op afstand, maar onze bijzondere band blijft bestaan. Dank je voor al jouw begrip en steun.

Lieve Amanda en Ruth, wat een onbeschrijfelijk intense jaren. Jullie zijn topmoeders, een belangrijk voorbeeld voor ons.

Dankzij Lo zijn er nog meer lieve mensen in mijn leven gekomen, waaronder de greppels. Het is altijd hard lachen me jullie. Ik kijk uit naar de volgende vakantie!

Lieve Hinke, het stond voor mij als een paal boven water dat ik jou als paranimf wilde. Wat hebben wij mooie tijden gekend, niets te gek, tegen jou kan ik alles zeggen. Dank je voor je openheid, enorme flexibiliteit en steun. Ik hoop dat we nog heel veel mee gaan maken met elkaar en met onze gezinnen. Bart, ook jij bedankt voor je betrokkenheid en steun. Fijn dat ik vaak mocht komen logeren.

Lieve Iris, wat ben ik blij dat jij mijn paranimf wilt zijn. Het is altijd genieten met jou tijdens de vele concerten die we hebben bezocht, van goede muziek, goede wijn 
en goede gesprekken. Jij wordt nooit moe van het analyseren van het leven en staat daar dag en nacht voor klaar. Inmiddels delen we zelfs de liefde voor hardlopen haha! Ik kijk uit naar nog veel meer weekendjes in Drenthe.

Tot slot wil ik mijn grote familie bedanken.

Lieve Bert, Lil, Ward en Rosa, ik had mij geen betere schoonfamilie kunnen indenken. Jullie staan altijd voor ons klaar. Bert, bedankt voor de vele klussen die je voor ons hebt gedaan, voor alle hulp in het huishouden en voor de heerlijkheden uit de moestuin. Lil, bedankt voor al het lekkere eten en mooie creaties voor Loethe. Ik hoop dat jullie nog heel lang fit blijven. Ward, je bent van grote betekenis. Fijn dat we nu dichterbij elkaar wonen en we vaker even af kunnen spreken. Het lijkt me leuk als je een goede band kunt opbouwen met Loethe. Rosa, het is altijd gezellig als jij erbij bent.

Lieve Ier en Aal, wat kijken we ernaar uit om jullie weer te kunnen zien. De bezoekjes aan jullie in Berlijn zijn altijd heel fijn. Ier, je bent de enige echte andere wetenschapper in onze familie en je begrijpt als geen ander de ups-and-downs van een PhD-traject. Het gaat jou zeker lukken om het af te maken. Tot snel lieve zus.

Lieve Niels en Eva, het was fijn om jullie de afgelopen jaren als buurtgenoten te hebben. Even langs wandelen voor een pepertje of wat zonnestralen in jullie tuin, we zullen het missen. Niels, bedankt voor al die momenten waarop we een sterke man nodig hadden, jij stond altijd voor ons klaar.

Lieve Rut en Lex, mijn promotietraject kan jullie tropenjaren niet evenaren: in 3 jaar tijd 3 kinderen! Super handig voor ons dat jullie al zoveel ervaring hebben in het ouderschap. Ondanks de drukte vinden jullie altijd de ruimte voor een borrel of een goed gesprek. Bedankt voor al jullie hulp en steun.

Lieve pap en mam, bedankt dat jullie er altijd voor mij zijn. Jullie hebben moeilijke tijden gekend. Het heeft ons dichterbij elkaar gebracht, daar ben ik heel dankbaar voor. Jullie zijn een superlieve opa en oma voor al jullie kleinkinderen. Wij kijken uit naar de tijd dat we weer met zijn allen samen kunnen zijn. 
Lieve Lo, jij bent het grootste geluk dat dit promotietraject mij heeft gebracht. We wisten niet dat we het allebei wel wisten. Het heeft ons vele mooie avonden in Het Muzieklokaal, Tivoli en Het Concertgebouw bezorgd. Dat we het zo lang op 39 vierkante meter hebben uitgehouden zegt veel over hoe goed we het samen hebben. Dank voor al je heerlijke kookkunsten, verstopte paaseieren en warme pianoklanken. Het afronden van mijn proefschrift maakte dat ik het soms erg druk had. Jij bleef altijd geduldig en was mijn redder in nood als ik weer eens vastliep in R. Dank voor je oneindige aandacht en liefde. Afgelopen jaar hebben we onze prachtige Loethe gekregen. Ook al had ze geen idee van dit proefschrift, een goede timing heeft ze in de vingers. Wat ben ik blij dat dit proefschrift nu af is en ik meer tijd kan gaan besteden aan deze twee belangrijkste mensen in mijn leven. 


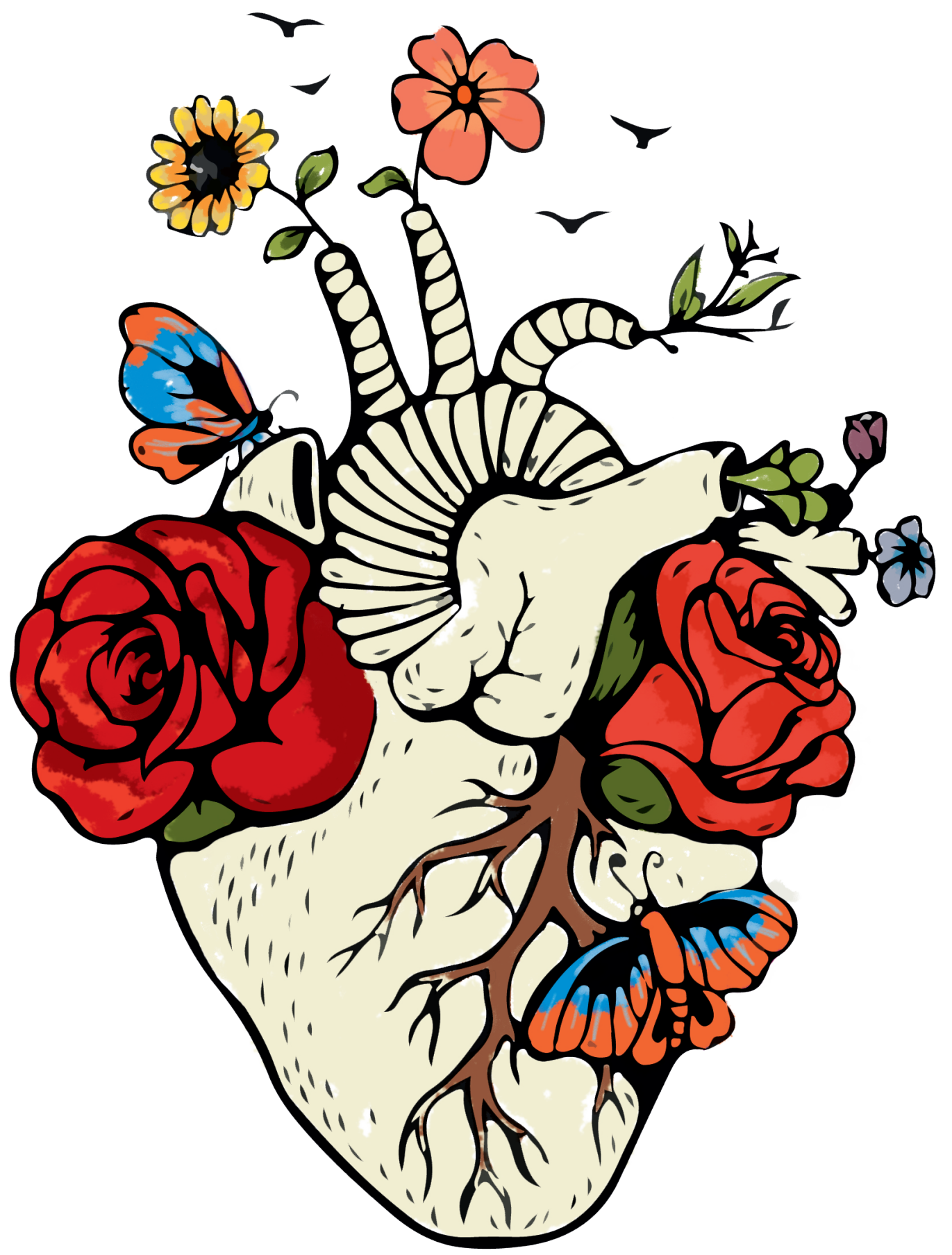


CURRICULUM VITAE 


\section{CURRICULUM VITAE}

Suzanne Marchal was born in Wijk bij Duurstede, the Netherlands, on 26th of June 1987. After graduation from secondary school in 2005 (Revius Lyceum, Doorn), she studied Medicine at the University of Groningen and graduated in 2012. Between 2012 and 2015 Suzanne worked as a resident at the intensive care of the University Medical Centre in Groningen, the emergency room of the Tjongerschans hospital in Heerenveen and the neurology department of Martini hospital in Groningen, respectively. In 2016 she started working on the research described in this thesis, at the Julius centre for Health Sciences and Primary Care of the University Medical Centre Utrecht, under supervision of prof. dr. A.W. Hoes, prof. dr. A.W.J. van 't Hof and dr. M. Hollander. She has combined her PhD project with the general practitioner vocational training at the Department of General Practice, Julius Centre Utrecht, of which she is currently at the beginning of the third year. In 2020 she received a master's degree in Clinical Epidemiology at Utrecht University. Results of her PhD research are presented in the current thesis entitled 'Integrated cardiovascular risk management in primary care'. 




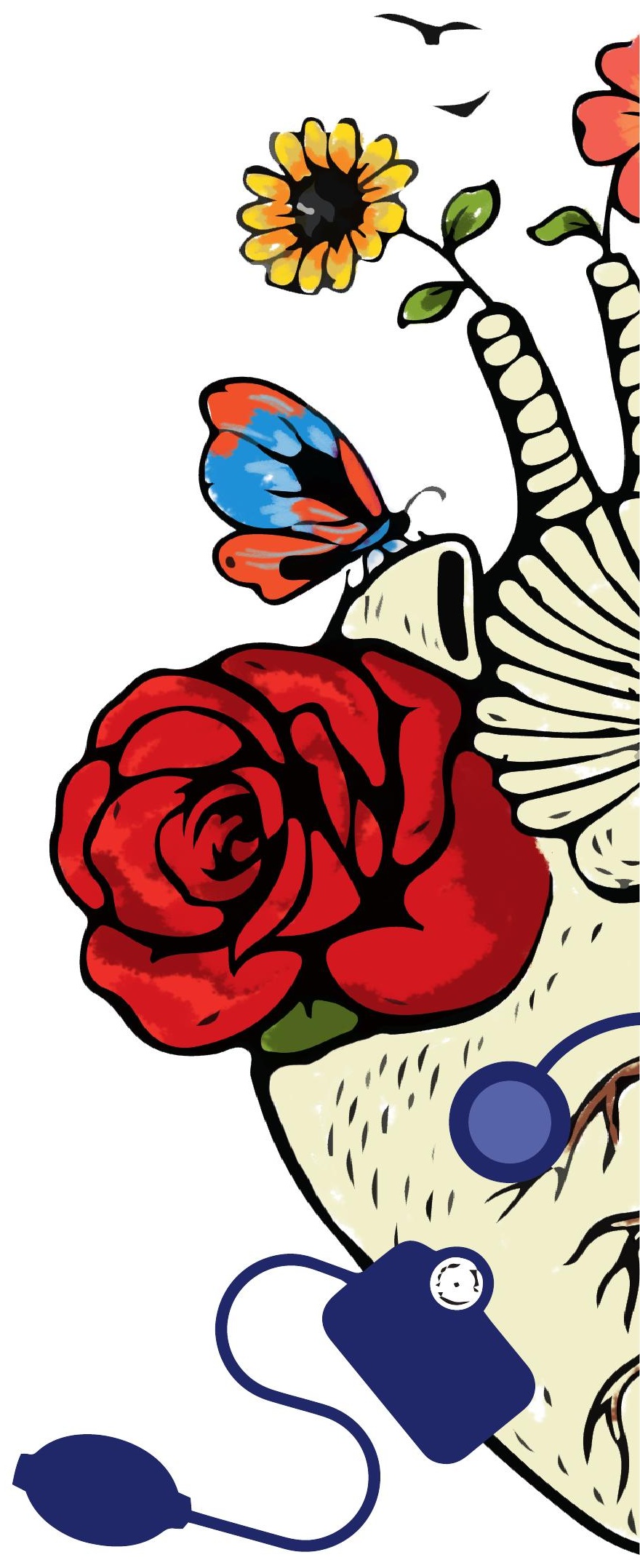

